\title{
STORYTELLING ARCHITECTURE
}

\author{
By \\ Adrian Bica \\ B.Arch.Sci 2012 \\ Ryerson University
}

A thesis presented to

Ryerson University

In partial fulfillment of the

Requirements for the degree of

Master of Architecture

In the Program of

Architecture 


\section{Author's declaration}

I hereby declare that I am the sole author of this dissertation. This is a true copy of the dissertation, including any required final revisions, as accepted by my examiners. I authorize Ryerson University to lend this dissertation to other institutions or individuals for the purpose of scholarly research. I further authorize Ryerson University to reproduce this dissertation by photocopying or by other means, in total or in part, at the request of other institutions or individuals for the purpose of scholarly research. I understand that my dissertation may be made electronically available to the public. 


\section{Abstract}

This thesis critiques contemporary architecture tracing its faults to favoritism of scientific thinking, diminishing urban culture and commodification of architecture. The effects of these shortcomings have fostered a loss of captivation between humanity and architecture placing people at odds with their built surroundings. This thesis aims to reintegrate captivation within design drawing metaphorical inspiration from storytelling to create engaging architectural spaces. In so doing, architectural storytelling is established as a new design theory with the aim of integrating rich narratives within the foundation of the architectural design process rekindling the strained relationship between architecture and mankind. Storytelling architecture will be showcased through the design of a subway station at Queen St. and Ossington Ave. in Toronto. 


\section{Acknowledgments}

Thank you to my family and friends who have been extremely supportive during this thesis. Secondly thank you to Kendra Smith and Hitesh Doshi who have both spent many hours guiding me through the complex world of architectural theory and practice. 


\section{$\mathrm{T}_{\text {ABIE OF CONTENT }}$}

\section{Chapter 1 - Introduction}

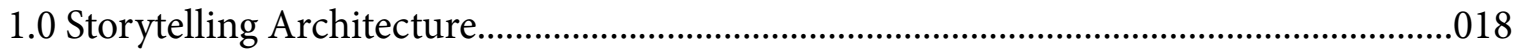

1.0.1 Loss of Captivation in Contemporary Architecture..............................019

1.1 Favoritism of Scientific Thinking........................................................................021

1.2 Diminishing Urban Culture..................................................................................

1.2.1 Stranger as Threatening Figure............................................................027

1.2.2 The Home as Escape...............................................................................028

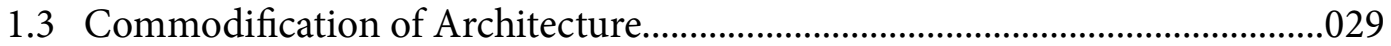

1.3.1 Architecture as Product..........................................................................029

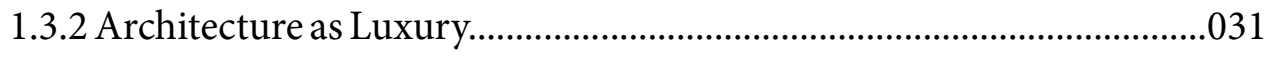

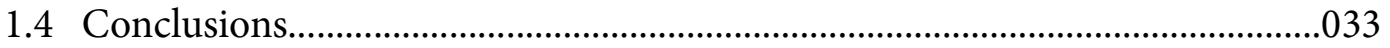

\section{Chapter 2 - Storytelling as Metaphor}

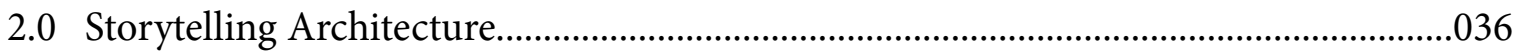

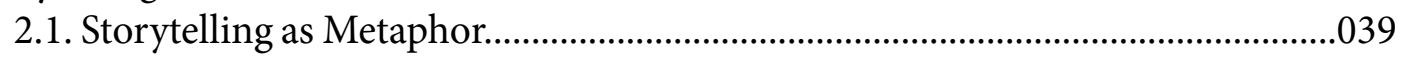

\section{Chapter 3 - Storytelling through Sequencing}

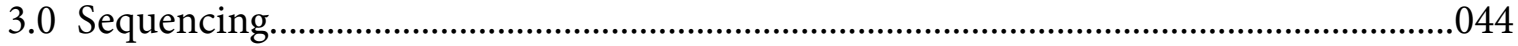

3.1 Precedent - Ribbon Chapel vs. The Hobbit............................................................046

3.2 Precedent - John F. Kennedy Airport.....................................................................048

3.3 Storytelling Through Chapters....................................................................................050

3.3.1 Architecture through Chapters: Chapter 1- Introduction.................052

3.3.2 Architecture through Chapters: Chapter 2 - Body..............................056

3.3.3 Architecture through Chapters: Chapter 3 - Conclusion.....................060

3.5 Design Experiment : Literary Tools in Architecture...........................................064

3.5.1 Foreshadowing ...................................................................................06

3.5.2 Hyperbole and Amplification..............................................................070

3.5.3 Characterization..............................................................................074

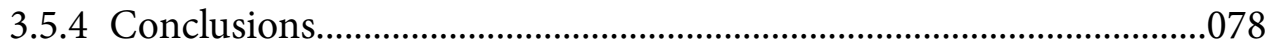

\section{Chapter 4 - Character in Stories}

4.0 Character.

4.0.1 The Disappearance of the Craftsman 


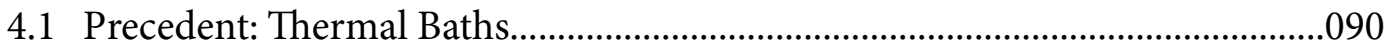

4.2 Design Experiment: Materials and Joints.............................................................092

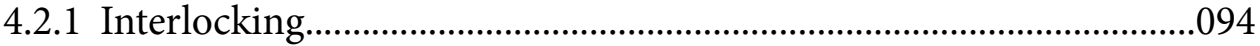

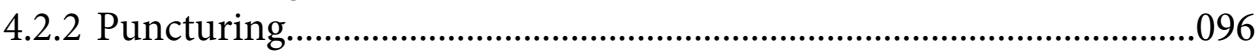

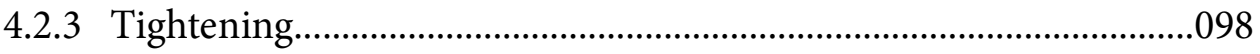

4.2.4 Conclusions...........................................................................................

\section{Chapter 5 - Emotion in Storytelling}

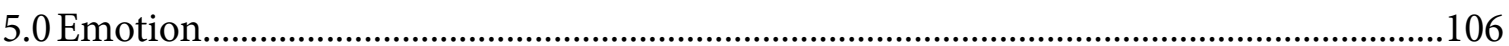

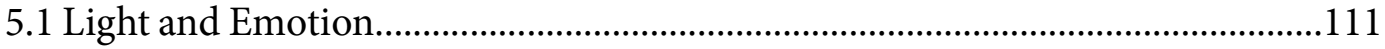

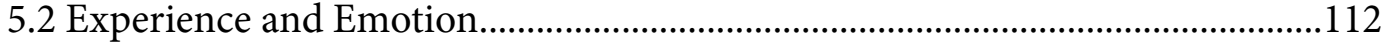

5.2 Navigation and Emotion..................................................................................114

\section{Chapter 6 - Site and Program Selection}

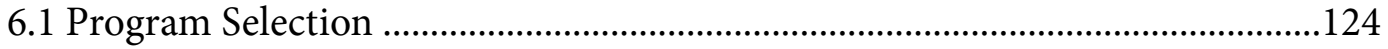

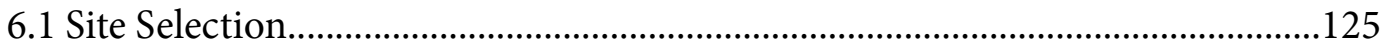

6.2.1 The Role of the Public Transportation ................................................126

6.2.2 The Feel of Queen Street........................................................................128

6.2.3 The Widened Sidewalk.......................................................................130

\section{Chapter 7 - Project Proposal}

\section{Speculation}

Speculation.

160

\section{Appendix A - TEDx Talk - Storytelling Architecture}




\section{List OF FIGURES}

Figure 1 : Pinocchio Illustration

Source: Edited by Adrian Bica, originally from http://mickeymousepictures.com/pinocchio/

Figure 2 : Frankenstein Illustration

Source: http://www.yellmagazine.com/the-curse-of-frankenstein-1957-review/29592/

Figure 3 : Peter Pan Book Cover

Source: https://en.wikipedia.org/wiki/Peter_Pan

Figure 4 : René Descartes's Illustration of Dualism.

Source: http://pacgyw08.tumblr.com/descartes-mind-body-problem

Figure 5 : American Family Dinner

Source: http://thetideym.org/family-dinner-2/

Figure 6 : Photograph of Factory Workers

Source: https://www.pinterest.com/pin/415808978070345735/

Figure 7 : Coca-Cola Production Line

Source: http://www.edie.net/news/12/Coca-Cola-Enterprises-reveals-five-pathways-to-create-factory-of-the-future/

Figure 8 : Biscuit Production Line

Source: http://www.fdbusiness.com/burton\%E2\%80\%99s-foods-becomes-the-bur-

ton\%E2\%80\%99s-biscuit-company/

Figure 9 : Top Luxury Brands

Source: http://alldubai.ae/dubai/directory/luxury-brands-in-dubai/

Figure 10 : Soane Museum House Drawings and Illustrations

Source: http://www.soane.org/

Figure 11 : Alice in Wonderland - Alice Meets Caterpillar

Source: https://en.wikipedia.org/wiki/Caterpillar_(Alice\%27s_Adventures_in_Wonderland)

Figure 12 : Alice in Wonderland - Alice Meets Red Queen

Source: https://www.brainpickings.org/2014/07/07/best-illustrations-alice-in-wonderland/ 
Figure 13: Le Corbusier's Ronchamp chapel

Source: http://inhabitat.com/le-corbusiers-iconic-ronchamp-chapel-damaged-beyond-repair-by-vandals/

Figure 14: Caricature of the Sydney Opera House by the Australian students of architecture Source: https://architecture.knoji.com/metaphor-an-aspect-of-postmodern-architecture/

Figure 15: Pan's Labyrinth

Source: https://fanart.tv/movie/1417/pans-labyrinth/

Figure 16: Latin American Memorial designed by Oscar Niemeyer Source: http://spauloetc.tumblr.com/post/12322625471/hand-m\%C3\%A3o-sculpture-designedby-oscar-niemeyer

Figure 17: Organizational Patters

Source: https://www.studyblue.com/notes/note/n/programming-planning-practice/deck/8571837

Figure 18: Ribbon Chappel by NAP Architects

Source: http://www.archdaily.com/594947/ribbon-chapel-nap-architects

Figure 19: The Hobbit Illustrations

Source: http://www.wired.com/2015/10/see-jrr-tolkien-lord-of-the-rings-middle-earth-illustrations-for-first-time/

Figure 20-23: John F. Kennedy Airport photos and Illustrations

Source: http://www.theatlantic.com/photo/2013/11/the-20th-century-architecture-of-eero-saarinen/100631/

Figure 24-35: Hand built models

Source: Photographs by Adrian Bica

Figure 36-38: Yad Vashem by Moshe Safdie

Source: http://www.archdaily.com/179679/yad-vashem-holocaust-museum-safdie-architects

Figure 39-50: Hand built models

Source: Photographs by Adrian Bica

Figure 51: Inspirational Architectural Photographs

Source: Various google searches 
Figure 52-54: Thermal Baths by Peter Zumpthor

Source: http://www.archdaily.com/13358/the-therme-vals

Figure 55-66: Hand built models

Source: Adrian Bica

Figure 67: Picture of Pantheon

Source: http://www.rome.info/pantheon/

Figure 68: Inspirational Architectural Photographs

Source: Various google searches

Figure 71: Exploded Axonometric Illustration

Source: Adrian Bica

Figure 72-76: Section Drawings

Source: Adrian Bica

Figure 77-78: Design Explorations

Source: Adrian Bica

Figure 79: Toronto Proposed Subway Map

Source: http://www.metrolinx.com/en/regionalplanning/bigmove/big_move.aspx

Figure 80-81: Existing and Proposed Queen Street Section Drawings

Source: Adrian Bica

Figure 82-90: Sketches Along Queen Street

Source: Adrian Bica

Figure 91: Queen Street Plan

Source: Created by Adrian Bica with information Ryerson GIS

Figure 92: Building Facade

Source: http://www.urbandb.com/img-thumb/height280-media-f1b8b7b3ceb65c188dcdc-

0851634cadf.jpg

Figure 93: Photograph of Jail Cell

Source: http://www.jhblive.com:85/136877

Figure 94: Photograph of a barcode

Source: https://worldbarcodes.com/wp-content/uploads/39123439-code39.gif

Note: All images without figure tags have been produced entirely by Adrian Bica 


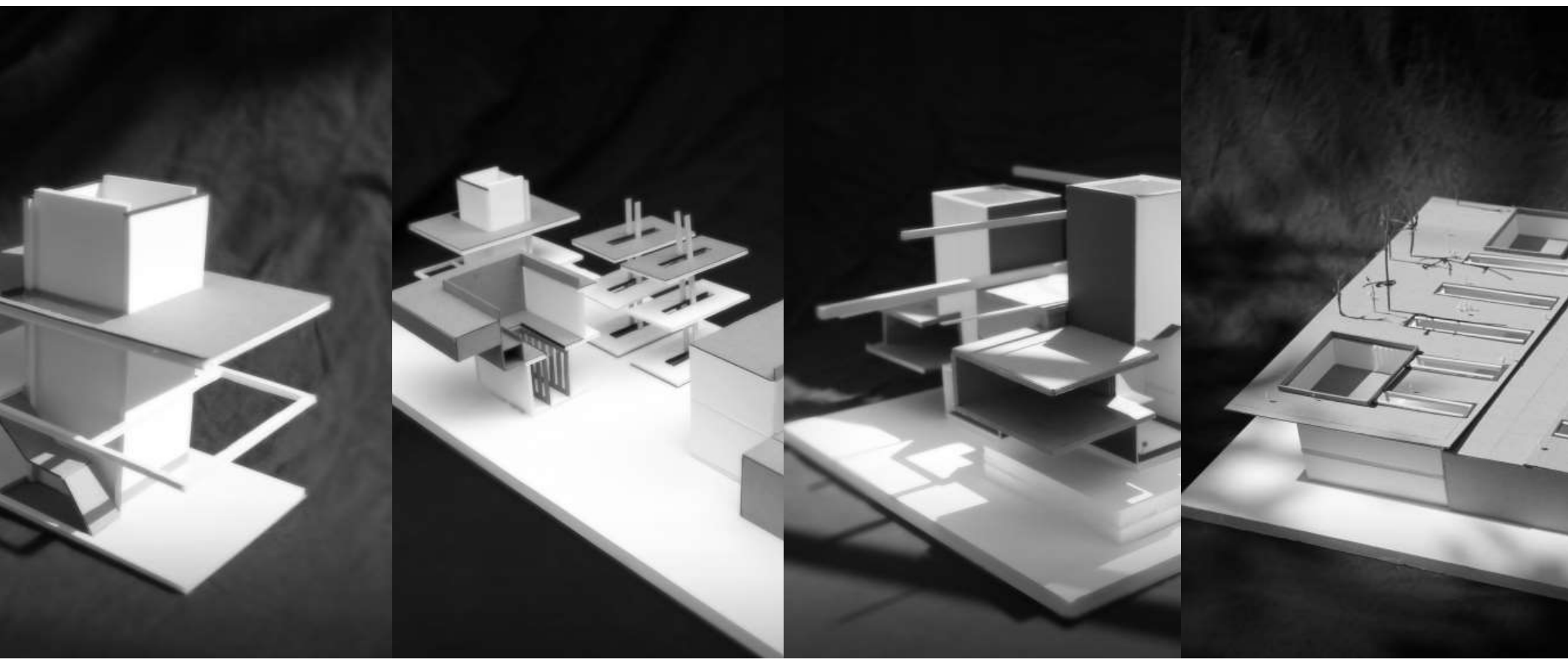




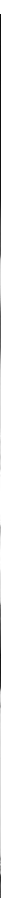

\section{Storytelling ARCHITECTURE Adrian Bica}




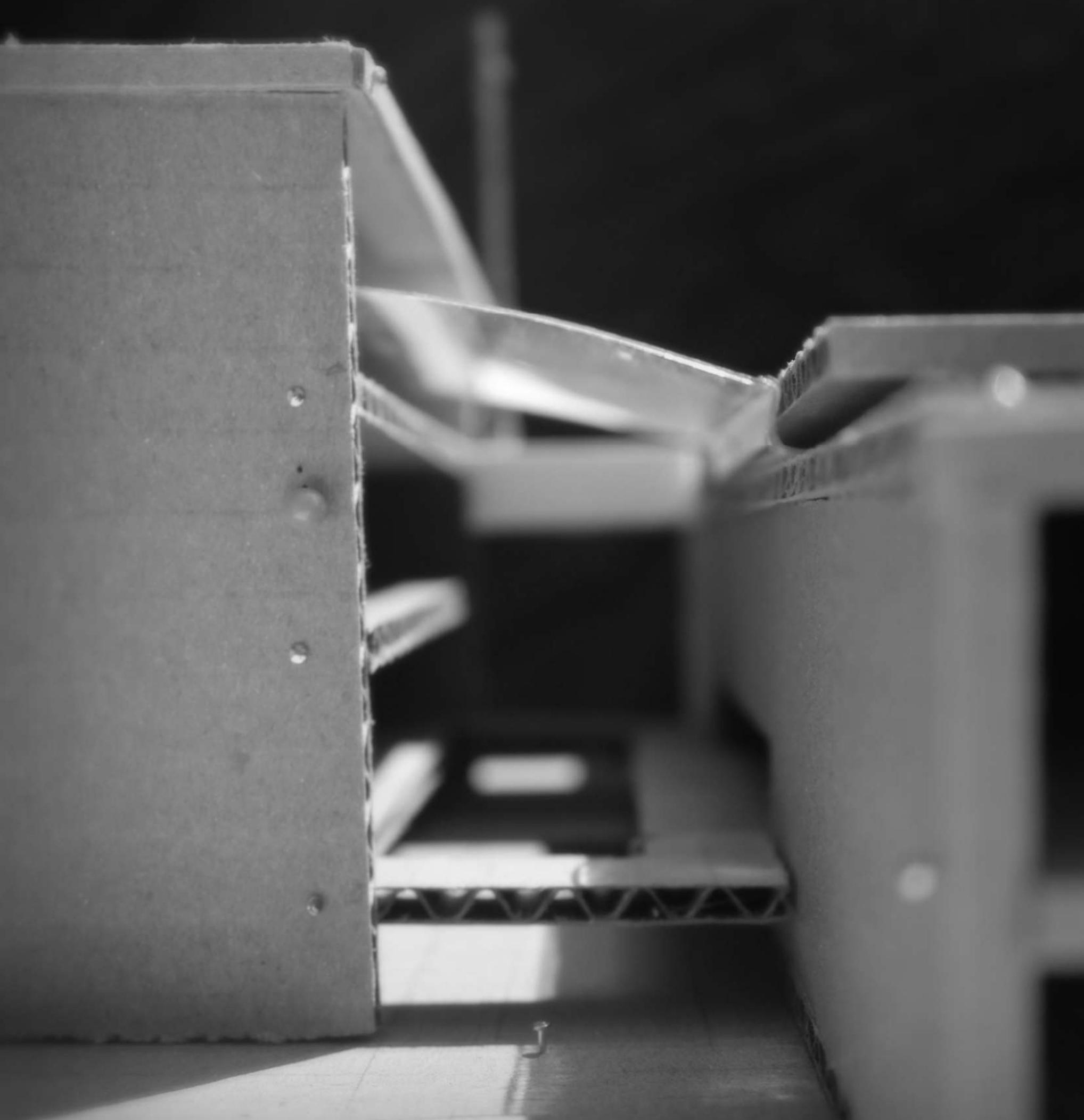




\section{CHAPTER 1. Introduction}




\subsection{S S $S_{\text {Torytelung architecture }}$}

Storytelling has been around since the beginning of time and people have often used this media as means to question that which is not yet known. These stories can take shape verbally, pictorially or spatially and engage the individual by exciting one's curiosity and imagination. If we consider some of the most-well known stories to date, we may come across characters such as Pinocchio and Frankenstein which, despite their differences, are both characters in narratives which put forth philosophically challenging questions. These stories both question what it means to be human alluding to the materialization of emotions in human created entities. These stories expand the mind leaving us with new perspectives that challenge many of our predefined notions defining how we see and understand the world. We typically think of storytellers as traveled individuals providing accounts of adventures discovering distant lore whose tales intertwine fact and fiction to create emotionally captivating narratives. It is the captivation of the unknown that draws us to these stories often leaving us with memorable themes or lessons for the future.

Architecture can similarly engage our captivation through 
well-designed narrative experiences. While a story is an unfolding of events, architecture is a composition of spatial sequencing. "... the curious citizen can easily discover architectural narrative everywhere. Narratives arise spontaneously in the course of navigating the world - from inside to outside, private to public, personal experience to collective myth." (Coats, 13). Nigel Coats believes each building tells its own story, and it is many of these stories that have made us question our relation to the universe and our place in the cosmos. Macleod's following quote pinpoints an essential aspect of mankind's captivation to storytelling as having to do with our fundamental humanistic nature.

"One reason why notions of narrative and storytelling have been so persistent is the fact that these ideas seem to capture something quite fundamental about what it is to be human." (Macleod, xxi)

Storytelling architecture is an interpretation of design in pursuit of meaning considering accounts of human experience. This form of architecture aims to understand the materialization of literature into the urban stories we live in today and aims to provide an account of a rich theatre of memory and imagination that is the cosmopolitan city. By using storytelling as a metaphorical means through which to understand architecture, design is privileged the potential to engage the complex narratives that constitute our current existence offering a new platform through which to understand design.

\subsubsection{Loss of Captivation in Contemporary Architecture}

“...by now almost nothing that happens benefits storytelling; almost everything benefits information.” (Benjamin, 89)

Contemporary architecture has diminished the ties between design and storytelling. The prime reason for this divorce is the diminishing value of experience. This concept is best illustrated by Brendan Sweetman in his publication The Failure of Modernism in which he identifies the foundations of modernism as laid out by Descartes to have led the profession down an unintended path. "Modernism in philosophy is characterized by skepticism and antirealism...." (Sweetman, 1) The skepticism referred to within the text alludes to an attitude of questioning unempirical knowledge that is essential in storytelling. He further states the following.

"Soon, however, arguments for and against skepticism came to dominate and even eclipse the search for knowledge, and slowly

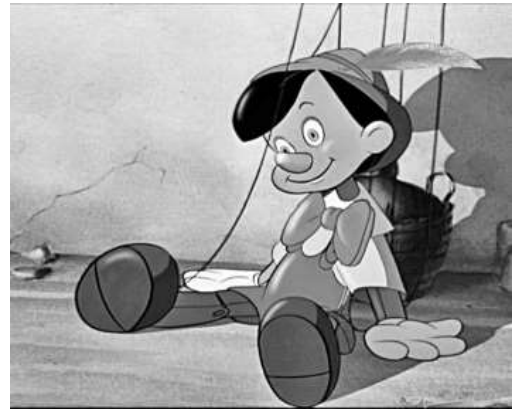

Figure 1. The Adventures of Pinocchio by Carlo Collodi. Pinocchio the wooden toy becomes a real boy through magic.

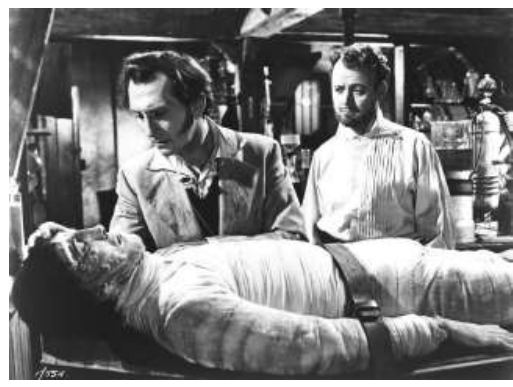

Figure 2. Frankenstein by Mary Shelley. Frankenstein's creation sought societal approval yet was hunted down in fear that it was not human. 
began to breed a certain cynicism and even nihilism about the quest for objective knowledge". (Sweetman, 2)

It is the skepticism of unempirical knowledge deeply rooted within the foundation of modernism that has fostered an architecture distancing itself from spiritually satisfying storytelling which once use to play a major role in the creation of our cities.

"As a pragmatic alternative it has proposed [Modernity] that buildings should fulfill the wishes of individuals on a democratic society: a desire for shelter and protection from the elements, for a home and a place to work where humans may live their lives in as pleasurable a way as possible. In the wake of god's demise, arguably nothing else may be necessary" (Pérez-Gómez, 3)

Alberto Perez Gomez above echoes the critiqued shortcomings of modernity disembodying buildings with the complexities of existential thinking and removing the closeness storytelling once had with architecture. "The evident shortcomings of such a view could not be more dramatic; our cities are becoming a vast world village where the external reality of man is at odds with man himself and whose reason for being is to express a mute universal process embodying the values of technology rather than to establish a meaningful framework for man's finite existence”. (PérezGómez, 3)

Architecture's distancing from soft knowledge can be traced to thee main pressures which will be discussed in the next sections; the favoritism of scientific thinking, diminishing urban realm, and the commodification of architecture. 


\subsection{Favoritism of Scientific Thinking}

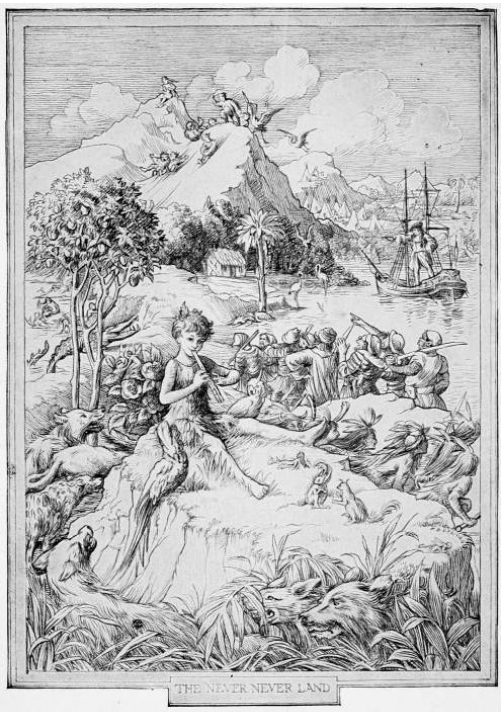

Figure 3. The highly creative and inspirational setting of Never Never land in J. M. Barrie's Peter Pan. "...even though the objective model of the sciences may be truthful, they are not able to account for the richness of our shared experience."

Marc J. Neveu

The duality of hard and soft knowledge defining the impetus of information within the built world has been skewed. While there is no singular philosopher who has brought these terms directly into the field of architecture, hard knowledge can be understood as quantifiable or precise data while soft knowledge refers to abstract, unregulated data that is difficult to summarize in numbers. Technological favoritism in architecture has overwhelmed design, yet many factors which influence how and why we choose to design are difficult to quantify and are regarded as soft knowledge, which are currently perceived as a less legitimate form of information in western culture. As a means through which to legitimize soft knowledge, many choose to rigorously apply a scientific lens attempting to solidify this information. Unfortunately, soft knowledge is heavily reduced when being explained through current mode of scientific justification. Inspiration, for instance, is influenced by such a multitude of factors in that boiling this information down to a science diminishes the very essence it attempts to convey. Stories like Peter Pan engage our soft knowledge with setting that spur curiosity and imagination without seeking to numerically contextualize this 


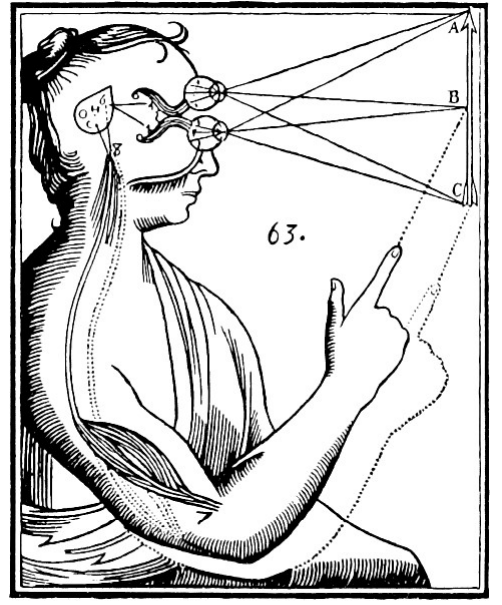

Figure 4. René Descartes's Illustration of Dualism. Descartes's introduction of the scientific method based purely on the maths and sciences heavily influenced philosophical thought. His work aimed to distinguish between the non-physical or that of the mind and the physical body which he often described making reference to the figure above. form of experience. Similarly, many factors affecting design are not yet ready to be represented through scientific representation and doing so eliminates essential aspects of what they are. In Feenberg's analysis of noteworthy philosophical texts, he comes across a similar thread.

“... calls for an improbable spiritual transformation in response to the domination of technology." (Feenberg, 9)

Favoritism of scientific thinking has spurred major discourse in architecture over the past hundred years in writings from authors such as Husserl, Alberto Perez Gomez and Marc Neveu. Marc Neveu addresses this concept in his review of Husserl's publication Crisis of European Science in which he states the following.

"...even though the objective model of the sciences may be "truthful," they are not able to account for the richness of our shared experience." (Neveu, 1)

While this statement in no way aims to reject theincorporation of technological advancement in architecture, it does raise a caution as to the use of medium and the potential for said medium to taint the very nature of what it is trying to convey. Flusser echoes the writings of Neveu and Husserl stating the following.

"The words design, machine, technology, and art are closely related to one another, one term being unthinkable without the others, and they all derive from the same existential view of the world. However, this internal connection has been denied for centuries (at least since the Renaissance). Modern Bourgeoisie culture made a sharp division between the world of the arts and that of technology and machines; hence culture was split into two mutually exclusive branches: one scientific, quantifiable and 'hard', the other aesthetic, evaluative and 'soft.' This unfortunate split started to become irreversible towards the end of the nineteenth century" (Flusser, 18)

The division between technology and the arts allowed for the two to be perceived as independent and uncorrelated. Once a strong distinction between the two has been made, the favoritism of scientific thinking or hard knowledge overtook the subjective soft thinking as described by Flusser. This scientific proliferation is recognized by some of the most famous philosophers of our time including the works of Martin Heidegger who urged for a rebalancing of objective and subjective based knowledge. 
"Heidegger deplored the dehumanizing advance of the machine while democrats and socialists cheered on the engineers, heroic conquerors of nature. However, all agreed that technology was an autonomous force separate from society, a kind of second nature impinging on social life from the alien realm of reason in which science too finds its source. For good or ill, technology's' essence-rational control, efficiency--ruled modern life." (Feenberg, 2)

The crisis of our current obsession with scientific representation as the dominant medium of architecture is further described by Alberto Perez Gomez in Architecture and the Crisis of Modern Science where he posits the following.

"The evident shortcomings of such a view [functionalism] could not be more dramatic; our cities are becoming vast world villages where the external reality of man is at odds with man himself and whose reason for being is to express a mute universal process embodying the values of technology rather than establish a meaningful framework for man's finite existence." (Pérez-Gómez, 6)

This technological favoritism occurred in part due to the transformation that occurred at the end of the 17th century where scientific thinking rejected the interpretive and non-tangible aspects of architecture resulting in buildings that no longer were concerned with their relationship to humanity. The unrelenting use of scientific thinking in architecture has placed architecture at odds with itself and the balance between the quantifiable and the subjective has been heavily skewed. It is this architectural unbalance which has fostered an unfavorable architecture distancing itself from inspiration such as that found in storytelling. As a major consequence, things that could not be measured lost their place within the process of design and many of the existential factors which use to heavily influence the creation of our cities lost their traction as we adopted the Cartesian grid as our new architectural bible.

"While recognizing the dangers of traditional religions, mortal dogmas, and ideologies, true architecture is concerned with far more then fashionable form, affordable homes, and sustainable development; it responds to a desire for an eloquent place to dwell, one that lovingly provides a sense of order resonant with our dreams, a gift contributing to our self-understanding as humans inhabiting a mortal world." (Pérez-Gómez 4)

As a result, the practice of design was transformed into a technological science predicated on optimizing space yet distancing our world from captivating storytelling which mankind so adorns. 
"This functionalization of architectural theory implies its transformation into a set of operational rules, into a tool of an exclusively technological character. Its main concern becomes how to build in an efficient and economical matter, while avoiding questions related to why one builds and whether such activity is justified in the existential context." (Pérez-Gómez, 4)

Perez Gomez implies that our current understandings of the universe is now no longer integrated within our structures and as a result, the sense of spiritual satisfaction which use to once be contained in the very essence of architecture is now no more. Similarly, Sophia Psarra argues for a re-immersion of the abstract immaterial essence back into the creation of architecture that fosters expression and meaning.

"...Architecture cannot be reduced to the duality of the conceptual realm and the reality of bodies in physical space. This duality appears as a long-standing division between mind and body endorsed by architectural and philosophical theories. In architectural practice it is often manifested as a poetic illusion of a dichotomy, advancing either the humanist view of a universe ordered by abstract relations or the romantic view of individual sensibility and freedom. It is argued that architecture orders experience through space-time relationships that interface the realm of the conceptual and the world of the senses, away from the traditional binary model of abstract and physical." (Psarra, 3)

Although Psarra does use different terminology, there is striking parallelism between soft and hard knowledge described at the beginning of this chapter and the abstract \& physical she understands architecture to be a duality of. Architectural design must recognize the necessary union between technological and intangible engagement in the creation of meaningful architectural spaces. Architecture whose meaning is to be interpreted by the general population must speak to its audience and it must do so in a fashion that can best be heard and understood by the people willing to listening. The architects needs not be scared of soft knowledge and must learn to embrace this form of information as fundamental in design. Only with a realignment of the intangible and the technical will we be able to create inspirational architecture reflecting the grandness of the narratives of our civilizations. 


\subsection{Diminishing Urban Culture}

Up until the 18th century life occurred in the public realm. It was a form of relaxation and enjoyment that offered a platform for the development mankind's social narrative to unite its citizens with stories that defined its generations. People enjoyed being out on the streets and it was the place where one felt connected with the greater social establishment that constituted their society. It was around the time of the industrial revolution where a sharp divide was made between private and public living discontinuing the social narrative that once brought together friends and strangers alike. In order to provide enough background to convincingly argue the point that current state of urban culture has diminished the effectiveness of storytelling in architecture, analysis need be made to better understand the changing roles of the home and work in relation to the wider social narrative within society.

"Not only did the factory and the office cause work to become physically separate from home, but the oppressive conditions also encouraged people to keep the two separate in their minds. Giving the home positive virtues made it into a heaven where some of the self-respect that was lost in the workplace could be recovered. Keeping home and work apart remained important, and a great deal of feeling had been invested in the separation." (Forty, 100)

This is largely in part due to the industrial revolution moving the production out of the homes of craftsmen and merchants causing the home to become exclusively a place for eating, sleeping, raising children and leisure. The complexities of public life were no longer privileged entrance into private setting and the stories that once took place on the public streets have dwindles into nothingness. As the execution of these trades moved into factories, fierce application of managerial rule decided on behalf on the workers 
what they were to work on and how long. This shift initially intended to increase production efficiency through management consequently resulted in oppressive environments where workers placed themselves at the mercy of rules and regulations. (Forty, 100) In an attempt to maintain dignity, workers exacerbated the values upheld within the home so as to balance the oppression felt as a result of the industrial working conditions. "One method of making the home as unlike the office as possible has been to construct it in the antithesis of environments in which work has habitually taken place." (Forty, 102) The home became a retreat and individuals used it as a means to shut themselves off not only from the harsh realities brought forth by new systems of governance but also the general public. As a result of the focalization of private, the public became a plateau no longer respected and upheld by society and the values and virtues it was once regarded with have evaporated. The rich narratives that were once born and nurtured along pubic streets were no more as people began to look to family rather than the public for their social engagements. The public is now a place of transition between the places we are and the places we want to be. The segmentation of the public experience as a mutually exclusive element that is to be dabbled in only in limited doses has hugely impacted general culture fostering a society that is at odds with the importance of its social form. David Reisman discusses the importance of social form within society highlighting the very make up of man as a result of social society. "Social character is the product of social form; in that sense, man is made by his society." (Reisman, 1) Resiman discusses the other throughout his texts as an element of key importance in the process of self-actualization.

"The presence of the guiding and approving "others" is a vital element in his whole system of conformity and self-justification. Depriving him of the sociability his character has come to crave will not make him autonomous, but only automic - resembling this cruelty of depriving the addict of liquor or drugs by sudden incarceration. Moreover, if the if the other directed man is seeking autonomy, he cannot achieve it alone. He needs friends." (Reisman, 327)

Much of Resiman's texts focus on the achievement of personal autonomy and fulfillment and much of the arguments presented within his publication Lonely Crowd traces the potential of this achievement through social engagement.

"...if he should begin to find himself among people who welcome and appreciate or at least do not punish expression and exploration of these buried parts of the self, he may be able to move towards greater autonomy". (Reisman , 328)

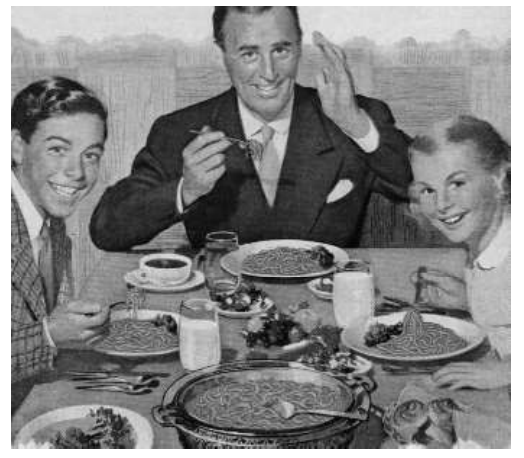

Figure 5. The perfect American family propaganda showcases the privileging of the home over the public sphere.

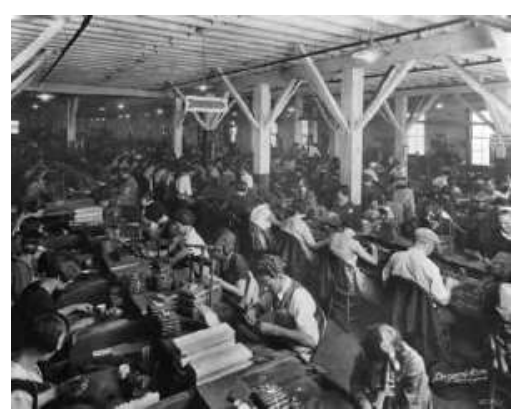

Figure 6. Workplace values lost as a result of strict manegirial rule 
The evaporation of the public realm is further discussed at large in Richard Sennett's publication The Fall of Public Man. The premise of the book seeks to highlight the unbalanced personal life and empty public sphere since the industrial revolution which can be attributed to two forces; the stranger as a threatening figure and the home as escape which will be discussed in the following sections.

\subsubsection{Stranger as Threatening Figure}

"Manners and ritual interchanges with strangers are looked on as best formal and dry, at worst as phony. The stranger himself is a threatening figure, and few people can take great pleasure in the world of strangers, the cosmopolitan city." (Sennett, 3)

While Sennett does not speak directly to the effects on architecture, he paints a broad picture of a tainted urban culture which heavily influences the underpinnings of architecture. One such example as outlined in the quote above is the designation of those whom compose the cosmopolitan city or the "stranger" as a threatening figure. In the past the public was enmeshed with an understood social order that was upheld by society offering those within the public sphere a sense of familiarity and comfort. As these social orders have changed our culture has adapted by excluding the stranger from essential aspect that constitutes our lives. Sennett goes as far as to claim that the rejection of the stranger brings about a new found danger; a danger as a result of a society composed of the unfamiliar. This skeptical state of mind unwelcoming of those whose motives are unknown has triggered a shift in how we fundamentally behave towards the unknown. Stories of that which are unfamiliar are avoided for the unknown is no longer perceived with curiosity and interest.

Architecture that was built prior to the urban collapse reflected the complexities of the public realm but as a result of our new societal constructs, there has been a withdrawal in the desire to create spaces reflecting the social narrative of society. With the sterilization of the public realm has come the privatization of architecture that no longer aims to host unique and diverse public activities fostering rich narratives and instead focuses on creating spaces of exclusivity geared to the individual. It must be noted that these claims are made not to romanticize or attempt to reemerge the period in which the public was celebrated, they are an attempt to understand a shift in urban culture and its influences on architecture so that moving forward we are to be better informed of the pressures shaping design within current practice. 


\subsubsection{The Home as Escape}

"In private we seek out not a principle but a reflection, that of what our psyches are, what is authentic in our feelings. We have tried to make the fact of being in private, alone with ourselves and family and intimate friends, an end in itself. Modern ideas about the psychology of this private life are confused... This psychic life is seen as so precious and so delicate that it will wither if exposed to the harsh realities of the social world, and persons self has become his principle burden; to know one's self has become an end, instead of a means through which one knows the world." (Sennett, 4)

The re-framing of the home as a place of escape from the uncertainties of the public sphere transformed the dwelling into that which aims at establishing firm boundaries between what is constituted as public and that which one recognizes as private. In so doing, the home becomes a vehicle for an experience of a personal matter while at the same time distancing one's self from the outgoings of communal society. As a consequence for this comfort, mankind withdraws from the collective societal narrative in favor individualism rather than the communal good. As the mind becomes more and more privative it becomes significantly more difficult to engage with others in meaningful ways and feel a genuine sense of connection.

"And precisely because we are so self-absorbed, it is extremely difficult for us to arrive at a private principle, to give any clear account to ourselves or to others of what our personalities are. The reason is that, the more privatized the psyche, the less it is stimulated, and the more difficult it is for us to feel or express feelings." (Sennet,4)

Through an inner self-absorption and privatization of the ego as facilitated by the surrounding urban culture, interaction between those unknown is undercut in importance and made to seem as an activity unworthy of facilitation. We treat those who stand between us and our destination as obstacles that are to be avoided and ensure that as we hurdle over our fellow citizens, our bodies, thoughts and eyes never meet. Being in public is no longer desirable, and architecture has started reflecting these principles focusing on creating exclusive private spaces which speaks not of the wonders of human curiosity and imagination. Architecture use to engage the social narratives of our societies but as we have turned our back to the public realm, design has adopted an exclusive character which consequently has damaged the public realm further sterilizing it from creating spaces that could bring those who are unfamiliar together. 


\subsection{Commodification of Architecture}

Commodification of architecture is a direct influence of weakening sovereignty and the rise and cultural embrace of big corporations. With the shifting of power from the nation state to the consumer oriented businesses, architecture has shifted from what was once understood as a liberal profession to a service-providing industry. The economic power of corporations today outweigh the GDP of the most developed world nations and it is this inversion that has led to a full entwinement of commodification in the realms of architecture. This section looks to shed light on the transformation of this new architectural culture and how its effects have transformed the field into a product creating machine that has undercut many of the previously rich and enhancing characteristics that architecture use to once embody. Commodification in design can be attributed to two transformations; the creation of architecture as a product and the transformation of said product into an object of luxury.

\subsubsection{Architecture as Product}

Corporations are becoming increasingly more impactful in the lives of consumers than the government. Many of the contemporary regional and national issues demanding our attention are expected to be resolved no longer through the efforts of governance but the sheer economic strength of that regions corporations. The following is an excerpt by Kenneth Frampton summarizing the viewpoint of Michael Benedikt in relation to the influence of rising power of corporations and their influence in the field of architecture.

"In societies at peace that can maintain free markets, people can get what they want; what they want depends on how successful their needs and values are addressed by competing producers. With a 


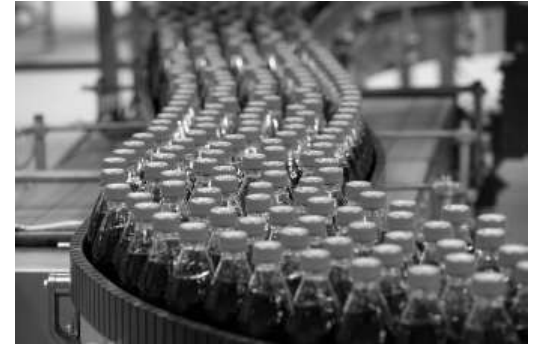

Figure 7. Coca-Cola production line

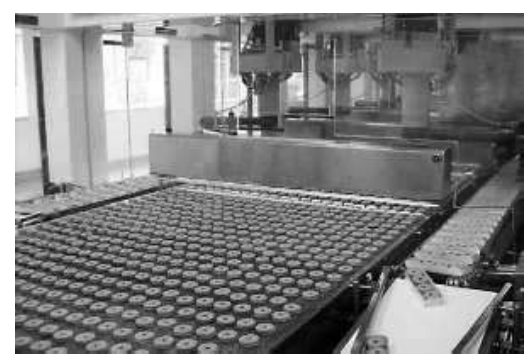

Figure 8. Biscuit production line medicum of prosperity, people have choices. This is the context in which architecture, as an industry broadly conceived, has become less and less able to deliver a superior evolving, and popular engaging product that can compete with other more successful products - with cars, music, movies, sports, and travel to name a few. And the less successfully architecture has competed with these "growth industries," the less architects have been entrusted with time and money to perform work on a scale with a quality that could, perhaps, turn things around.” (Saunders, 10)

The quote seems to imply a new transformation is occurring in architecture, one rooted within the changing political and economic structures of our times and placing architecture in the same category as products which the public is intended to consume. To make sense of this transformation, one might ask what did architecture once have that it has now lost as it became a service for the masses? Let us consider laser technologies. The first laser pointers were released as products to be purchased somewhere between the 80's and 90s' and could be acquired for a few hundred dollars. The release of this new technology grasped the attention of many researchers and with the novelty and potential future applications of the product being seemingly limitless, laser technology was at the forefront, being researched, respected and applied. With fruitful research available, laser technologies began solidifying into products available for the masses. It is now that we can acquire a laser pointer for less than ten dollars. While this may seem like a positive, and it is, the implication commodification brings to the table a totally new nuance. The question underpinning the forward momentum of this creation is no longer bound to research but purely to the monetization of a moment within the research. Laser pointers are now products that hang in front of the cashier isle by the chocolate bars tempting a purchase out of sheer impulse alone. At some point, a profit needs to be made, and it would be unrealistic to think in such a way that dismisses this notion. Recognizing this questions our perspective on how we view the general act of commodification. The transformation of goods, services and ideas into commodities or objects of trade is fruitful and has helped the world markets reach the point they are today. This critique is not of the entire process of commodification since such a broad general claim would be neither here nor there, the critique is of a moment within the process of commodification intending to show a pivotal moment which when abused leads to the creation of substandard products and means of distribution. As mentioned previously, products were solidified out of the research of laser technologies. The creation of products with the potential to be made available to the masses aiming to better the quality of human 
life is a noble cause and yet there seems to be something unsavory about the sheer force through which products are marketed towards consumers. The overexposure we as the consumers have towards objects of consumption has saturated to a point in which we detest their appearance, and product sales rely on new marketing platforms to re-brand and re-conceive the same product into something that is considered new that is once again worthy of attention and more importantly worthy of a purchase. If we were to draw parallels between this example and the creation of modern day architecture, we would come across striking resemblances. The monetization of architecture, similar to the product we have described above seeks maximum profits. In architecture, if the principle cause of the practice is the creation of capital and the fostering of public good takes a back seat position, architecture begins to act no differently than the selling of unnecessary products to people who have been deceived by marketing strategies creating a desire that was once not there.

\subsubsection{Architecture as Luxury}

As architecture entered the service industry, design became a marketing strategy and in so doing eliminated the potential for genuine emotions in response to creative architectural design solutions. Consider for instance the design of fast food chain establishments. Hundreds of identical buildings spread across the world resemble products more than they do the creation of an intricately designed society. We preserve beautiful historic architecture of the past because within it are contained the values and principles that time period. We as a society invested in architecture and the character that came with this investment has given identity to some of the major cities of today. Our current contemporary mentality seeking the fastest and cheapest solutions have inevitably shattered the principles on which architecture was once founded and in so doing has diminished the connection between mankind and buildings creating a robotic process through which we design and build our cities. The speed of this robotic architectural process is discussed in William Sanders' book Commodification and Spectacle in Architecture in which he states the following.

"Why does he sardonically state that in China architects product ten times as much, ten times as fast and do it ten times more cheaply than their European counterparts and therefore can be said to be a thousand times as good, and say this at the opening of an exhibition of projects that have taken an ungodly amount of time to design, for small fees, only to make something desperately unique, utterly au- 


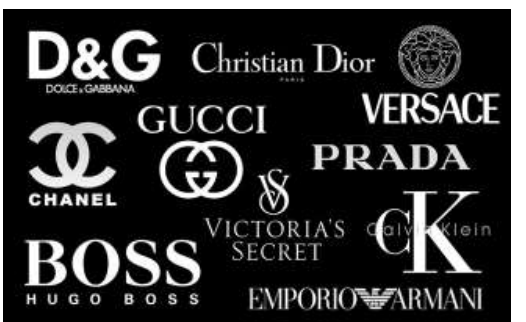

Figure 9. Top Luxury Brands thentic, personal, and seriously Architectural." (Saunders, 14)

Any architect knows the creation of truly beautiful architecture takes motivation, perseverance and time. If we consider some of the most renown architecture that has been built to date, it would downright be insulting to even propose that these works are the creation of products. And yet, this transformation moving architecture into a product-based category has already taken place. Just like any product, marketing schemes are created to boost sales and create maximum profit. In doing so, architecture has been transformed into a product of luxury, and the firms creating the works themselves become the branding.

"The regime of the last 20 to 25 years, the YES Regime, the regime of the market economy, which has infiltrated every single pocket of autonomy, has turned architecture into a different art. Thirty years ago architecture was a very serious effort, using workers and presumably producing buildings that were not luxury items, but necessity. And therefore, not necessarily committed to immediate or obvious beauty but, in a genuine way, much more interested in doing what was necessary”. (Koolhaas, 21)

Just as one may wear and display a brand that places them within a socio-economic class, architecture now does the same. Architecture has become a product acting as a brand for the economically gifted aiming to showcase the power and success of those that are wealthy enough to purchase it. The illusions of boundaries and separations of economic classes are strengthened by possessions, states of mind and other associations which are alluded to in Guy Debords' Society of the Spectacle in which he states the following.

"The spectacle is not a collection of images; rather it is a social relationship between people that is mediated by images. The spectacle appears at once as society itself, as a part of society and a means of unification. As part of society, it is that sector where all attention, all consciousness, converges. Being isolated - and precisely for that reason - this sector is the locus of illusion and false consciousness; the unity it imposes is merely the official language of generalized separation." (Debord, 5)

For architects, the thought of architecture acting as a product enforcing separation amongst socio economic classes is repulsing and yet without an activist approach to minimizing architectural commodification we will live in a world where the home will be created in a fashion quite similar to that of the automobile. 


\subsection{Conclusions}

The loss of captivation between humanity and architecture as a result of the favoritism of scientific thinking, diminishing urban realms and commodification of architecture have created a strain between people and their built surroundings. We as designers shape architecture and in turn are shaped by the experience made possible by the existence of the structures we have created. Without a realignment of architectural values to heal relationship between people and the built context, the state of design will continue to decline further aggregating a disillusioned architecture. The evidence suggests that the field of design is in a current state of crisis, demanding some sort of response from designers and architects to redirect towards recovery or continue to fall into termination. The loss of captivation is one of the major challenges architecture faces today. While there are undoubtedly many ways through which to begin exploring ways through which to once again reinvigorate captivation within architecture, the following chapters will look for inspiration in literature to compose a new design theory that can correct some of the shortcomings discussed earlier in this chapter. In the heart of this architectural crisis, a new architectural design theory is born - storytelling architecture. 


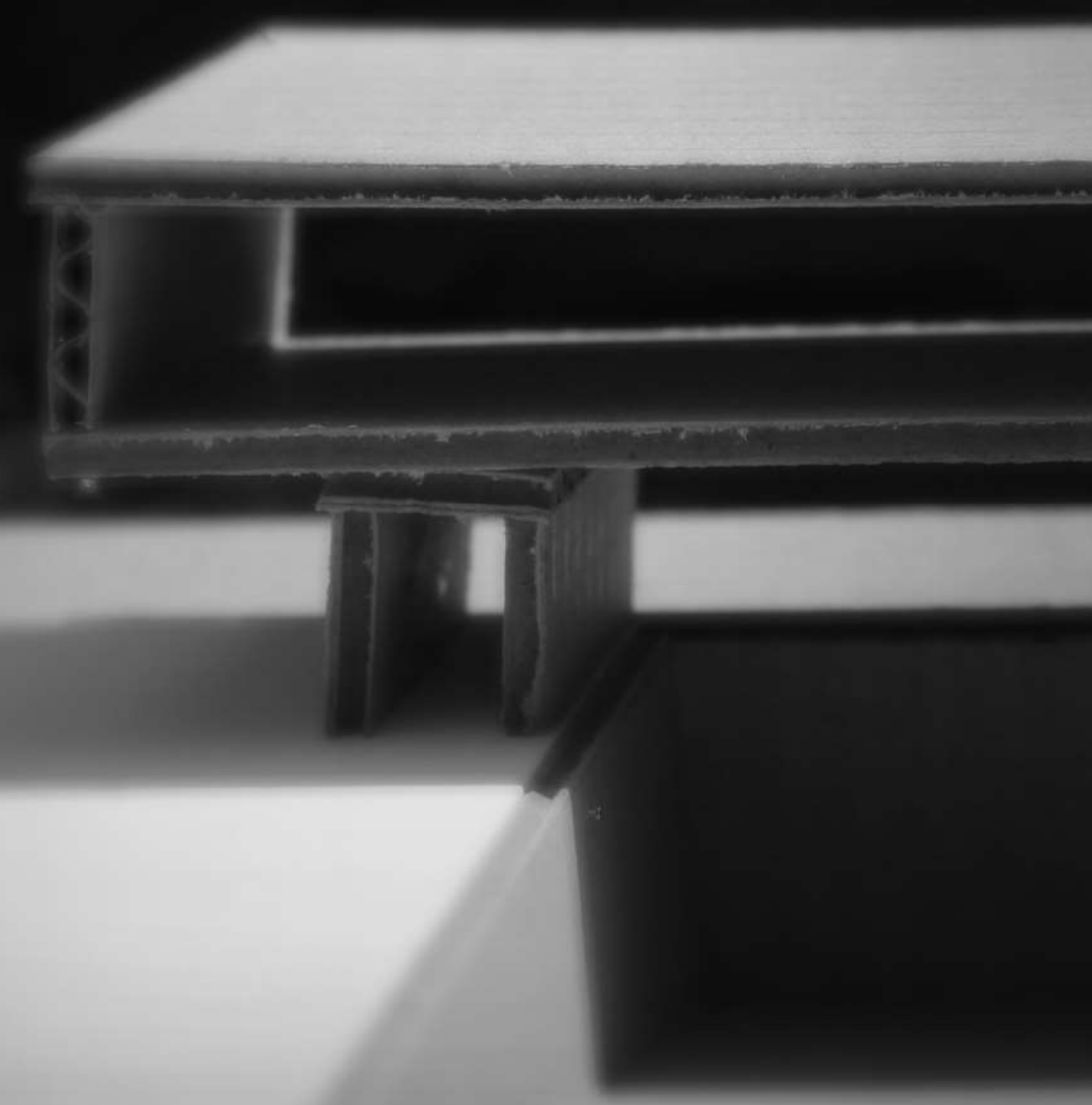




\section{CHAPTER 2. Storytelling as Metaphor}




\subsection{S Torytelung ARchitecture}

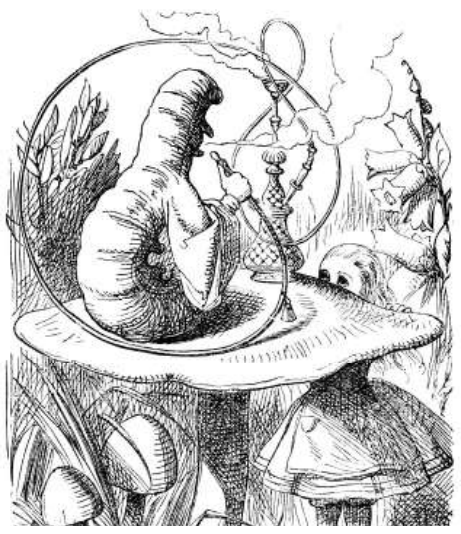

Figure 10. Alice meets Caterpillar. Alice meets a caterpillar who repeatedly asks her who she is despite Alice having answered the question to the best of her abilities. Audiences have questioned the symbolism of the scene with some tracing its deeper meaning to the struggle of selfactualization and self-identity.

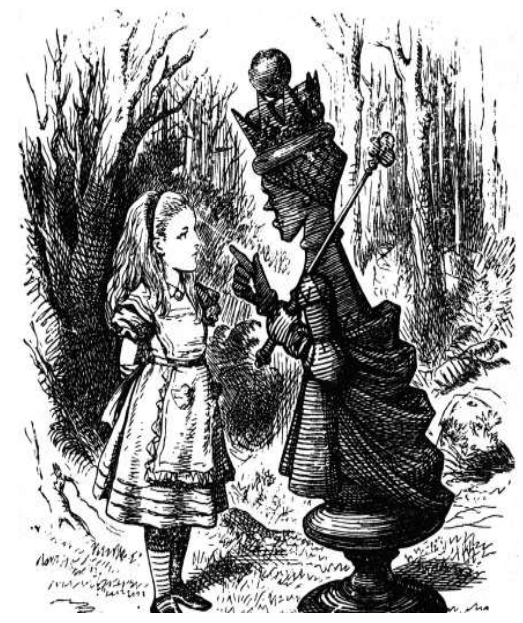

Figure 11. Alice meets Queen of Hearts. Regarded by many as a symbolic representation of unjust monarchies, the Queen of Hearts is the primary antagonist in the story showcasing blind fury and foultemperament through quick to serve death sentences for even the slightest offenses.
Since prehistoric times storytelling has served as one of the most powerful cognitive tools to help us make judgments about things and events, based on the emotions stirred by a story. Naturally, architecture can be understood as storytelling due to the striking similarity between the unfolding of narratives as one experiences sequential space within architectural boundaries. While storytelling is about the construction of a tale by setting up a timeline of events, design is the creation of a physical narration by organizing spatial relationships. Architecture has always been considered a carrier of messages. Stories and buildings have been tied up together since the beginning of conscious formation of space and the first attempts to understand the world around us. Understanding architecture through metaphorical storytelling offers designers a new range of tools through which to probe design and engage new lines of questioning that may prove to yield a more sensitive and emotionally engaging architecture. To better understand the potential relationship between architecture and storytelling, further analysis of the concept of metaphor need be presented so as to be better understand how storytelling can act as metaphorical inspiration in architect today.

\subsection{Storytelling as Metaphor}

An etymological study of the word metaphor traces its roots back to late 15th century French meaning "a transfer" and "a carrying over". We currently understand the word as a figure of speech which applies a word or phrase to an object or action to which is not directly applicable. We come across metaphors in some of the most well known stories to date in which the actions transpired allude to more than the sum of their parts. Metaphorical implications in stories such as Alice in Wonderland have left ts audiences contemplating the story to date, some claiming the story parallels a psychological journey of adventure and discovery while others claiming the story to be a result of the psychedelic state of mind of the author. See figure 10-11. The use of metaphors in storytelling offer a way of understanding something through a better or more delicate understanding of something else. In the case of Alice in Wonderland, the explicit story of a girl falling through a rabbit hole and encountering a series of unique, challenging and occasionally downright absurd situations is a fictitious delineation which offers insights into other more difficult to gasp concepts such as a ride of passage or a journey to enlightenment. These metaphorical implications deeply rooted within the story have captivated readers, making the book one of the most popular stories to date. 


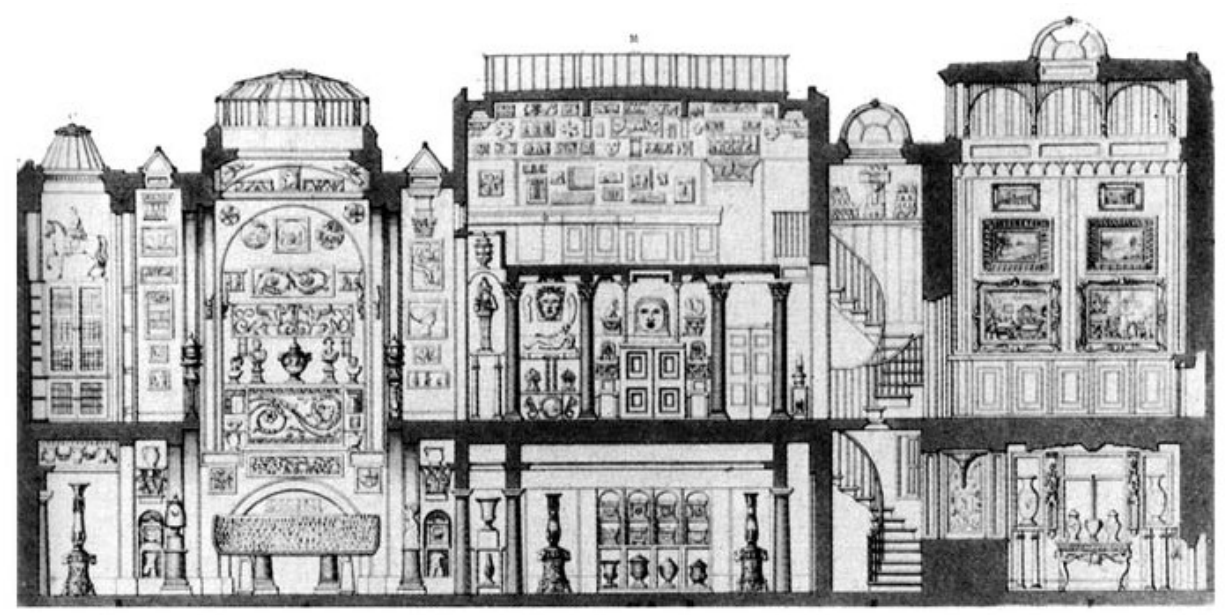

Figure 12. Sir John Soane's Crude Hints Towards an History of my House.

\section{Soane Museum House}

The following is an excerpt from Suzanne MacLeod's Making Museums publication.

“Take Sir John Soane's Museum in Fincolon's Inn Fields where downstairs in the Monks Yard Soane created the sham ruins of a monastery, with broken arches, pediments and other architectural fragments. It seems clear that Soane was storytelling, using things in three dimensions, and what's more, telling a very particular story, a story about himself. The Soane Museum is a form of autobiography - for ruins, it seems, expressed Soane's feelings of unhappy persecution. Confirmation of his taste for storytelling comes a short story he called Crude Hints towards a History of my House in which he imagined visitors coming to his house at some future time when Lincon's Inn Fields lie in ruins and visitors are trying to make sense of them. Soane, it seems was a storyteller by instinct - and was creating a museum, as many artists and writers have done since, as a way to tell stories about the world and about himself. " (Macleod, 5) 

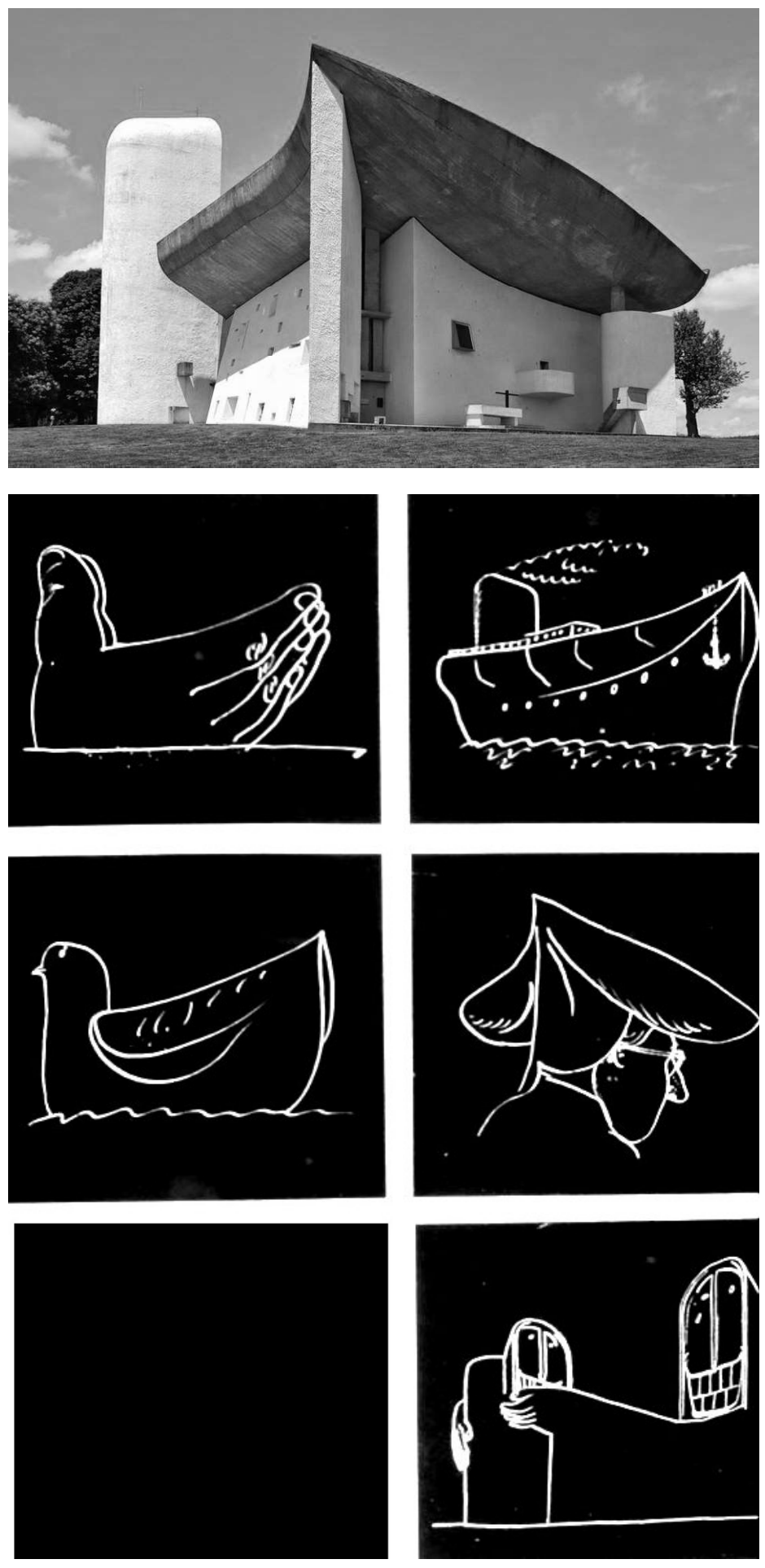

Figure 13. Le Corbusier's Ronchamp Chapel. The deeper meaning behind Le Corbusier's Ronchamp Chapel is not widely understood and as a result has drawn audiences to formulate their own stories of what the building means to them. Ranging from symbolic gestures to abstract ideas, the building has captivated audiences through the flexible perspectives through which it can be understood. 


\section{Storytelling as Metaphor}

Architectural metaphors offer us a system of understanding, helping us decipher and categorize the work presented before us. One of the most common metaphors in architecture is the use of parti pris or the "big idea." This departure point is often associated with something better understood which through design research will offer new insights into the creation of space for the project at hand. This concept is typically implemented to provide the fundamental direction for the project helping to ensure there a sense of unification once the project has been designed.

"The whole of the architectural metaphor is structured in such a way as to clarify, orient and provide reification of all the design parameters into a highly structured work. It is a work which homogenizes all these diverse disjointed systems and operates into a well-working machine. Very often the metaphor is not necessarily homogeneous but it is perceived as coherent, coordinated and complete..." (Fez-Barrington,3)

This investigation aims to explore how a metaphorical link between architecture and storytelling may expand the concept and practice of architecture. Stories are playful, captivating and exciting. They draw us in and make us imagine fictitious world whose boundaries are defined only by the bounds of our imaginations. Architecture has by some been argued to be understood as a visual language, similarly telling the stories of its essence and time. This argument has been explored by Ruskin in his book entitled Seven Lamps of Architecture in which his opening remarks aim to distinguish between building and architecture.

“...building does not become architecture merely by the stability of what it erects; and it is no more architecture which raises a church, or which fits it to receive and contain with comfort a required
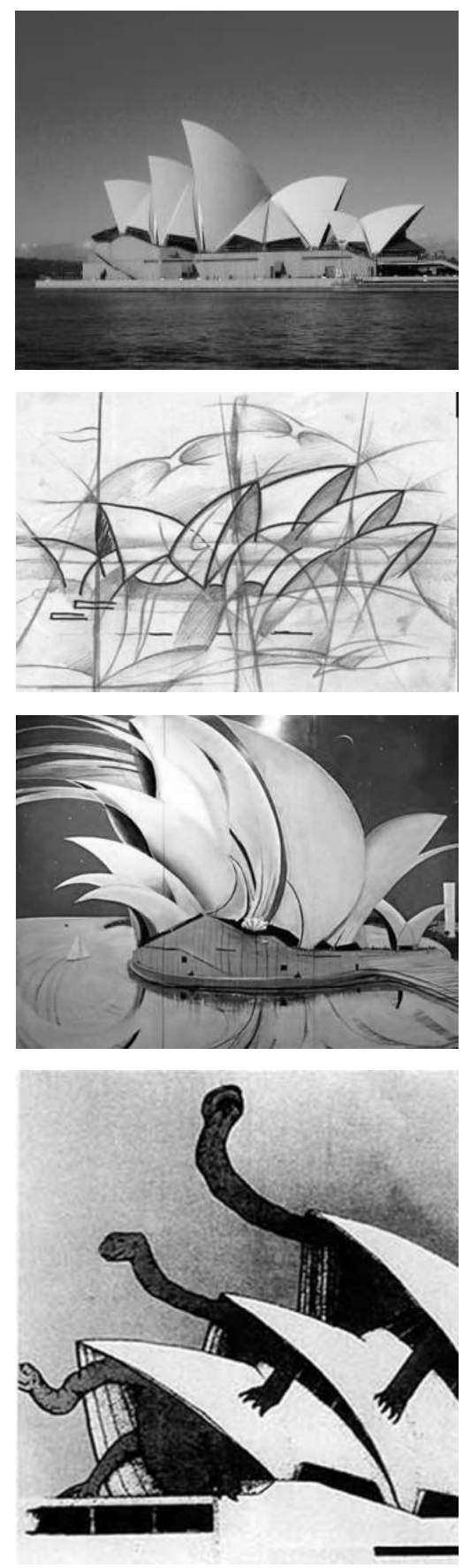

Figure 14. Official inauguration of the Sydney Opera House. The inauguration of the Sydney Opera House was celebrated with a ceremony of perspective through the creation of a gallery showcasing perspective delineations of how individuals perceive the building. 
number of persons occupied in certain religious offices, than it is architecture which makes a carriage commodious or a ship swift. (Ruskin, 15)

"Architecture is the art which so disposes and adorns the edifices by man for whatsoever uses, that the sight of them contributes to his mental health, power and pleasure." (Ruskin, 15)

It is through Ruskin's definition we begin to notice similarities between the purpose of stories and architecture. Architecture is more than the physical amalgamation of the materials which define its boundaries; it offers something intangible inherently linked the state of the human condition. Within architecture there is the telling of unique narratives and it is these narratives which transform mere building into noteworthy architecture.

To illustrate this concept we compare two works of art, one written and one built which both aim to provide commentary on the tragedies suffered as a result of cruel and ruthless political agendas. See Figure 15-16. The story of Pan's Labyrinth is a fictitious novel depicting the an unusual way of alleviating suffering as a result of cruel political actions. A young girl fabricates a magical world often going on adventures meeting unique and interesting characters that offer an escape from the tragedies that surround her everyday life. The story is told from the child's point of view, giving the reader the impression the child does indeed live in the magical world portrayed in the book. Only after much build-up near the end of the novel are audiences shocked to find the adventures they had been reading about were imaginative hallucinations to help the girl escape a reality that brought her pain and suffering. The Bleeding Hand Sculpture by Oscar Niemeyer is a physical narrative constructed to symbolize the damage done by political action against the Latin American Community. A hand reaching out for aid bleeds from a gash in the shape of South America symbolizing loss and tragedy.

While the medium in these works of art differ, the overarching theme of critiquing political action is a shared message across these two narratives. Both works have a common thread, and although the means through which that message is expressed is entirely different, the strength of the message in both examples have rung true with audiences that have brought about a sense of popularity to the pieces for the broader messages they convey. 


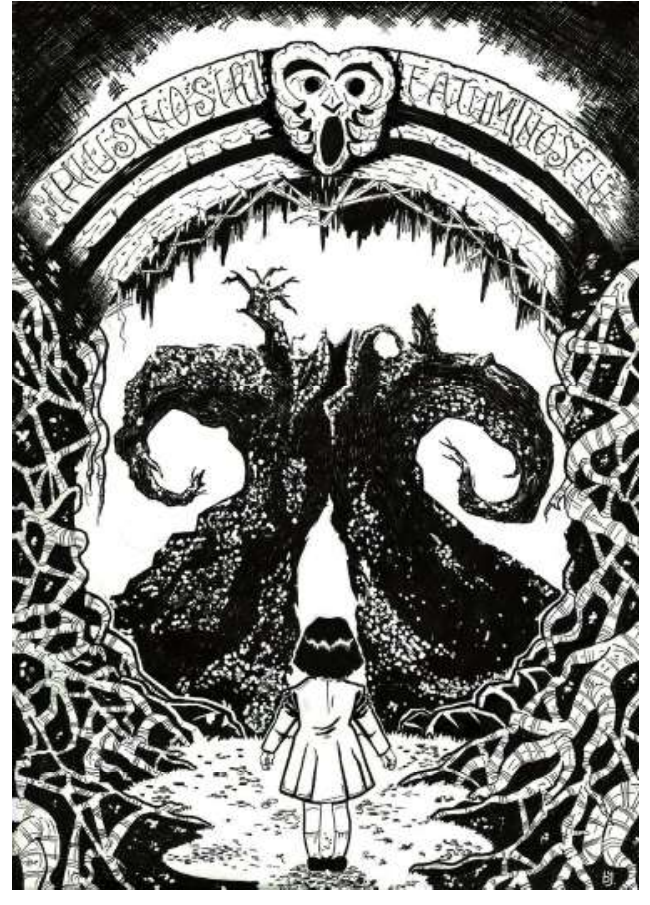

Figure 15. Pans Labyrinth. Guillermo del Toro's story is of a young girl's quest to escape the cruelties of Spanish Fascism by imagining a fictitious world in which she lives to evade suffering.

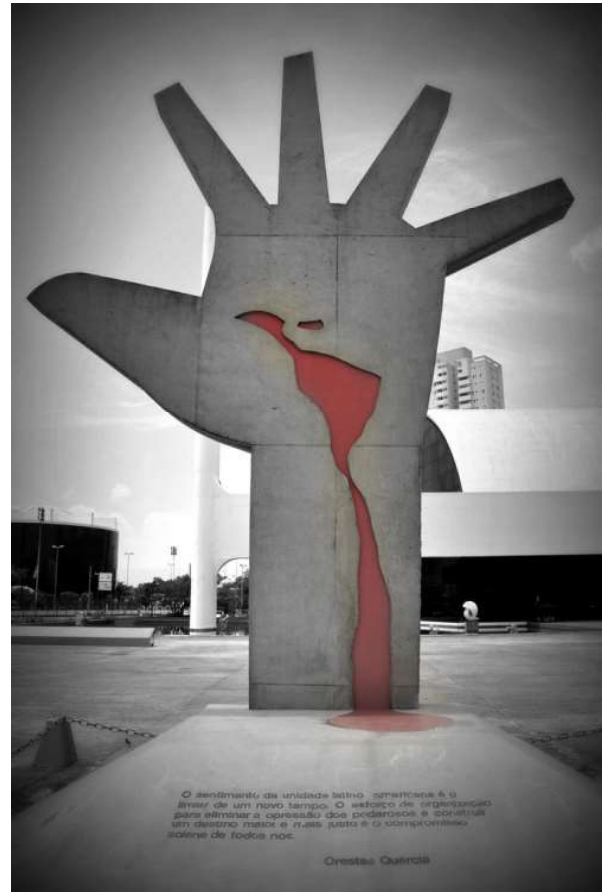

Figure 16. Bleeding Hand Sculpture. Oscar Niemeyer wounded hand depicting the suffering as a result of the political agenda of the Bush administration on the Latin American community. 


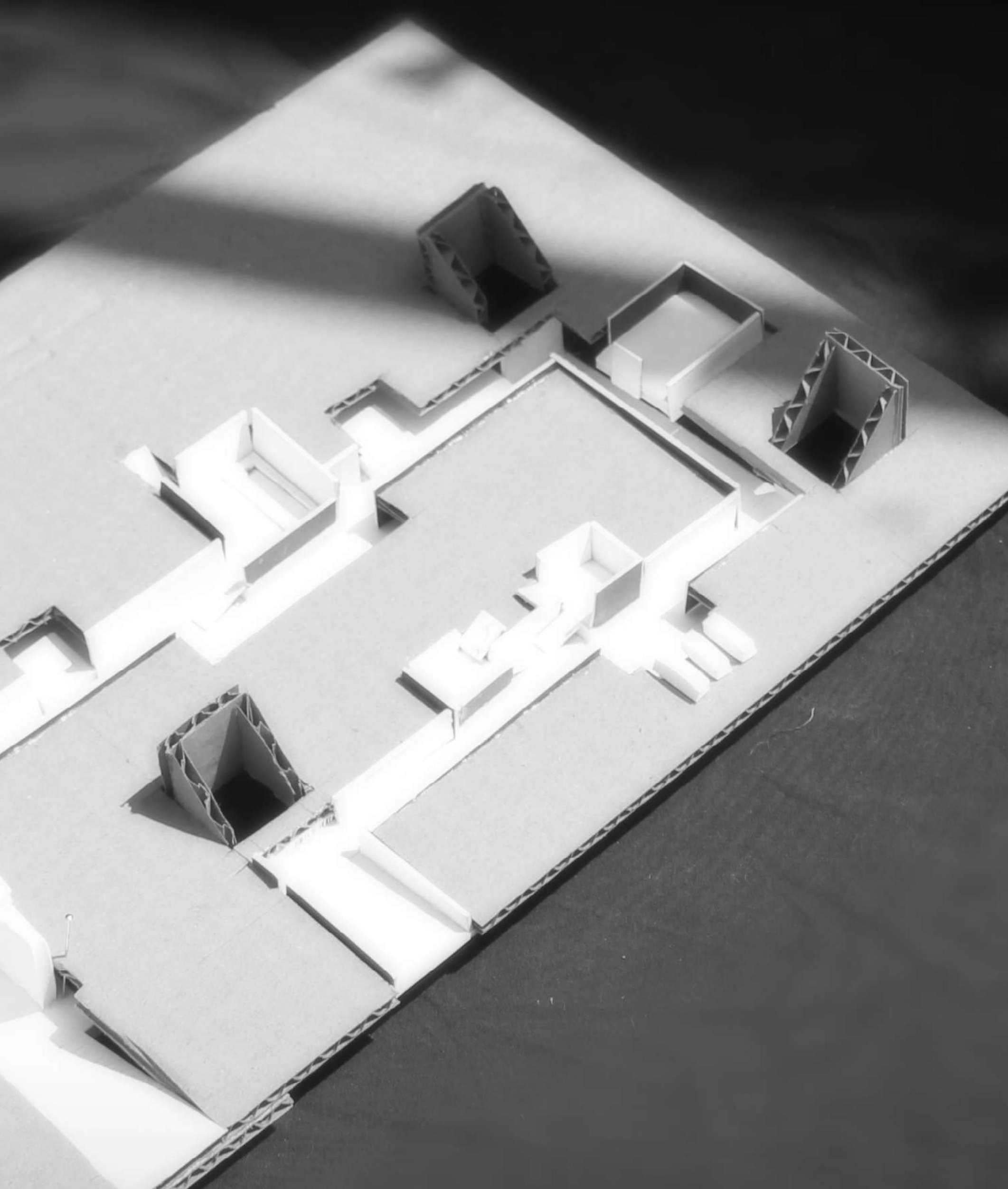




\section{CHAPTER 3. Storytelling Through Sequencing}




\subsection{S $S_{\text {Equencing }}$}

Verbal stories are passed down through language and text while architectural stories are understood through spatial experiences. The most effective spatial experiences are created by designers who have intimate knowledge of how to create compelling spaces by choreographing engaging and through provoking narratives. These effective narratives rely on the architects ability to sequence space in a fashion that best communicates that respective story creating a rich spatial experience that speaks to those who engage it. Traditionally, spatial sequencing is understood as a pattern of organization that is structured based on a linear, axial, radial, grid or precintual system which can be seen on the following page. These systems of organization define on a fundamental level the relationships between spaces in the building defining circulation hierarchies and program locations and ultimately the way in which one goes about in exploring and experiencing the building. While each work of architecture may choose to sequence a structure for reasons including but not limited to creating relationships with the surroundings, providing spatial organization for geometric forms or efficiently clustering program, it is to be noted that all forms of architecture have some form of organizational pattern that defines the spatial sequencing within the structure.

A sequence is commonly referred to as an order of succession or a series of continuous or connected scenarios or events. This definition implies that all architecture has some element of sequence involved since the experience of space occurs through time as one travels through and experiences a number of different spatial conditions. This thesis will explore 
the concept of spatial sequencing inspired by storytelling testing the potential in creating spaces that engage viewers through an arrangement of spaces that build tension and drama. In so doing, a number of experiments will be undergone to establish how drama can be build-up by creating architectural settings that captivates and mentally stimulates its audiences.

The following pages will examine two case studies to better understand narrative and spatial sequencing in architecture followed by two design experiments that draw upon the conclusion of the case studies to create architectural spaces inspired by storytelling.
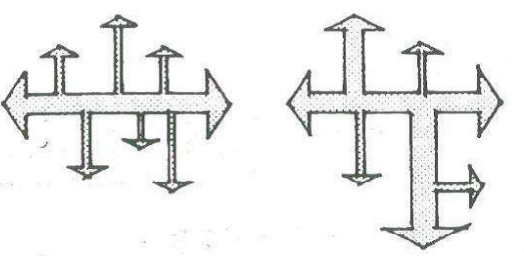

LINEAR

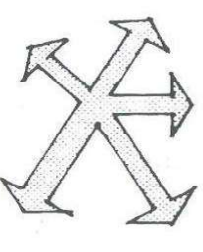

RAPIAL

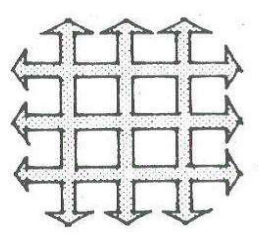

GRID

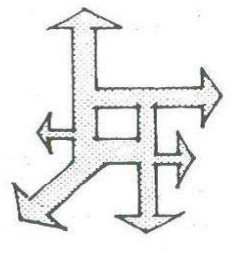

PRECINCTUAL

Figure 17. Organizational Patters through Spatial Sequencing 


\subsection{Precedent - Ribbon Chapel vs. The Hobbit}

The argument can be made that sequencing is essential in both architecture and storytelling to create a pleasing series of circumstances which when experiences in some sort of succession provide a unique interpretive journey that define the story. As such, spatial sequencing can be metaphorically be understood as the plot of a story, determining the way in which the architecture is organized and experienced. To illustrate the similarities between the plot of a story and spatial sequencing in architecture, a case study drawing parallels between the two concepts will be presented below comparing the all time favorite The Hobbit with a recently popular piece of architecture the Ribbon Chapel.

The structure of effective storytelling and captivating architecture have similar compositional elements. While these mediums of expression are inherently different, both works aim to engage audiences through unfolding narratives emotionally engaging those who experience the work. To illustrate this concept a comparison between J.J.R. Tolkien's The Hobbit and Hiroshi Nakamura \& NAP's Ribbon Chapel is shown to the right. The unfolding events in The Hobbit parallel the experiential journey one encounters when exploring The Ribbon Chapel. Within the introduction which has been captured in the first frame, both works achieve a similar goal; create a sense of intrigue to its audiences increasing the likelihood of further reading or exploration. Within The Hobbit, this is done so by hinting at the coming of a grand adventure that puts in peril all those who reside in middle earth. The Ribbon Chapel similarly peaks interest with a weaving path looping in and around the structure that seemingly becomes the facade of the building which visitors can discover and climb.

The second frame depicts Frodo's journey throughout middle earth while the chapel takes a winding journey from the ground plane to the rooftop above. Within both experiences there is a sense of novelty and uniqueness as one discovers the compositional elements that define and create the stories. While Frodo comes across obstacles and hardships to discover new friends and magically imbued items, the traveler of the Ribbon Chapel traverses a unique interweaving facade that itself is a path offering a new perspective on how circulation and facade can be combined into one seamless element in a piece of architecture.

The third frame encompass the climax of the story. A sense of drama is felt which is complemented by suspense and intensity. While the characters of The Hobbit defeat a menacing dragon, the explorer of the Ribbon Chapel discover a bella vedere at the top of the structure where the two paths that create the buildings facade converge into a small platform for viewing. 
Figure 18. [Frame A-D] - Hiroshi Nakamura \& NAP Architects - Ribbon Chapel. A wedding chapel whose exterior envelope is composed of the very paths that define its circulation. The wedding couple is expected to walk up the winding path reaching a bella vedere where they receive spiritual blessings for their future marriage.

Figure 19. [Frame 1-4] - J.R.R. Tolkien The Hobbit. The journey of Frodo traveling Middle Earth to reach Mordor to destroy an all powerful ring which could lead to ultimate destruction if fallen in the wrong hands.
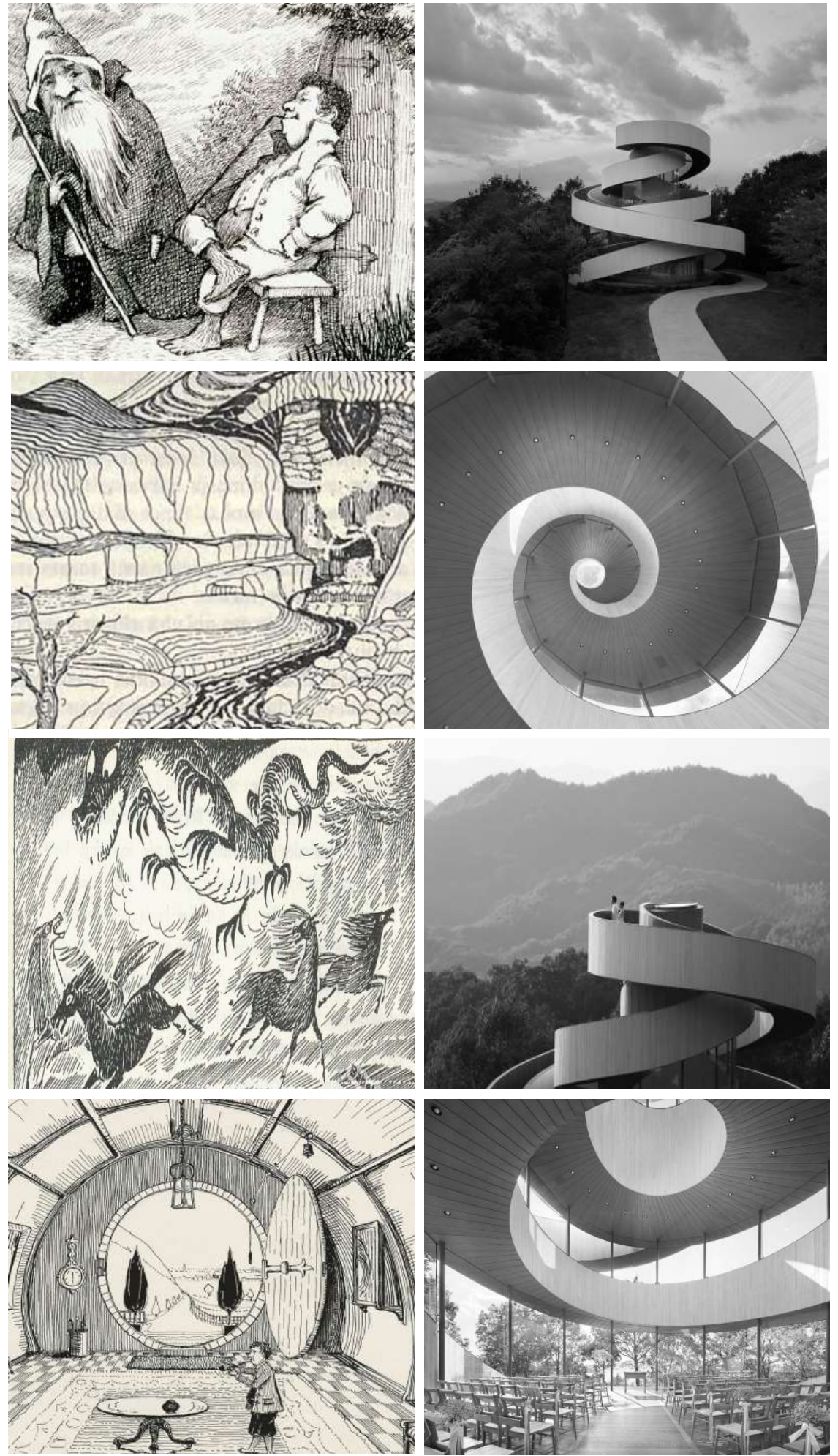

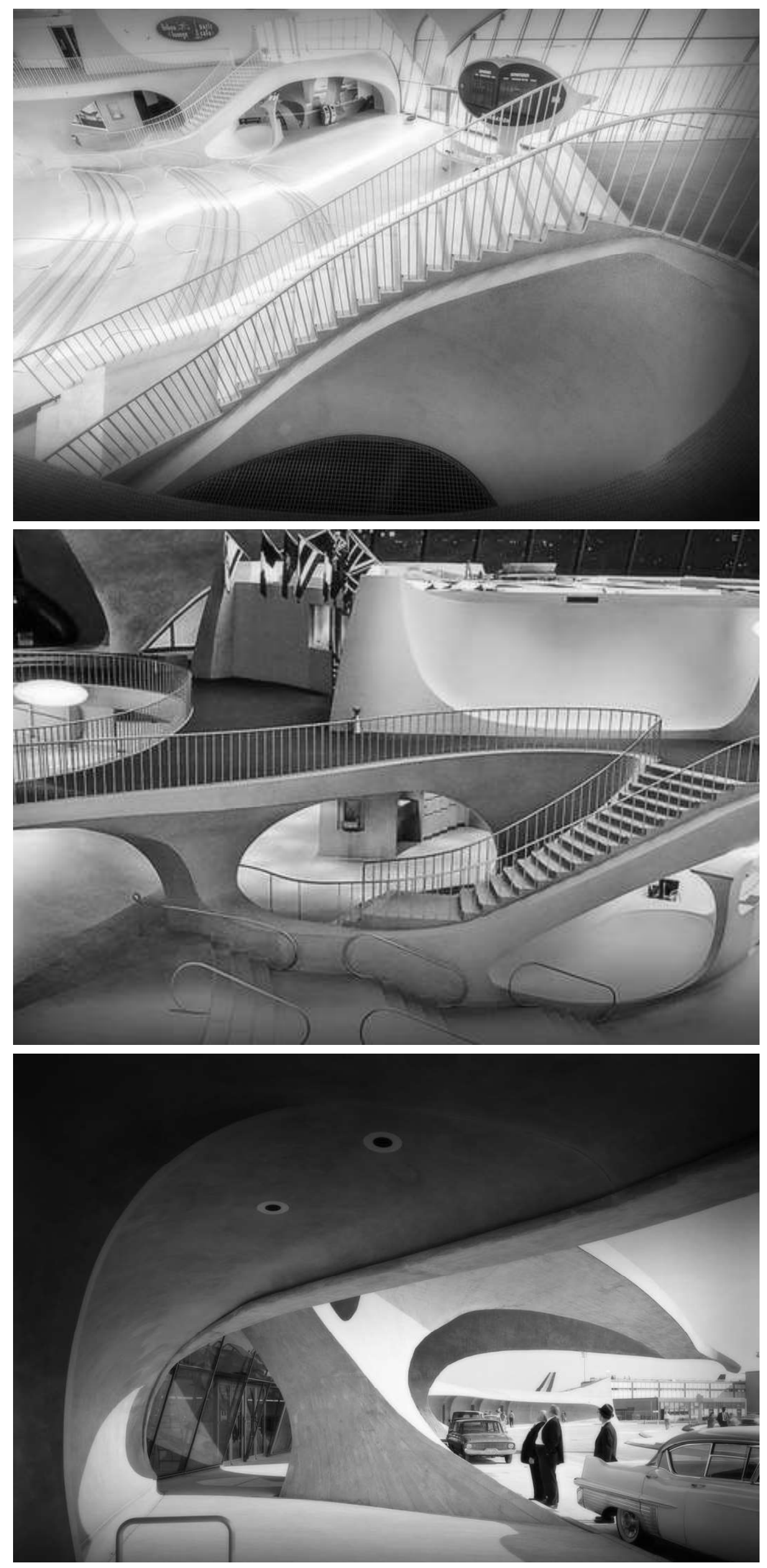

Figure 20. Curvilinear stairwells reflecting the upwards ascent and descent of planes as they take off and land.

Figure 21. Curvilinear circulation paths throughout the structure bridging together the gates at which people wait to board planes.

Figure 22. Curvilinear structural elements at one of the many entrances of the airport. 


\subsection{Precedent - John F. Kennedy Airport}

John F. Kennedy Airport exemplifies a unique narrative as individuals encounter building elements whose structure and materials encompass a story that is told through experience. Within Nigel Coats' publication Narrative Architecture he outlines a number of different narrative types as listed below.

Binary Narrative: "This constitutes investigating the object or situation with a parallel identity - not one derived from function but trans-function - that is a function of the mind, a transgression, a presence from the imagination that can heat up a otherwise banal object. (Coats, 83)

Sequence Narrative: “... lays out spaces along a predetermined route tying together several situations.” (Coats, 92)

Bioptic Narrative: "In architecture biotope suggests a urban field that includes a variety of functions and storyline that are mutually supporting yet independent, as on a university campus or in an urban village. "(Coats, 92)

Within the precedent, the structural form fully engages the narrative of flight and in so doing tells the story of airborne trajectories. The story is inherently linked with the typology by drawing inspiration from the movement of planes nearby to design the structural elements of the architecture. The narrative is neither binary since the experience is not representational and not sequential since there is no restriction to linear experience. This leads us to conclude the narrative presented in the John F. Kennedy is a bioptic narrative whose story is derived from an inherent function and whose stories develop naturally from the supporting yet independent scenarios that unfold throughout the structure.

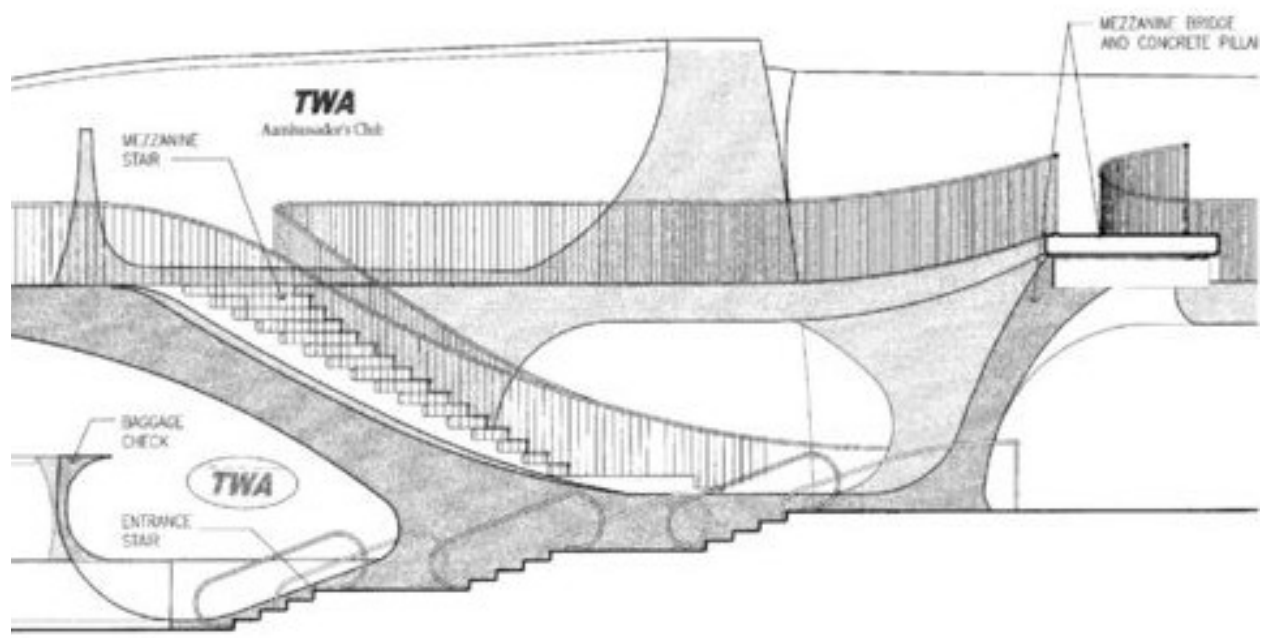

Figure 23. Precedent: John F. Kennedy Airport. Architect: Eero Saarinen. Address: New York, NY, 11403, United States 


\subsection{Storytelling Through Chapters}

If we were to consider the format of some of our favorite novels, we would no doubt be referring to a story whose make up is segmented into a series of chapters. This is done primarily to partition the story into a series of smaller fragments each focusing on specific chunks of information that are more easily digestible than the whole. Although chapters are segments of the whole, in many cases they each tell their own sub-story which when considered in relation to the other chapters tell the story in its entirety. Chapters help readers with story comprehension by packaging information into smaller and more easily digestible sections. It would without a doubt be much more challenging to read a book from the beginning to end without some form of structure in place to manage and break down the presented information.

The usefulness of chapter segmentation in architecture is two fold. Firstly, chapters can allow the designer the freedom to explore unique scenarios without having to fully commit to designing the entirety of the building. In so doing, architects are able to test multiple ideas at a much faster pace than in traditional design easily jumping between chapter explorations. Secondly, the compartmentalization of design into chapters can help in sequencing architecture to achieve a well organized narrative. Just like a story, a building is composed of a introduction, a body and some form of conclusion and by explicitly considering a design as such, architecture can be composed just like a story.

The following design experimentation aims at composing an architectural story drawing through three separate chapters. These chapters were inspired by narrative sequencing within storytelling which typically is composed of an introduction aiming to peak readers interest, a body to build up suspense and drama leading to a climactic point, and a conclusion that looks to unify the ending of the story. 
Figure 24. Model designed with inspiration drawing from the introduction of stories. The space looks to peak curiosity in its audience instigating further discovery.

Figure 26. Model inspired by the body of stories. The model looked to develop architectural character and drama.

Figure 25. Model inspired by the conclusion of narrative sequencing. The model looked to offer sight-lines to reflect back on the transpired journey.
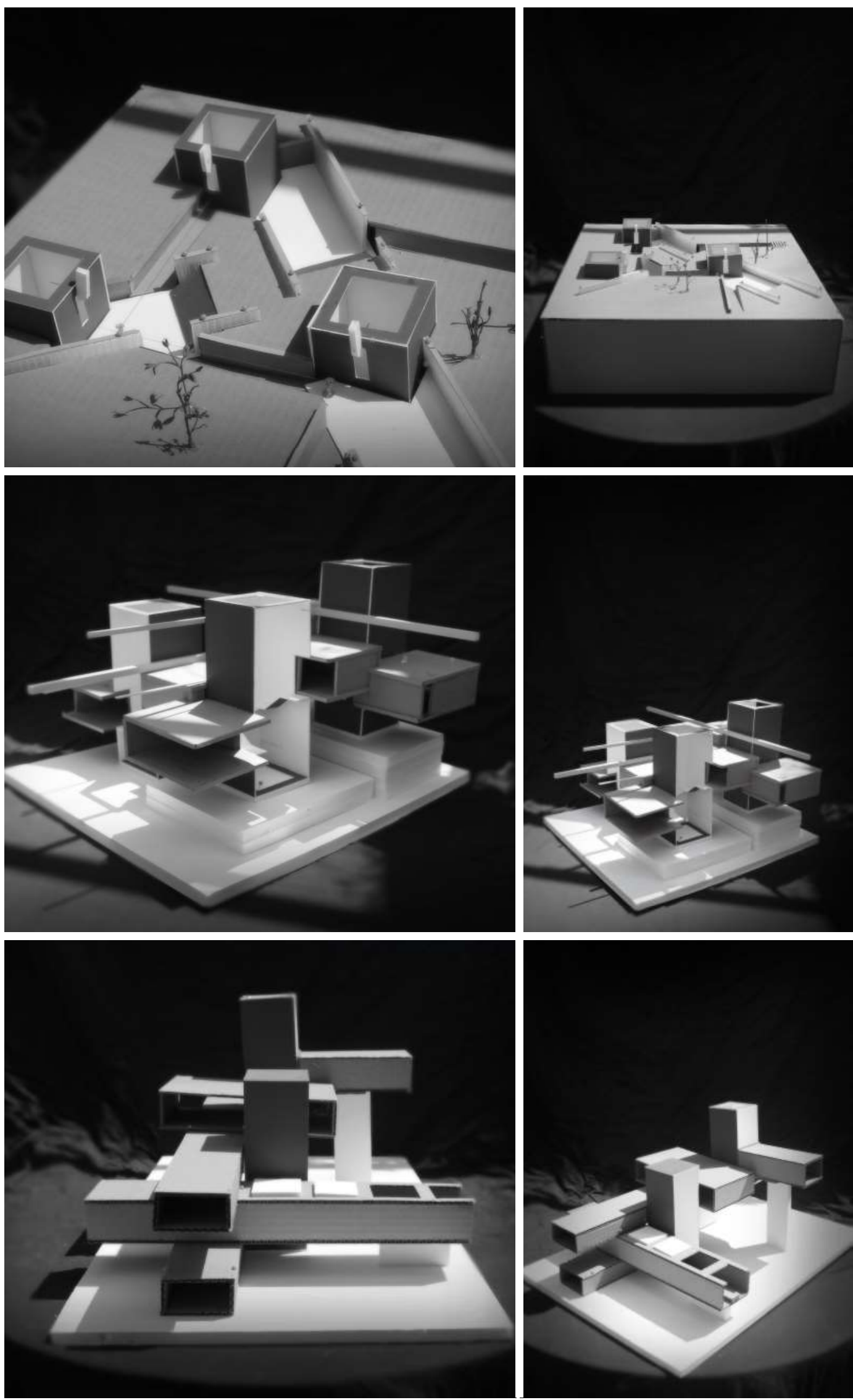


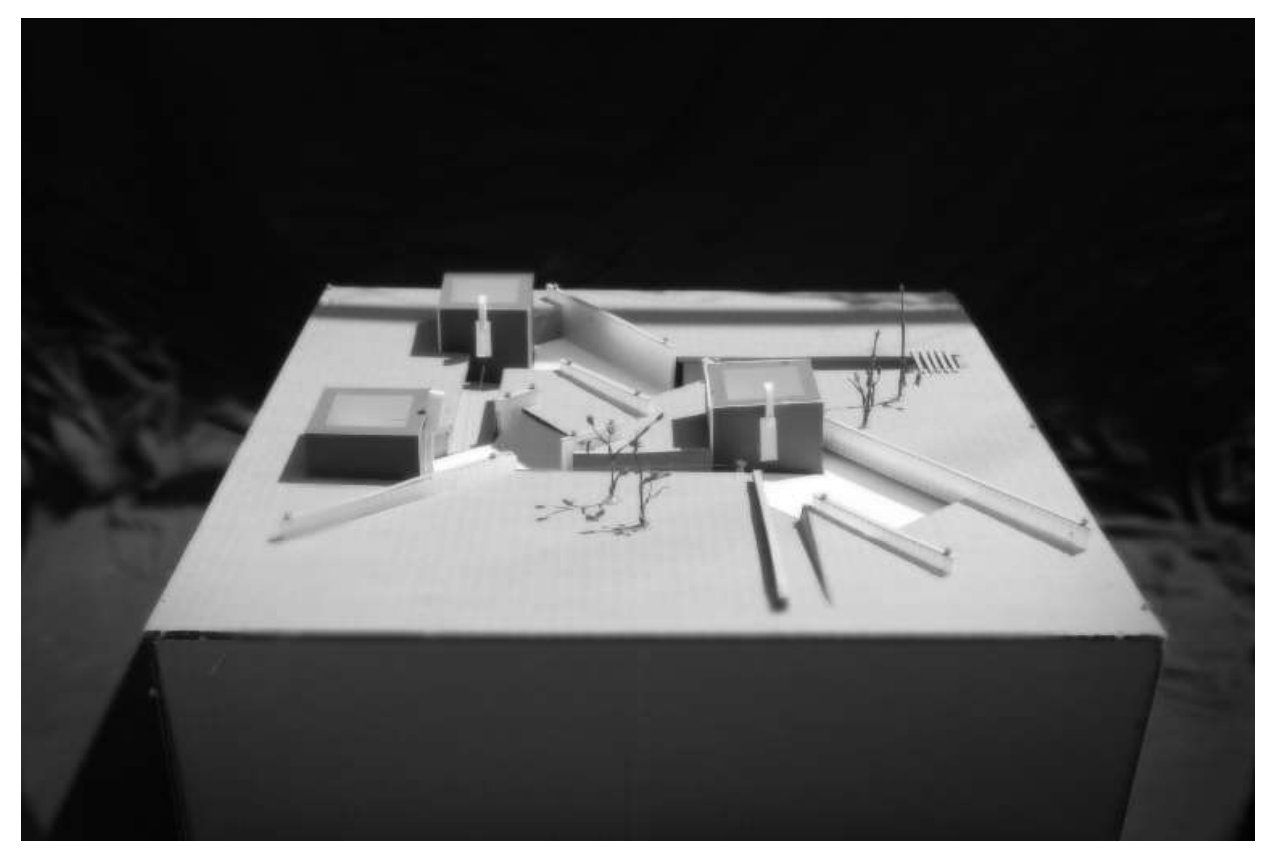

Figure 29. Framed views throughout the downwards sloping path to peak curiosity.
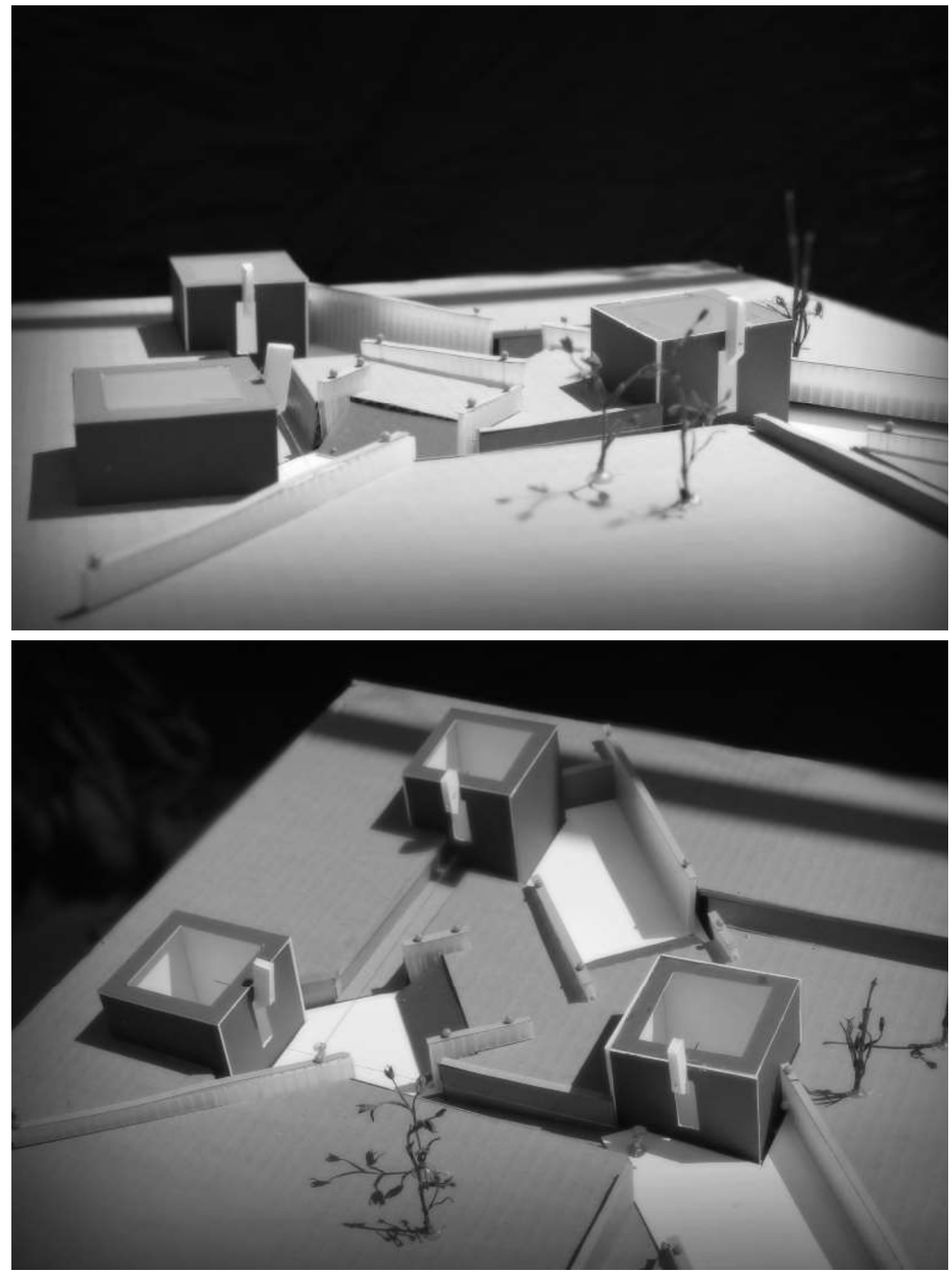

Figure 27. Multiple paths through which to engage the narrative.

Figure 28. Slow and thoughtful entrance as one approaches the skylights.

to engage the narrative. 


\subsubsection{Architecture through Chapters: Chapter 1 - Introduction}

The introduction of most literature is one of the most important segment of the story. Rarely will audiences continue reading past an introduction they did not feel some sort of attraction to the content and writing style. The introduction is what attracts your readers pulling them into the story and spurring their curiosity to continue reading the novel. In architecture, an introduction engages its audiences in a similar fashion by peaking the interest of travelers whose destination happen to take them past the location of the architecture. The model on the left hand side is composed intending to showcase an architectural introduction through three tactics that are described below.

\section{Framed Views Encouraging Discovery}

Once the traveler has begun their descent on the sloping ramp, a series of framed views intend to grasp their attention drawing them to continue along the path into the structure. These frames views are slits within large concrete skylight forms that offer views to the station below. Figure 29 shows this condition occurring 3 times, once at each location the traveler is to turn direction by 90 degrees. These frames views aim to hook the traveler into engaging the structure raising their curiosity about the rest of the building and heightening the chance that they will explore the remainder of the structure.

\section{Slow and Thoughtful Entrance}

To encourage a slow and thoughtful entrance, each stairway leading into the sloping path is designed with an extended threshold. By elongating the physical geometries that define the sides of the stairs, the threshold between park and path is blurred, creating an transient journey as one travels from park to structure. In so doing, descent is elongated, offering those along the path an additional moment of contemplation as they prepare to enter the depths.

\section{Unique Entrance Through Multiple Paths}

By providing varying entrances through which to connect to the story, visitors are offered the potential to choose how they would like to engage the narrative and in so doing provide the visitor control over how they experience the choreography. In so doing, entering the station becomes a unique activity that is to reflect the individuality of the person entering the station. 


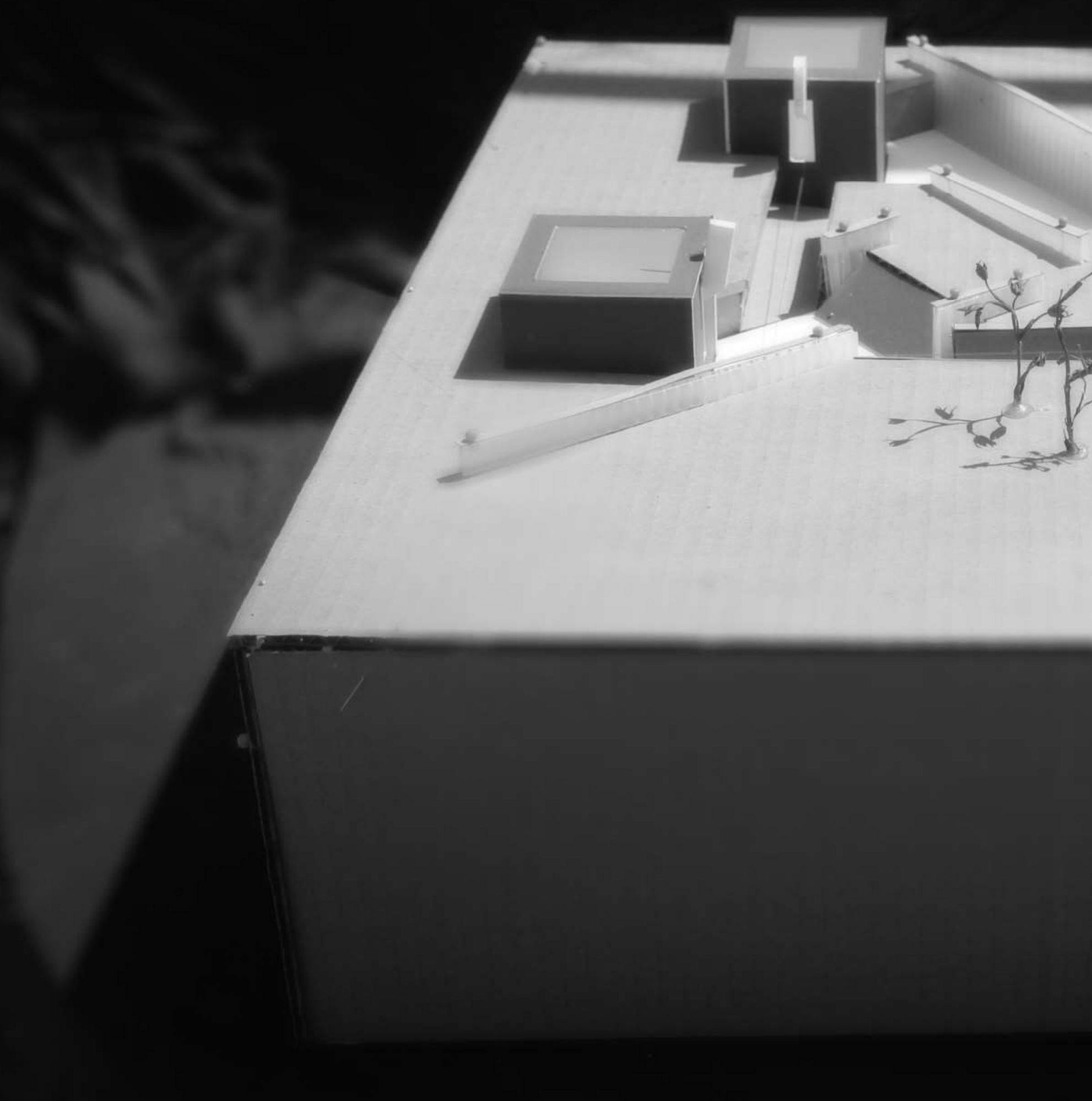




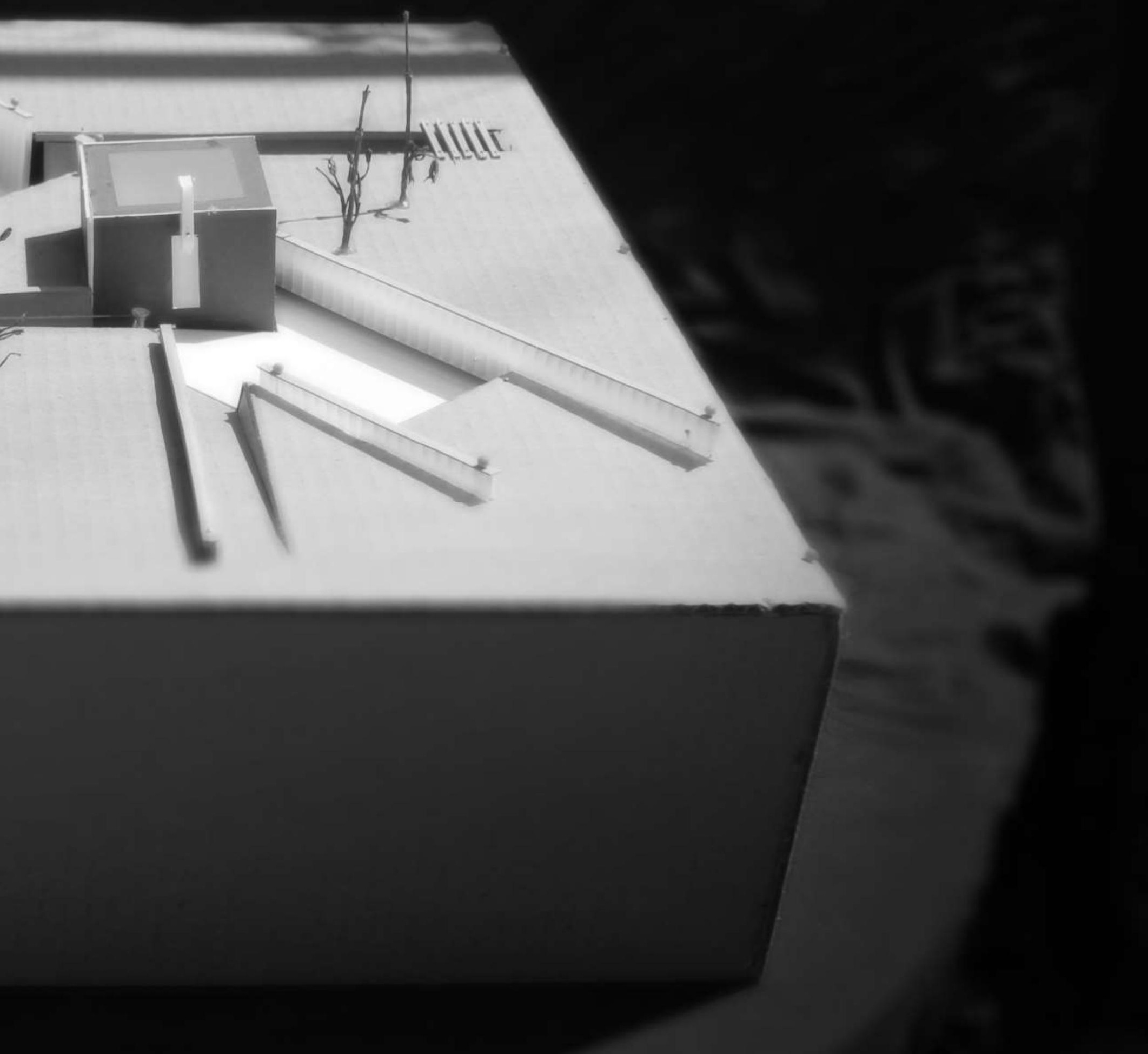




\subsubsection{Architecture through Chapters: Chapter 2 - Body}

Within most stories, the body composes the majority of the narrative with the purpose of creating drama. This drama is commonly achieved by introducing obstacles that bring fourth intriguing complexity to the lives of the characters. These obstacles add challenge to the narrative, often leading to critical moments that bring tension and excitement to the tale. A built up of drama usually leads to a high point refereed to as a climax within the story. Within architecture, the body of the structure can parallel the drama commonly achieved in storytelling to captivate the visitor and immerse them into experience. The model on the right is a design exploration seeking to foster a sense of architectural drama through three main design considerations listed below.

\section{Compartmentalized Volumes}

Rooms composed of brown cardboard are staggered both vertically and horizontally creating spatial pockets that are to be discovered and explored by those visiting the station. By providing smaller compartmentalized volumes, the structure is not immediately revealed to the visitors and individuals are encouraged to explore that which they cannot yet see.

\section{Emphasis on Downward Movement}

All vertical circulation has been placed within the skylights privileging the association of light with ascent and descent. To foster the deep penetration of light, materiality on the interior of the skylight is intended be smooth and to accentuate luminosity while other surfaces within the model are more rugged offering texture and character.

\section{Foreshadowing}

Opening are provided within each interstitial zone offering the potential to look into other rooms that one has not yet visited. Frames perspectives spanning across multiple rooms through these interstitial zones act as extended or borrowed views which aim at foreshadowing future experiences. 
Figure 30. Compartmentalization

volumes creating unique spatial pockets to be discovered.

Figure 31. Emphasis on downward movement through penetration of daylight at all stairwells.

Figure 32. Foreshadowing through framed perspectives spanning across multiple rooms.
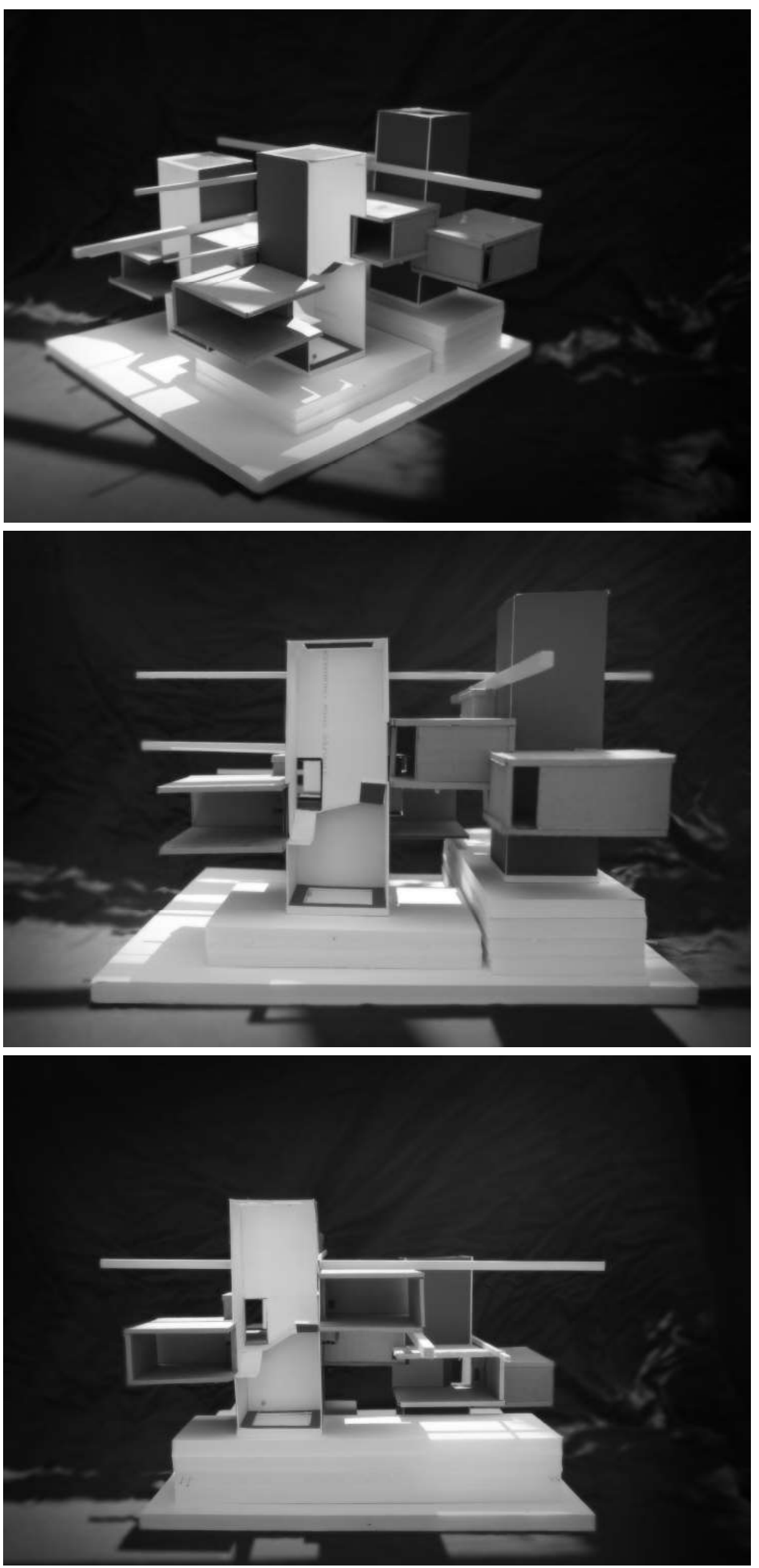


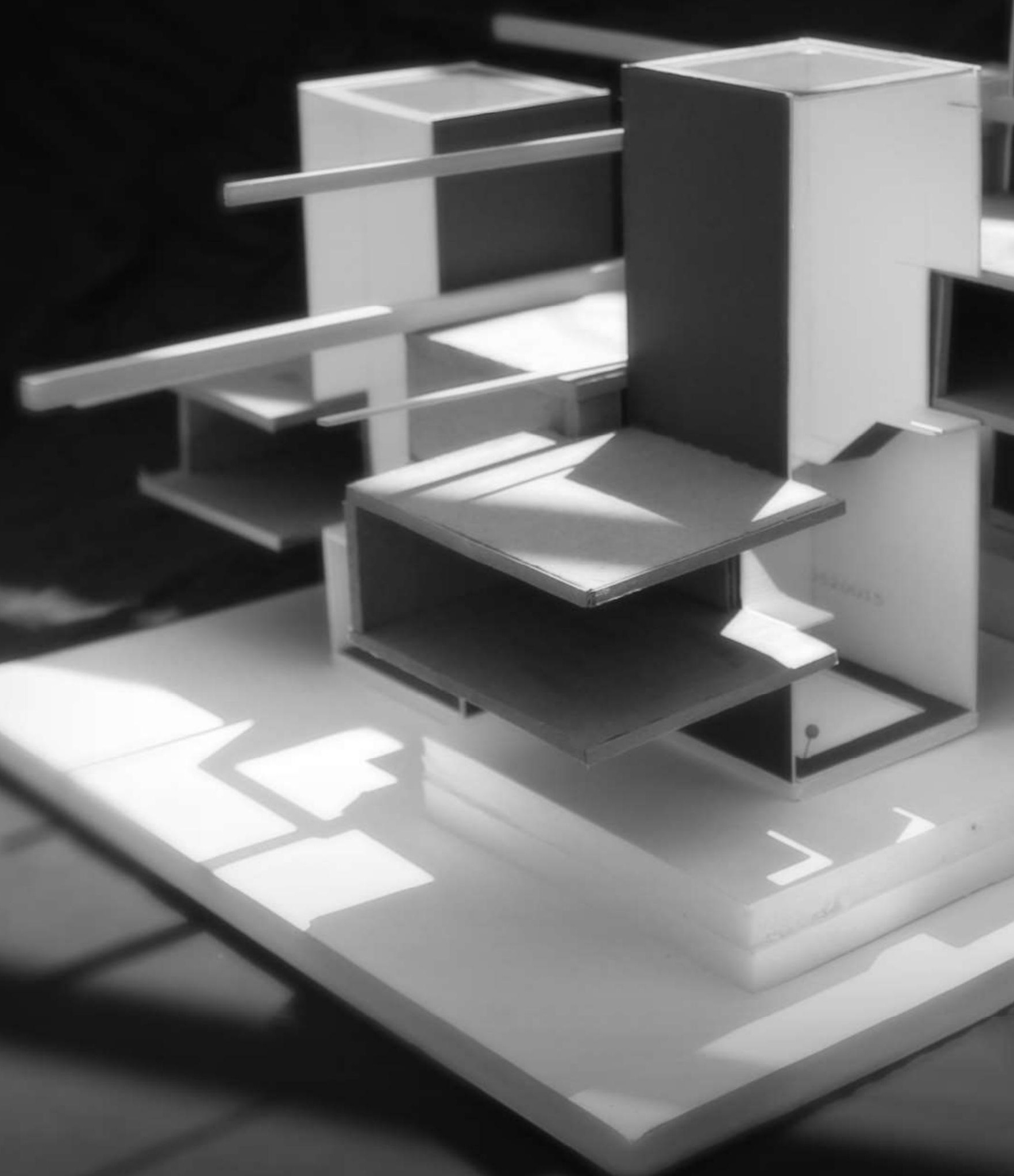




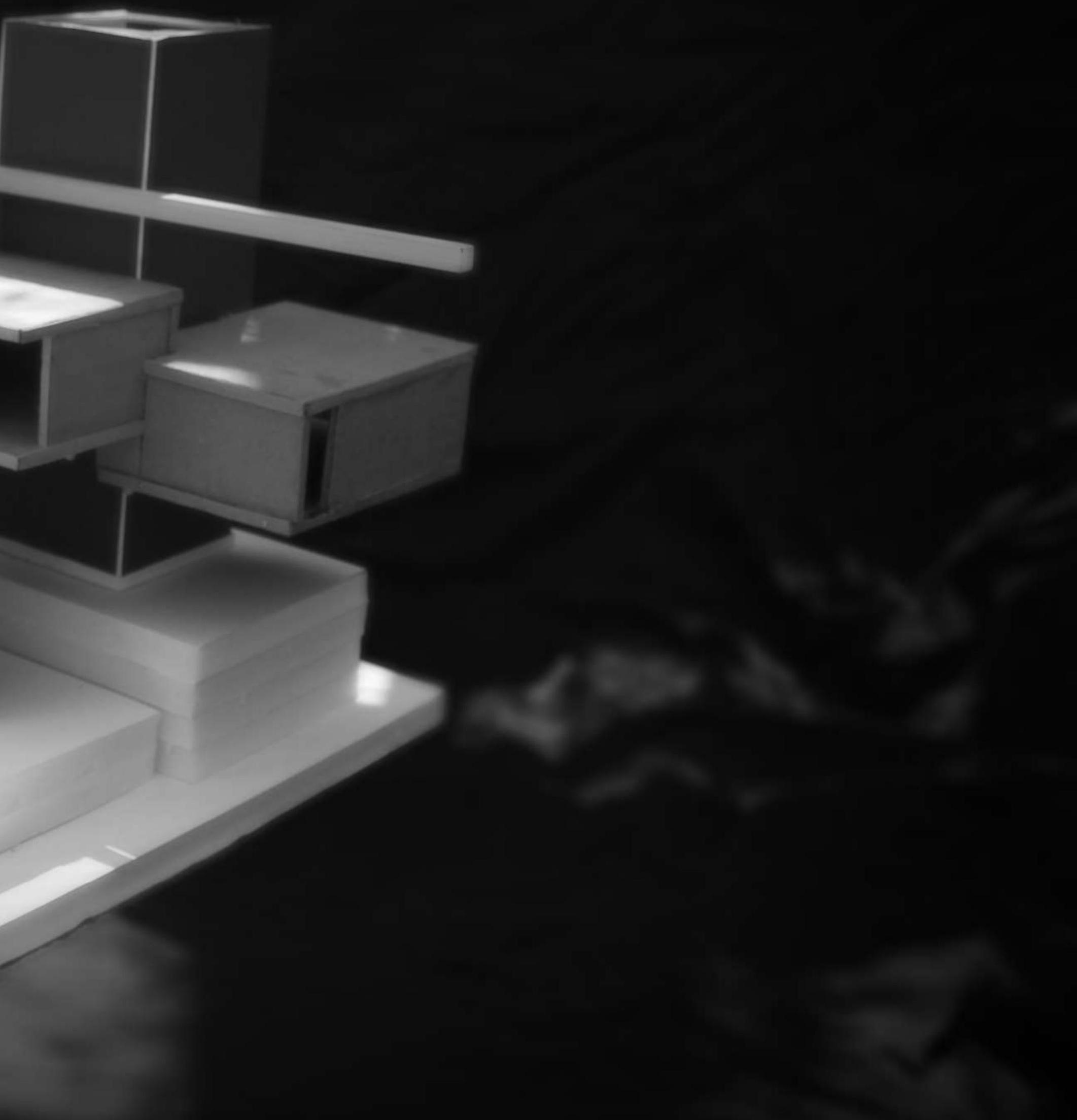




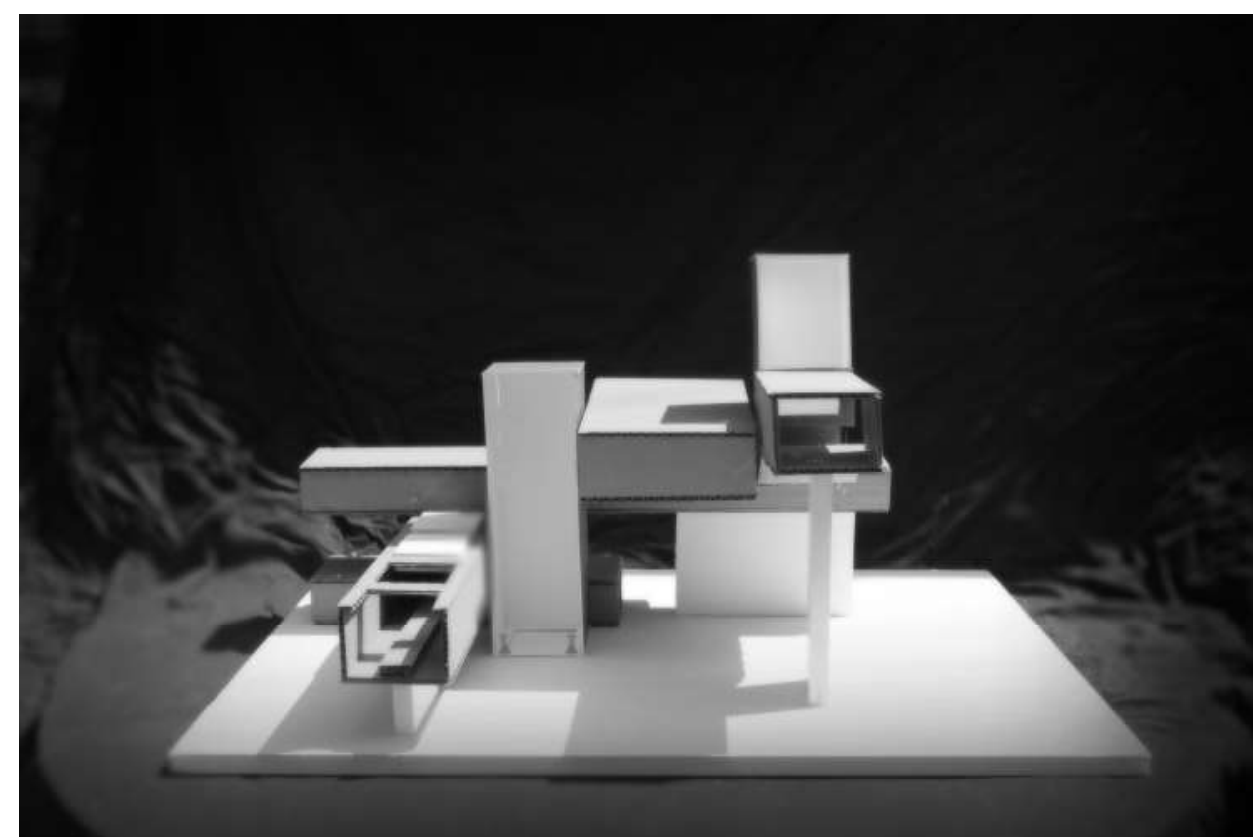

Figure 35. Opportunity for reflection along long corridors that connect the larger volumetric spaces

Figure 34. Closure of themes by reaching places which one previously only had glimpse of.

Figure 33. Termination of events by reaching and boarding transit. 


\subsubsection{Architecture through Chapters: Chapter 3 - Conclusion}

The telling of a story is not complete without a conclusion to wrap up the narrative in a way that provides the reader closure on the topics encountered within the tale. Conclusions typically occur after the climax within the body of the story acting as the falling action within the tale giving the reader the opportunity for reflection, terminating the events of the story and offering a sense of closure regarding themes encountered within the story. The model shown on the left hand side is an experiment into designing a space inspired by the common strategies used in writing effective conclusions. The goal of the design experiment was to compose a space that showcases how a space can embody similar characteristics as the conclusions of a story. The characteristics selected for this experiment were the opportunity for reflection, termination of events and closure of themes.

\section{Opportunity for Reflection}

The implementation of long rectilinear spaces woven around vertical skylights disperse the simple downward circulation into multiple elongated paths. By providing opportunities for descending the station along a unique array of circulational routes, the traveler has the option to select the path that is most convenient, from quick descents to transit, to long journeys privileging time to reflect and contemplate the spatial experience of the station.

\section{Closure of Themes}

Within the other two chapters, travelers encountered moments of light penetration at the vertical light wells as they traveled through the depths of the station. Light was used to place importance on vertical circulation creating moments of brightness as visitors of the station move downwards in the structure. Within the conclusion of the story of descent, visitors reach the end of the light well to discover social spaces embedded at the base of each well. The closure of the theme of light within the narrative end with social spaces where people can engage in discussion and share experiences.

\section{Termination of Events}

As the obstacles and hardships encountered within the story come to an end, so does the narrative sequence that composed the spatial tale. Within the model, the connection to transit demarks the ending of the story of descent and is spatially designed so as to conclude the experience of the structure with a sense of depth and heaviness that one might associate with being deep below the earth. Large heavy stones define the boundaries of the waiting platform embodying the feeling of being deep within a subterranean cave. 


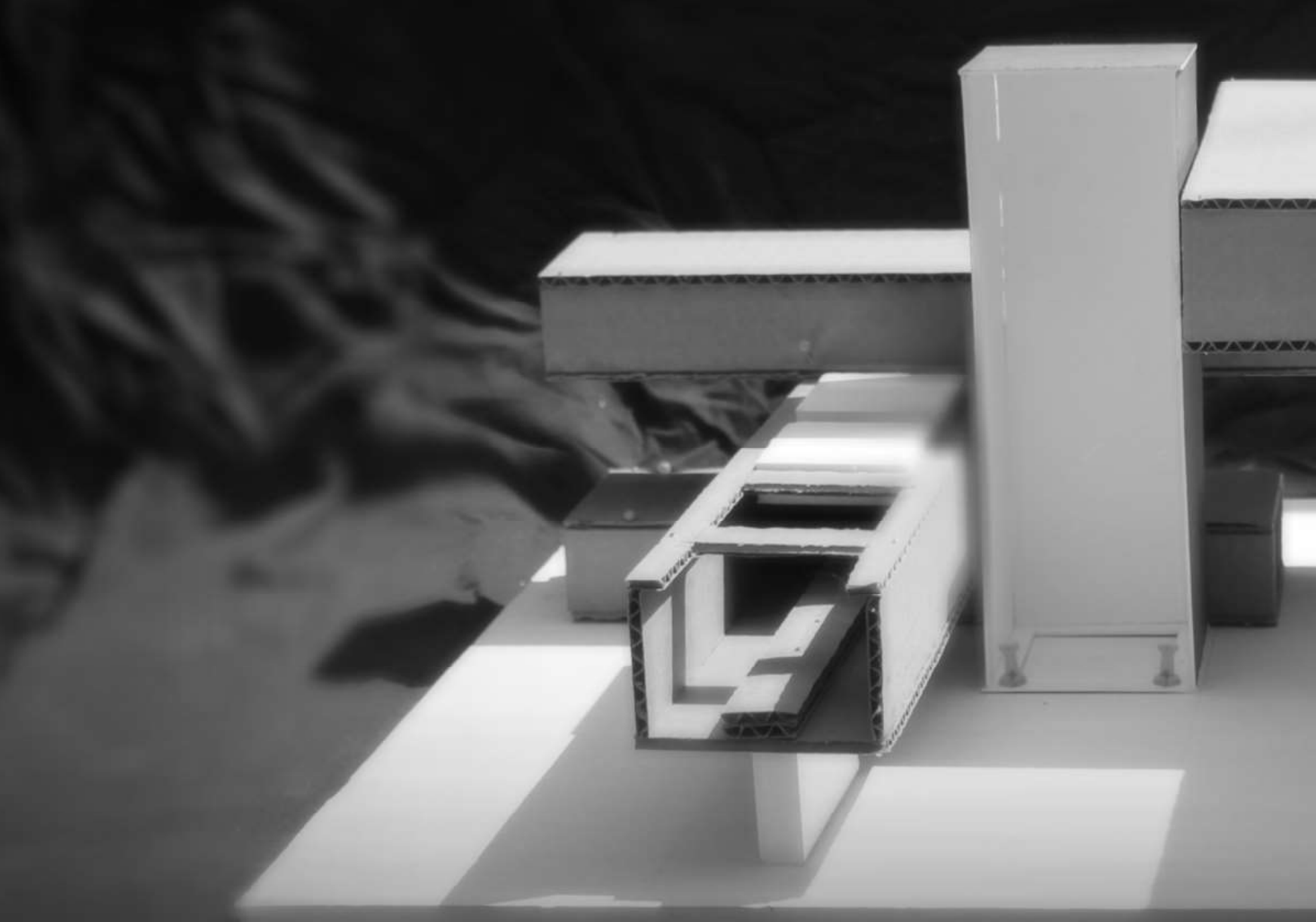




\subsection{Design Experiment : Literary Tools in Architecture}

Within stories, intrigue is created through a wide array of tools fostering an engaging narrative that compels readers. Literary devices are one of the many tools used in stories to achieve a sense of drama which leads to exciting, emotional and unexpected series of events or circumstances. Some of the most well known plays to this day have been renown for their use of literary devices to provoke the user, pulling them into the story and immersing them within the narrative. Shakespeare's Romeo and Juliet is one example where the plot of the story was so carefully crafted with literary devices that we study the play in high school literature to this day. One example of the use of literary devices in the story is within Act 1 Scene 2 where Benvolio tells Romeo the following. "Take thou some new infection to thy eye, and the rank poison of the old will die." By dropping hints as to potential hardships to come, the reader is made curious as the future dealing of the characters involved.

The creation of an architectural story can similarly be composed with inspiration drawn from devices found in literature. Suspense, drama and tension can be experienced both in language \& text as well as through experience as one engages an architectural structure. The following design exploration looks to craft an architectural experience through the composition of spaces that reflect unique literary devices.

Three individual models of scenarios within a subway typology are designed with inspiration from foreshadowing, amplification and characterization. Each space looks to achieve a sense of architectural drama through the use of light and materials to create a space that can captivate its users. For this design experiment, the precedent photos from the previous page were used as architectural inspiration while the literary devices were used as storytelling inspiration. Both forms of inspiration are brought together to craft three unique spaces which are to be distributed throughout the station to create an intriguing architectural experience that visitors can explore. The design of these spaces can be seen on the right hand side of the page and contain a subway entrance, explorations with light wells and structural explorations. Each model will be described on the following pages with respects to their influence on creating a captivating architectural story of ascent and descent. 

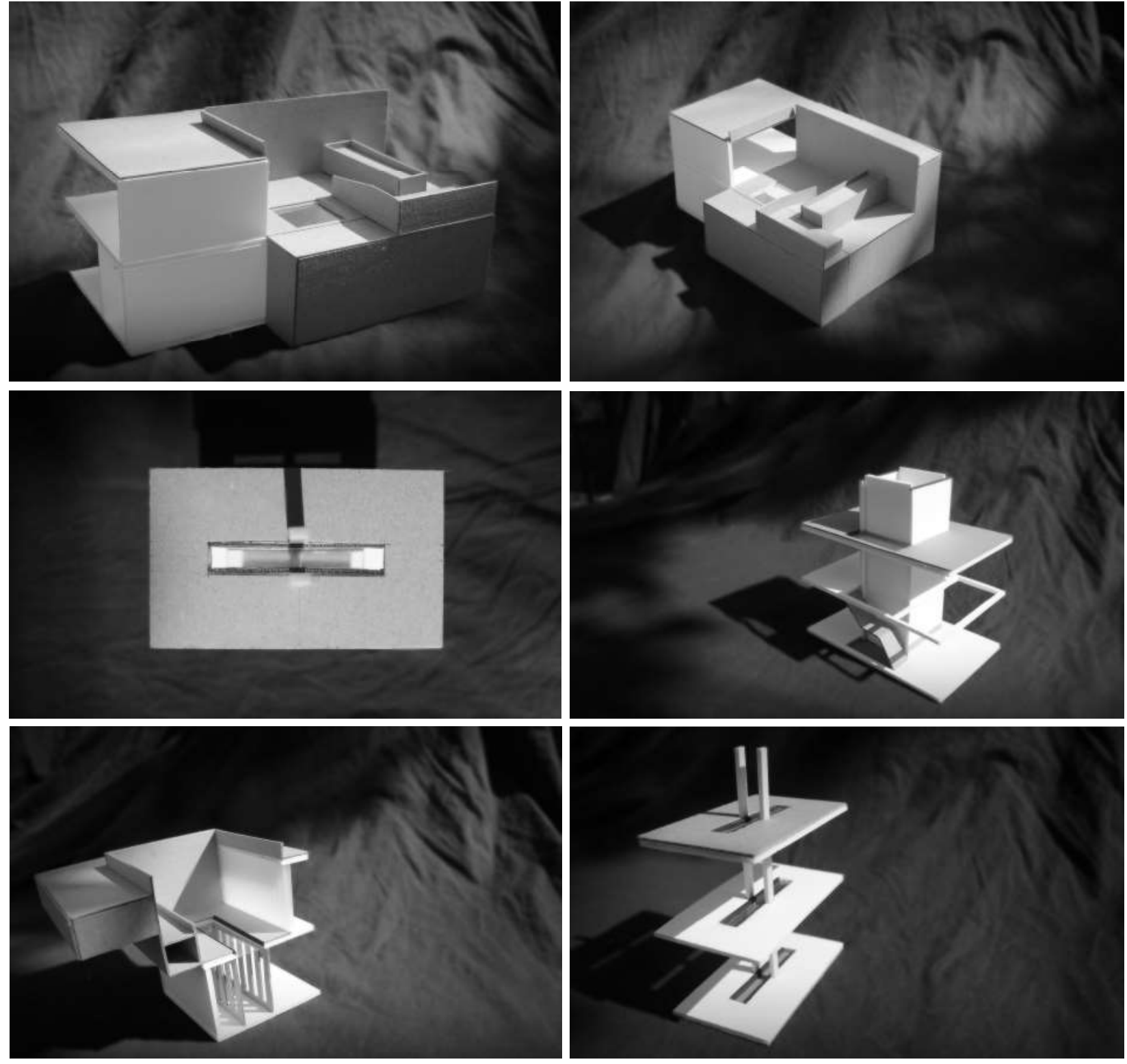

Figure 36. Design explorations seeking to design captivating spaces that are to be sequenced within a subway typology. 


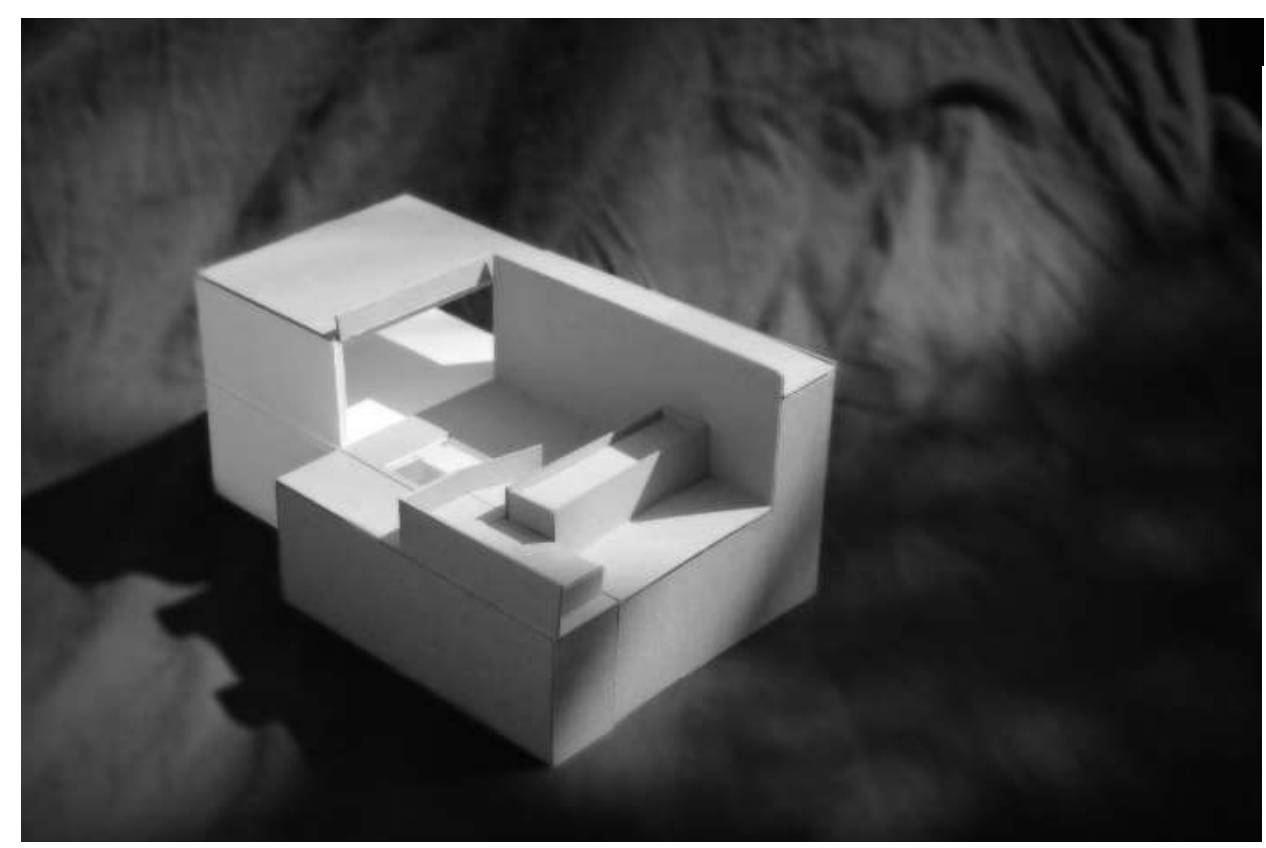

Figure 37. Subway entrance inspired by foreshadowing. The model consists of a ramp leading down to a platform containing a skylight providing views to an art gallery below. Visitors are encouraged to look through the skylight as they enter the subway station.

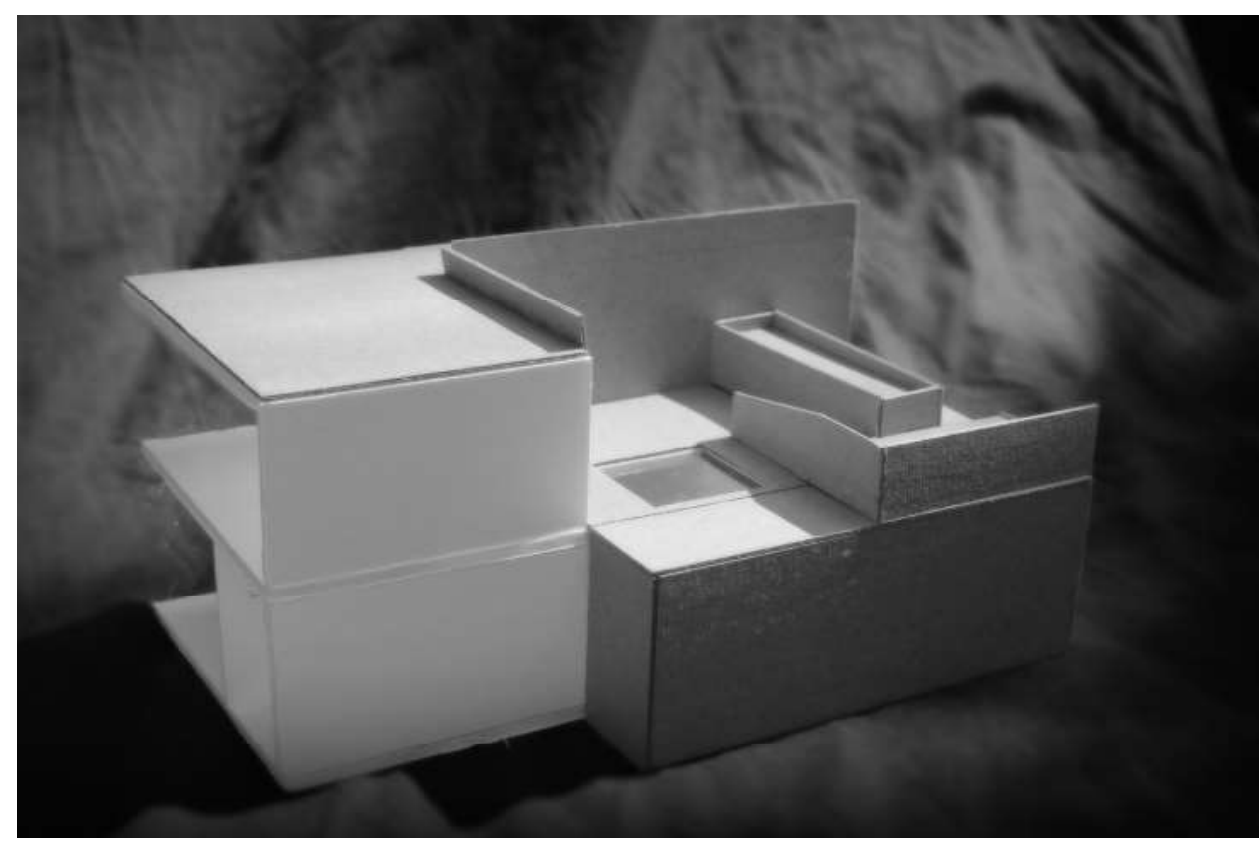

Figure 38. By locating the entrance below grade, the skylight just in front of the entrance can be peered through even by those standing on the grade level looking down.

Figure 39. View of the skylight from the art gallery below. Light pierces into the structure from above allowing natural daylighting into second floor basement level where it rarely reaches. Travelers may also look up through the skylight to see those near the entrance of the structure. 


\subsubsection{Foreshadowing}

Foreshadowing is used within stories to hint at events that are to come. This literary device intends to grab reader attention and create a sense of curiosity encouraging them to continue reading to discover the rest of the story. Architectural spaces inspired by foreshadowing achieves a similar outcome by providing glimpses of spaces that are to be encountered only should the visitor choose to continue exploring the structure. Spaces inspired by this literary device promote discovery providing visitors a visual tease of that which is yet to come.

The model shown to the left looked to explore the creation of a space inspired by the literary device of foreshadowing. The model is composed of a ramp leading down to the entrance of a subway station one level below grade. Before the traveler has reached the entrance of the structure they encounter a skylight providing a glimpse to the level below. This window acts as foresight illuminating one's understanding of what lays below and providing a mental que for a location within the building they have been made aware of without being present in that space. Before the visitor enters the building they have been made aware of a point of interest within the structure and in so doing, increases the chances that area will be sought out.

In stories, foreshadowing typically hints at dramatic events that change the course of the text. For example, storms typically indicate times of great turmoil ahead foreshadowing hard times for the characters within the scene. Within architecture, that which is foreshadowed must also be of high importance so that those peering through are captivated by what they see, increasing the effectiveness of the foreshadowing.

Within the model, the space below the skylight is an art gallery with displays that visitors can choose to explore. By providing a glimpse to key expositions withing the art gallery, those traveling by the entrance of the station are able to determine if the art gallery is of interest to them allowing them to decide if they should continue on their daily commute of if a detour through an art gallery may be something they wish to entertain.

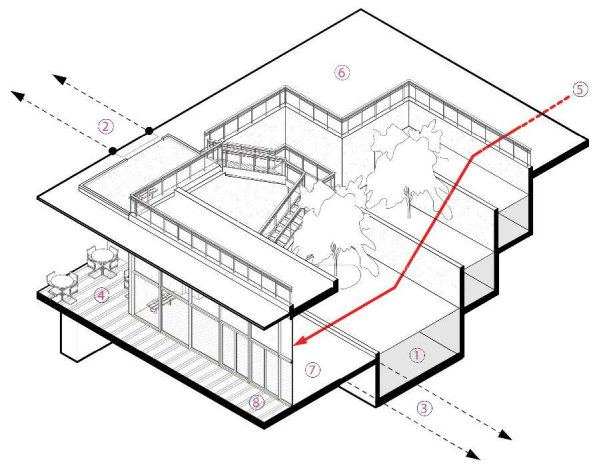

Figure 40. Axonometric drawing of model iteration. 


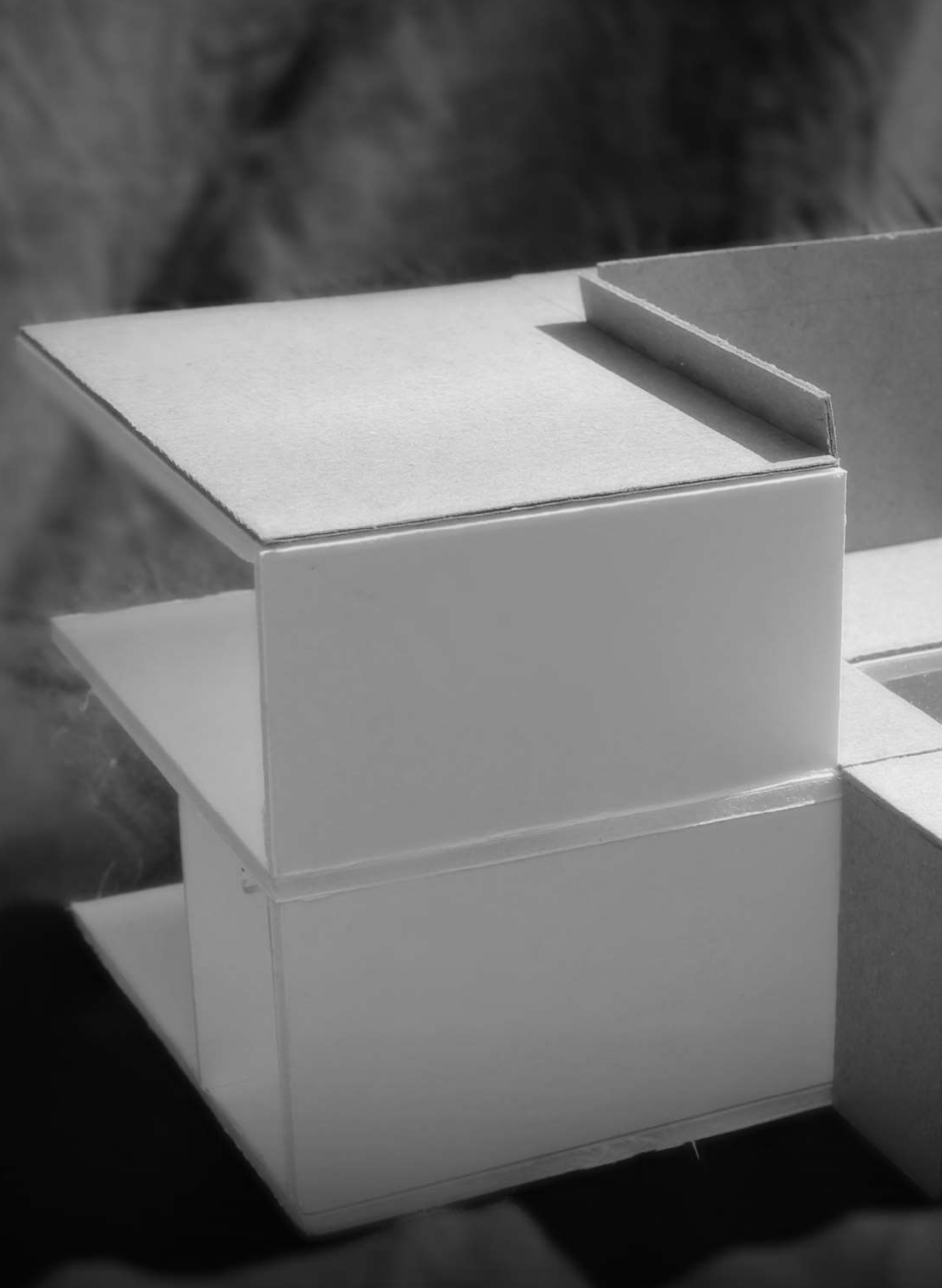





\subsubsection{Hyperbole and Amplification}

Hyperbole or amplification is a literary device wherein the author uses specific words and phrases that overemphasize the basic crux of the statement in order to produce a grander, more noticeable effect. This literary device can be understood as $\mathrm{s}$ a form of exaggeration heightening the importance of scenarios, statements and actions throughout the story. In so doing, the author creates moments of heightened importance throughout the story helping the reader identify what part of the narrative is more important and what part of the story to pay special attention to.

The model shown on the right is a design exploration of a space inspired by hyperbole and amplification. A large window well is sunken into the earth creating a platform at the first basement level. Along this platform is a longitudinal skylight which frames a social space directly below it that is lined with repetitive wooden louvers. In addition to providing a level of privacy, the louvers accentuate both the social space and immediate surroundings by filtering light coming in though the skylight above. The social space is enriched and in doing so, is amplified in importance within the structure. By imbuing this sitting area with light, rest is declared to be of importance within this architecture worthy of bathing in natural light and engaging with family, friends or strangers in a semi enclosed area that provides a form of privacy. Figure 43 illustrates the transforming qualities of light as is pierces through in-between the louvers creating rhythmic shadows along the floor and wall.

Within stories, hyperbole and amplification is used to frame important scenes which enhance the story by increasing the importance of the scenario taking place. These literary devices are used sparingly throughout most novels so as to maintain a sense of genuineness and not over-exaggerate the story. Sequencing the design of spaces influenced by hyperbole and amplification is similar to selecting where along a story's narrative to implement the literary device. Placing too many spaces of heightened intensity in adjacency may take away from the effect the spaces could achieve. By offering buffer spaces between areas of heightened importance and intensity, travelers are more likely to engage the full effect these spaces can offer. 
Figure 41. Window well inspired by hyperbole and amplification. A sitting area is located directly below a longitudinal skylight framed by wooden louvers enhancing the importance and effect of the light in the space.

Figure 42. Social space directly below skylight is infused with openness and light as the sun moves overhead. Social space is enriched with privacy and natural lighting.

Figure 43. Rhythmic shadows are created by wooden louvers as light penetrates from above enriching the adjacent corridor transforming it into a space of light and shadow that travelers can enjoy.
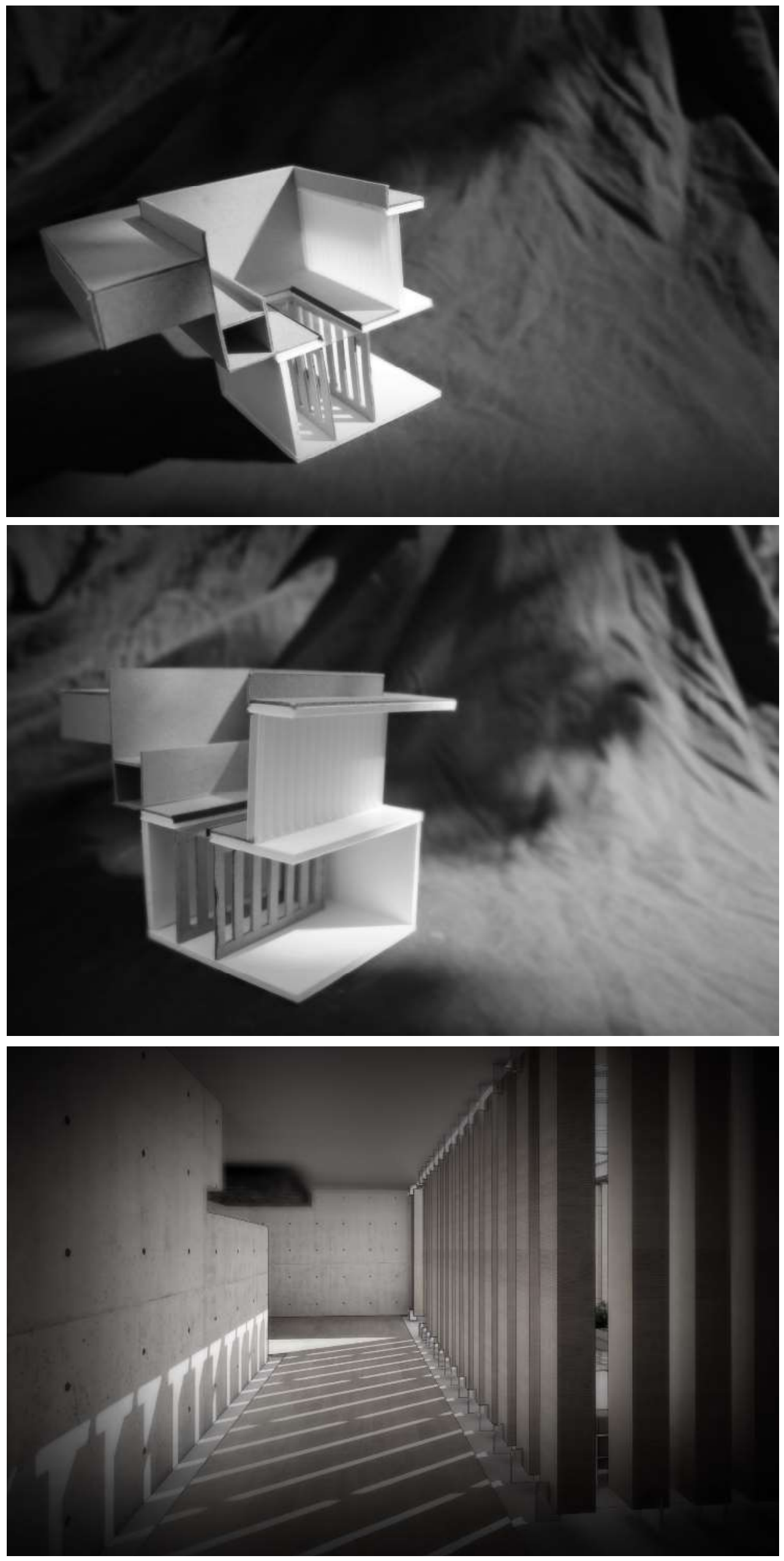


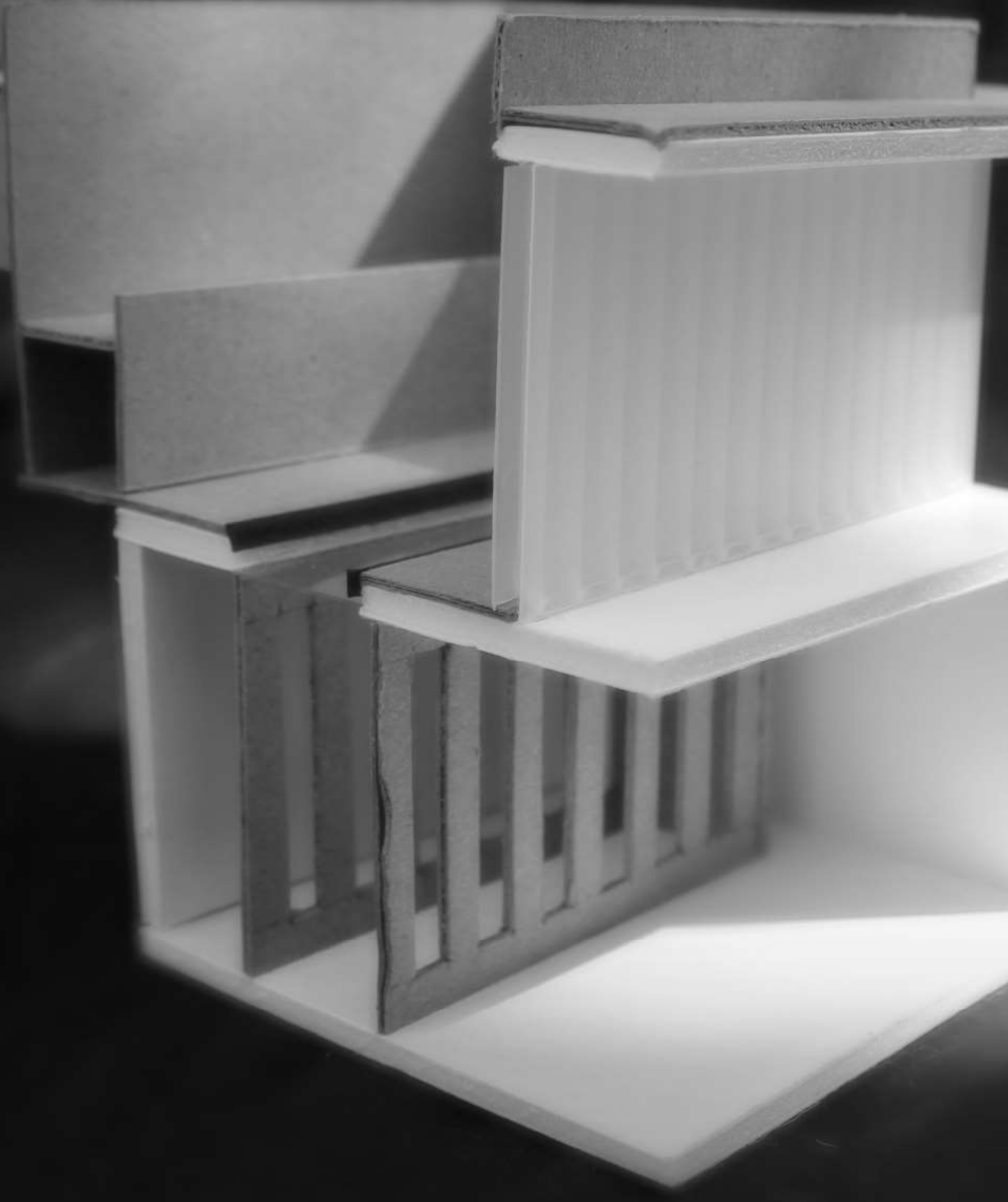



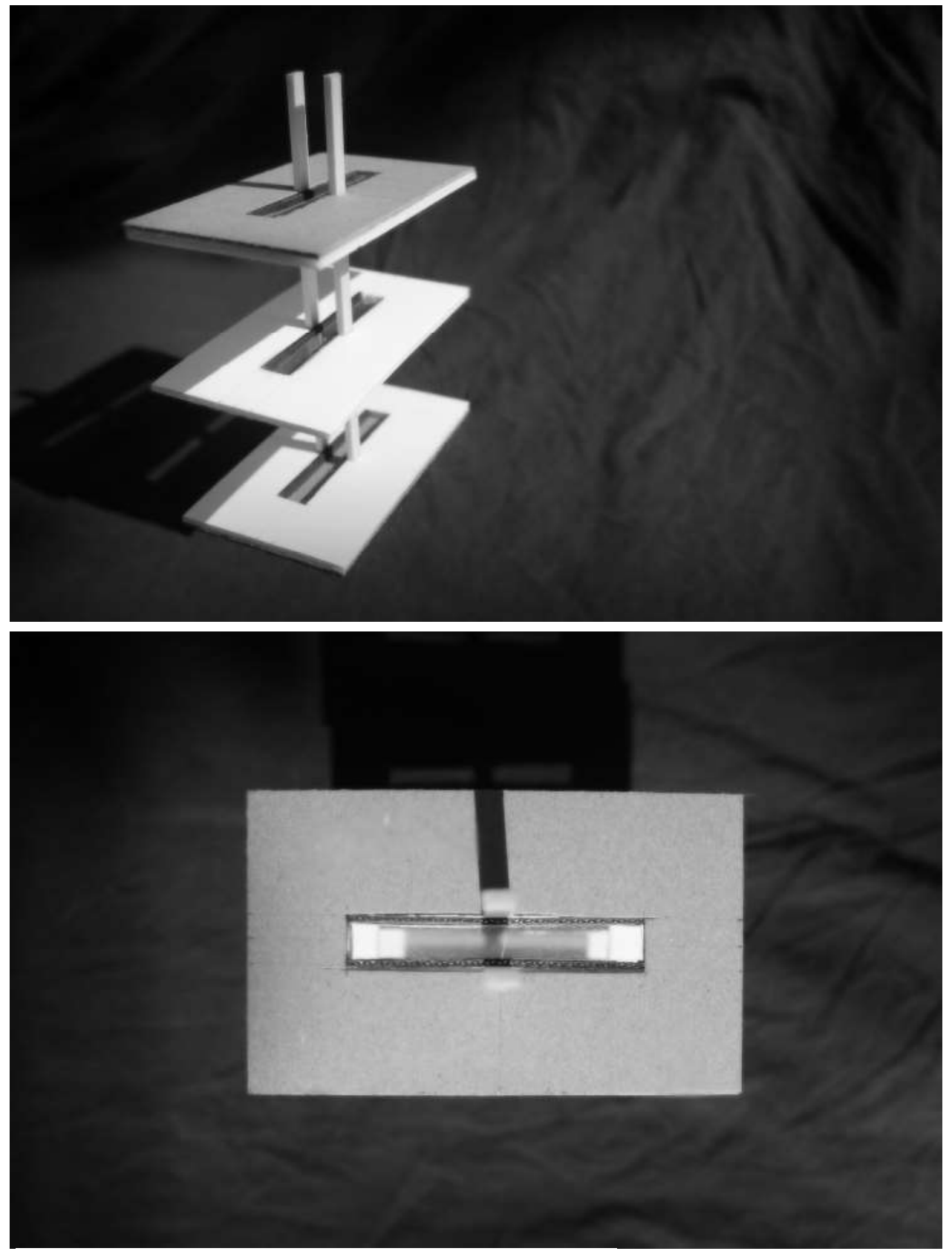

Figure 44. Structural explorations inspired by the literary device characterization. Columns are bifurcated and illuminated with a longitudinal skylight drawing attention to and showcasing the structural composition of the building. 


\subsubsection{Characterization}

Many of the most compelling stories told are done so by establishing a strong relation between the reader and the characters in the tale. By reading about tales with relateable characters, readers become invested in the story creating an attraction to key figured within the narrative, developing an emotional attachment to their struggles and achievements.

The strength of ones relationship with architecture similarly relies on ones relatability to the elements that compose that structure. By being able to understand the way in which the architecture was designed and created, the viewer is able to understand and form a relationship with the structure investing them within their experience of the building.

The model shown on the left explores column structure within a subway typology. The experiment bifurcated a singular column into two factions allowing the placement of a longitudinal skylight along the center of the structure. In so doing, the continuity of the column can be followed along multiple floors by those peering through the thin skylights. This privileges visitors within visual comprehension of the buildings structure allowing them to understand the fundamental components that keep the building erect.

Within stories, characters capture our attention not only by being relateable but also by being fascinating. In many cases, the protagonists and antagonists in the narrative either have fascinating traits or are placed in compelling situations; often both. Similarly within this architectural experiment, the skylight at the center of the column attempts to imbue the column with a sense of fascination. Structure within typical buildings is perceived as solid and heavy, carrying the loads of the entire volume into the earth. Within this exploration, light is brought into the very core of each column, bringing a sense of luminosity and lightness to a component which typically does not embody these traits. By placing light at the center of the structural composition of the building, the heaviness of the structure is uplifted and the columns that define the structural composition of the architecture are made unique. 


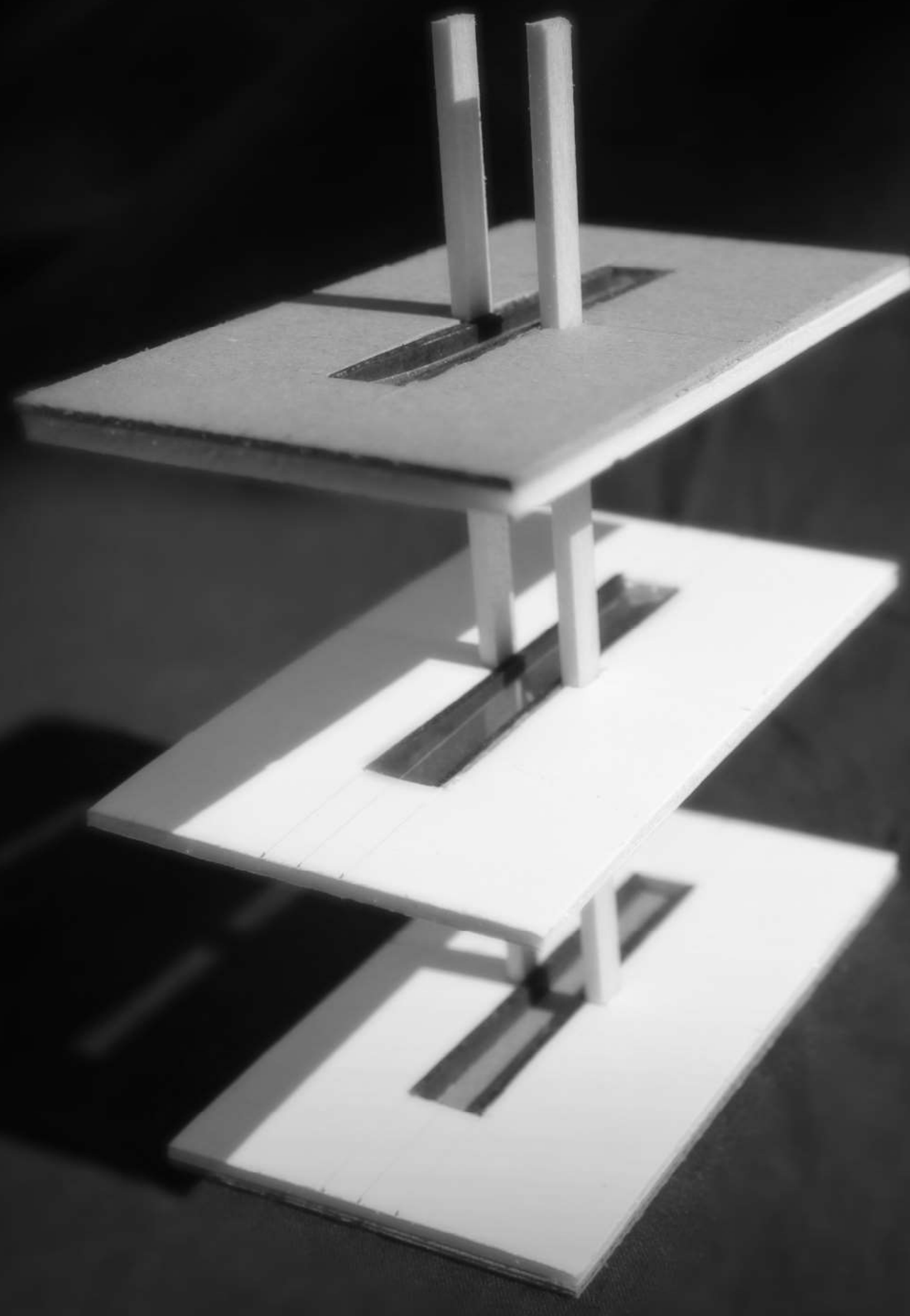





\subsubsection{Conclusions}

The composure of unique independent scenarios each aiming to establish architectural drama through inspiration drawn from literary devices has allowed for the both a series of new conclusions as well as posed new challenges for the development of a new storytelling architecture. These findings have been summarized below in two sections; the successes of the experiment and consideration for the future.

\section{Successes of the Experiment}

This design experiment offered a way through which to explore the integration of literary devices into the creation of architectural spaces. By drawing metaphorical inspiration from literary devices in the creation of architectural spaces, techniques used in storytelling were ingrained at a fundamental level in the scenarios of the three spaces. Additionally, the creation of hand made models of these experiments offered many ways through which to explore the finished product, allowing one's body to move around the object, view it from multiple perspectives and draw conclusions based on a dynamic form of engagement with the spaces created.

\section{Considerations for the Future}

By focusing on the design of unique individual scenarios, each space is independent and entirely separate from the other two spaces that have been designed and built. As a result, the three spaces lack a sense of unification, bringing them together so that each space provides a fragmented experience of a more unified whole. While explorations in the sequencing of these spaces did occur as can be seen on the right hand side of the page, further development of this experiment would include investigations into how a common theme across all spaces designed could provide a unified foundation on which all conditions are designed. In so doing, these conditions could reflect similar compositional design elements rather than each space begin regarded as a unique snippet in a uncorrelated pallet of experiences. 


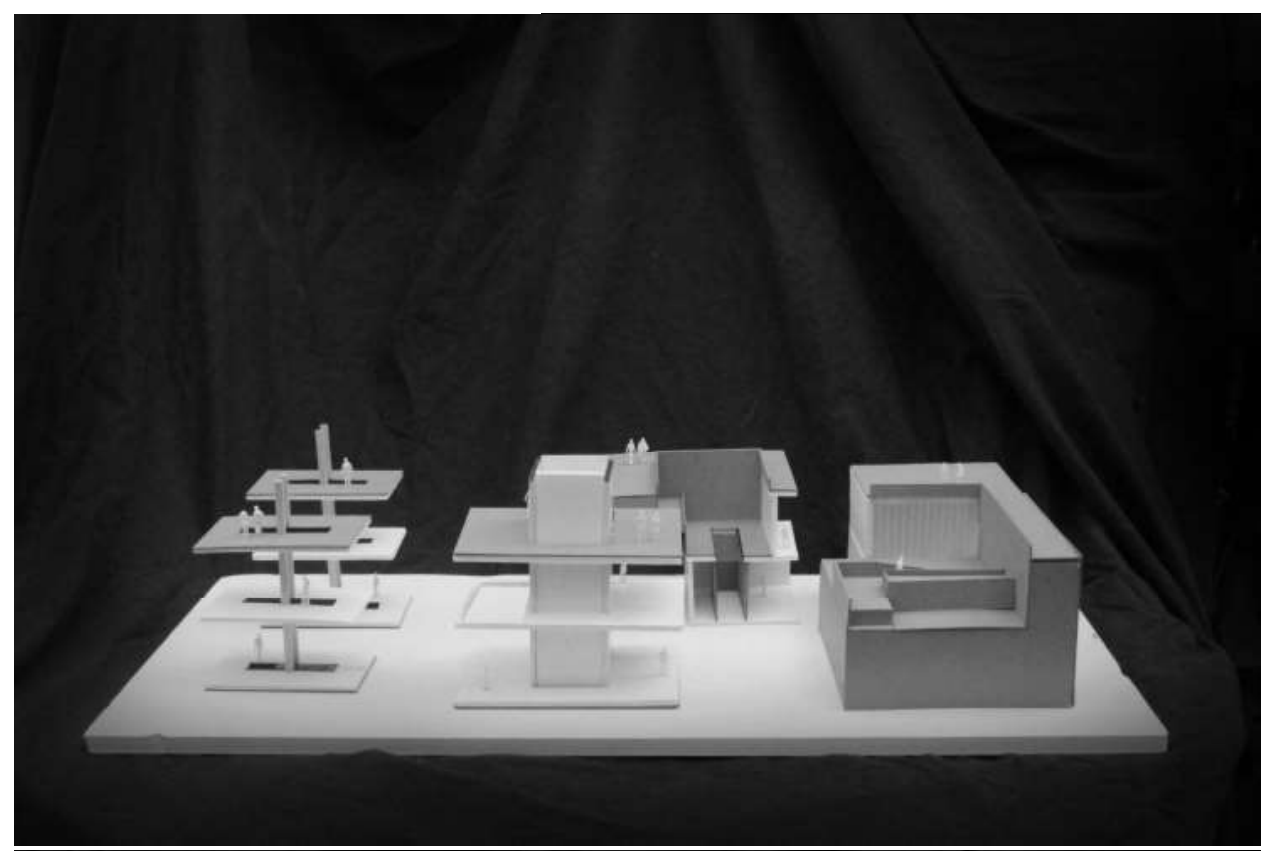

Figure 46. Sequence two

Figure 47. Sequence three
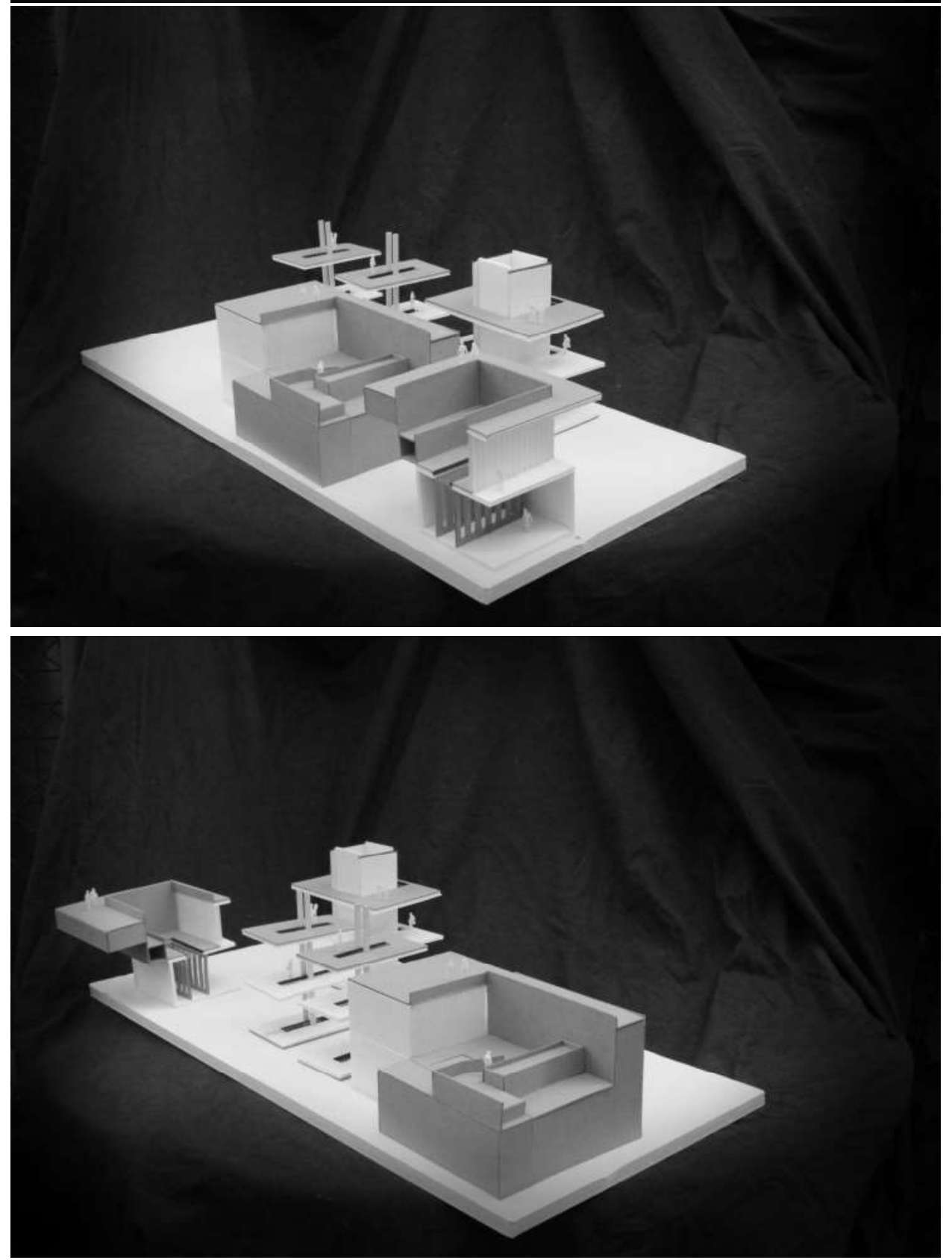


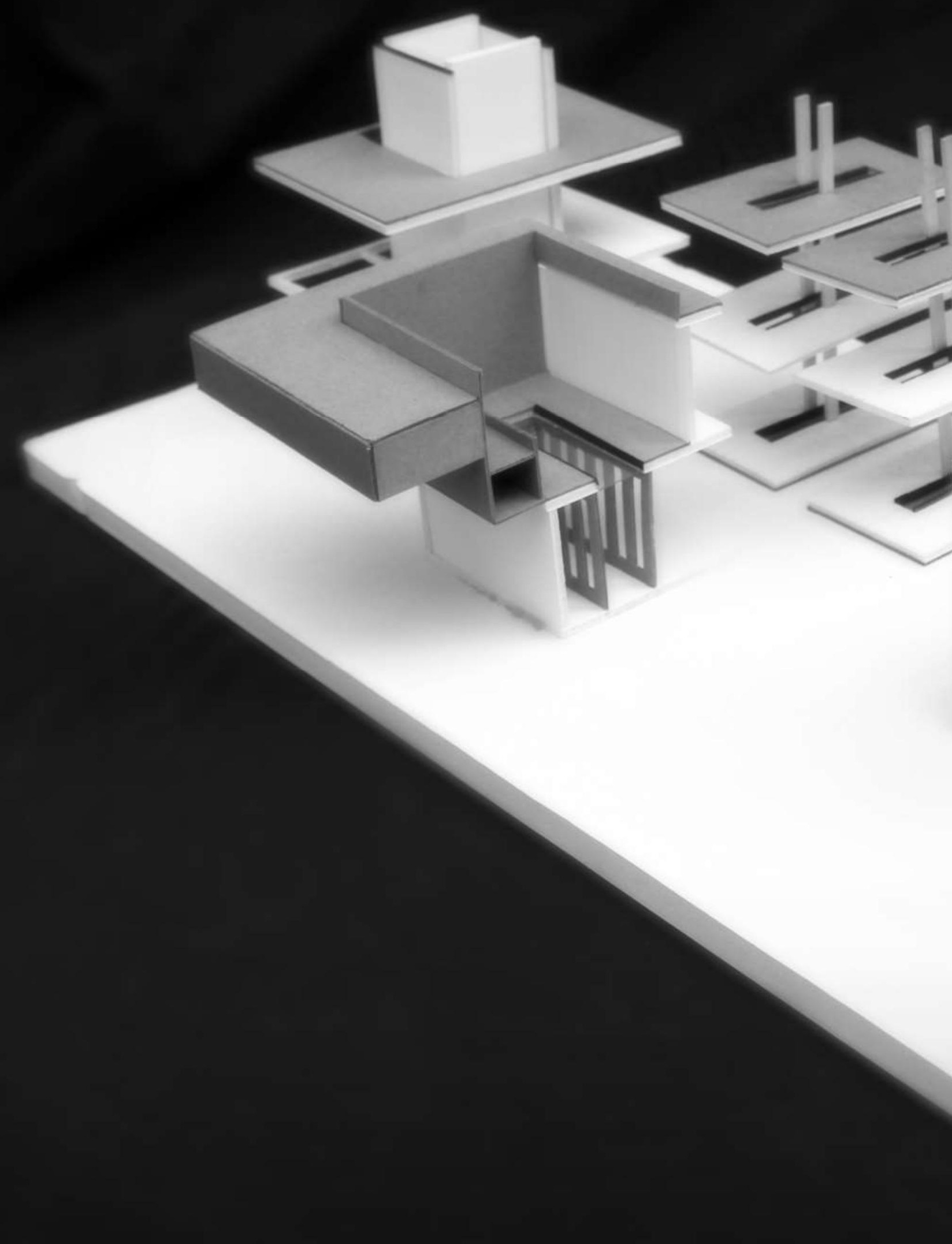




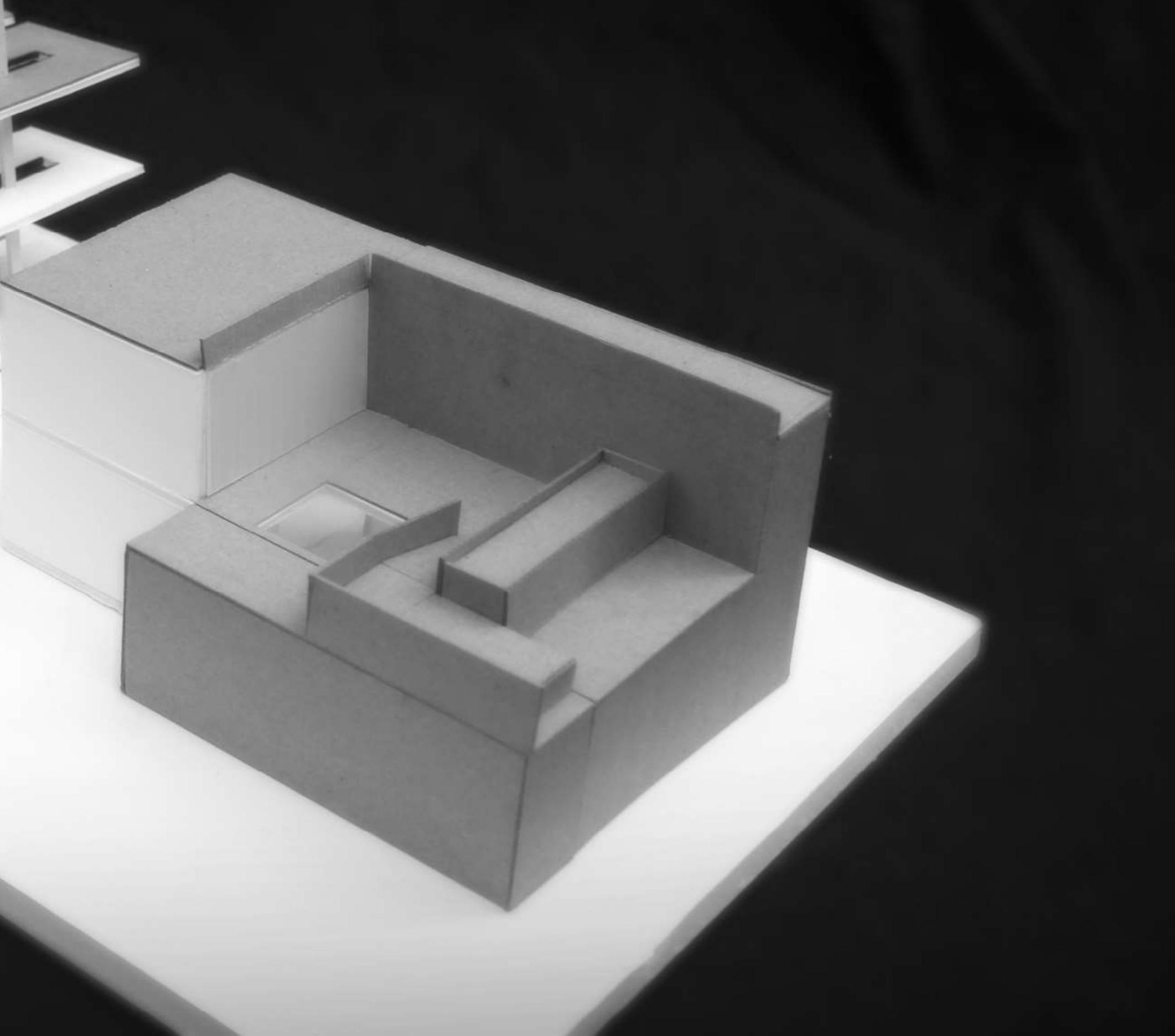




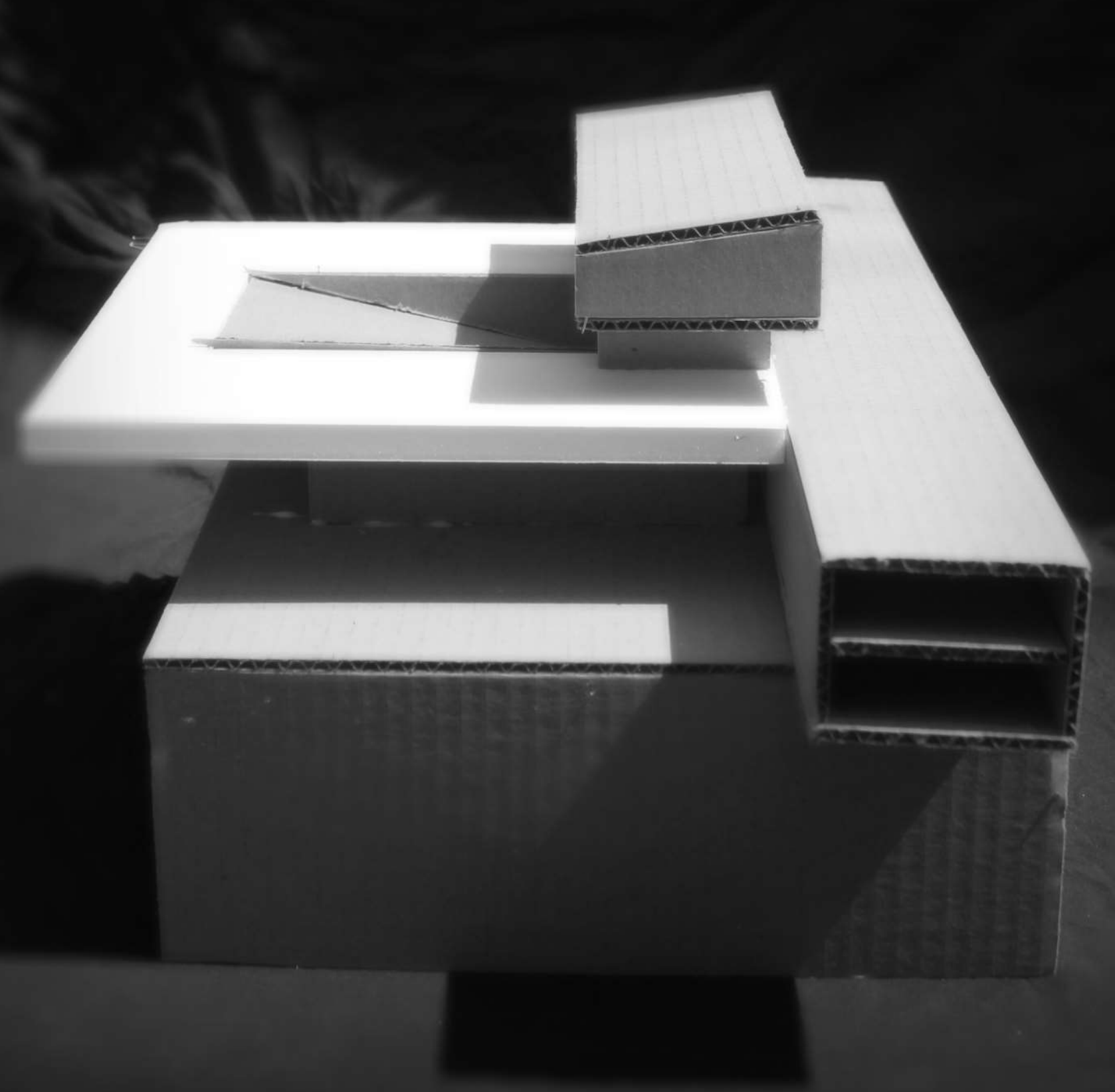




\section{CHAPTER 4. Character in Storytelling}




\subsection{Character}

We start off this section through a discussion on tectonics and ontology acting as a precursor for the definition of architectural character presented near the end of this chapter. There have been numerous philosophers whose writings gear specifically towards achieving a better understanding architectural ontology through study into that which defines the very existence and being of architecture. While there are a variety of perspectives through many have chosen to begin the discussion of tectonics, there have been two common themes throughout many of the presented arguments; the disappearance of the craftsman and the rise of scenography. The following will present a brief account of both to better understand the inception of the argument to help us in defining architectural character in the latter stages of the section.

\subsubsection{The Disappearance of the Craftsman}

Marco Frascari critiqued that craftsmanship in architecture has evaporated in parallel with the disappearance of craftsmen from the field of design. Draftsmen have taken over the position and solve the problem through drawing rather than through the knowledge of construction. "Draftsmanship was substituted for workmanship, and the development of the "real details" was replaced by "virtual "procedures. The detail was no longer seen as a joint, it was instead seen as a production drawing." (Frascari, 24) While the treatment of detail is becoming a question of technical resolution, the joints that define the very character of building have been disassociated from the greater architectural design scheme and are considered as an afterthought. In 


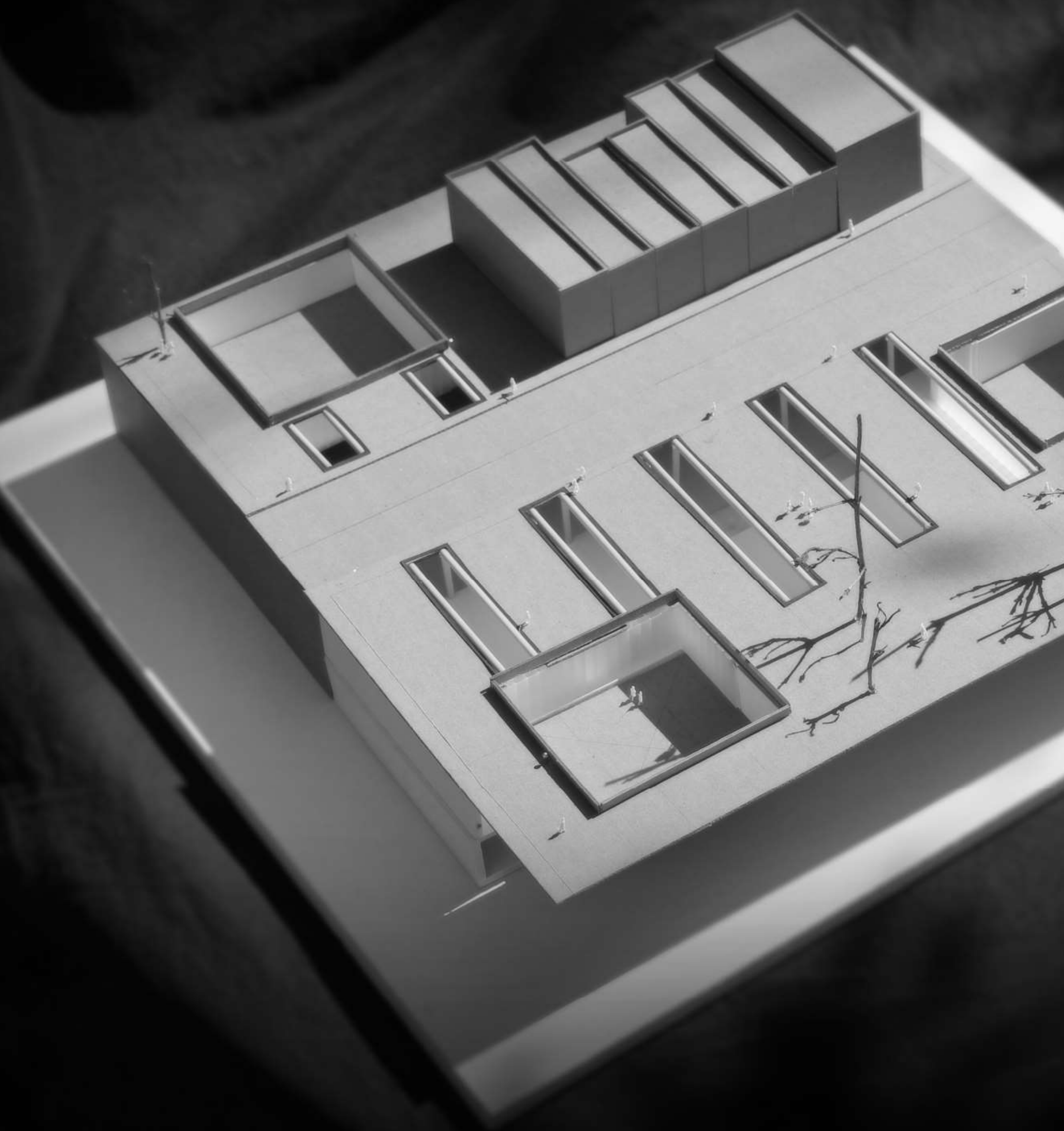



so doing, the very character of building is seen as frivolous and unworthy of design attention.

"The geometrical and mathematical construction of the architectural detail is in no sense a technical question. The matter should be regarded as falling within the philosophical problem of the foundation of architecture or geometry, and ultimately within the theories of perception." (Frascari 27)

\subsubsection{Rise of Scenography}

Kenneth Frampton's discourse on tectonics critiques scenography arguing for ontology in buildings rather than representational forms of expression. A building itself is not a representation of something, it itself is something and forcing upon it representational qualities diminishes the very architecture itself.

"However, building remains essentially tectonic rather than scenographic in character and it may be argued that it is first and foremost an act of construction rather than a discourse predicated on the surface..." (Frampton 93)

Architectural meaning was originally attained through the manifestation of symbolic forms. Take for instance a renaissance church. The impressive sculptural decoration speaks to the highly valued level of craft prominent within the Renaissance society. Sculptures of angels and demons are symbols intended to capture the expression of something that is not physically present and portray it as a form of visual decoration. Architecture in this form speaks to its users through preconceived notions and previously associated meanings of recognizable shapes and forms. Typically scenarios depicting the triumph of good against evil are formed into sculptural elements embedded within architecture attempting to empower the building with an association of a higher order. Meaning attained through this form of symbolism has been heavily critiqued in contemporary architecture for its divergence from ontological forms of expression. Tectonic expression concerns itself with the material expressiveness of building, primarily with respect to elements rooted within the ontology of architecture. This form of expression looks to recognize a building as a bearer of intrinsic properties which can tell its own story rather than be granted meaning though symbolic representation. If architecture is telling a tale, a story based on symbolic expression is a story about something other than itself. A tectonic mode of representation that recognizes a building as a bearer of intrinsic properties can tell its own story. Tectonics is focused with the sequencing of unfolding information that presents us with information as our bodies pass through space. Based on our perception, we navigate through a path of our own choosing and are presented with physical elements containing information which we process, interpret and create a spatial experience.. Maulden echoes Venturis writing 
on The Duck and the Decorated Shed referring to a building as a thing rather than a sign. He proclaims the following:

"The physical qualities of a building -- structure, materials, organization, services, detail, as well as its process of assembly and constructional technique - can be brought into meta-physical presence: that a building be thought of as a "thing" rather than a "sign." In short, tectonics is primarily concerned with the apparent self-consciousness of a building with respect to its construction." (Maulden, 11)

It is notable that the creation of meaning from the perception of the physical can be attained both through symbolic and tectonic means. When the physical expression of the building is has been sculpted in a way that form and function are deeply connected, the stronger the relationship between these two, the stronger the overarching concept of the structure.

An etymological study of the word character reveals its mid-15c. Greek root kharakter meaning engraved mark, imprint on the soul or the sum of the qualities that define something. It is through these qualities or imprints that a subject or object can be understood and it is the character that these qualities express that reflect the story of its past. As an example, the character of a hammock can include but is not limited to the stitch pattern, location of seams and type of fabric consisting of qualities that make up the object. Similarly, character in architecture consists of the qualities which define its conception, specifically with regards to the way in which it was built and the way in which it has aged. The art of construction focused on elevating material requisite construction to an art form is commonly referred to as tectonics and it is through an understanding of tectonics that will lead to a strong establishment of character in architecture. The following section will provide an account of theorists whose discourse concerns tectonics and will be presented in relation to the creation of character in architecture.

\subsubsection{Detail Types}

Edward R. Ford defines the detail though five definitions. The following will provide a brief summary of each and their relation to the capacities to foster spirit in architecture.

Detail as Abstraction: It is argued here that modernism eliminated the detail. It is this school of thought that suppresses information with regards to construction to give rise to other forms of expression.

Detail as Motif: The detail as a motif of the building is an understanding of the joint as a fragment of the entire building. This understanding is quite literally the opposite of detail as abstraction in that the entirety of the structure is the addition of the individual details that compose the whole. 
Detail as Structural Representation: Details can be understood as modes of representation of that which constitutes the structural assembly of the structure.

Detail as a Joint: Through this definition, details are understood as an articulation of construction.

Detail as Autonomous or subversive element. Details that do not relate to the previous 4 conditions. Constitutes an independent part of the design. These are moments of singularity. These autonomous details who are not to the overall concept following its own rules and seeking its own configurations. "This type of detail is autonomous detail, disconnected from concept, unrelated to an all-encompassing composition, following its own rules and seeking its own configurations". (Ford 45)
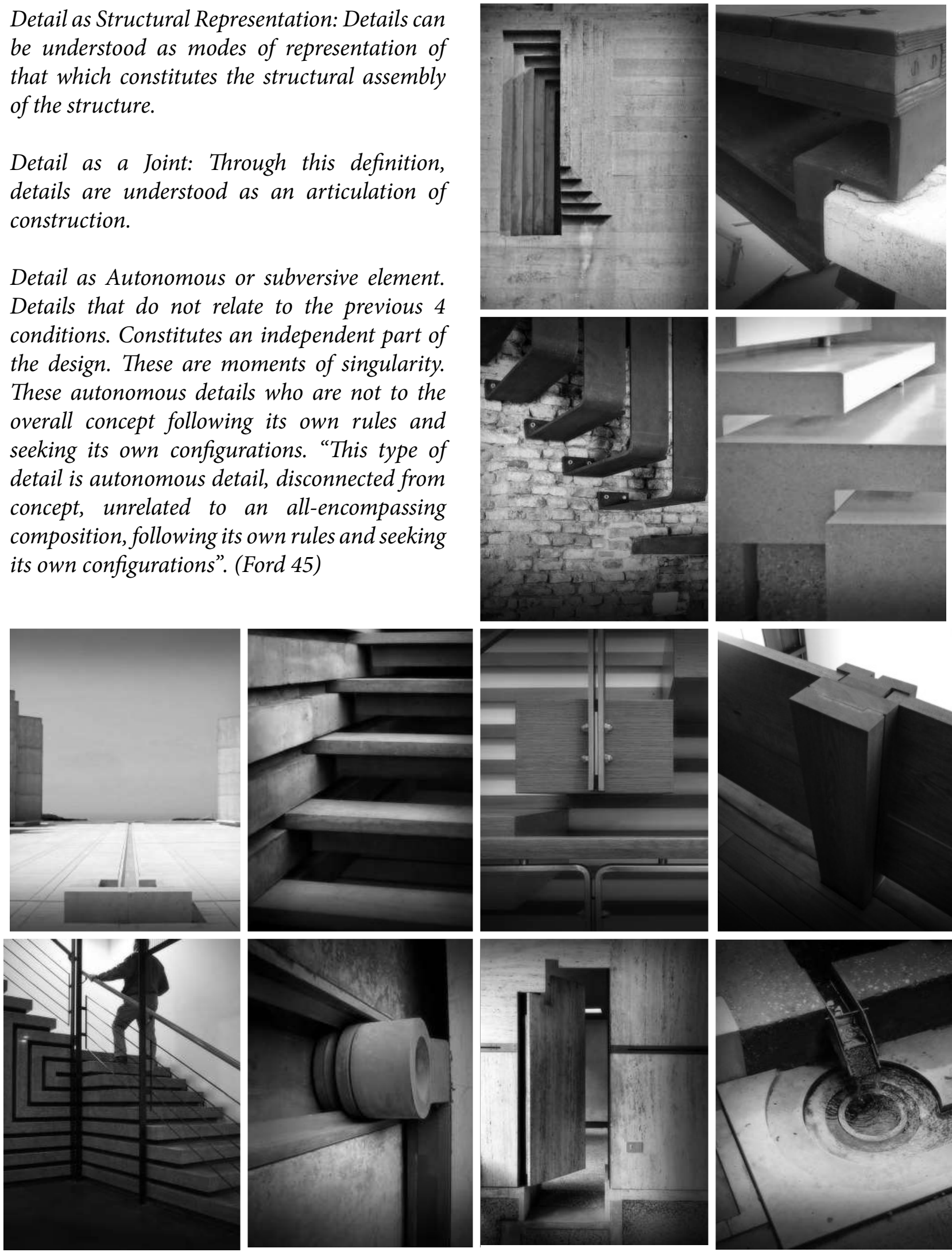

Figure 48. Inspirational phot graphs of captivating architectural spaces that bend and manipulate light. 

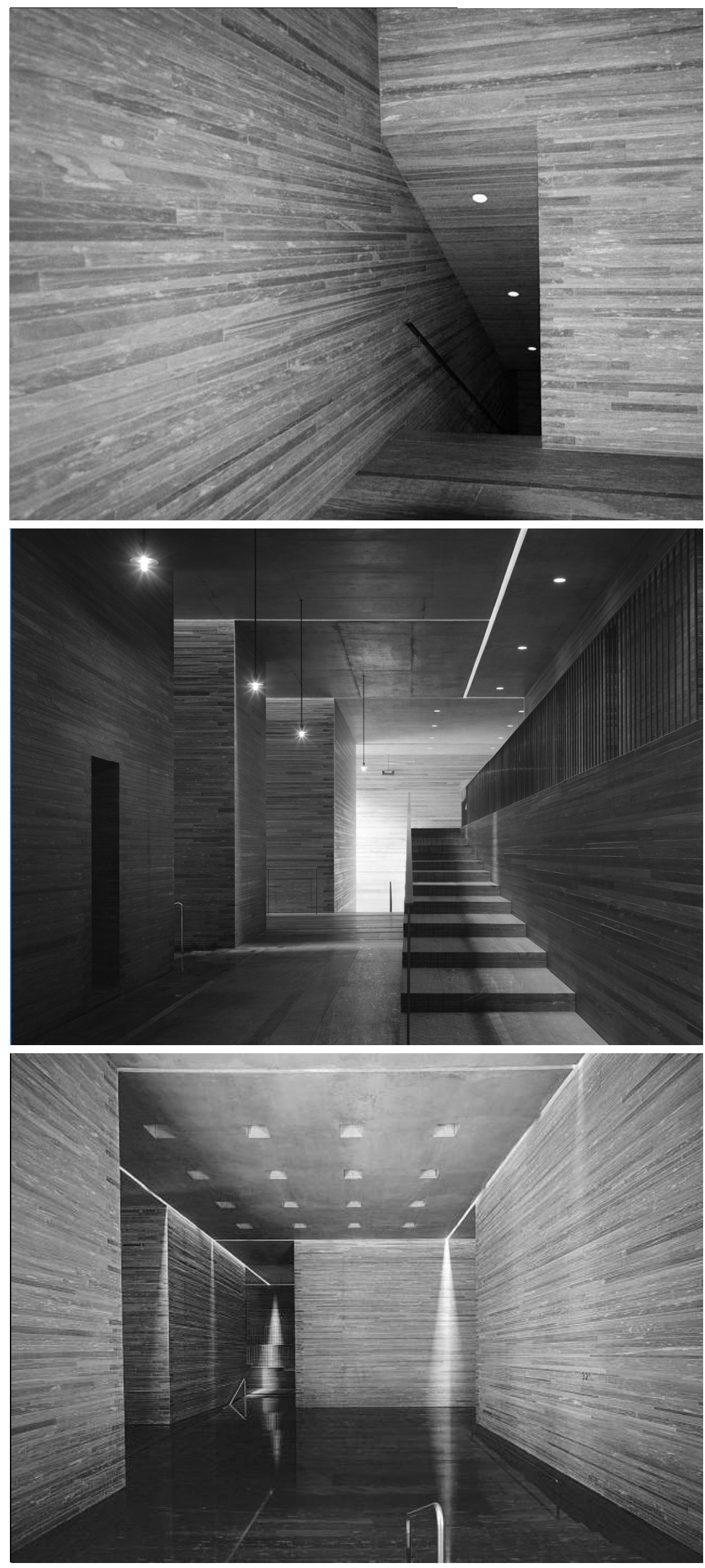

Figure 49. Precedent: Therme Vals. Architect: Peter Zumpthor. Address: 7132 Vals, Switzerland

Figure 50. Stone veneer within the building is organized in select increments so no stone required additional cutting.

Figure 51. Expansion joints within the structure allowing the penetration of light. 


\subsection{Precedent: Thermal Baths}

The Therme Vals by Peter Zumpthor is an excellent example showcasing character deeply ingrained within the design of the structure. Seams within the building are carefully designed so as to accentuate and heighten moments within the structure creating a rich architectural experience that has been renown since the buildings construction in 1996. Character within the structure will be discussed in relation to three design components; skylight joints, stone veneering and expansion joints.

\section{Skylight Joint}

The first is the glazed joint which functionally is used as an expansion joint yet at the same time serves as a reveal to break up the monolithic mass of the heavy stone structure. By allowing light to pierce through the seams of the building, the light accentuates the immersive atmosphere within creating a spiritual and emotionally experience. You can see these dramatic building seams in the first and second picture on the left hand side of the page.

\section{Stone Veneer}

Isolating the stair as the smallest surface in the building, the stone strip heights were made in intervals 31,47 and 63 millimeters which could be used in combinations such that no stone veneer had to be cut so as to fit along the wall surface. In so doing, the sense of material continuity and unobstructed stone brings about a sense of material empowerment creating a space that fosters a relationship between man and stone.

\section{Expansion Joints}

In most architecture, expansion joints are an afterthought. It is a necessary component that is grafted onto an already established design and typically hidden so as to not distract from the more important elements in the architecture. Within this precedent, the expansion joints define a building grid which in tern divides the building into a series of structural table top shapes, each divided by expansion joins that allow the penetration of light within the structure. The consideration of expansion joints at a fundamental level in the process of design allows the building to showcase its seams, displaying them as aesthetic and embracing the character that is portrays in doing so. 


\subsection{Design Experiment: Materials and Joints}

Within stories, the development of character establishes relate-able individuals with which the readers can associate. Readers empathize with their hardships and achievements throughout the book by, to some extent, understanding or paralleling similar scenarios in their own lives. In many cases, grand themes emerge from the character flaws of the individuals within the story. For example, in Aesop's The Boy Who Cried Wolf, the desire for attention of a young child brought about suspicion from the rest of the townspeople, who chose not to reach out and provide aid when a real danger presented itself in fear that the boy was once again falsely calling out. The development of character within stories strengthen the tie between those reading the novel, and those within the novel and in so doing creates an emotional relationship between mankind and story.

Within architecture, establishing character within the components of a structure can similarly strengthen the relationship between mankind and architecture. By designing material assemblies that come together in ways that can be understood, the viewer can better understand the ways in which the building has been fastened together privileging the potential for poetic interpretations as travelers engage the building.

The fastening and composure of material assembly is vital is the creation of an expressive system that fosters character within the union of its parts. This design experiment looks to explore a variety of material assemblies that are fastened together through unique and expressive methods of joining so as to be used as inspiration in the design of building seams in the chapters to come. Three models were conceived that explore fastening inspired by puncturing, interlocking and tightening in relation to establishing character within an architectural structure. Each experiment used three materials; wood, concrete and steel and will be presented on the following pages.

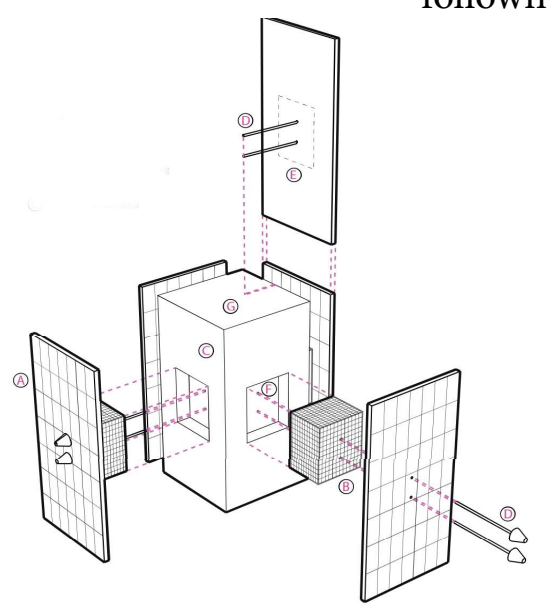

Figure 54. Model exploring the fastening capabilities of wood, steel and concrete through puncturing.

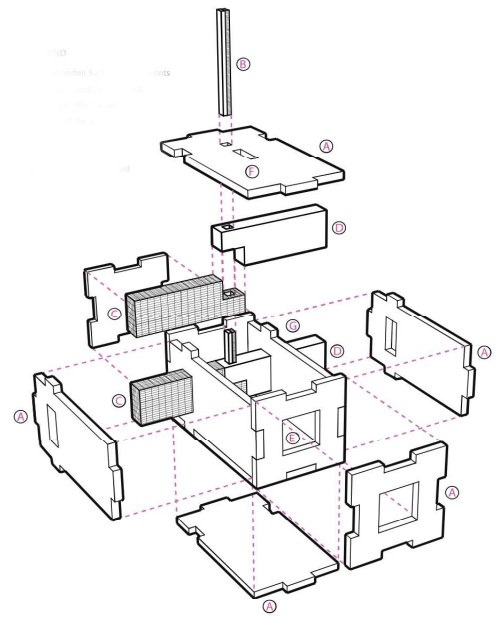

Figure 52. Model of material assembly exploring seams inspired by interlocking planes and volumes.

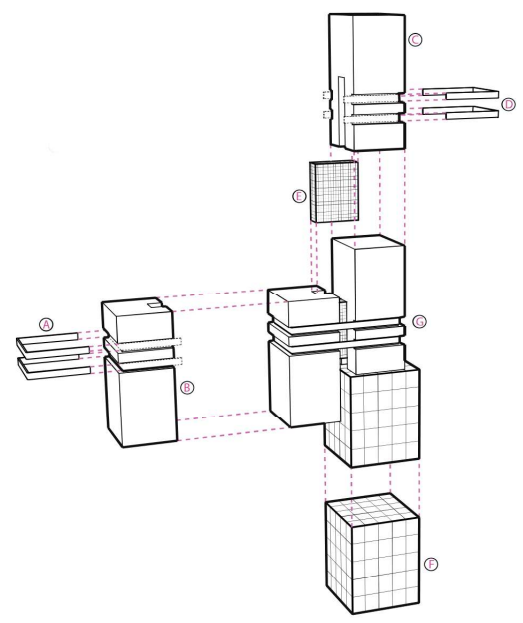

Figure 53. Explorations of material seams fastened together through tightening. 


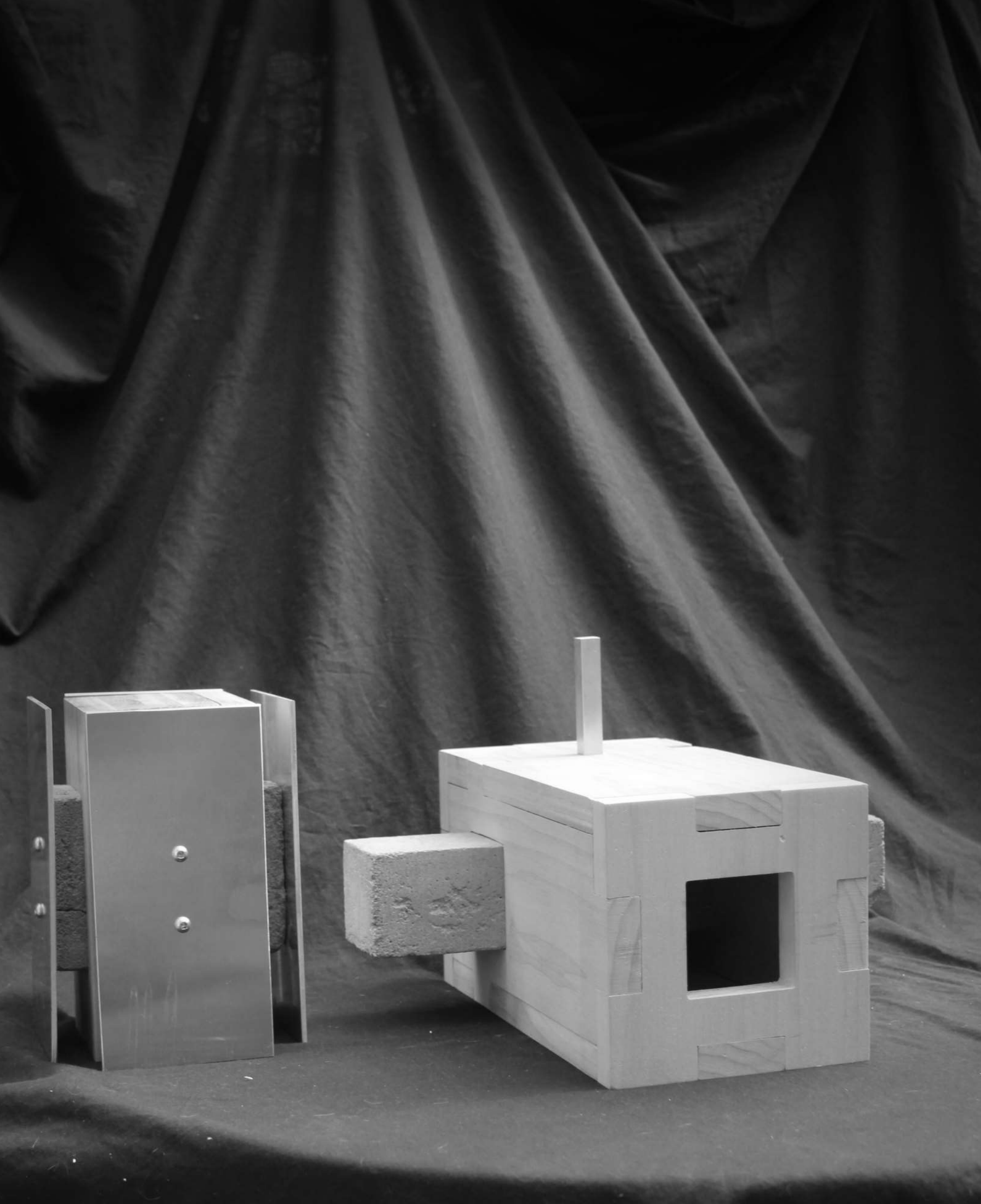



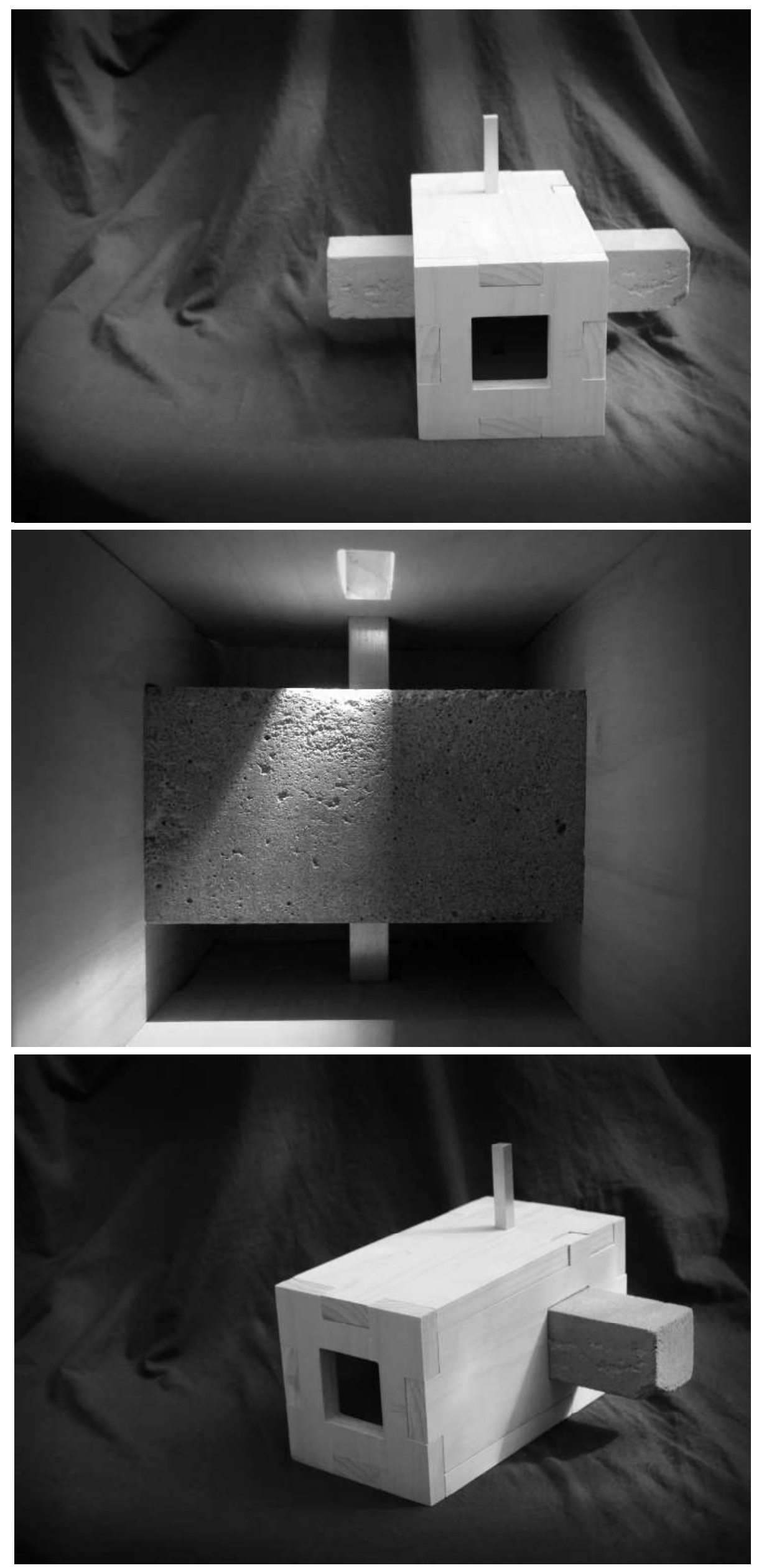

Figure 55. View from front elevational perspective.

Figure 56. View within the wooden box at the junction of steel rod and concrete.

Figure 57. View from the side showing all three materials. 


\subsubsection{Interlocking}

In the creation of architecture, assembly of material in a way that fosters character is, in most cases desirable and sought after. By celebrating the method in which wood, concrete and steel interlock to create a material assembly, an artifact is created that will be used as inspiration in the design of building details in the latter portions of the thesis. The first model designed is an exploration into the design of seams that interlock. Interlocking is commonly referred to as a the engagement of two or more things through overlapping or by fitting together of their projections and recesses. To showcase the coming together of wood, concrete and steel in fashion that explores the interlocking capabilities of these materials, a rectangular wooden box is created with various penetrations within its shell allowing the other two material to be inserted through and immobilized, holding all 3 materials in place entirely through the strength of the interlocked parts.

\section{Wood}

A wooden rectangular box was assembled with six planes. The edges of each of these planes have been chamfered in such a way that the planes fit into each other requiring no other mode of connection other than the force of inserting the extrusions from one plane into the recesses of another. In so doing, the wooden box edges show a unique array of seams as planes push and pull into creating an edge condition that visualizes the connection of the planes.

\section{Concrete and Steel}

A long rectangular concrete box is inserted through the two elevational walls of the wooden box. This immobilizes the concrete in all directions but the $\mathrm{X}$ axis. To immobilize the $\mathrm{X}$ axis, a steel pin in dropped from the top of the box, through the wooden shell and concrete box down to the base of the artifact. The steel pin slides down along a groove at the back of the concrete volume requiring the removal of the steel in order to achieve any form of movement for the concrete.

By fitting together the groves of each of the three materials, connection is achieved entirely though interlocking requiring no additional fasteners. The edge detail is expressive and clean, showcasing the groves of how each side fits in with the other while eliminating the need for fasteners that would bring clutter and busyness to a joint that has the potential to express character. 


\subsubsection{Puncturing}

One of the most common means of assembly in the construction industry are fasteners that puncture through multiple materials so as to hold them in place, securing them structurally to the building. This form of fastening is often hidden from sight since the body of the fastener is embedded within the material it is securing. This material exploration explores the fastening of wood, concrete and steel in a way that seeks to place importance on the puncturing fastener as it holds the assembly together.

A rectangular wooden box defines the center of the artifact with groves provided on each of the elevational sides of the object. Four smaller concrete boxes are inserted into each of these groves that temporarily hold them in place. Four sheets of steel are then placed against the concrete and two fasteners are punctured through all materials on each side.

By placing a intermediate small block of concrete in-between the wood and steel, a buffer is provided between the larger surfaces placing emphasis on the space in-between, The body of the concrete buffer is the vehicle through which the fastener travels bridging the steel and wood and by denoting importance to the buffer, the intermediate connection between materials is made to be more attractive and interesting.

Figure 58. Top corner

condition of artifact one - puncturing

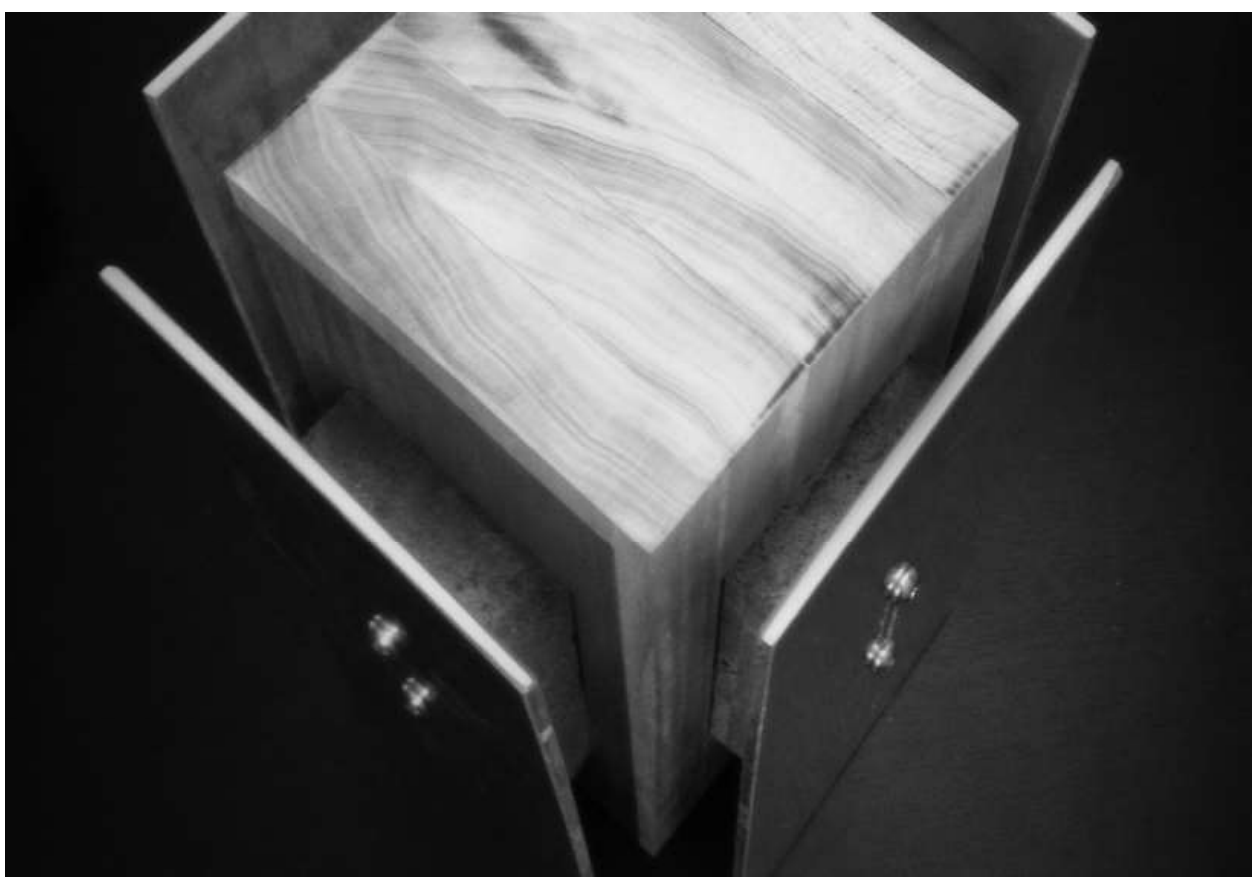


Figure 59. Buffer between steel and wood achieved with an intermediate concrete block.

Figure 61. Overview photograph of artifact one-puncturing

Figure 60. Partial plan view. Showcasing the space between the wooden box and exterior steel faces.
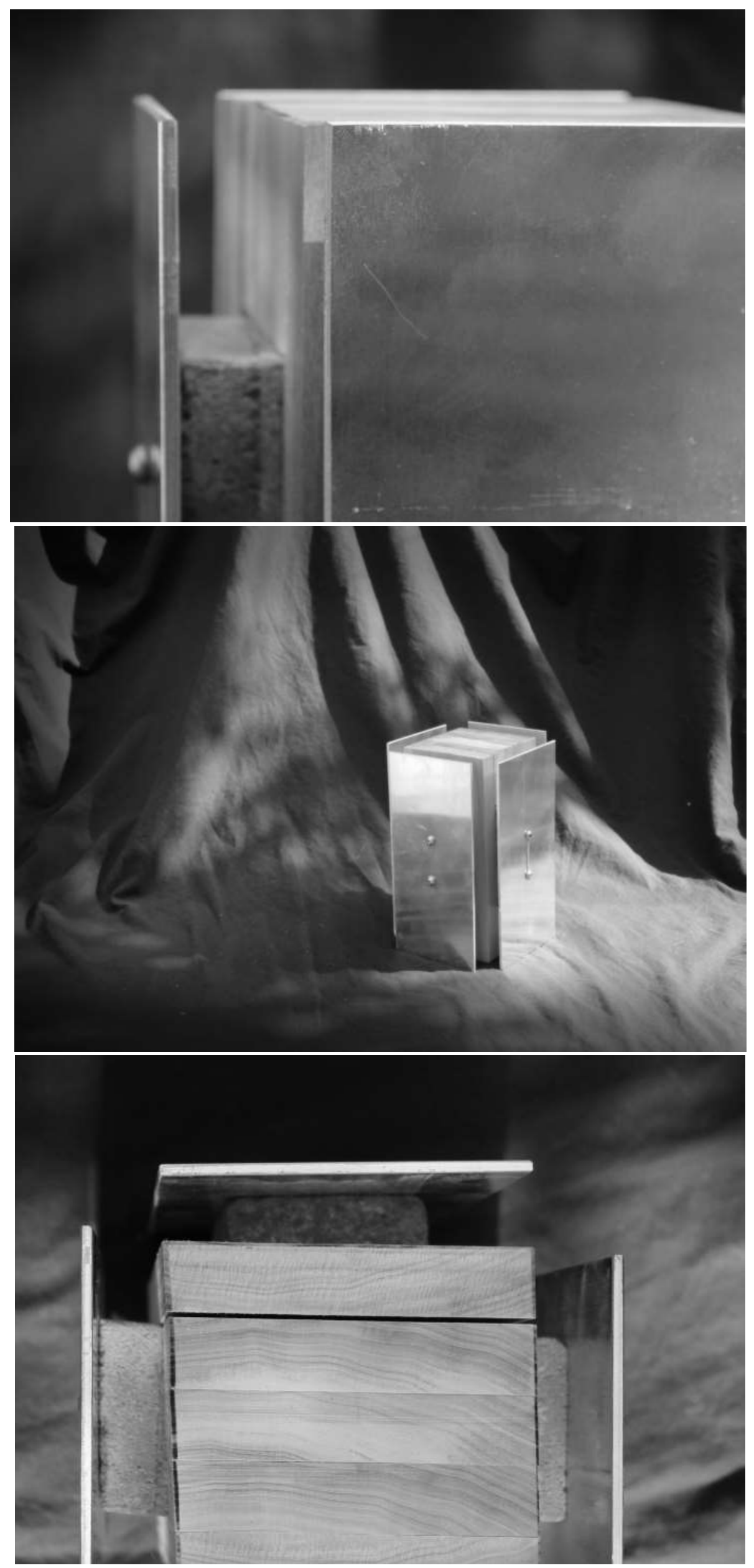


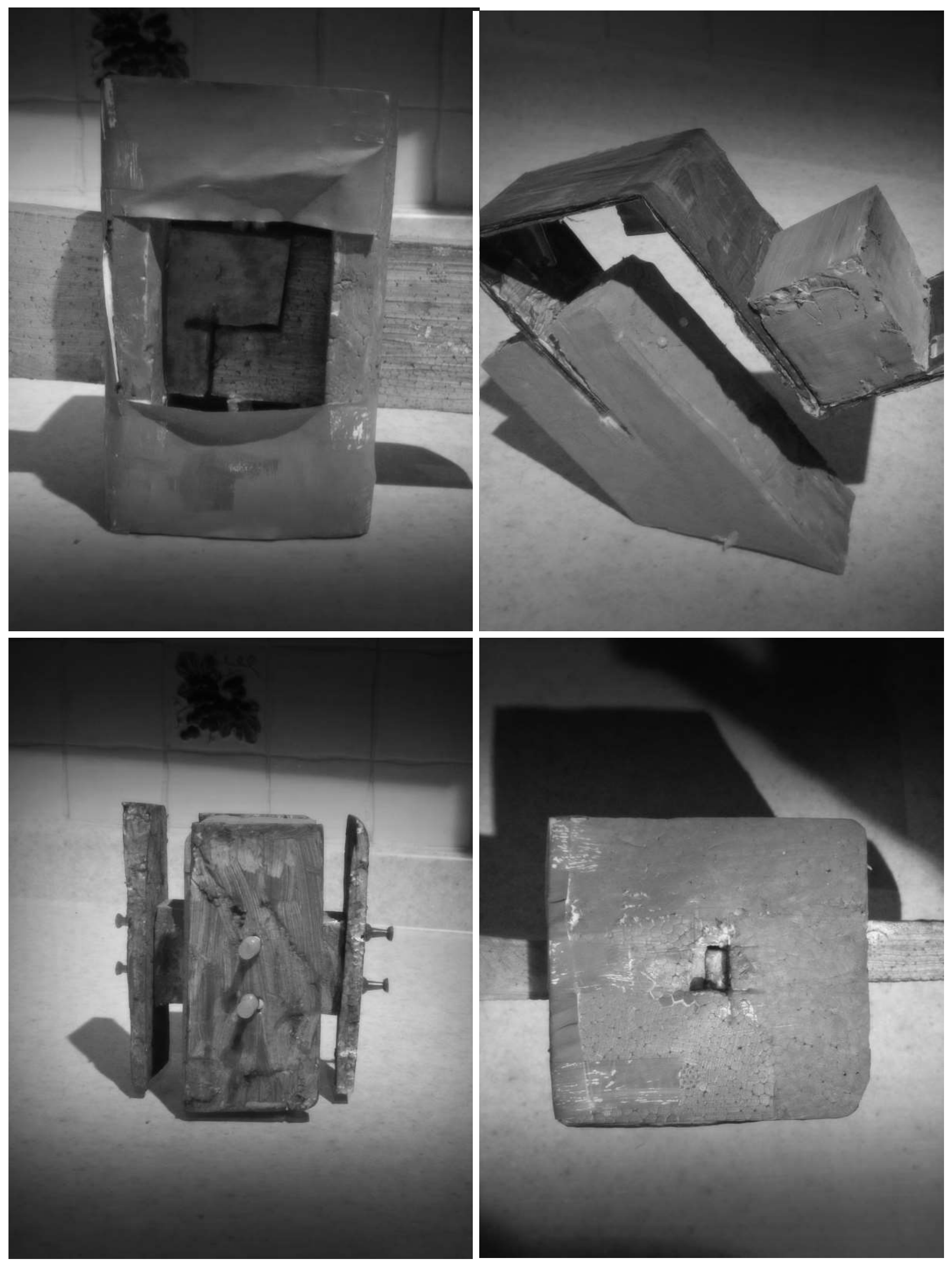


Figure 63. $L E F T<$ Various artifacts exploring unique seams that express character.

Figure 62. RIGHT> inspired by tightening.

Artifact

\subsubsection{Tightening}

While not as common as the other two models of fastening, tightening is a method through which material can be brought together in an assembly to establish a tectonic aesthetic that showcases character. Tightening is the pulling together of materiality often associated with stretching and tensity. This mode of fastening squeezes materials together keeping them secured which is often done by a tertiary material such as cable or rope.

This design experiment looked to compose a inspirational artifact by fastening wood, concrete and steel together through tightening, showcasing the fastening technique as a means through which to achieve character in the creation of materials seams. Two wooden rectangular boxes are squeezed together with a steel strap keeping the wooden shape together through tightening. Ridges along path of the steel strip have been provided in the wood to accentuate the strength and clenching power of the strips visualizing the tightening character of the joint. An intermediate interior concrete box is provided to prevent the wooden members from touching so as to be able to visualize the wood as two separate elements which are being pulled together yet are unable to reach each other. See first picture on left page.

By emphasizing the tightening of the steel strip within the material assembly, viewers are easily able to decipher the method through which the 3 components are held together offering a perspective through which to be able to appreciate the composure of the materials.

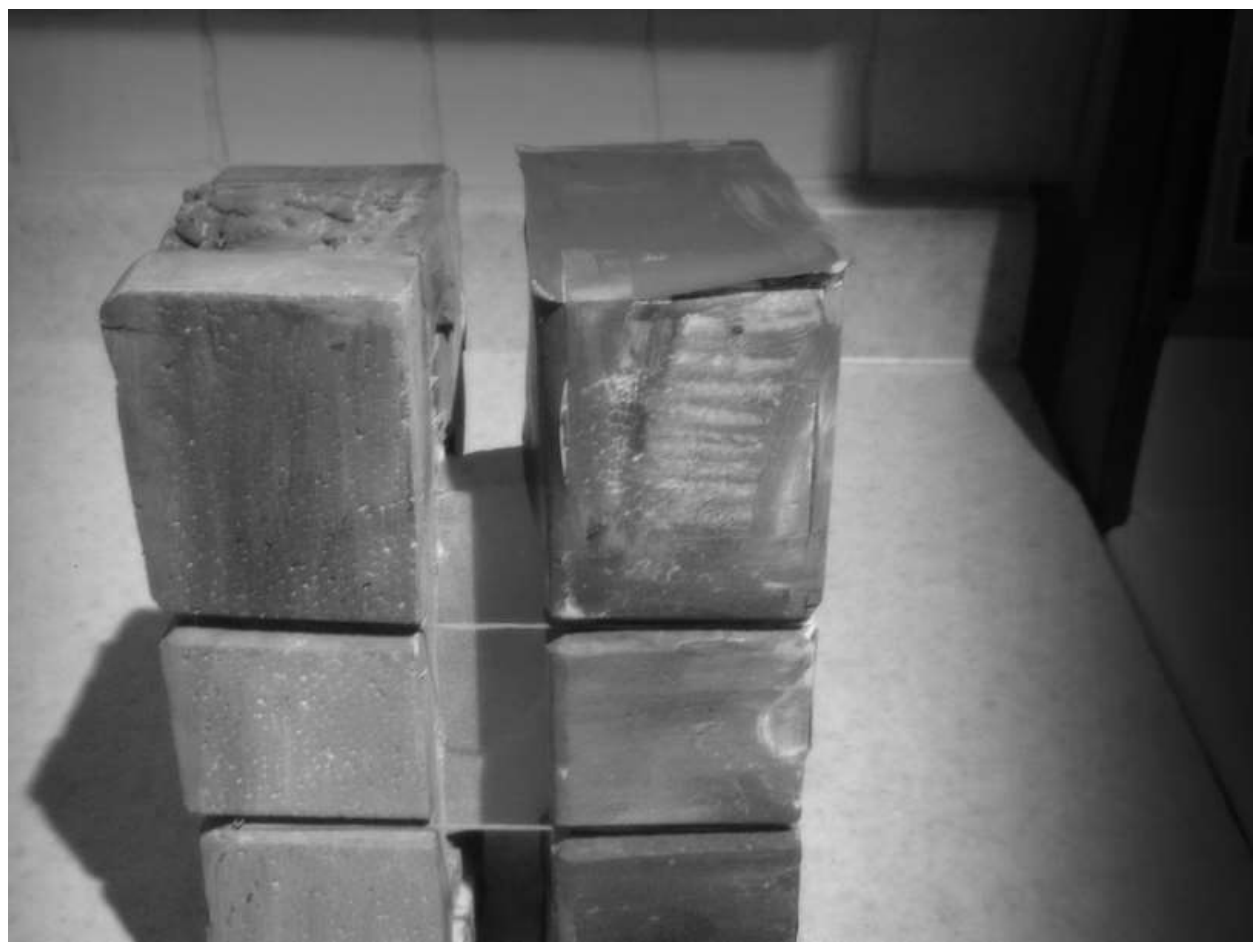




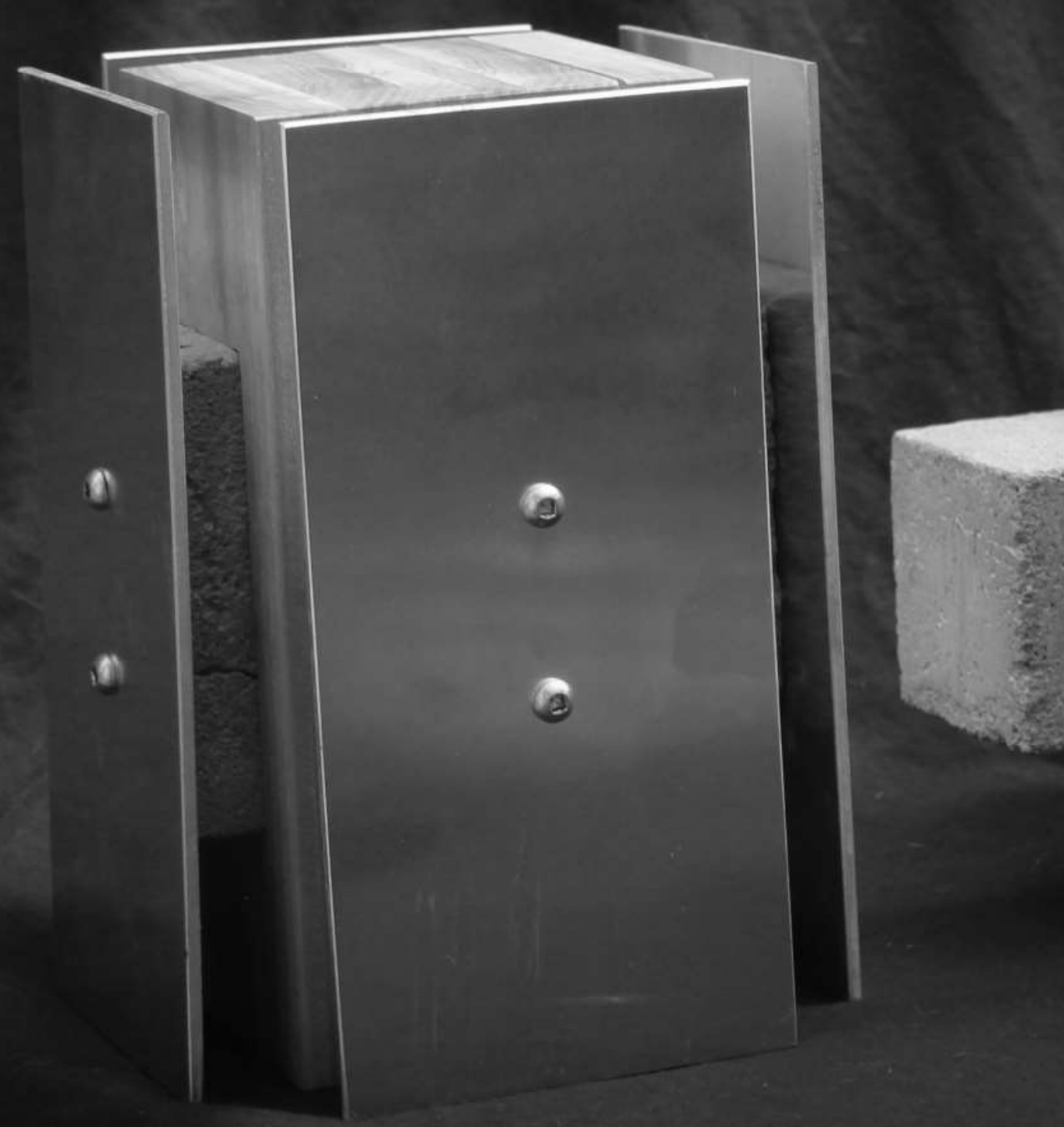





\subsubsection{Conclusions}

The development of character is an important aspect of both storytelling and architectural design. Character across both of these mediums is used to strengthen the relationship between the medium and the reader by establishing characteristics with which people are able to relate to. In the same way a story with character that seems not to face relatable situations often causes disinterest in the plot, architecture with components whose assembly are incomprehensible can similarly lead to a dis-interested crowd for lack of understanding and comprehension that composes the building. Designers of stories and buildings alike face the challenge of creating media that speaks to its audiences about relevant issues that define the unique narratives of our contemporary society. A mute architecture unable to express its character to audiences is a missed opportunity for strengthening the relationship between people \& buildings and strengthening captivation in contemporary architecture.

\section{Successes of the Experiment}

The design experiment as part of this section was an exercise in constructing an artifact showcasing the method of assembly. Each model can be used in the later stages of the design of the project as inspiration in the composure of building seams that express character. These artifacts will be used as tools to help compose the grander narrative of storytelling architecture by providing a small pallet of seams which can be employed within the design project should they be deemed to amplify the story showcasing storytelling in architecture.

\section{Considerations for the Future}

Each artifact designed was void of function. Unrestricted explorations allowed for the creation of abstract components that could be used as inspiration for the design of more specified building elements or concepts in the later stages of the thesis. The development of such abstract model is useful in the early stages of design since their unspecified nature can remain relevant even in the later stages of the design when many of the original ideas may have changed. A high level of abstraction privileges an flexible perspective and it is this perspective that can change as a project is developed. A further investigation into this exploration would begin to narrow the scope of the experiment choosing specific building components to design in a way that showcases character. 


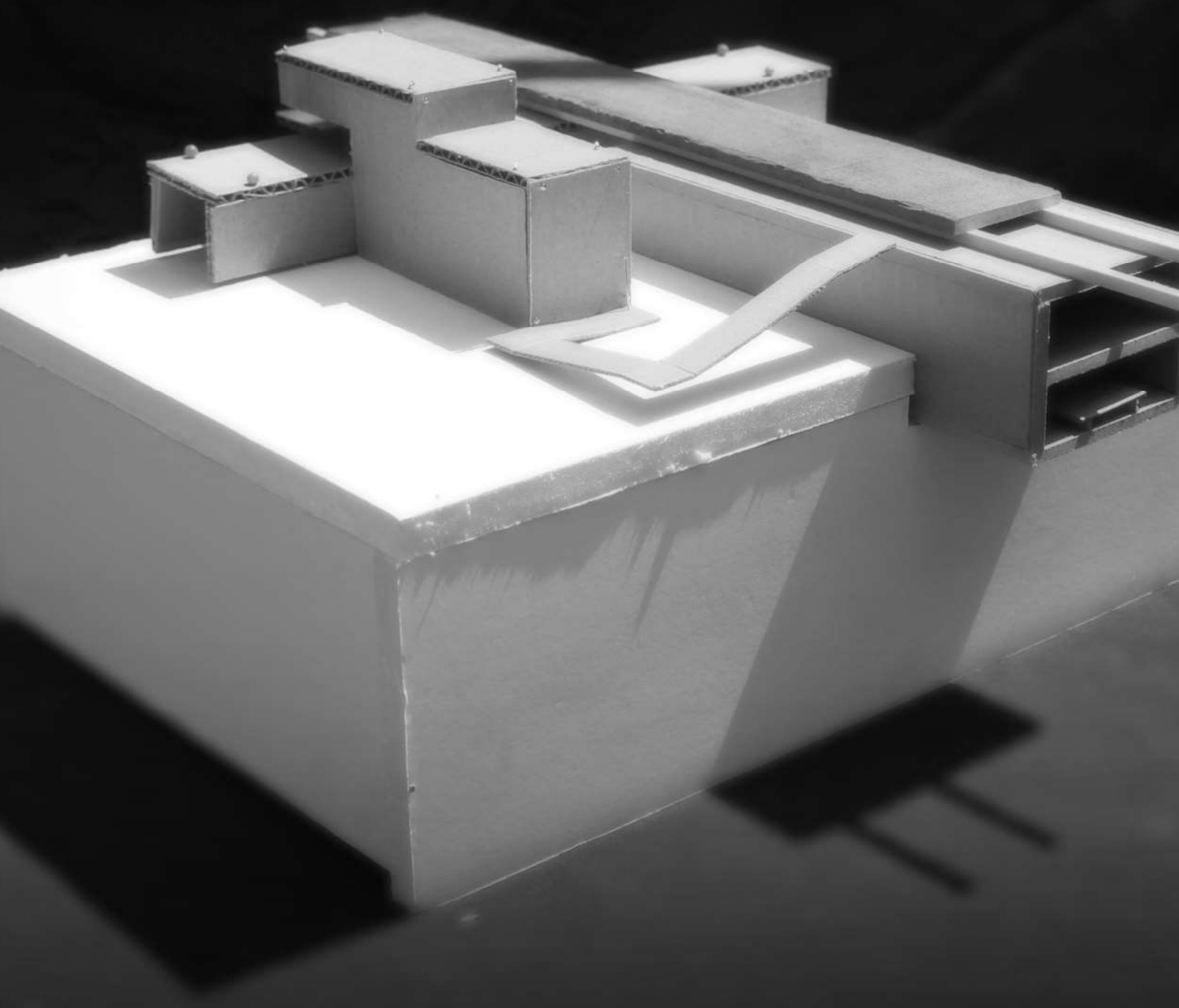




\section{CHAPTER 5. Emotion in Storytelling}




\section{$5.0 \mathbf{E}_{\text {мотіок }}$}

When asking an avid reader what makes a story so compelling, they will most likely describe an attachment they have formed with a part of the story they relate to. Within captivating tales, readers are drawn in, pulled by an invisible force binding the reader to the story through intrigue and captivation. Fostering a sense of intrigue within audiences is no easy feat and requires the talents of skilled writers and storytellers to establish a narrative filled with through provoking themes and situations that challenge the reader is some way.

In architecture, fostering intrigue can be a difficult but rewarding task emotionally investing visitors within the experience of exploring the structure. Although we have all experienced architecture, not all of us can confidently say we have been intrigued by architecture. Although there is no equation which when accurately executed will result in a intriguing series of architectural spaces, the creation of a diverse architectural pallet throughout the structure can spur a sense of curiosity in the viewer that will enhance the relationship between mankind and architecture. Emotional attachment between mankind and architecture as a result of exceptional architectural design is arguably the goal of every architect and yet the concept of emotion in architecture is unsolidified, requiring definition and further examination.

An etymological study traces the word emotion to mid-16c. Old French whose roots are further traced to the Latin 12c. word emovere meaning to move out, remove, agitate. Between mid-16c. and 18c, the meaning of the word emotion evolved to mean a sense of strong feeling which was extended to any feelings by 18c. Current day understandings of the word according to Oxfords dictionary is strong feeling deriving from one's circumstances, mood and relationship. An architectural definition of the term would focus primarily on the way in which a person is emotionally affected by a first person account of the architecture in question through sensory input as well as hermeneutic associations. This experience of emotion implies a heavy correlation with study of structures of experience or consciousness of being.

One such example showcasing intriguing architecture through exceptional architectural spaces is Yad Vashem by Moshe Safdie. Expressive spaces within the building create a strong relationship with the visitor as they travel along the structure to discover spaces of heaviness and light which are placed in opposition to create tension reflecting the state of mind of the tragedy of the Holocaust. Sequencing in the building lead visitors through an array of spaces, some narrow and tall with cold concrete walls while others are wide open rooms with wooden flooring bringing in a sense of warmth in select rooms. 
Figure 64. Grand view to nature at the end of the structure in Yad Vashem Memorial.

Figure 65. Contrasting tall concrete narrow hallway with large exposition rooms play with visitors emotions as they engage contrasting spaces.

Figure 66. Memorial space for the lives lost in the Holocaust. Deep hole below the names of people lost in the tragedy signifies the loss of the Jewish population. 
"A great building must begin with the immeasurable, must go through the measurable means when it is being designed, and in the end must be unmeasured."

-Louis I. Khan

Julio Bermuzed from the Catholic University of America has conducted research on experience and extraordinary architectural experiences. In this section, I will summarize his findings specifically those whose results speak to emotion in architecture. The scope of the following research was to provide a report on the central role that embodiment and emotion play during the highest aesthetic encounters with architecture through a survey (Bermudez, 369). Throughout the survey, 1980 English speakers and 982 Spanish speakers were asked to select five main qualities describing what they constituted as their exceptional aesthetic experience. The percentage of those who used the word emotion in their responses are identified below. Poll results of English speakers can be seen in bold while Spanish speakers is denoted in italics.

\author{
Emotional \\ (70.5\%, 76.5\%), \\ Sensual/Perceptual/Physical \\ $(71 \%, 50 \%)$, \\ Timeless \\ (50\%, 37\%), and \\ Pleasurable \\ $(41 \%, 38.5 \%)$
}

"The very high ranking of "Emotion" in comparison to all the other experiential descriptors in the Spanish responses suggests that, for this population, the arrived internal state (i.e., the effect of architecture in the person) is central to the experience, and probably what drives and brings everything together into a coherent phenomenology."(Bermudez, 370)

With emotion being central to the experience of extraordinary spaces, the next logical questions would be to inquire into how a designer goes about in creating a space with qualities that foster emotional responses. This is no easy task since a deep analysis of what constitutes high emotional association is considered to fall out of the field of architectural design and averted within academia. Rather than a deep investigation into the mind, an analysis of case studies and design experiments will be presented in the following pages from which a series of conclusions and takeaways aim to provide guidance in the design of spaces that privilege emotional responses.

To begin probing this investigation, a better understanding of what types of space embody perceptual qualities that affect its audiences on an emotional 
level is required. A series of inspirational photographs have been selected that many find to possess qualities that foster emotional associations. These photographs were analyzed and categorized so as to better understand the movement of light within each of the spaces.

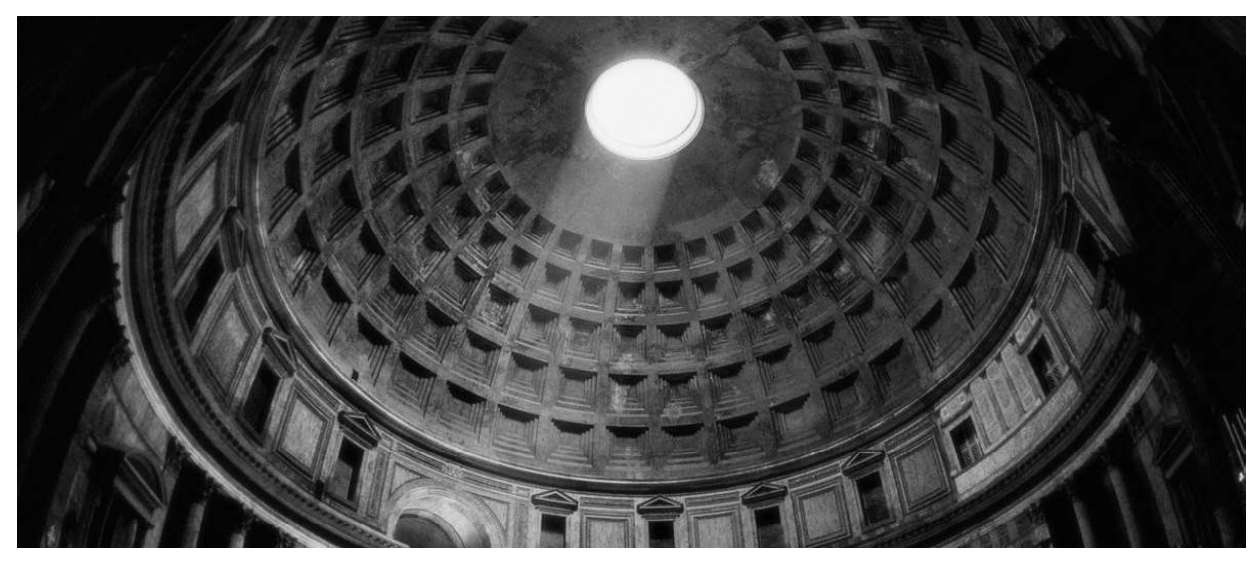

Figure 67. Survey from the University of America suggests the Pantheon to possess the most emotional qualities as voted by the public. 

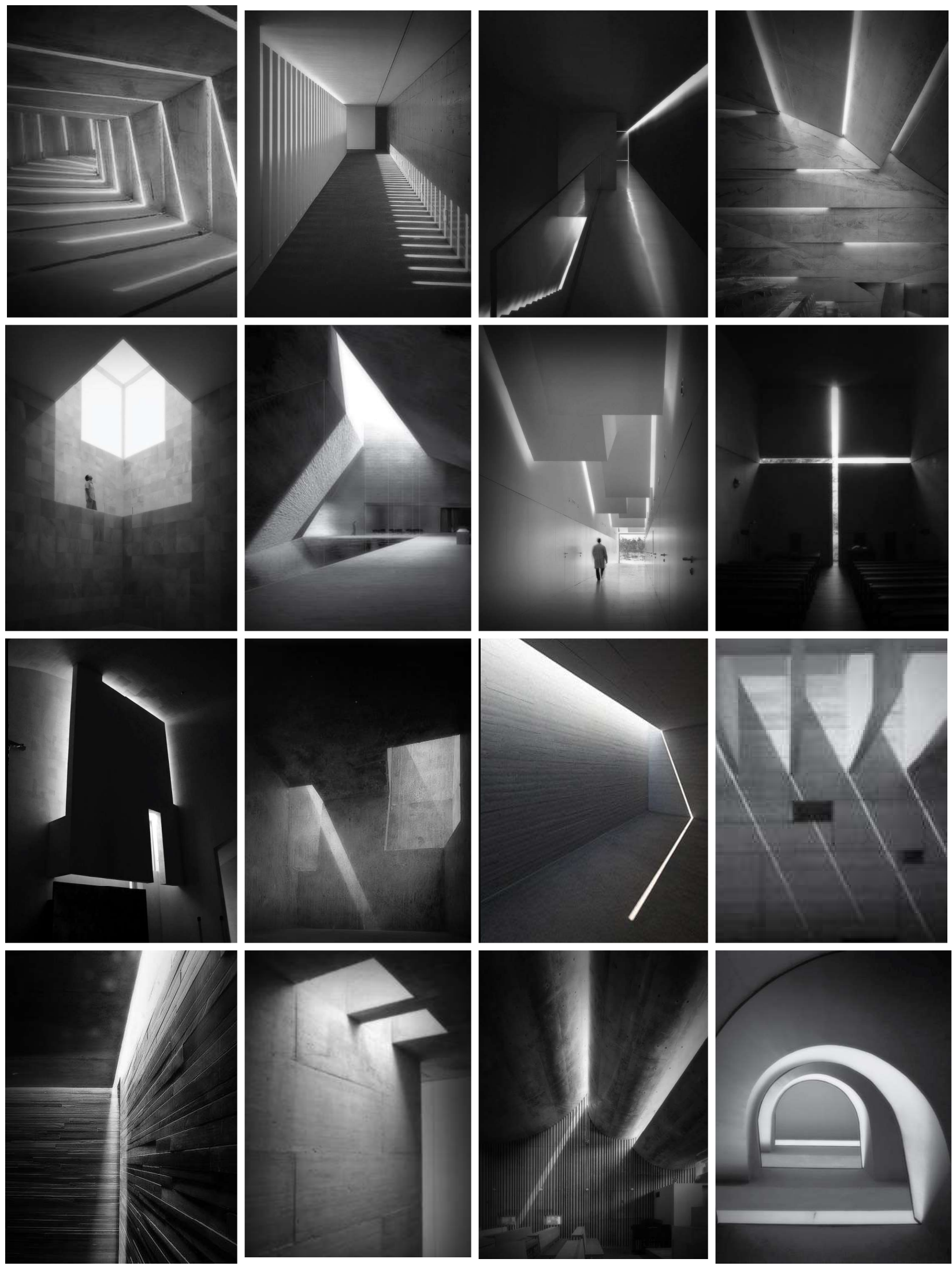

Figure 68. Inspirational photographs of captivating architectural spaces that bend and manipulate light. 


\subsection{Light and Emotion}

\section{Rhythmic Light}

By providing incremental penetrations within the body of the structure, light rhythmically enters the interior spaces heightening the presence of the materials within and imbuing them with light and shadow. Incremental light penetrations create a contrasting effect, placing shadow and light in procession and heightening the presence of both through the contract they create o each other. This form of light penetration is typically axial and works well along corridors such as the in the first two photographs on the first row.

\section{Flood Light}

Flooding an area with light creates moments of vast reveal such as in the first two photos on the second row. These major penetrations within the building place high importance on that specific location denoting a hierarchy through the use of light. This form of light penetration is seen to work well in focalized areas with high contrast.

\section{Indirect Light}

The penetration of light within a structure need not always be direct. Bouncing light can often enter through a building skin that privileges such permanence. The first two photos along the third row exemplify this example by manipulating light through a series of crevices that eventually reach the inside of the building.

\section{Diffused Light}

The presence of material is heavily reliant on the lighting conditions in the respective space. Within the first two photographs on the bottom row, light is diffused along the body of stone and concrete drawing ones attention to the material. By heightening material expression with light, light and materiality work together in creating spaces that have the potential to affect visitors emotionally. 


\subsection{Experience and Emotion}

The first design experimentation looked at composing a series of individual sectional frames telling the story of ascent and descent as one transitions from the condition at grade to the subterranean subway below. These frames were than organized into the creation of a conceptual experimental section which can be seen below. In addition, a number of joints were designed that reflected the coming together of materials through puncturing, tightening and interlocking. These joints were intended to be used as inspirational models speaking to the character that would be present in the detailing of the section once further developed. The following will provide a first person description of the experience of an individual as one passes through the section in efforts to paint a picture of the types of spaces that choreograph the story of ascent and descent through the individually composed frames.

[Frame A] The ground begins to descent as the traveler retreats from the city. The building form calls out and as the visitor moves forward embracing the invitation, the earth around begins rise. A slow and thoughtful entrance prepares the traveler introducing light and shadow as vital elements in the subterranean journey that is to come.

[Frame B] Natural light from overhead accentuates the downward steps that lead further into the station. This downwards transition privileges an upwards gaze into the skylights emphasizing the distance between earth \& sky and between city \& traveler.

[Frame C] A deep long corridor stand before the visitor. A gaze that pierces to the end of this corridor reveals natural lighting as a terminus condition ahead. Although the subway train is immediately below, a peak of interest as to what may be at the end of the corridor overrides the tendency to hop on the train and with curiosity as a guide, the traveler continues to the end of the corridor.
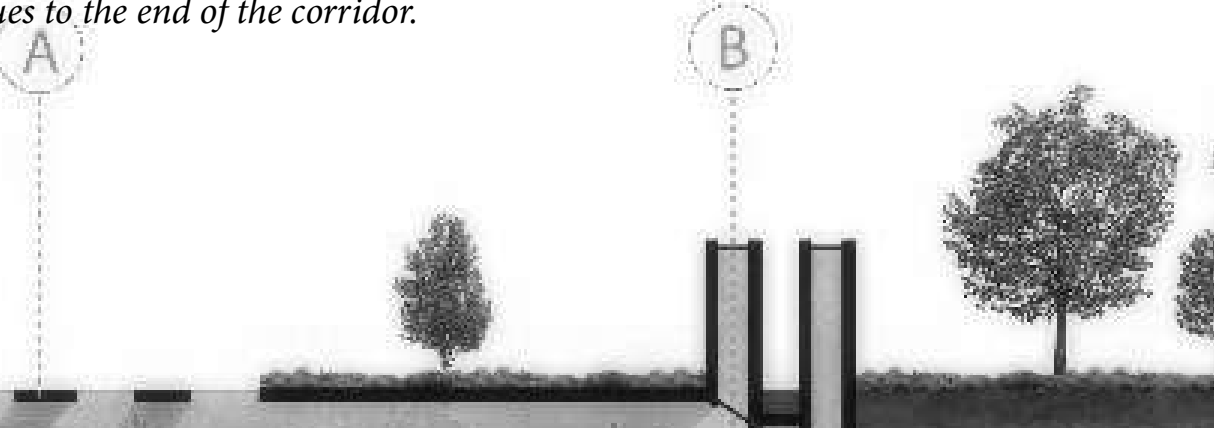
[Frame D] Having reached the end of the corridor, the guiding light that once peaked interest is to be left behind as the traveler descends down a series of steps that bring them beneath the skylight. The darkened corridor below seems to be tightening and spatial liberation is seemingly evaporating as the boundaries of the structure come closer and closer together.

[Frame E] Another row of steps lie in front and yet unlike many of the previous vertical descention before, these darkened steps beneath the large stone mass above proclaim the feeling of being submerged within an subterranean cave.

[Frame F] Within the final approach, the traveler comes to a silent and eerie room. Within the center lies a deep dark hole emphasizing depth and unknown as the darkness prevents a clear view within. This deep meditative space is composed of stairs surrounding the hole which are occupied by people in silent reflection. It is through a moment of pause and contemplation that the journey comes to an end and the traveler is encouraged to remain in a state of mental engagement as they continue towards their final destinations.

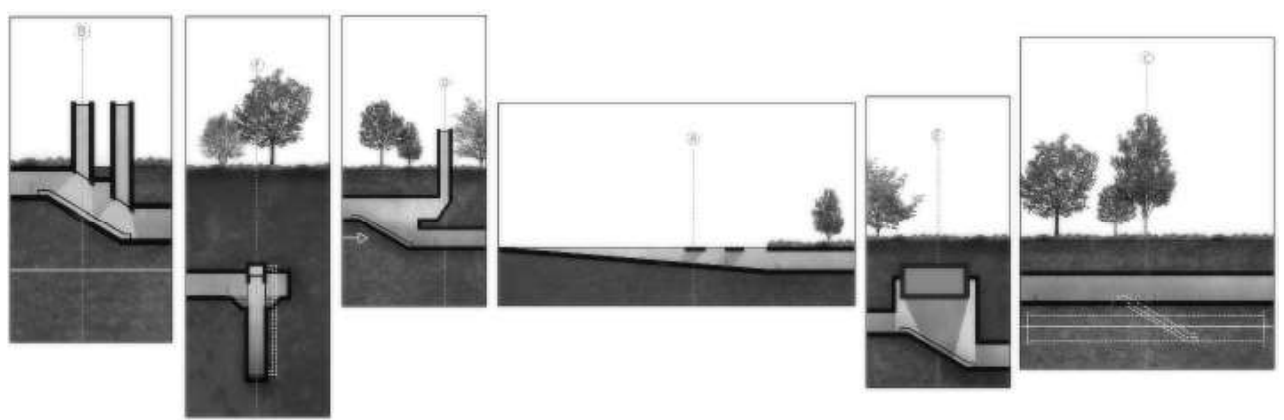




\section{3 navigation and вмотtoN}

Circulation within architecture heavily influences a space's ability to foster emotional associations. Spaces that provide linear navigation are often perceived as restrictive, not allowing the travelers the freedom to choose paths of their own liking. Providing a unique array of circulational paths within a structure is an easy way to offer visitors circulation freedom increasing the consciousness of a person as they actively decide which routes to take. In so doing, travelers have a sense of ownership over their selected route making the journey seem more special since they were in charge of selecting it.

Figure 70. Concourse Plan. Explorations in the design of multiple circulation routes from the ground level to the transit level of a subway station.

Figure 69. Transit Plan. Explorations in the design of multiple circulation routes from the ground level to the transit level of a subway station.
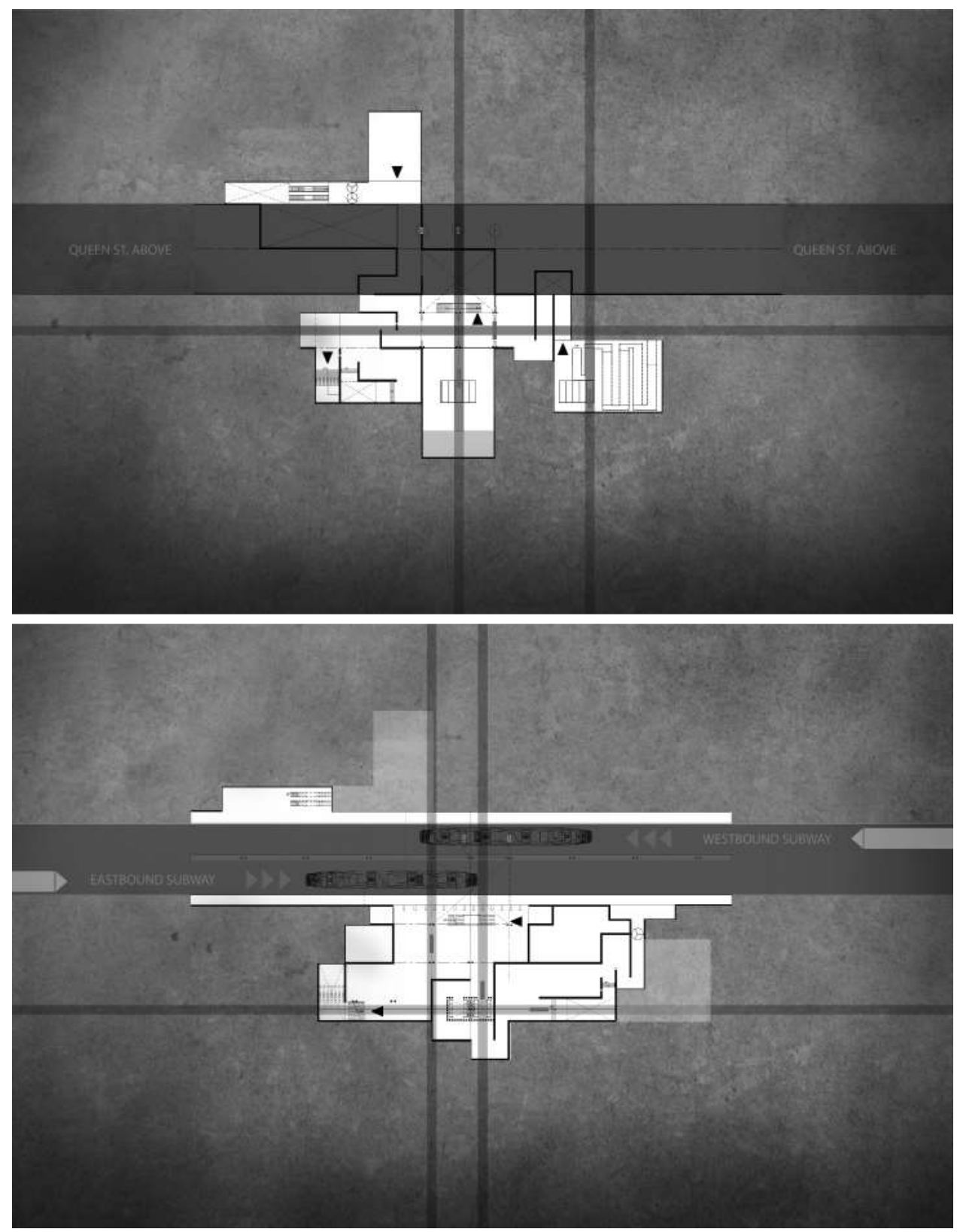


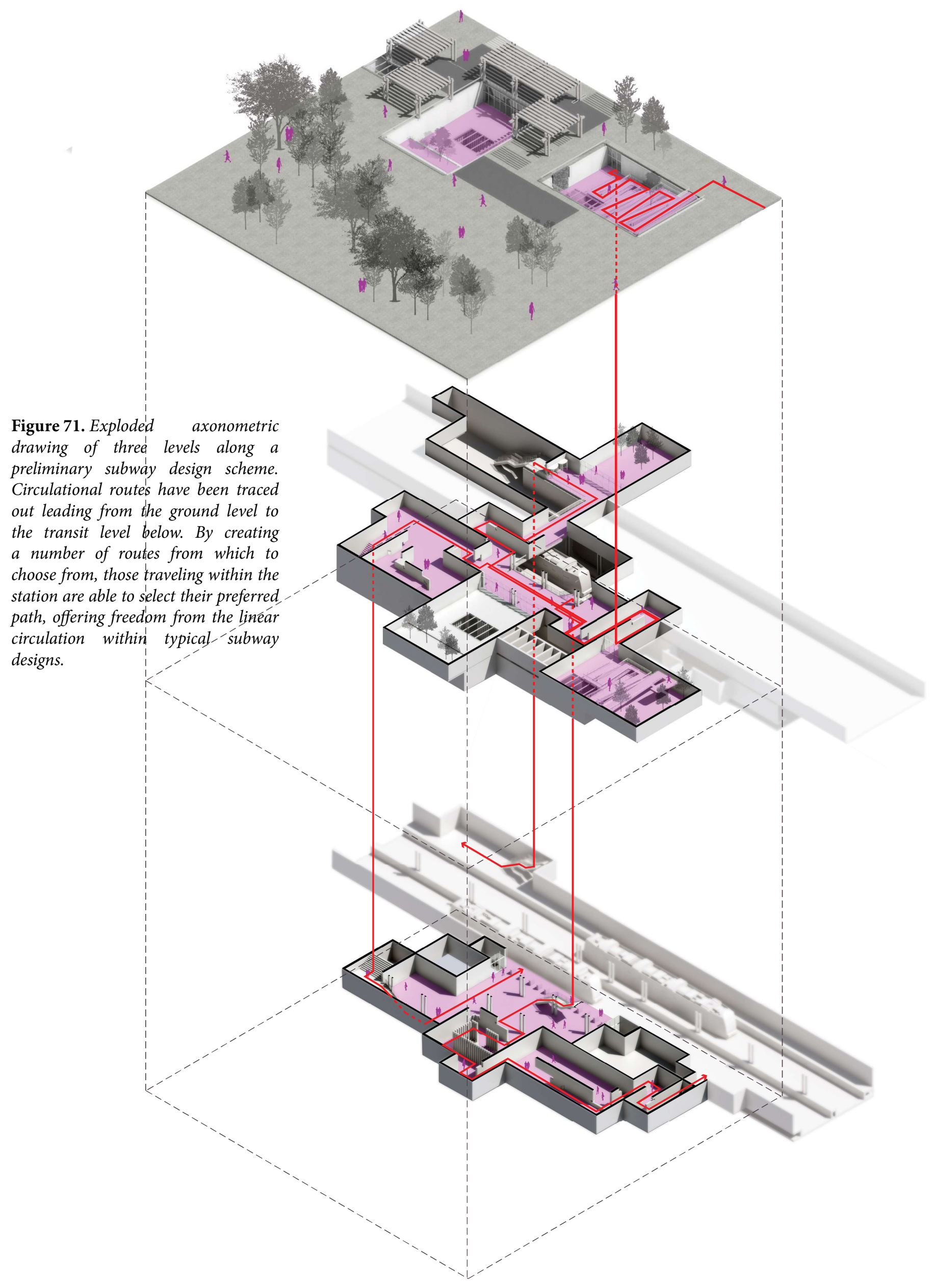




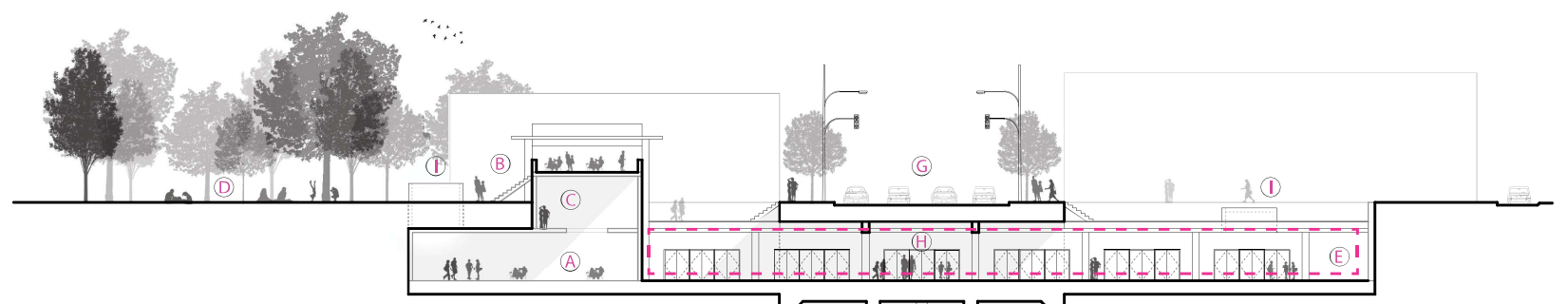

Figure 72. Travelling below the road.
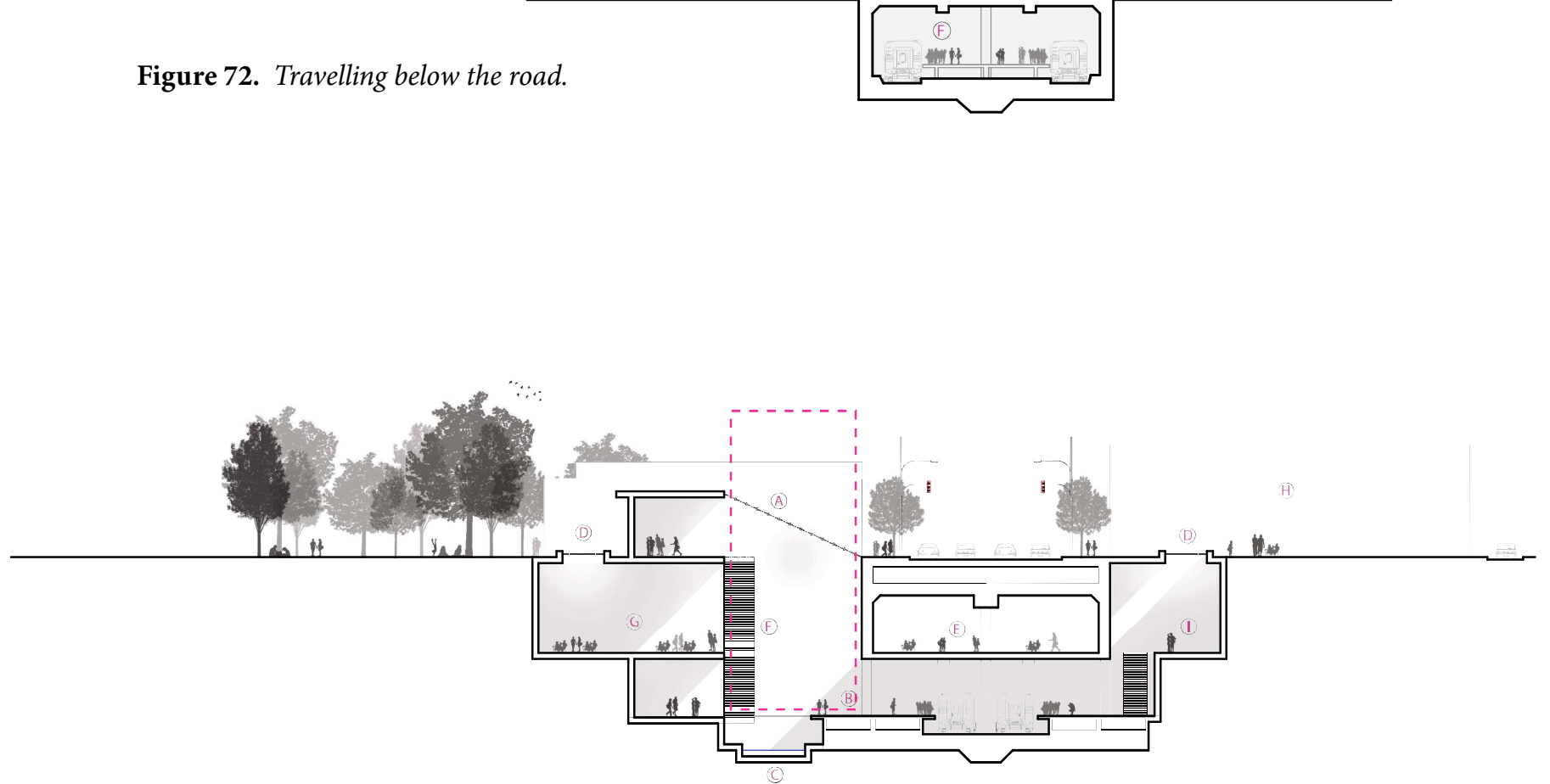

Figure 73. Travelling along a deep light well.

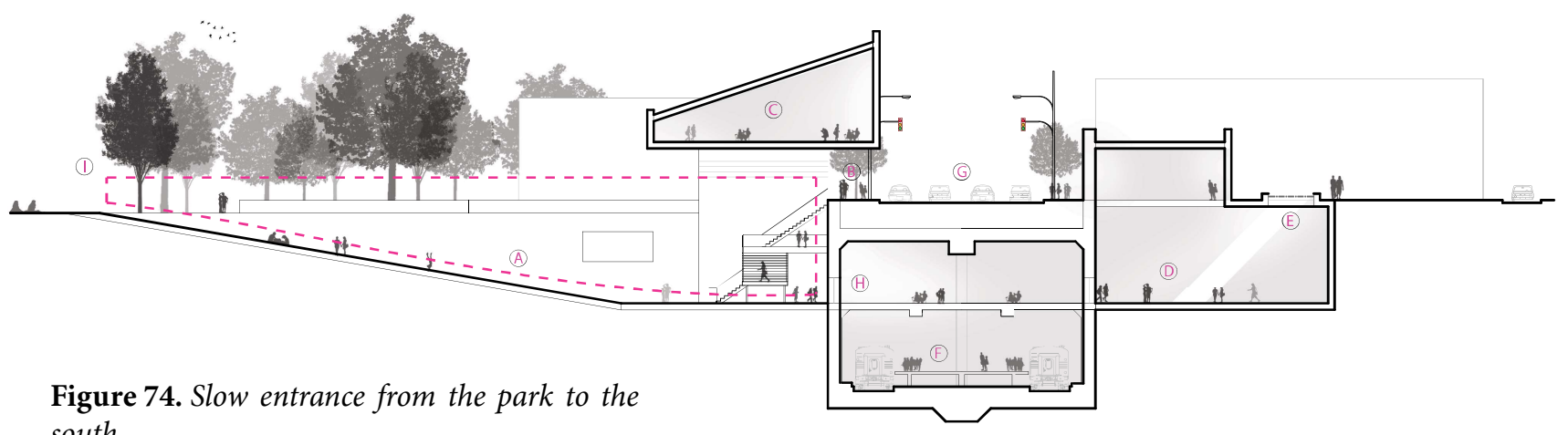
south. 


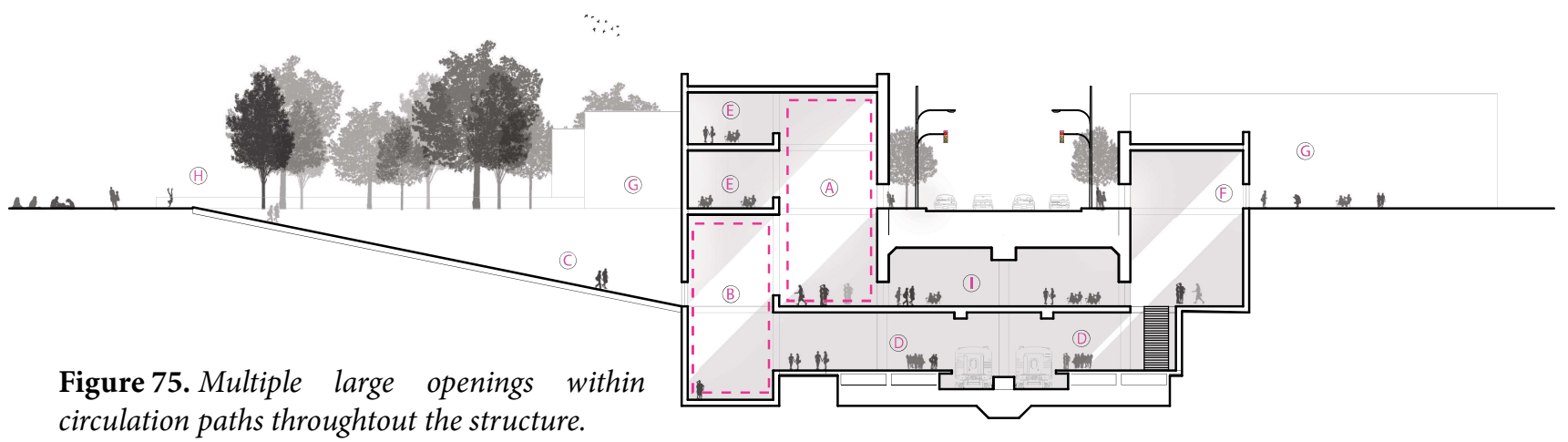
circulation paths throughtout the structure.

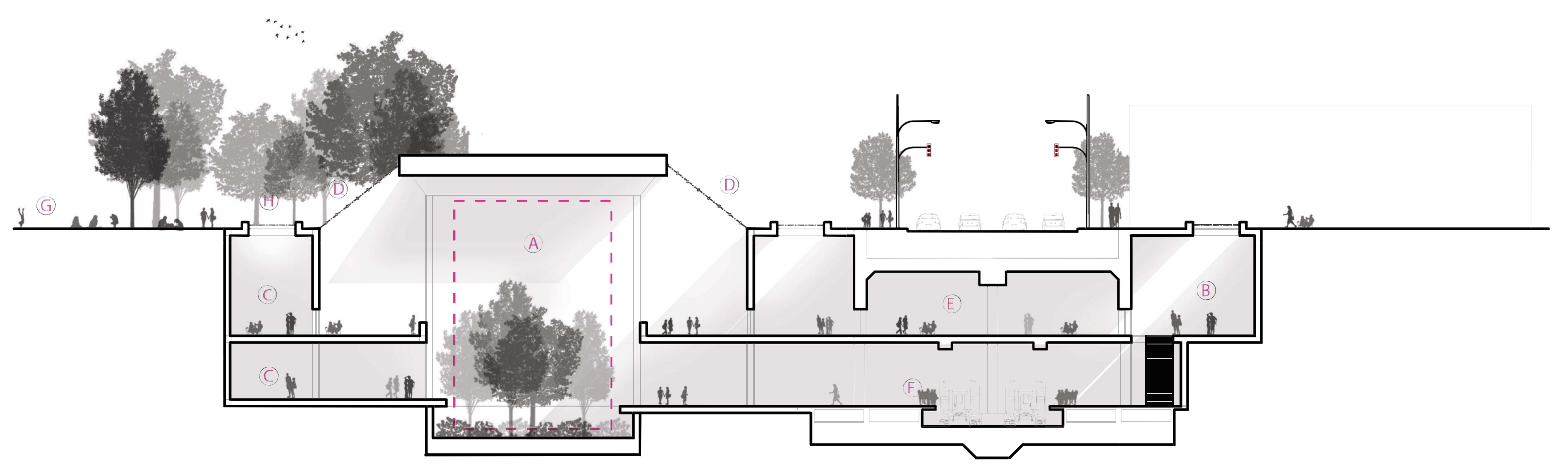

Figure 76. Circulation along greenscape brought within the building. 


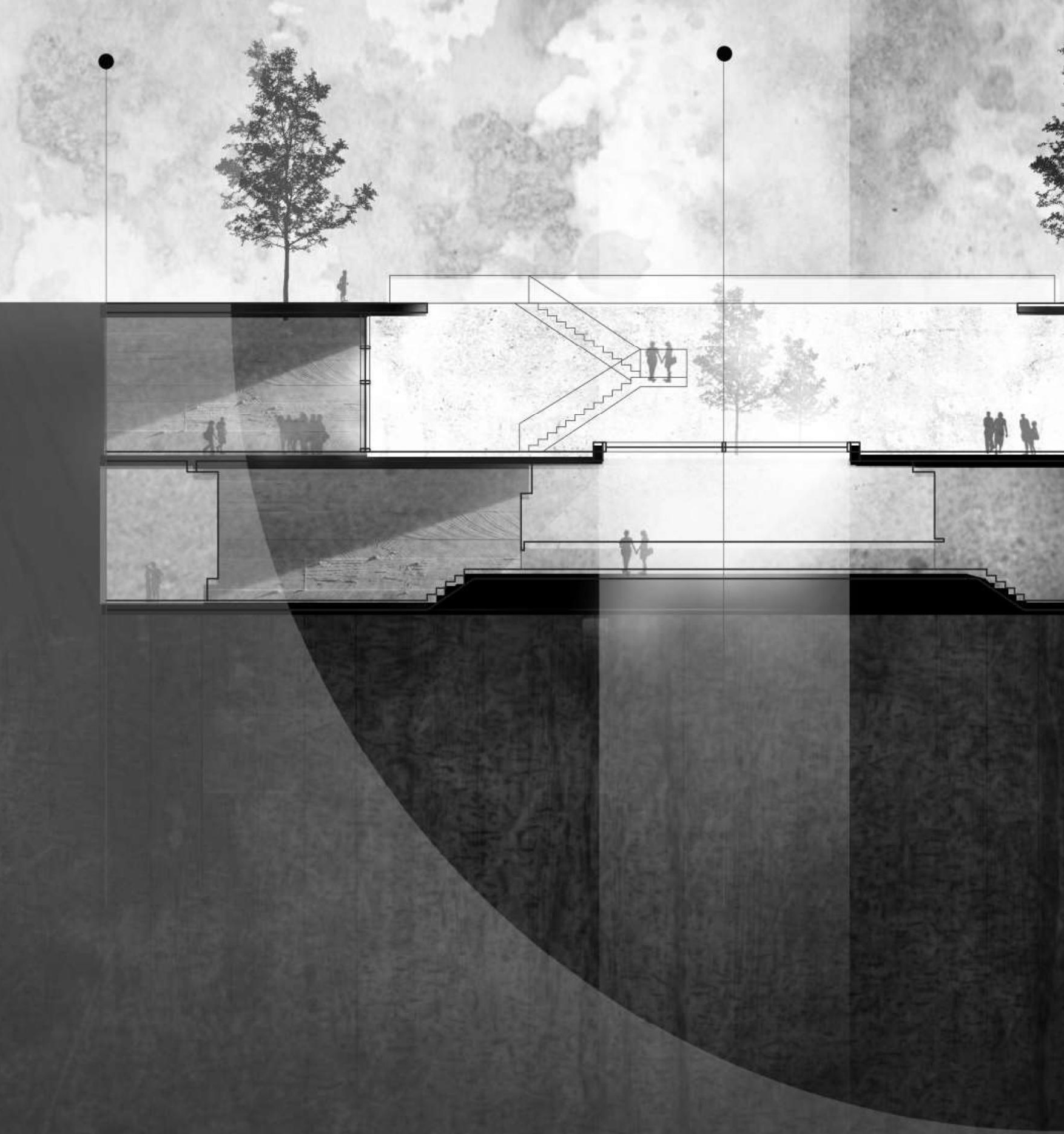



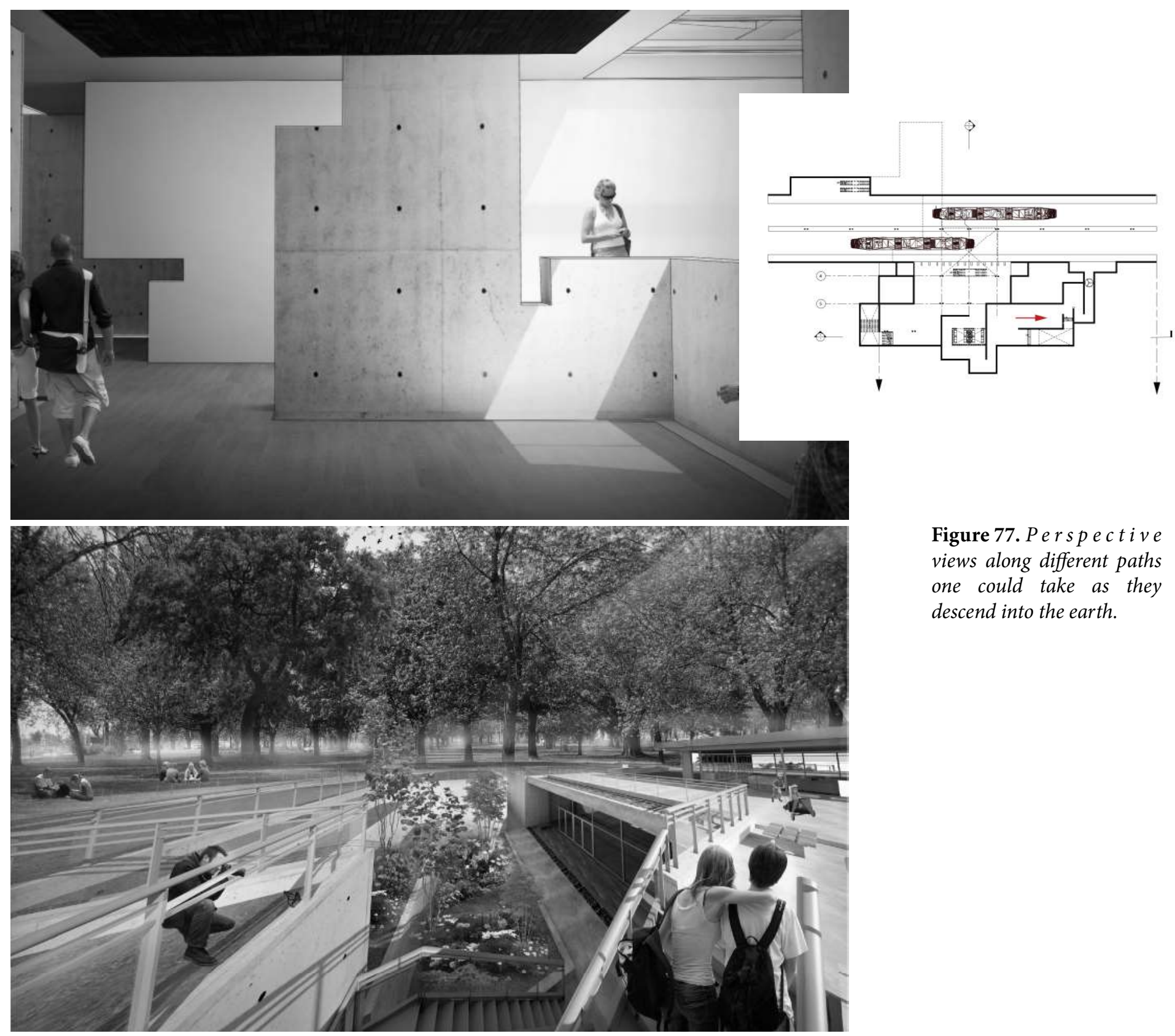

Figure 77. Perspective views along different paths one could take as they descend into the earth.

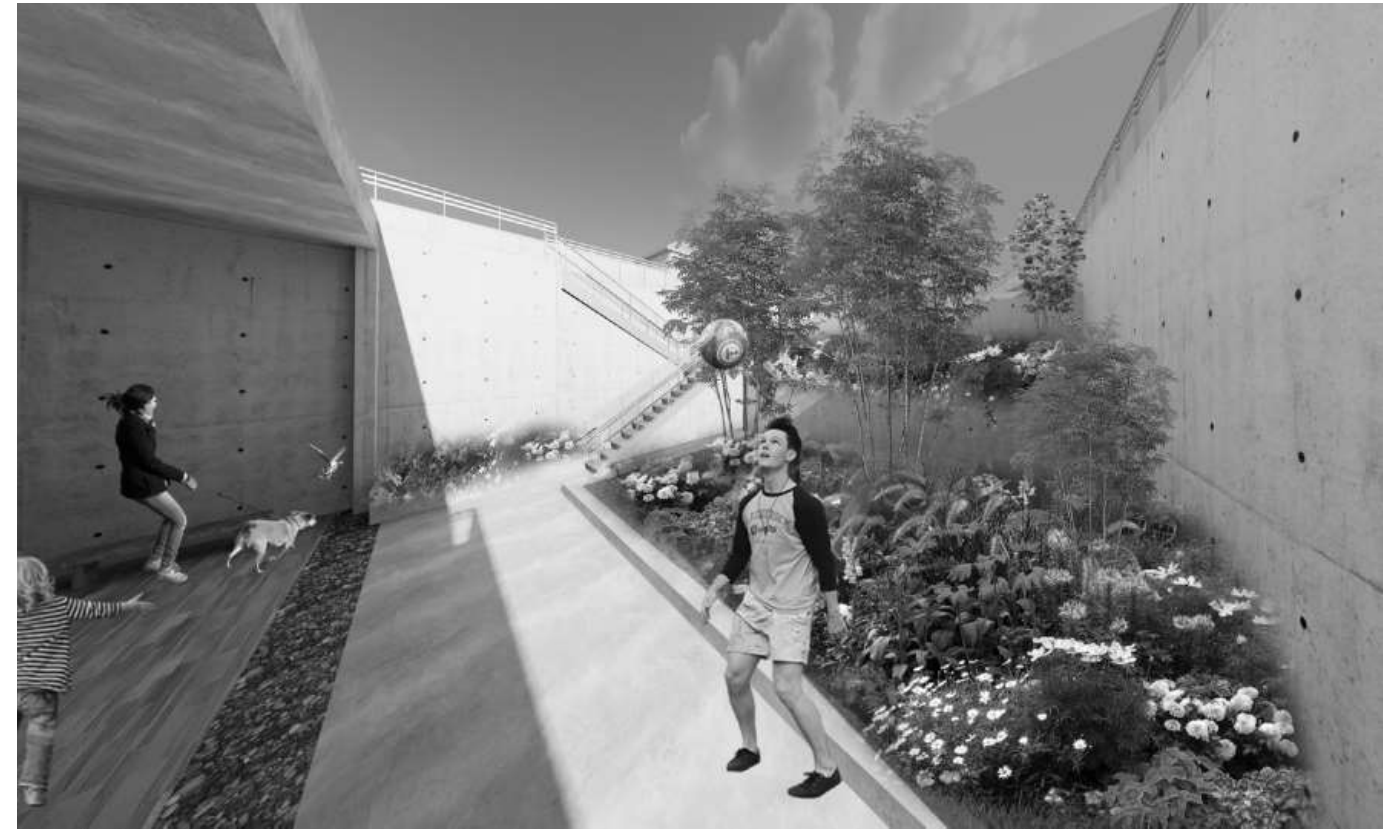

Figure 78. $E x t$ e $r i$ or renderings showcasing multiple entrances through which to engage the building. 


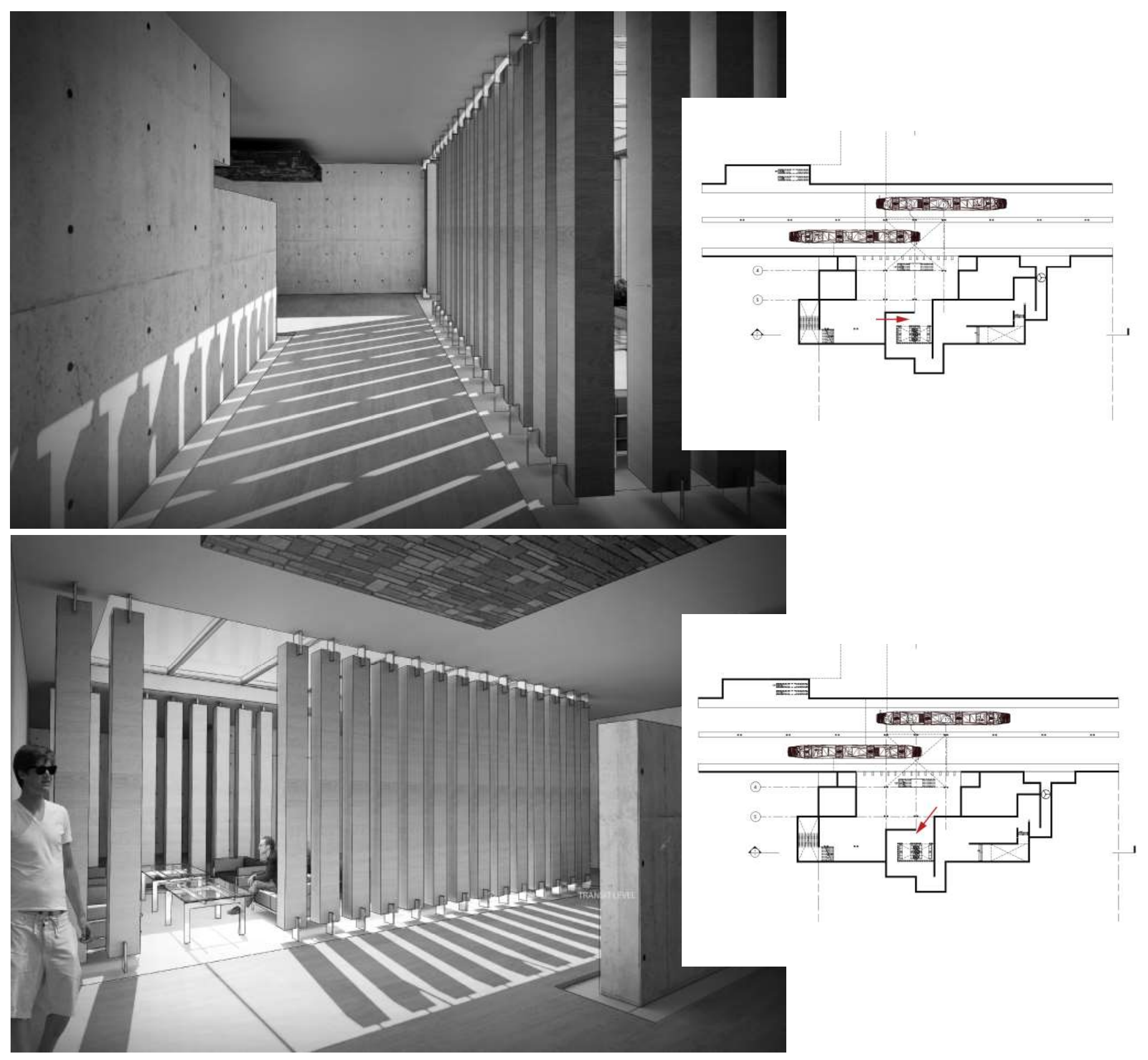




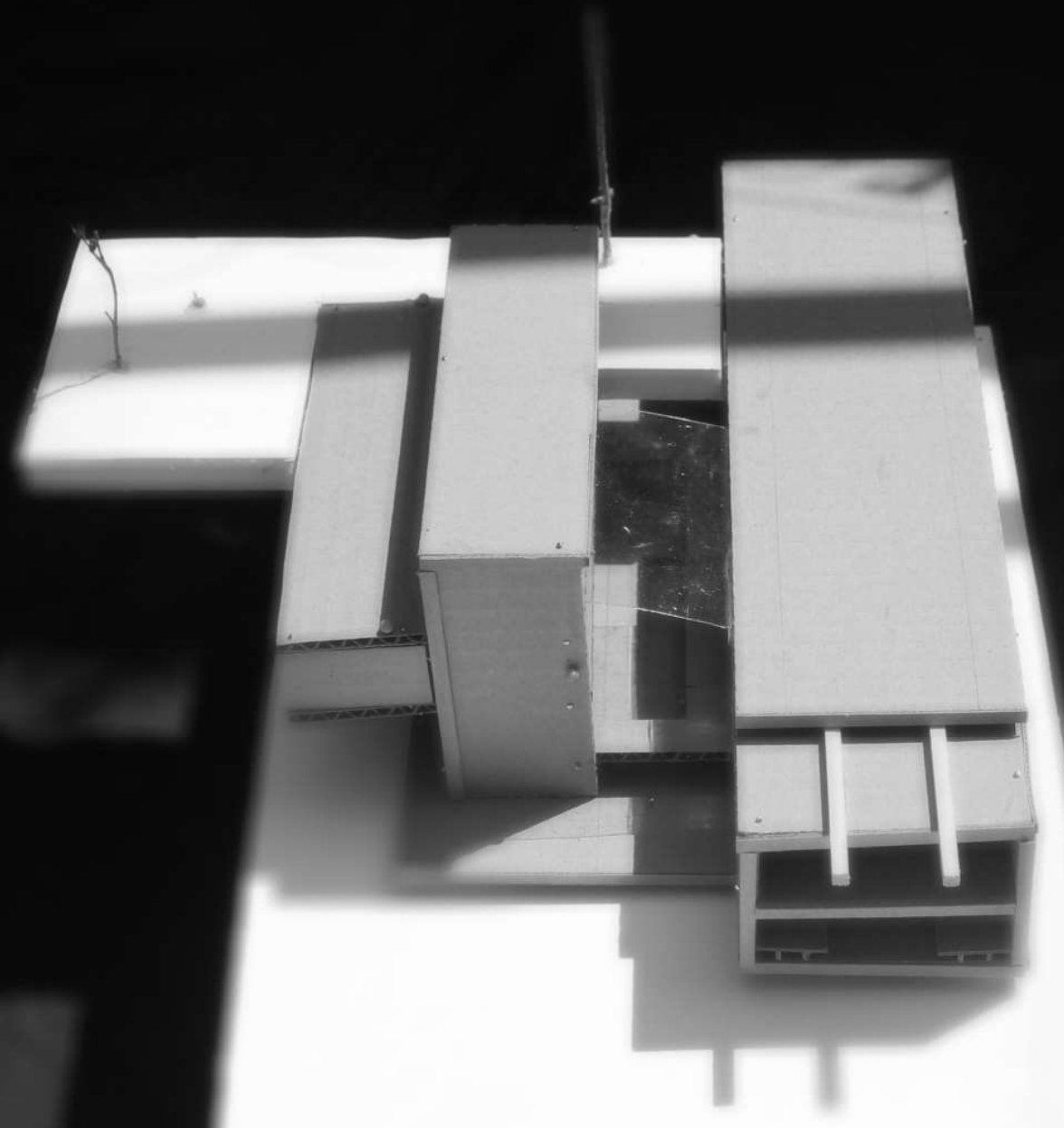




\section{CHAPTER 6. Site and Program}




\subsection{Program Selection}

This thesis aimed to select a program that has been heavily influenced by the loss of spirit in architecture. Although a variety of options were considered, a subway terminal was selected based on the following rationale.

\section{Program as Antithesis}

A subway station is truly the last program that comes to mind in the consideration of typology that possesses the capabilities of showcasing Spirit in Architecture. The hyper-pragmatic design of transit terminals are rarely privileged noteworthy expression especially in relation to Spirit as defined within these writings. Although case studies of transit terminals will be provided in the latter stages of the thesis critiquing the mentioned factors in addition to many more, the current focus of this section is not to dive into analysis but to understand them as factors present in the design of subway design that is leading to an experience undermining architectural Spirit. By selecting a program that is in direct contrast to the theoretical underpinnings presented thus far the aim is not just to validate the thesis through application of the concept manifesting a structure but to do so through a program that is considered an antithesis of the presented argument of what constitutes Spirit in Architecture. This is done to showcase the universality of application aiming to prove that Spirit in architecture is not restricted to architectural typologies like museums and art galleries as many may be inclined to believe. The program selection of a subway station is intended to be recognized as an antithesis and a successful application of Spirit to such a program would imply a potential application of Spirit to any other typologies.

\section{Scenography undermining Experience/ Typology privileging}

While much of contemporary design aims at showcasing the body of the created architectural works, scenography has been heavily critiqued for undermining the way in which the visitor engages the structure focusing on how the buildings appears to be rather than the way in which it is experienced. Since experience is of the up-most importance in the scope of the project we are aiming to create, the selection of a subway terminal reflects this importance since it is through the creation of an internal experience that we seek to achieve our goal and not through a display of architectural form that defined the aforementioned scenography. 


\subsection{Site Selection}

Queen Street West is known for its unique blend of historic architecture and its diverse commercial settings. The street acts as a transition from the core of downtown specifically the financial district to the more residential and pedestrian scaled surrounding areas. While many attractions peak the interests of residents and tourists alike, the combination of historic architecture and pedestrian oriented retail make Queen Street West a popular destination creating a vibrant community along the streetscape. Although a master plan of Queen street has not been developed West of Bathurst, the master plan of Fashion District just East of the selected site has been consulted aiding in the development of a number of defining characteristics that compose Queen Street just west of Bathurst Street.

\section{Queen Street Future Transportation Infrastructure}

The site was selected so as to situate the project within Toronto's twenty five year transit plan. (See figure $\mathrm{x}$ ) The following transit map is provided from Metrolinx identifying two major expansions to Torontos current subway system; the new Queen St. line shown in red and the northern extension of the University St. line shown in yellow. My intent was to select a site that is high in density and situated within the downtown core, is part of a vibrant community that would appreciate the scope of the project and is near public space so the spatial dynamics of the thesis is not confined to be strictly below the road. The intersection just west of Ossington St. and Queen St. was selected as the project site on which a transit terminal will aim to showcase Spirit in architecture.

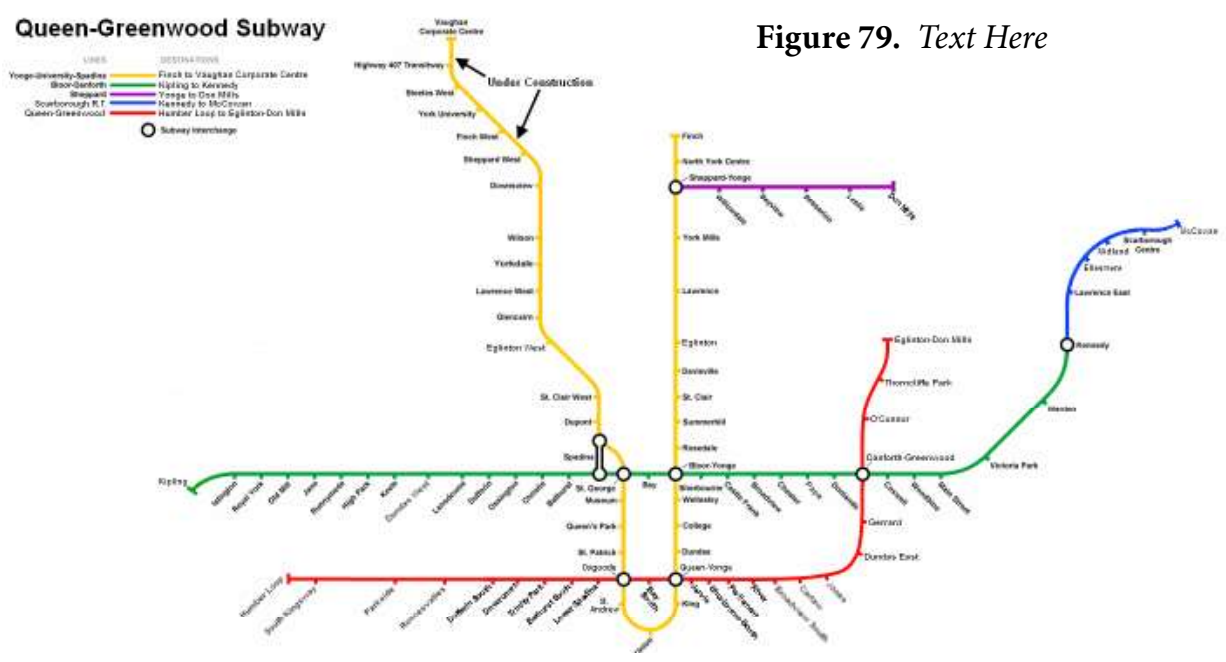




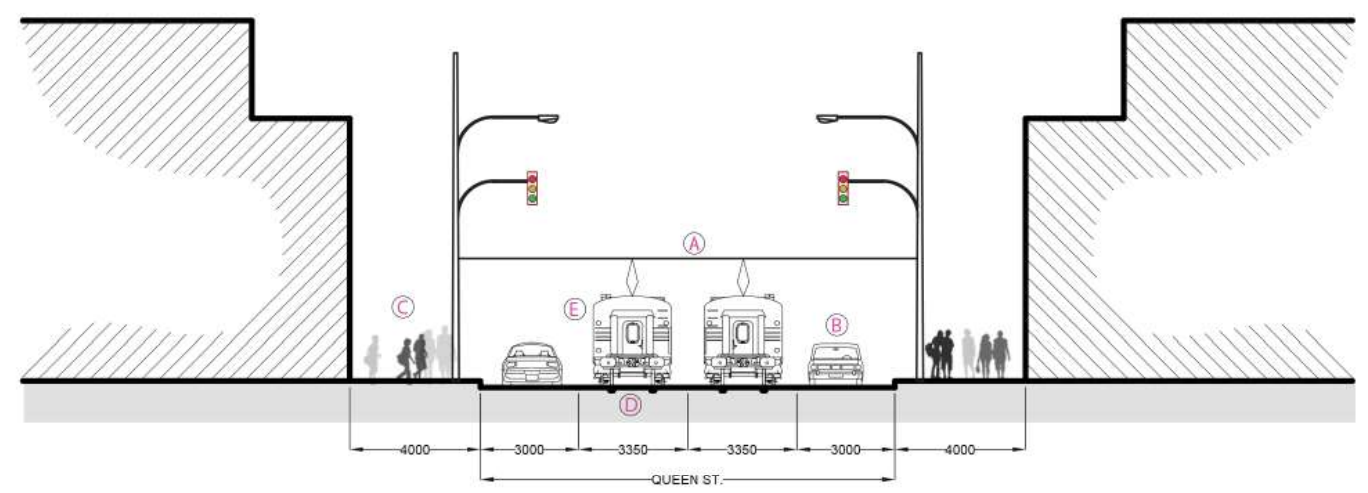

NEGATIVES POSITIVES
(A) Overhead Wires
C People on the Street
(B) Congestion
(E) Views while Traveling
(D) Streetcar Tracks

Figure 81. Existing Streetcar Condition

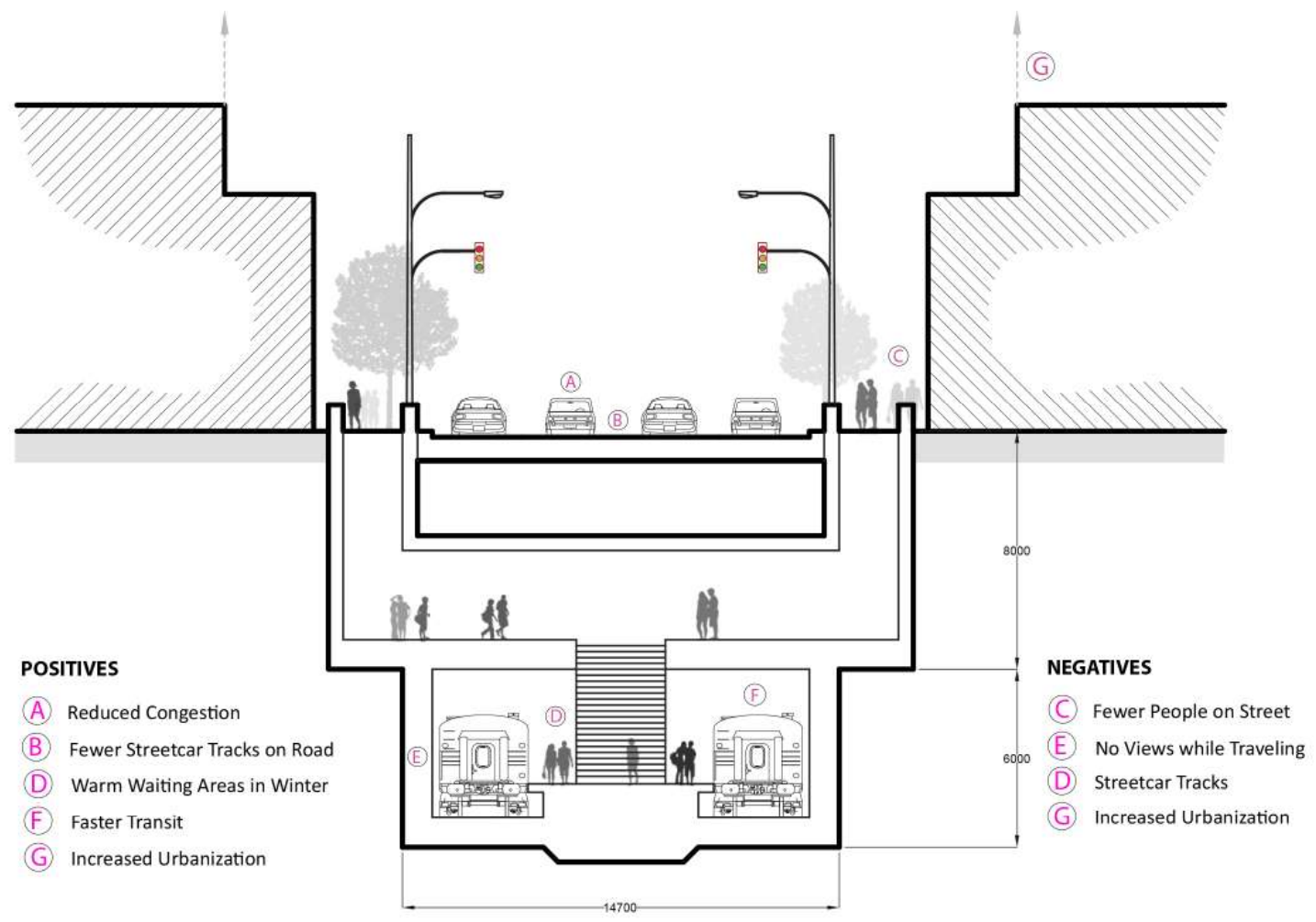

Figure 80. Proposed Subway Condition 


\subsubsection{The Role of the Public Transportation}

The role of public transportation along Queen Street West is of key importance connecting the heart of downtown Toronto with Roncesvalle Ave. in the West. This importance has been recognized as part of the twentyfive year Toronto Transit Plan which looks to improve transportation through the implementation of a subway along Queen Street as previously mentioned. This section will not seek to provide further evidence as to the needed subway on Queen Street since the decision to do so had already been federally approved and the rationale for this decision is readily available in Metrolinx documentation which can be accessed through a link in the provided Appendix 1 at the end of this document. The following will provide an account of the cultural shift that would occur with the phasing out of streetcar and introduction of the subway and how the design of a transit terminal can alleviate some of the unwanted characteristics.

\section{Takeaway}

The design of a subway station with access and views that enrich the relationship between pedestrians and the street corridor. 


\subsubsection{The Feel of Queen Street}

The urban fabric defining both the North and South Queen Street wall reflects the unique character of the area. The conglomeration of low rise structures tightly packed into a continuous wall showcases unique architectural elements including the rhythm of the street section, use of glazing along the street wall and roof conditions. The following section will provide an analysis of these three elements relating specifically to how they affect the user experience as one travels along the extents of Queen Street. The scale of the urban fabric along the Queen Street wall is low rise, with most buildings ranging between two to four stories in height. By maintaining a low street wall, the Queen West feels like a town nested within a cosmopolitan city. Although numerous factors imbue Queen Street with town-like qualities, low rise building are one of the prominent and distinguishing features that empower the human along its street corridors. The following section will analyze the existing zoning, street section and building entrances in relation to the scale of the human and their effects the town-like atmosphere of Queen Street West. The existing zoning allows for a maximum of sixteen meters in height to be built along the street front with a stepback of forty five degrees at thirteen meters or higher.

\section{Takeaway:}

The design of an experience reflecting the feel of Queen Street through rhythm and scale.

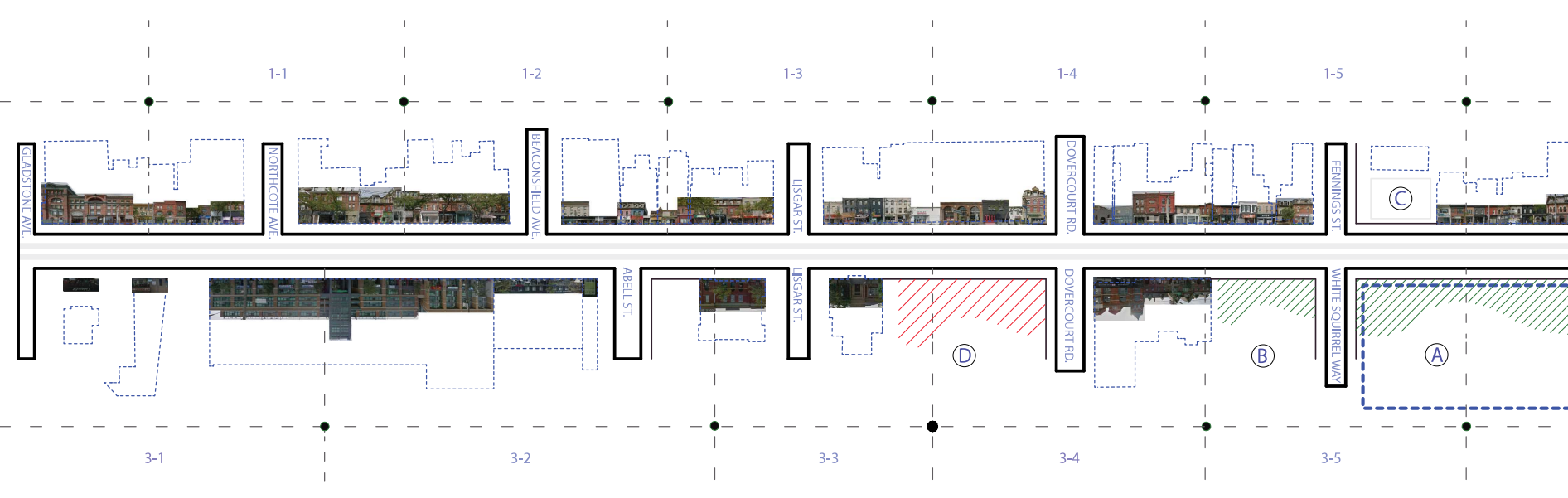

Figure 82. Proposed Subway Condition 


\subsubsection{The Widened Sidewalk}

Much of the commercial along Queen Street spills out into the street in locations where the sidewalk has been widened or should additional space be available such as in the drawing below where the Dark Horse Tavern on the corner of Queen and Euclid permit patio spacing immediately adjacent to the building. Although it is significantly noticeable that there is a decline in the outdoor commercial extensions the further West one travels on Queen Street, a street presence is notable and it is expected that with the implementation of the subway underneath, commercial activity is to thrive further urbanizing the western sections of Queen Street and enhancing the urban life that is currently present within the area.

In many locations where the sidewalk has been widened, the public has appropriated the space for a range of activities along the Queen Street corridor. Although the street is quite long and the appropriated spaces are spread out, an analysis of the corner of Queen and Brookfield Street has been provided below due primarily to the proximity in relation to the selected site. As seen below, the sidewalk in front of 111 Queen has been widened with the construction of the mid-rise building immediately adjacent. As a result, the sidewalk has been able to house numerous informal activities such as the Bike Share program as well as various vendors selling books and other goods. The additional space along the sidewalk has also permitted the planting of new trees incrementally along the side walk and although during the visit the trees were not used as a source of shade due to the colder temperatures at the time of visiting, it would not be unexpected to find visitors lounging around near the adjacent shops and under the share of surrounding vegetation.

\section{Takeaway}

The creation of a transit hub that offers flexibility for both formal and informal commercial and community events. 


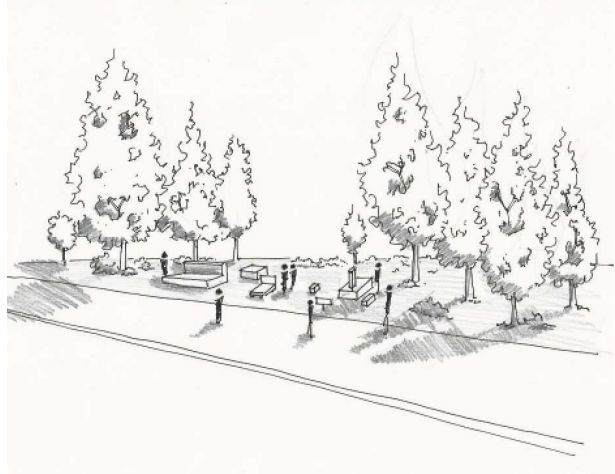

Figure 83. Parkscape

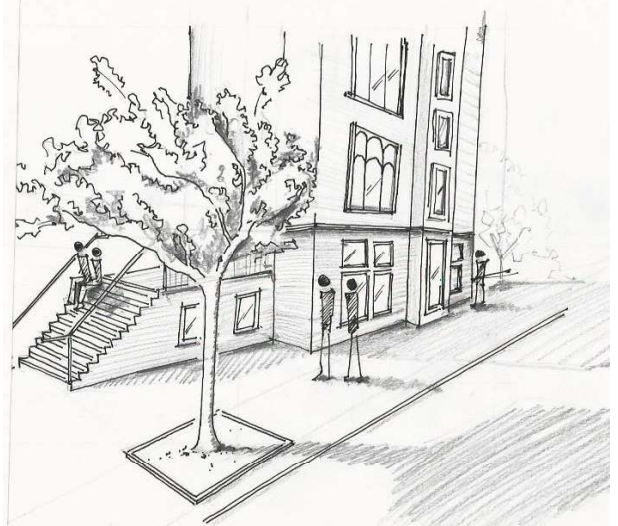

Figure 86. Steps of Existing Church

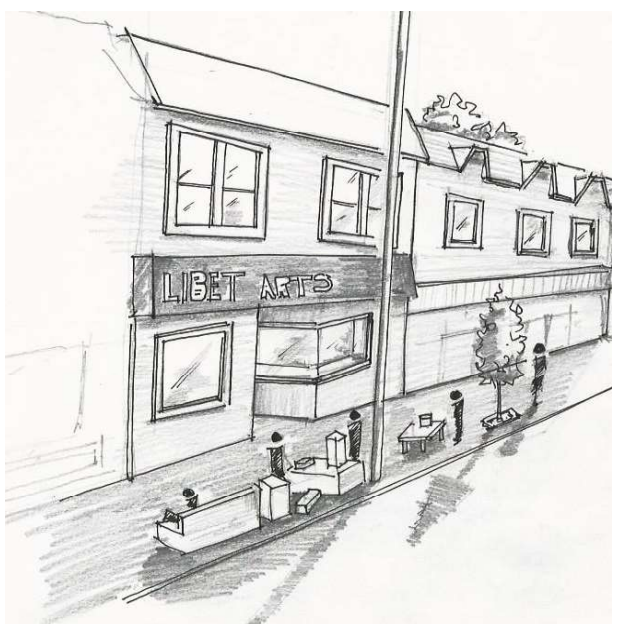

Figure 89. Selling Furniture along sidewalk

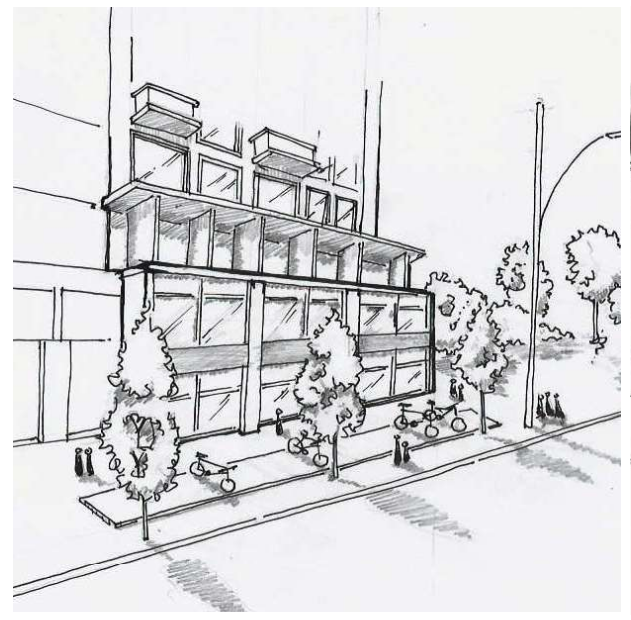

Figure 84. Bike Share Station

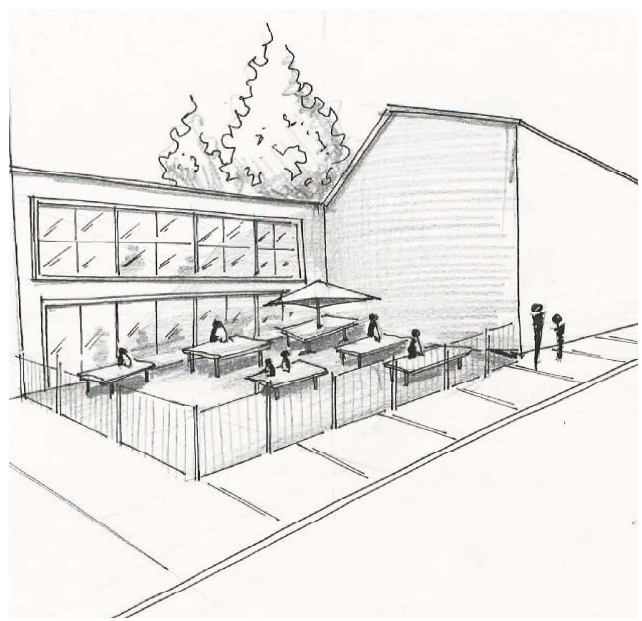

Figure 85. Pub Patio

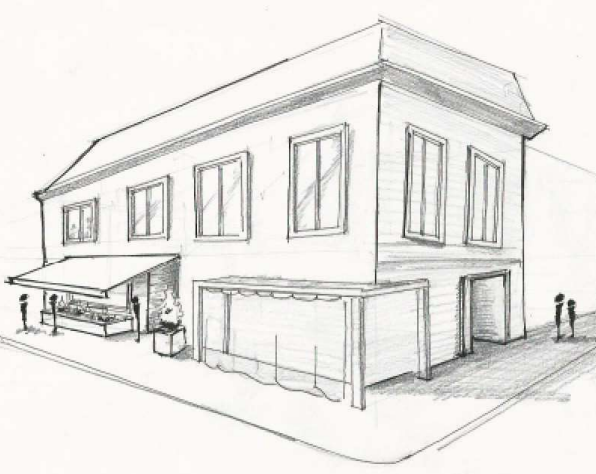

Figure 87. Fruit Market along Sidewalk

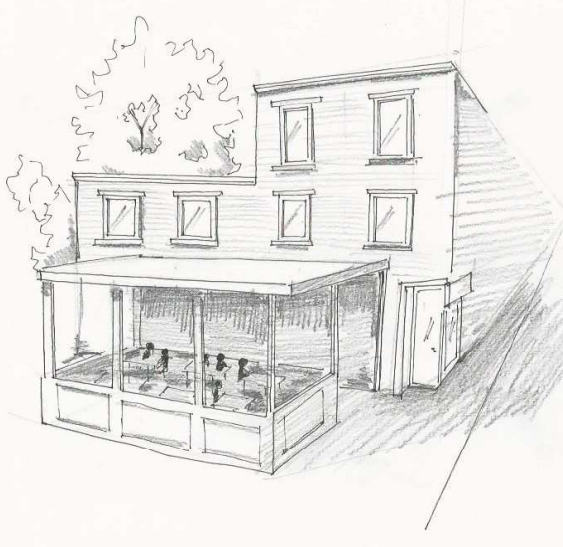

Figure 90. Dark Horse Tavern pub

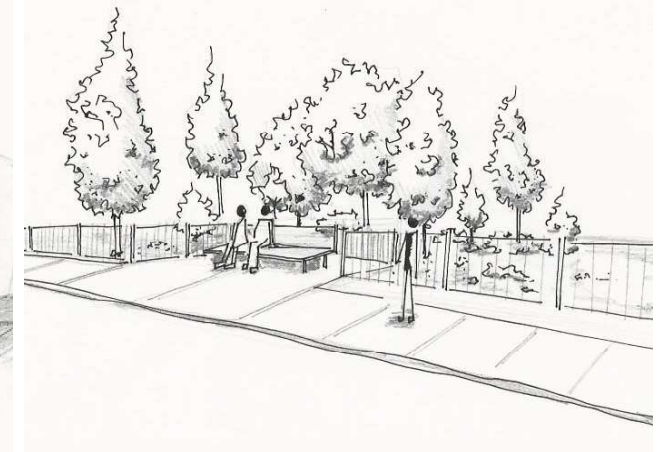

Figure 88. Secondary Parkscape

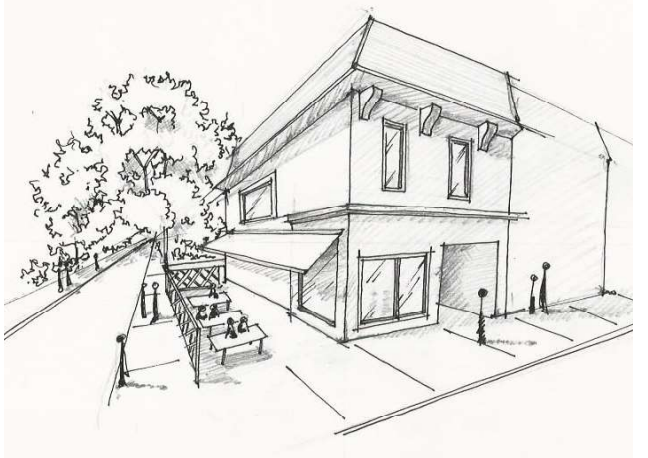

Figure 91. Seating along Sidewalk 


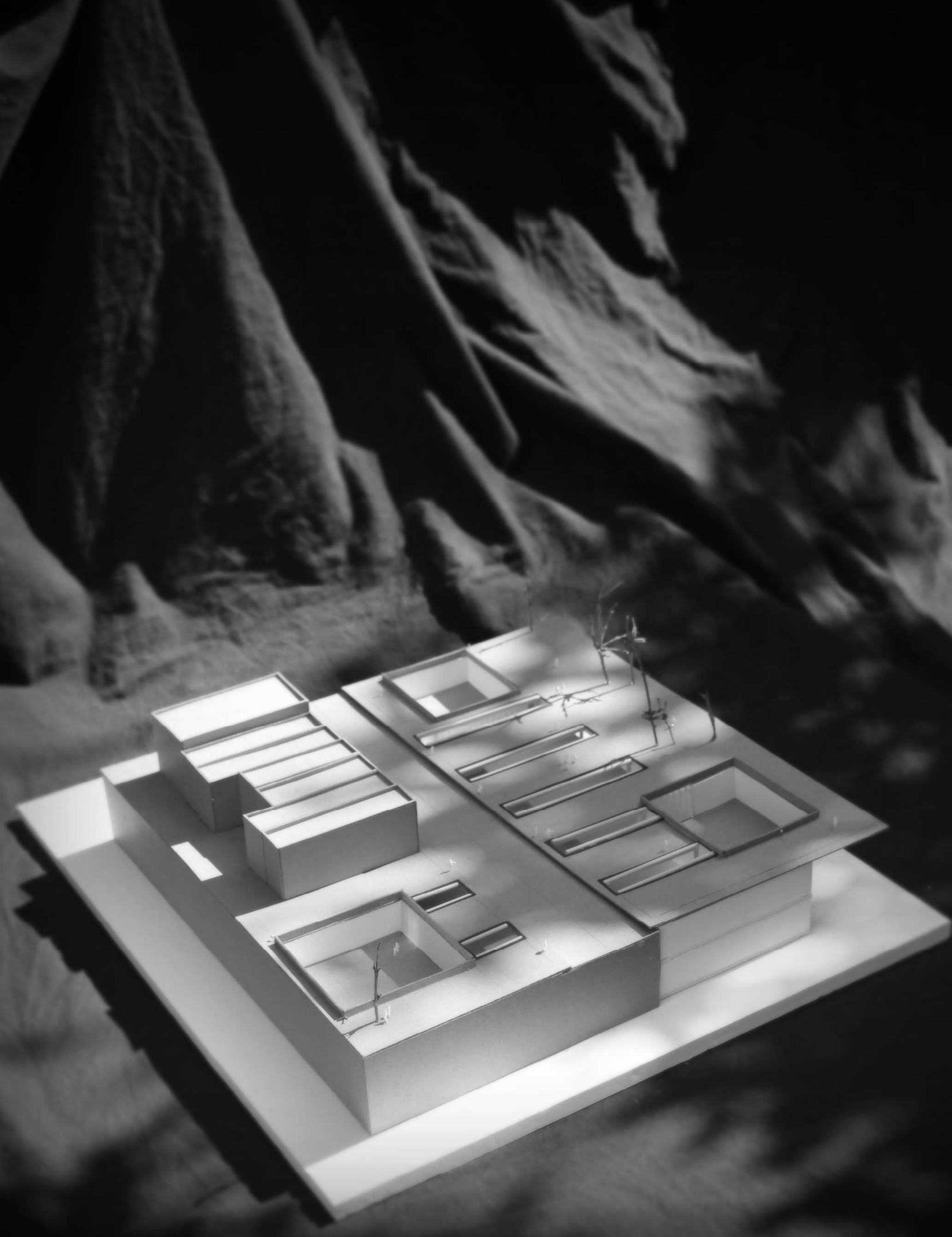


CHAPTER 7. Project Proposal 


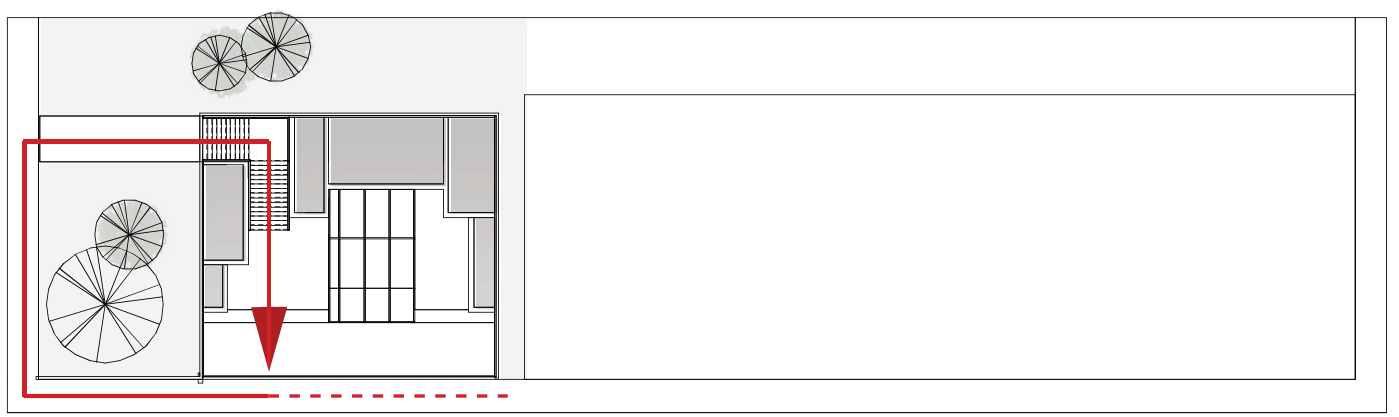

(c)

(B)

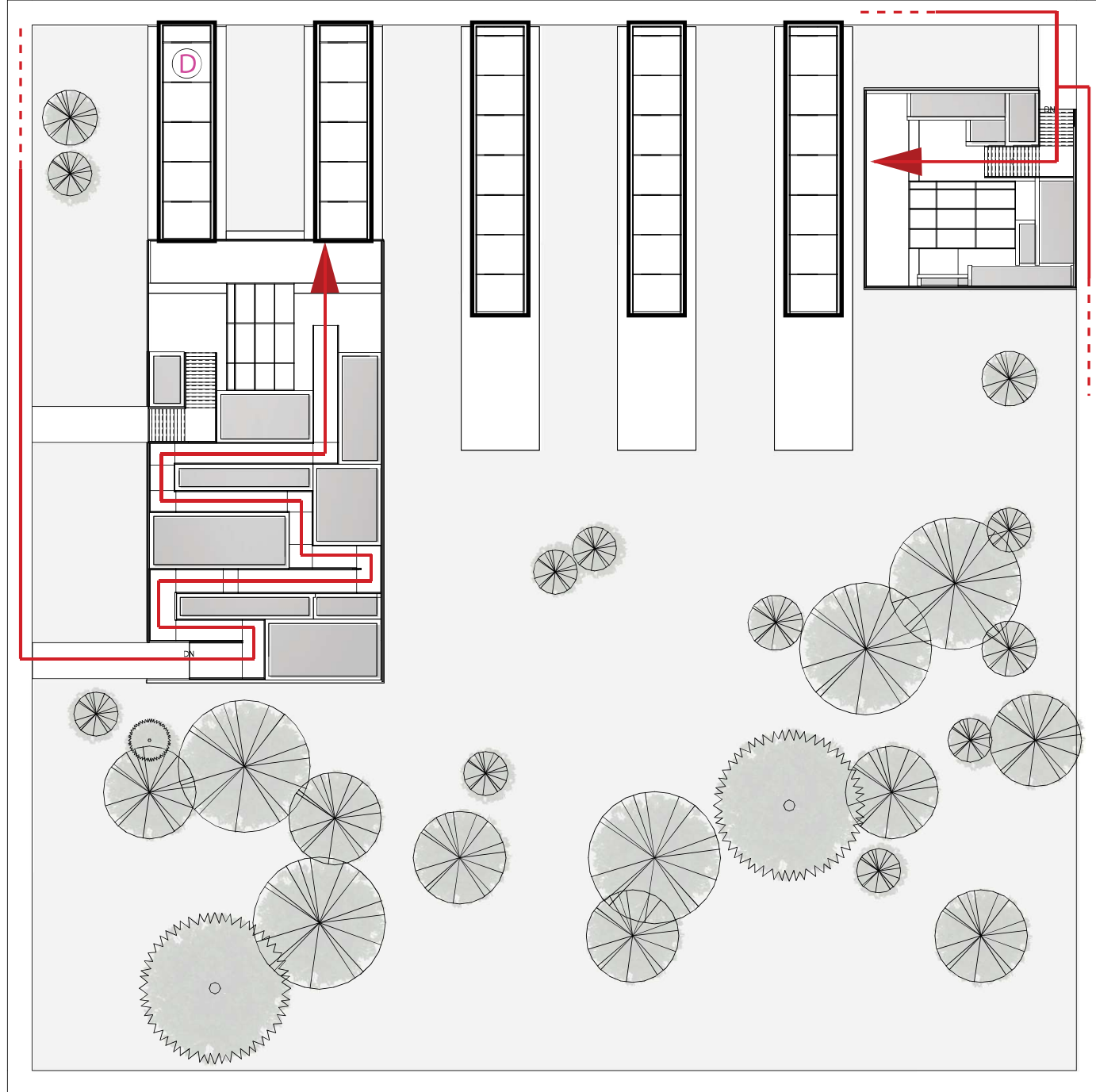

LEGEND

(A) East Entrance

(B) South Entrance

(C) North Entrance

(D) Open To Below 


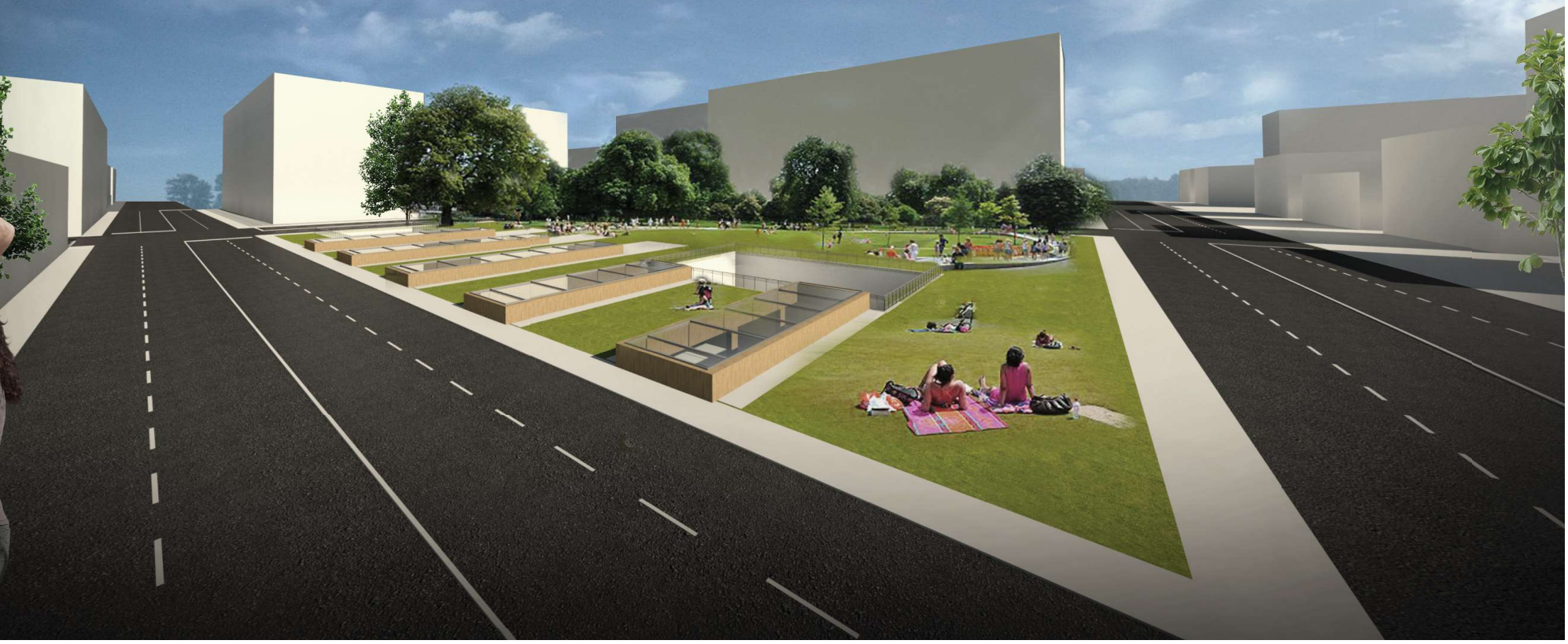




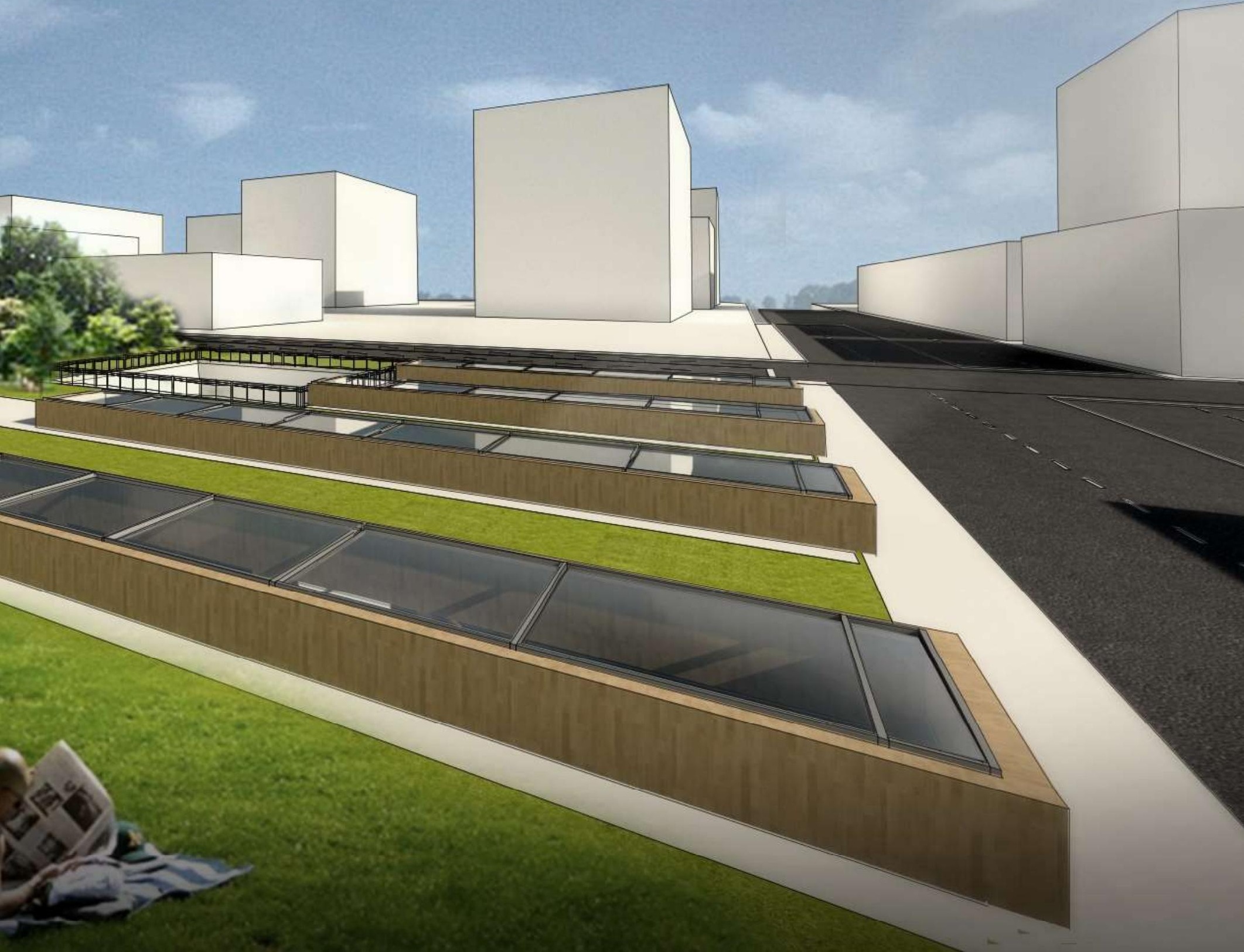




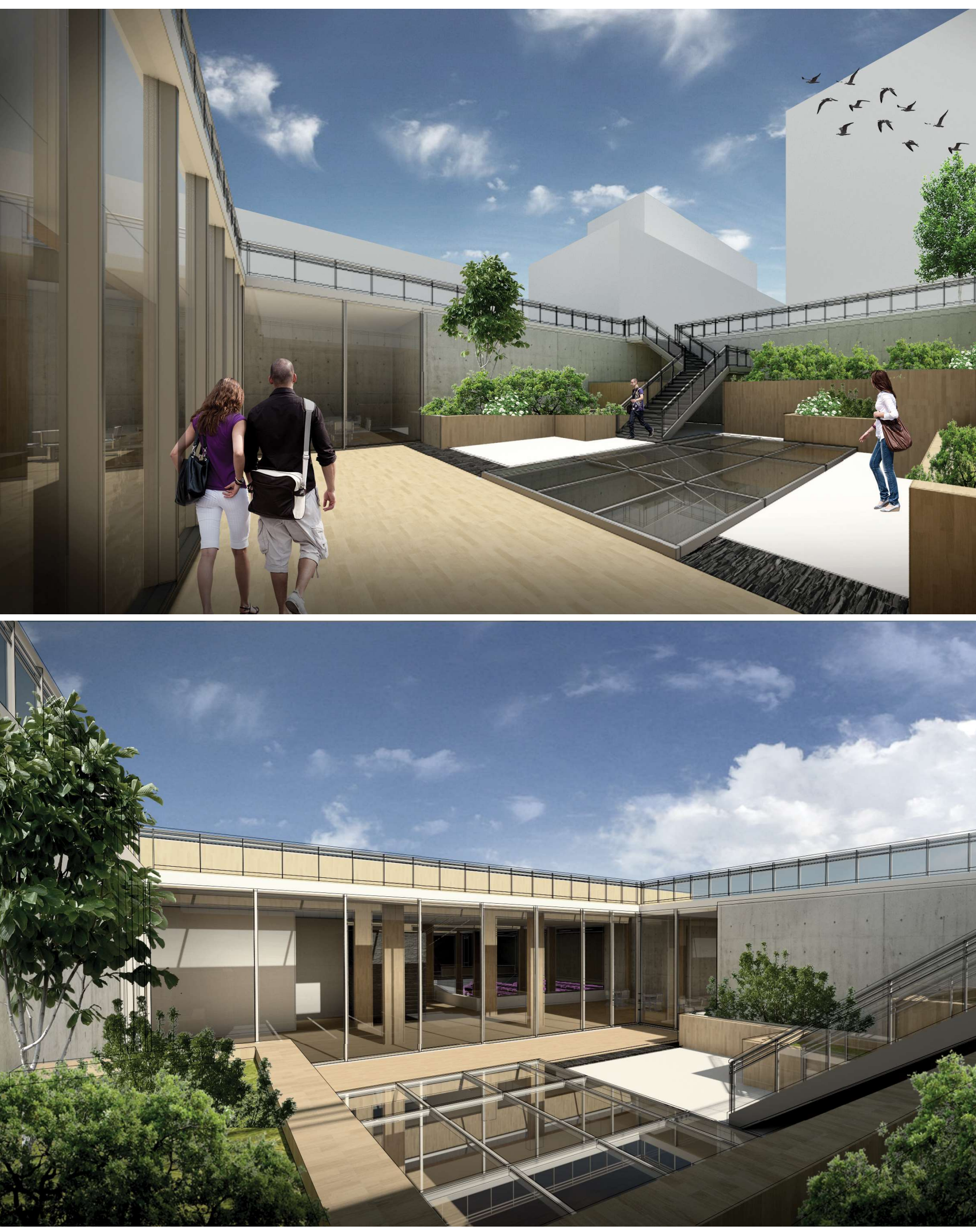



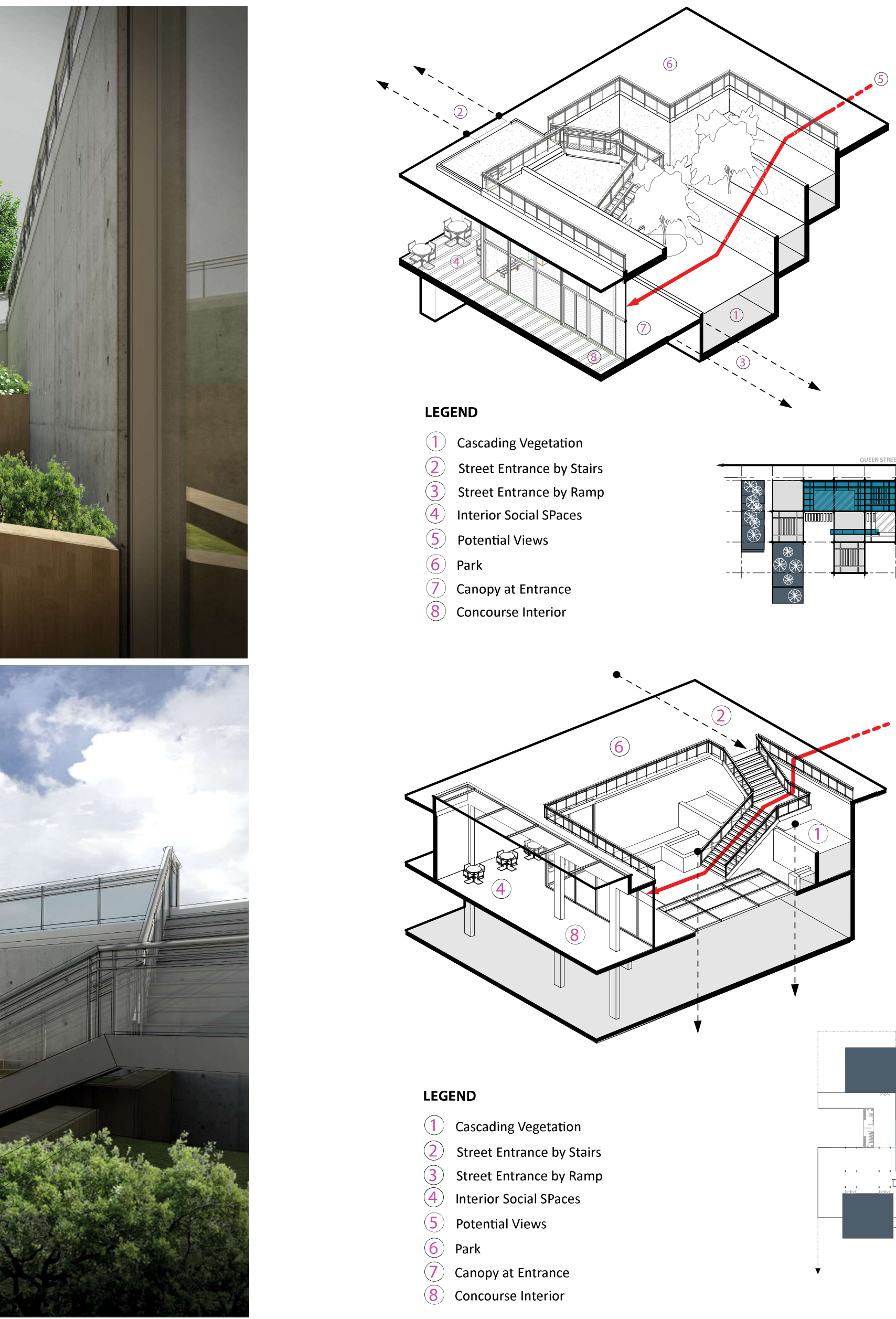

(1) Cascading Vegetation

(2) Street Entrance by Stairs

(3) Street Entrance by Ramp

(4) Interior Social SPaces

(5) Potential Views

(6) Park

(7) Canopy at Entrance

(8) Concourse Interior
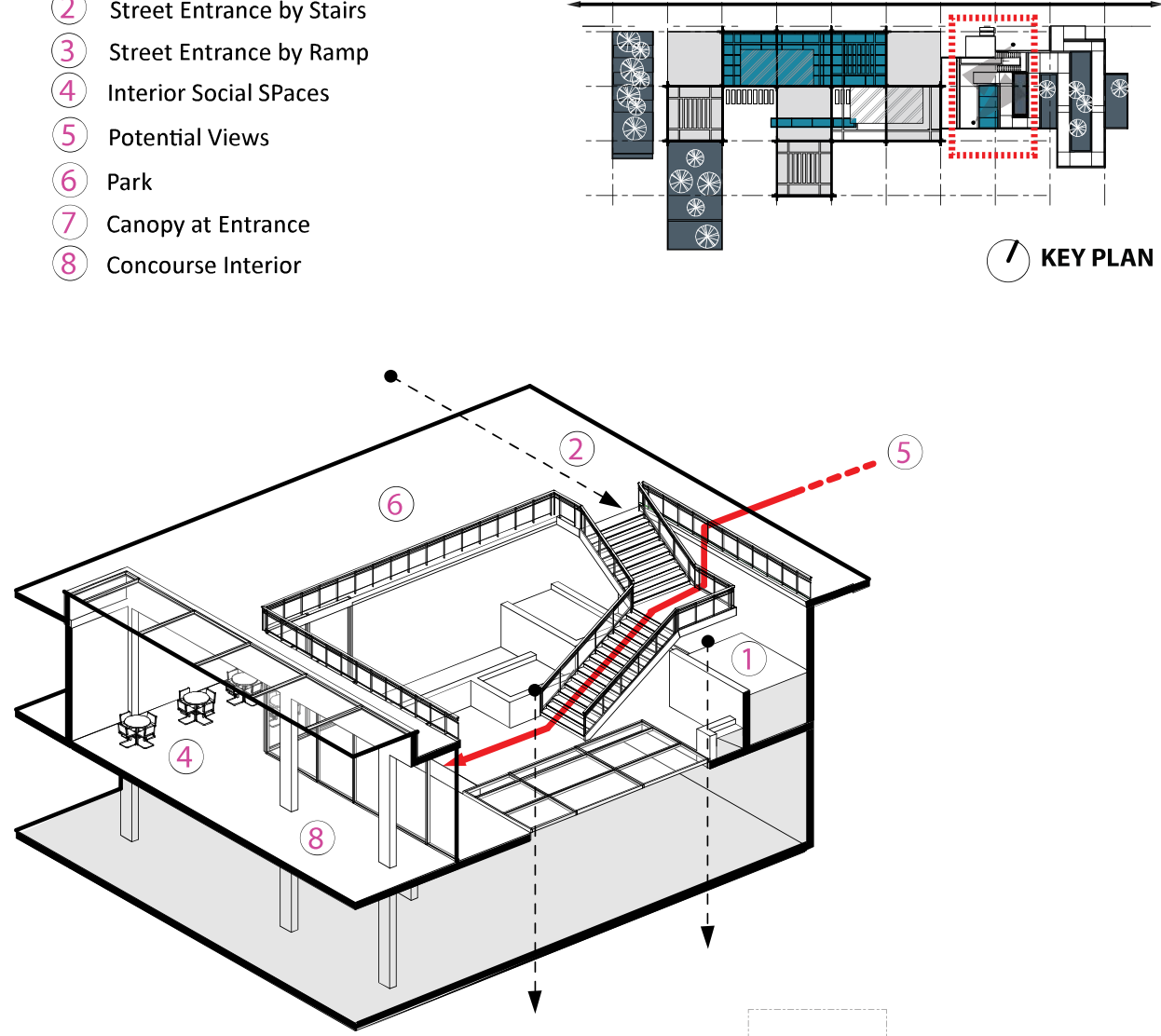

LEGEND

(1) Cascading Vegetation

(2) Street Entrance by Stairs

(3) Street Entrance by Ramp

(4) Interior Social SPaces

(5) Potential Views

(6) Park

(7) Canopy at Entrance

(8) Concourse Interior

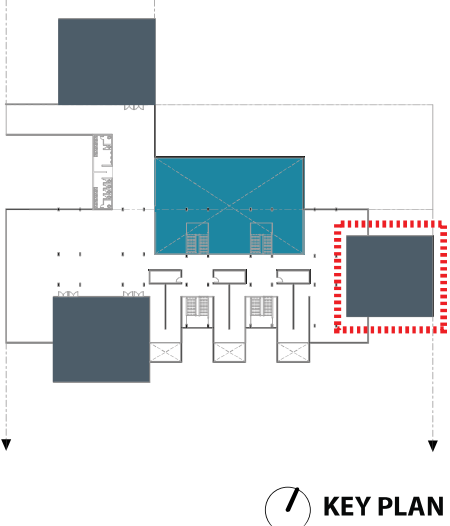




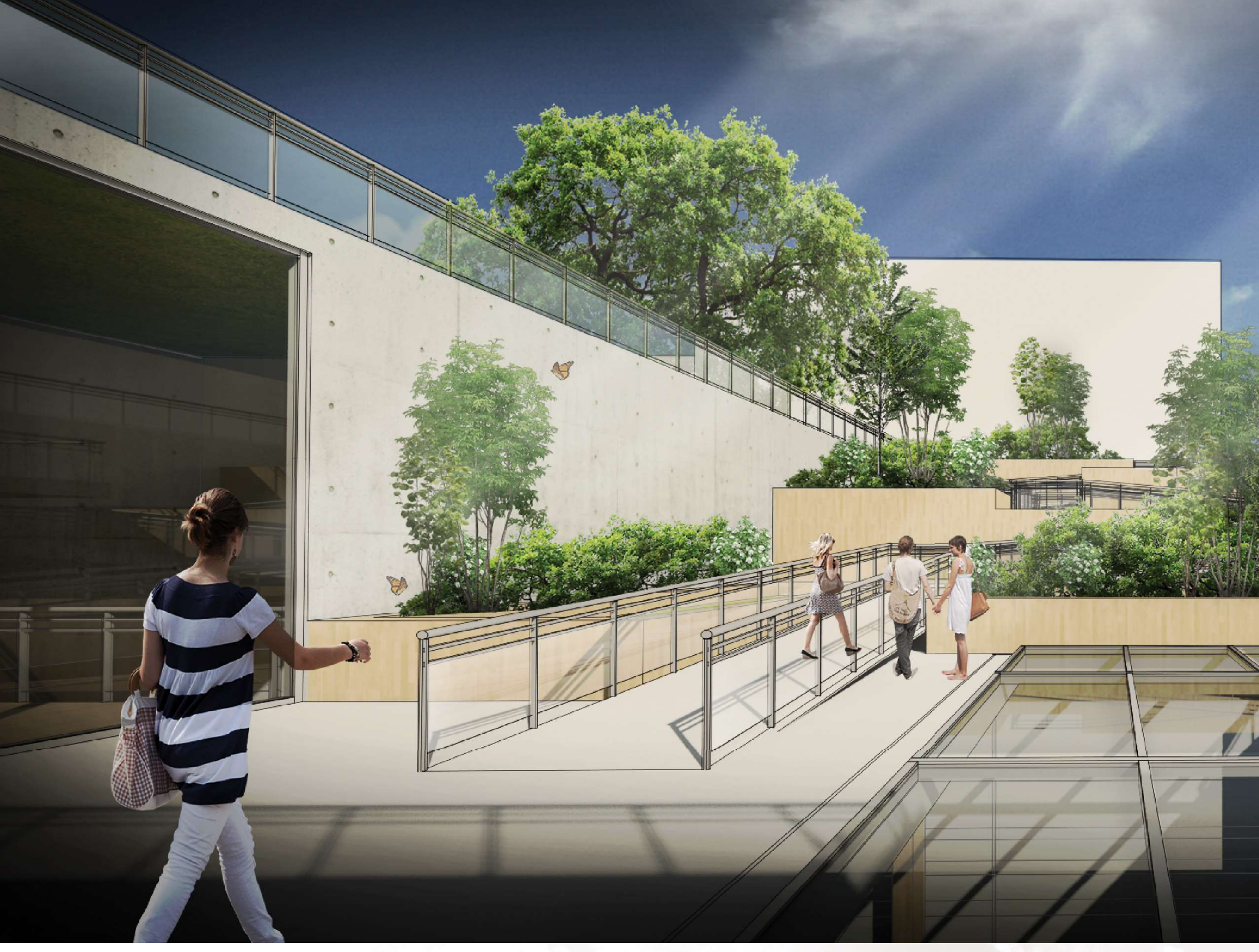




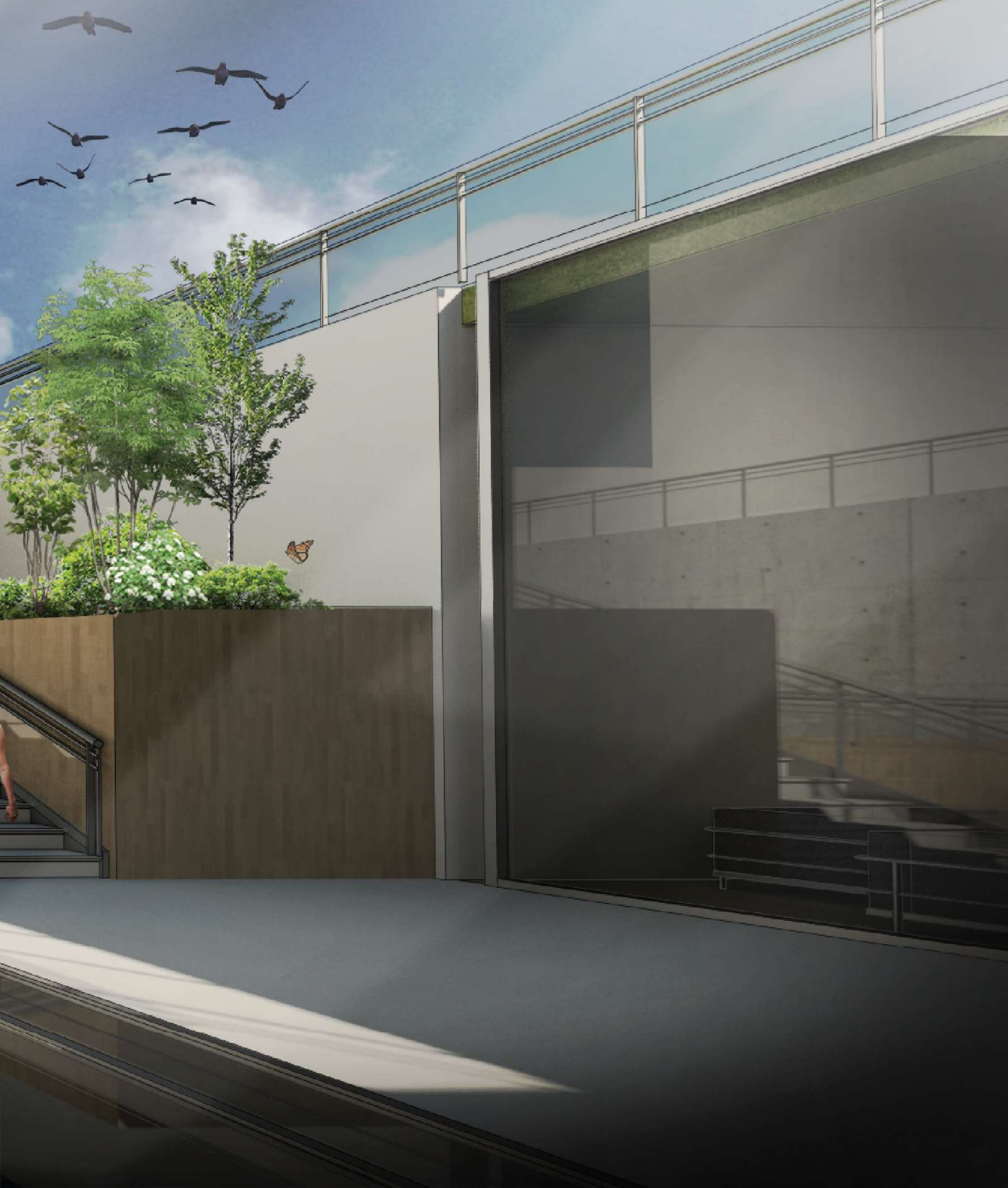




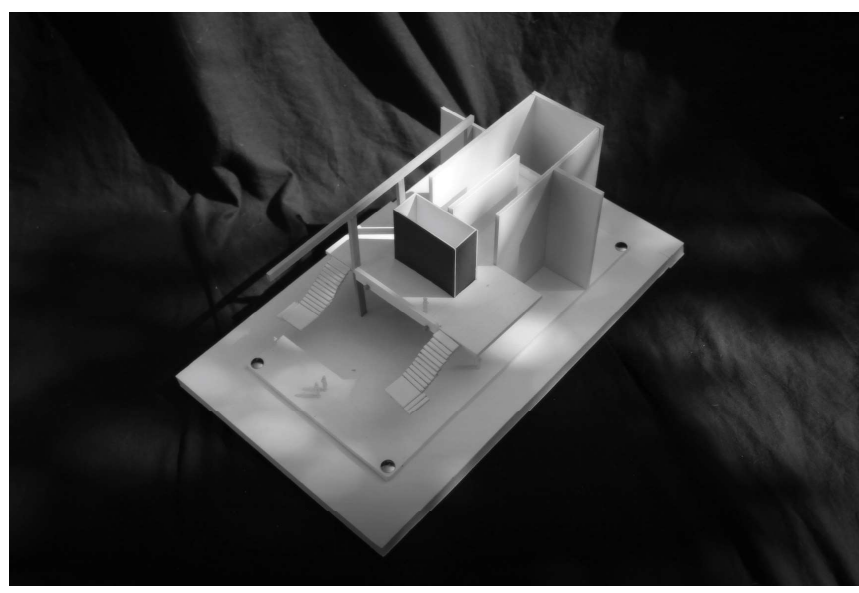

\section{LEGEND}

(A) Detour for those Wishing to Explore

(B) Glimpses to Transit Floor Below

(C) Dramatic Views to display Areas

(D) Tighter areas in Contrast to Open skylights Adja

\section{LEGEND}

(A) Light Penetration to Train Level

(B) Rhythmic Shadows emphasizing Materiality

(C) Terracing Vegetation privileging Views to Greenery

(D) Below Grade Entrance maintaining importance of Park
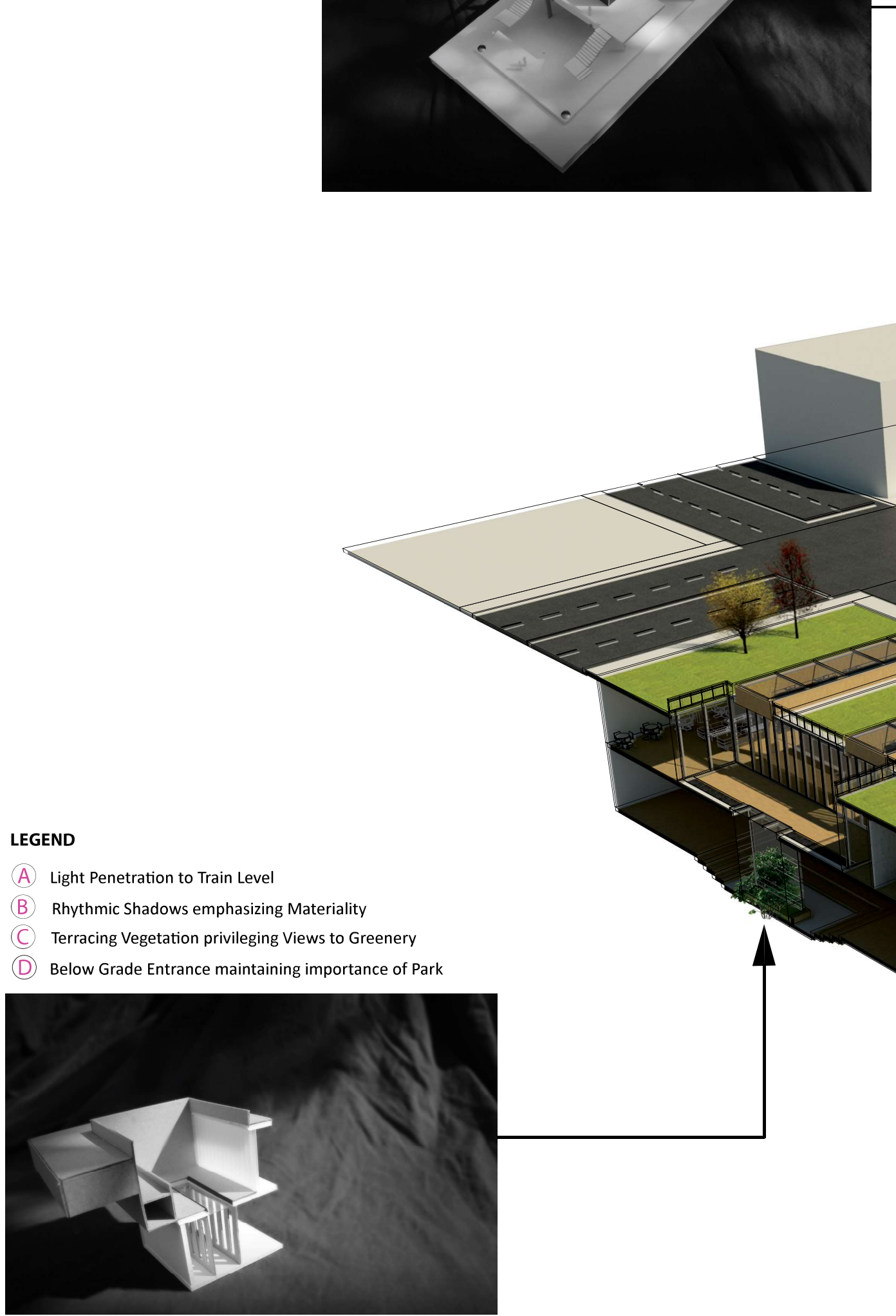


\section{Design decisions as direct response to Favoritism of Scientific Thinking}

Current Toronto-based subway design is highly pragmatic, often creating spaces optimized to achieve a certain floor area for the least amount of monetary resource investment. These banal spaces are a direct reflection of our favoritism of scientific thinking, considering only the quantifiable factors within architecture and dismissing that which cannot be measured. Within the design of the proposed station, moments of phenomenological intensity look to engage the user beyond the limited scope that is the transition from grade to transit. The penetration and movement of light throughout the building look to create spaces with characteristics that engage visitors through the unique composition of volumetric space at times contrasting tighter dark spaces with larger openings that open to the sky. These episodes throughout the building seek to privilege emotional responses allowing the development of a relationship to form between visitor and structure.

\section{LEGEND}

A Skylight to Train Level Below

(B) Gradual Ramp for Slow and Thoughtful Entrance

(C) Below Grade Entrance

(D) Maintaining importance of Park Above

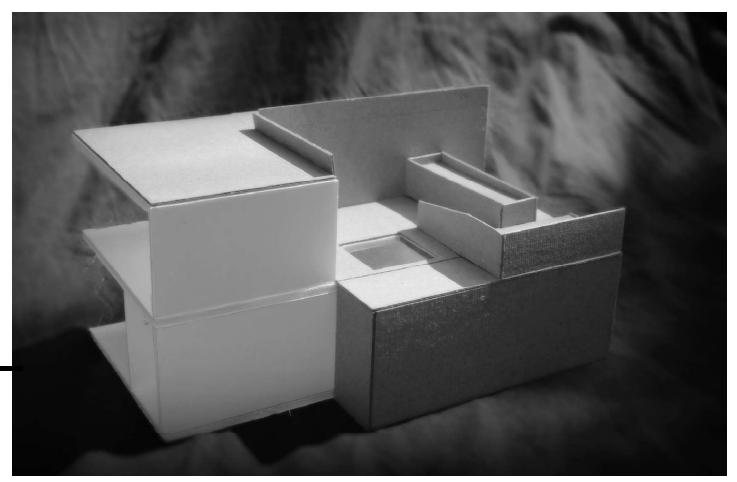




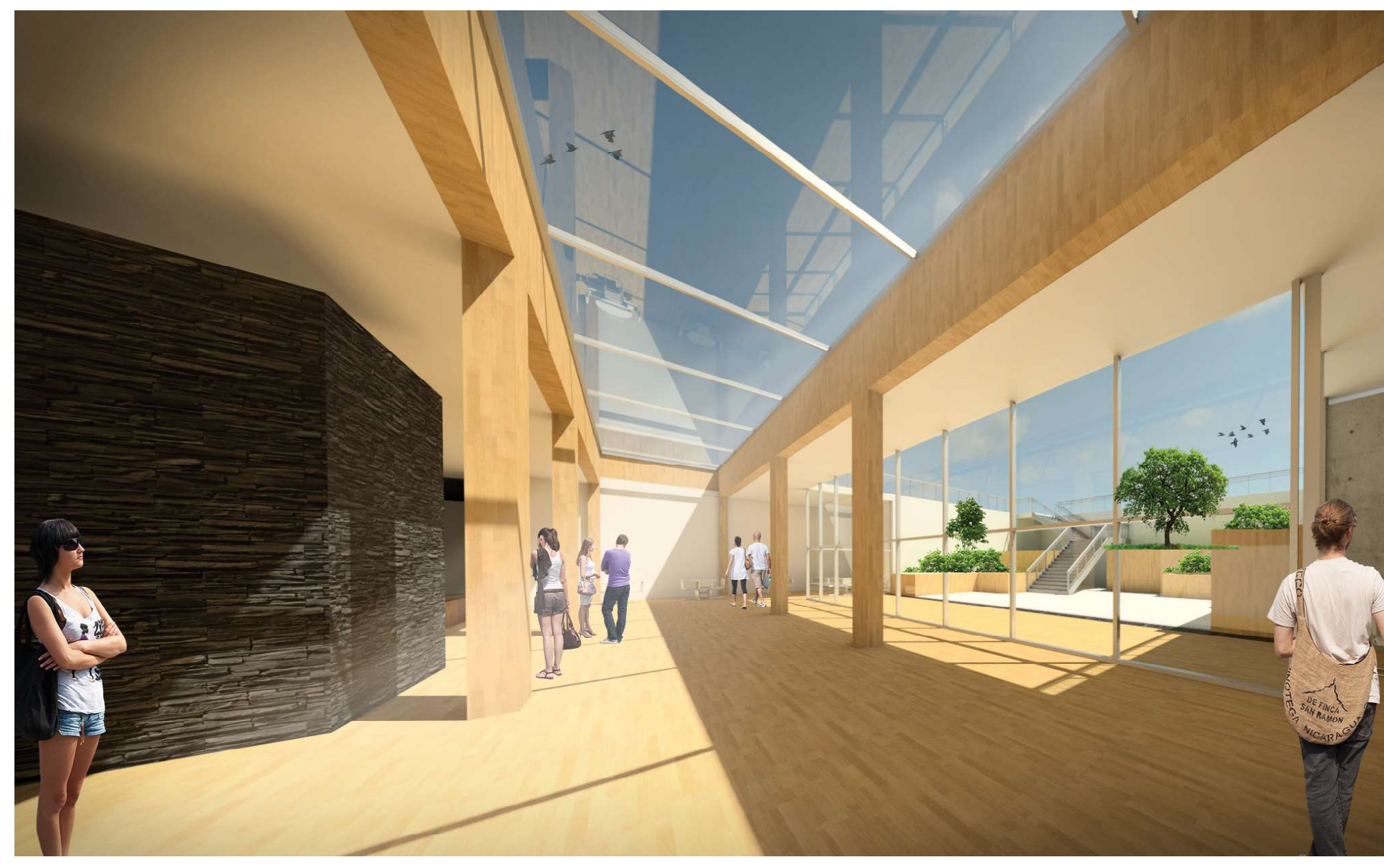

1

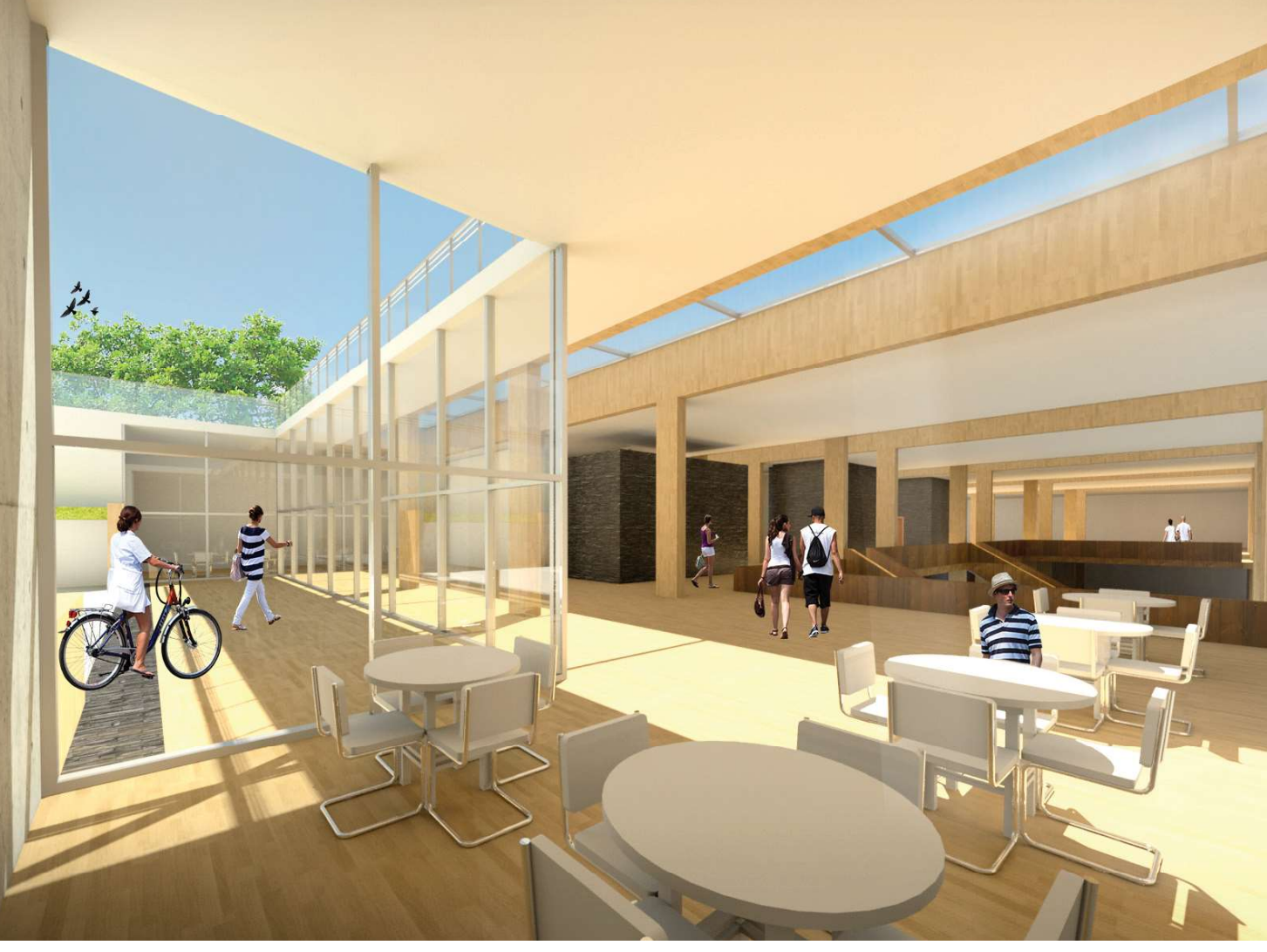



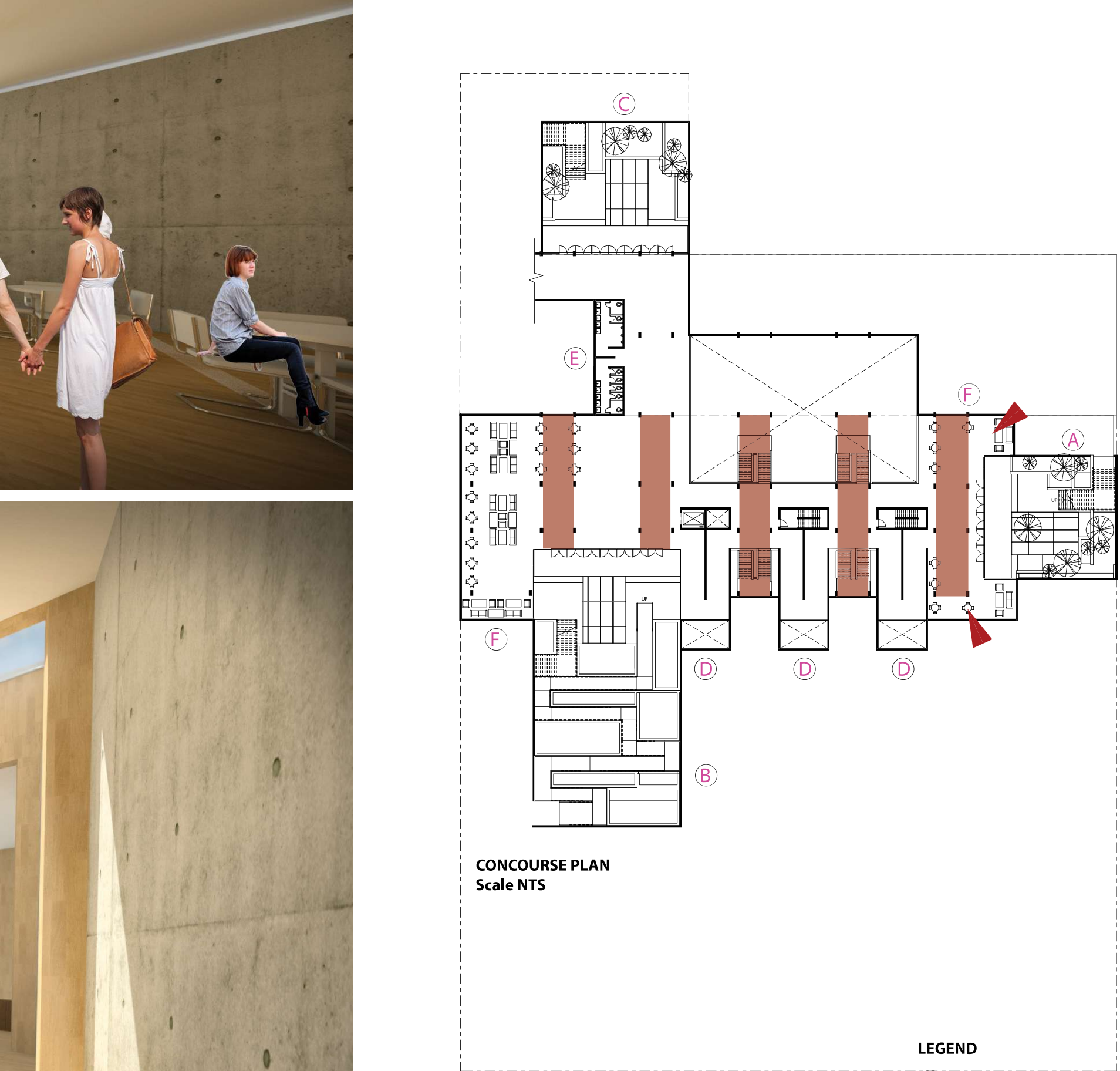
(A) East Entrance
(B) South Entrance
(C) North Entrance
(D) Open To Below
(E) W.C.
(F) Social Spaces 


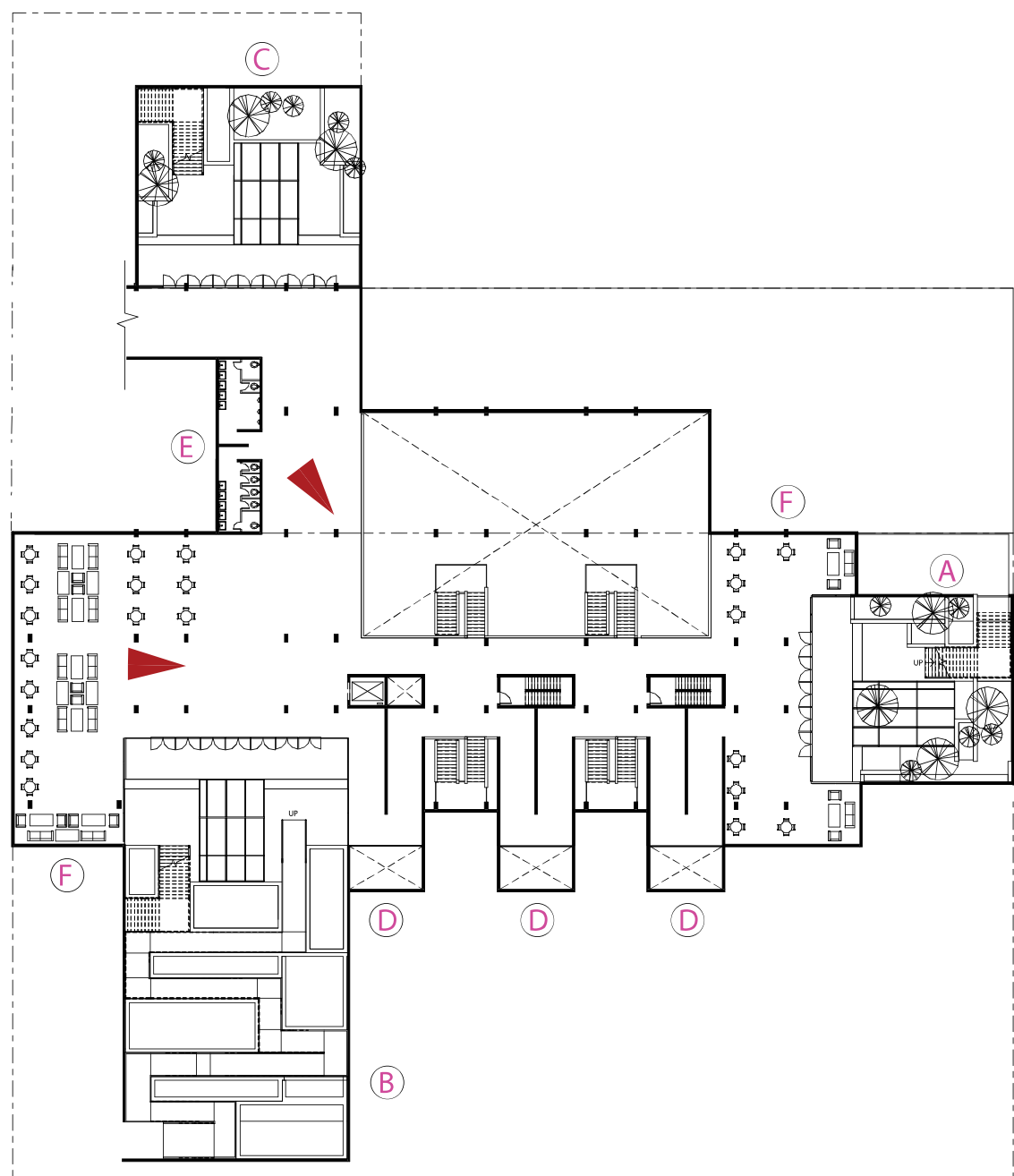

CONCOURSE PLAN

Scale NTS

\section{LEGEND}
(A) East Entrance-
(B) South Entrance
(C) North Entrance
(D) Open To Below
(E) W.C.
(F) Social Spaces 

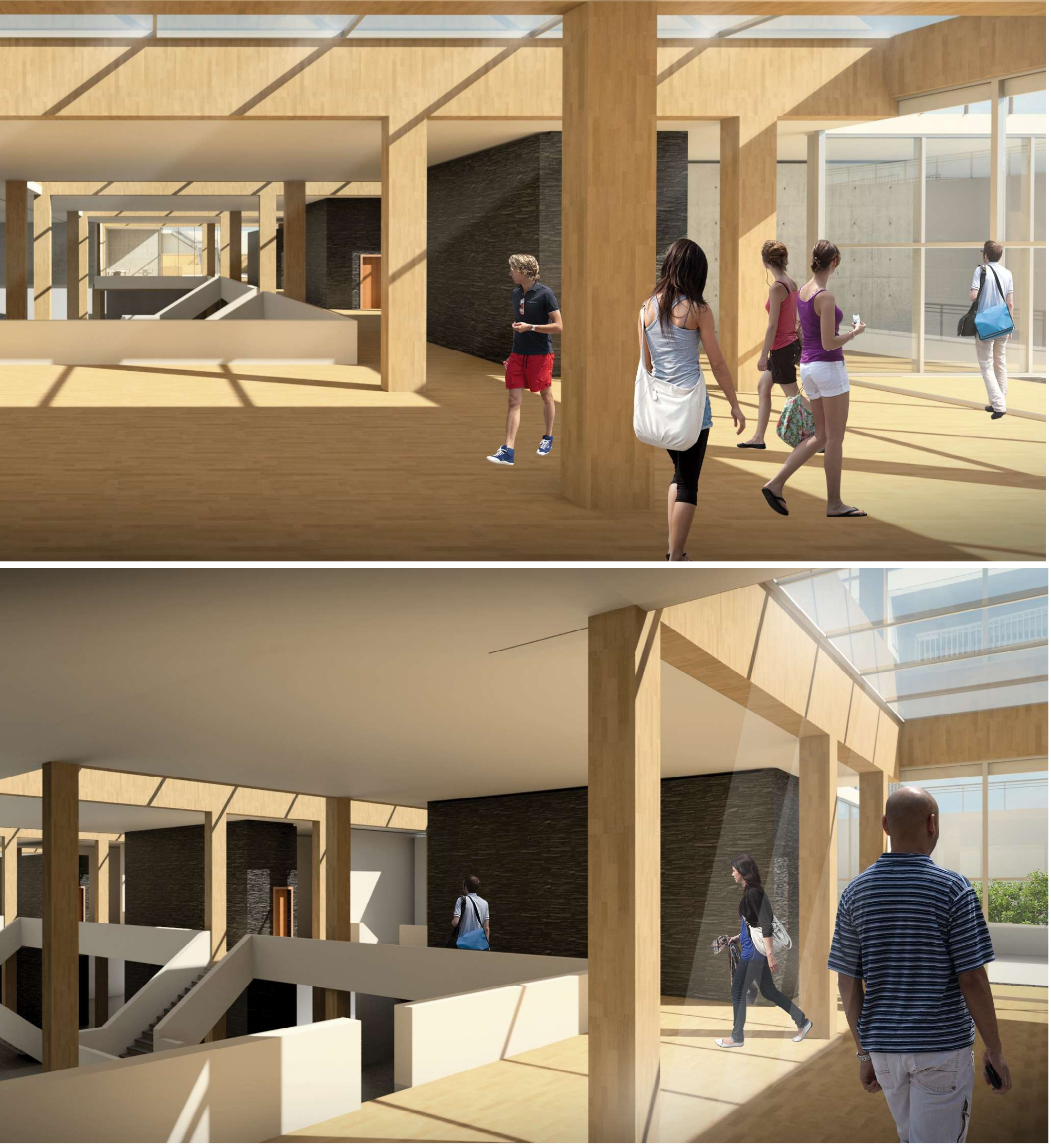


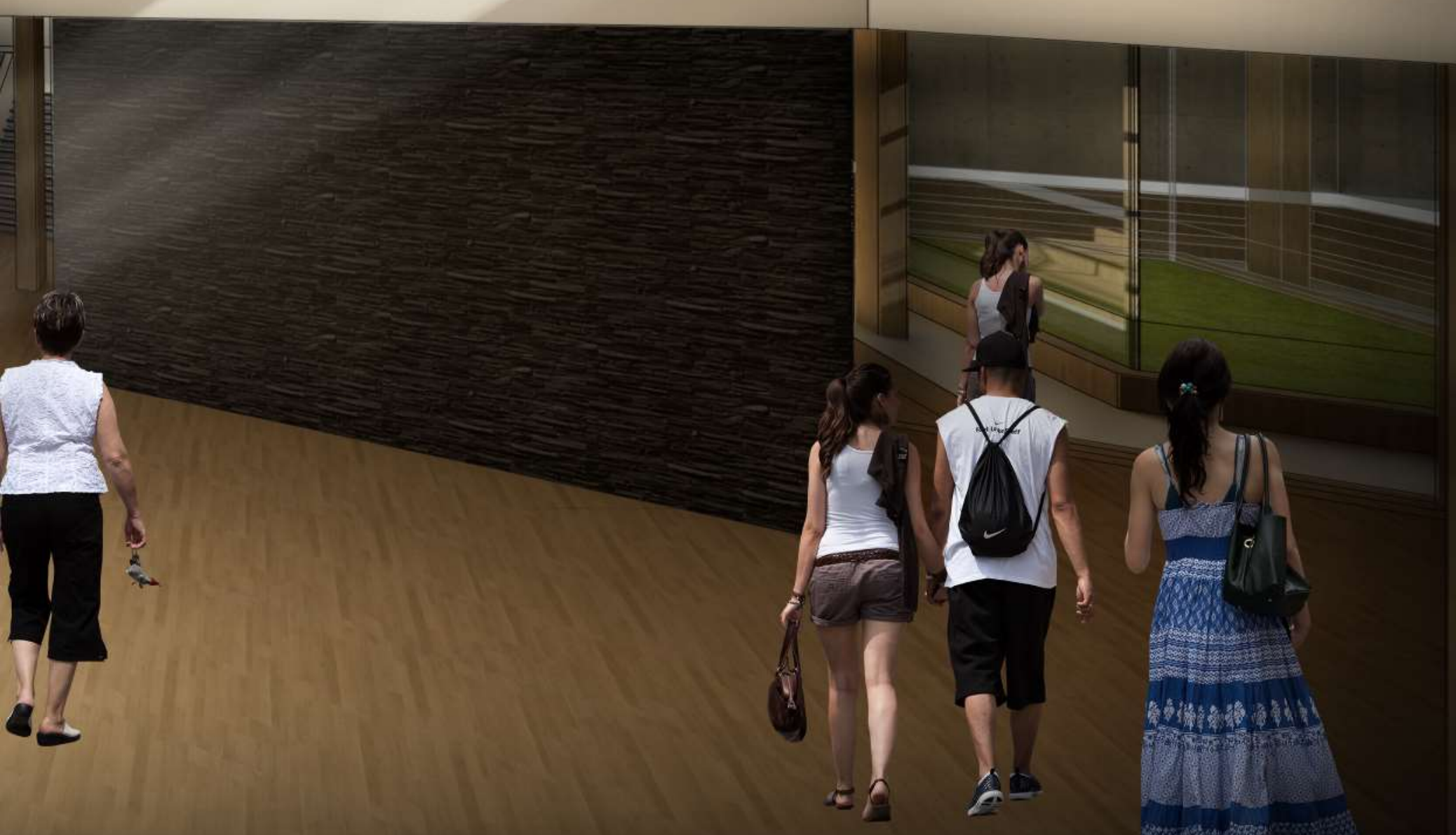

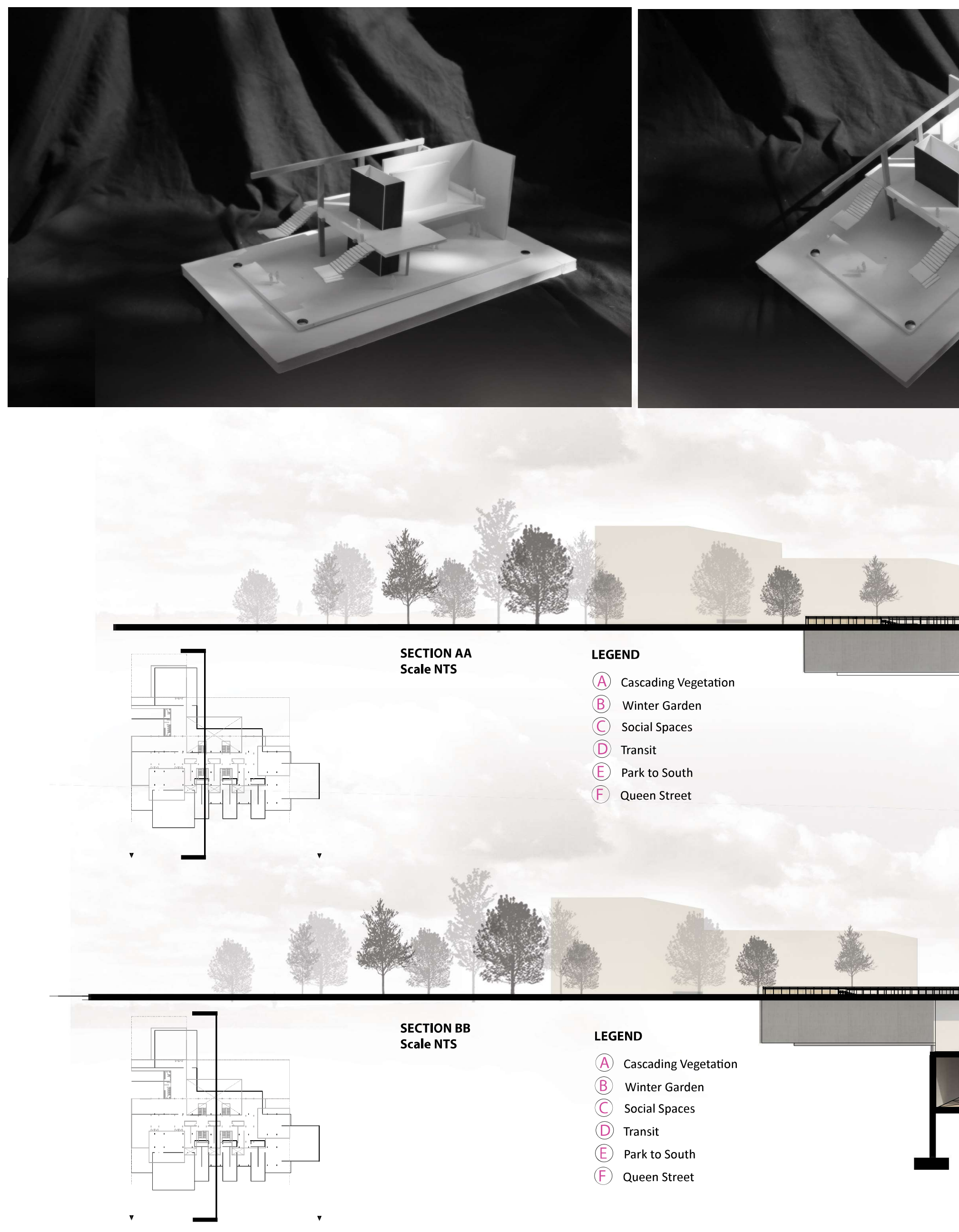


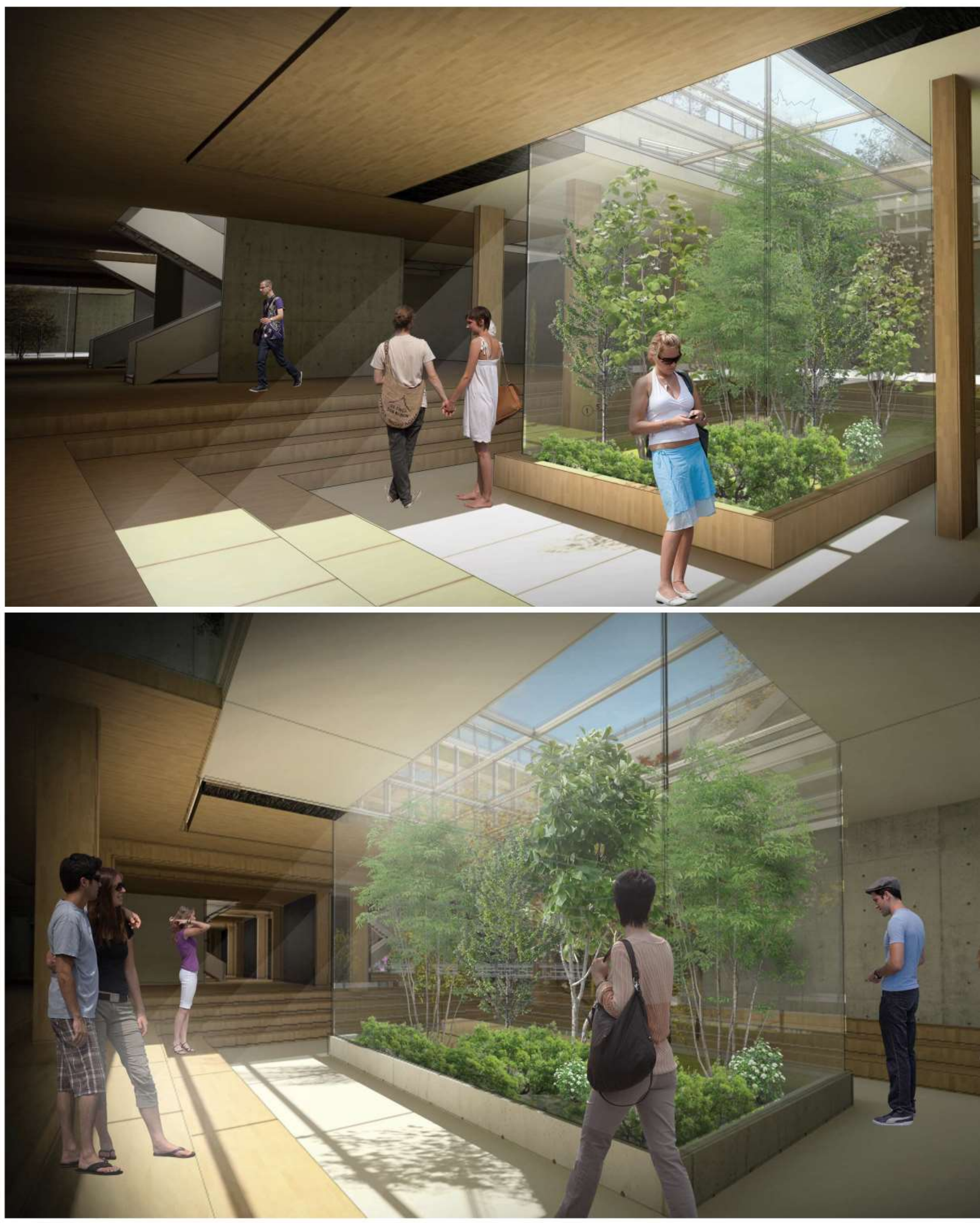




\section{Design decisions as direct response to Diminishing Urban Realm}

The cultural shift relocating architectures focus from public to private has left many areas of the downtown core feeling blocked off, shunning the streetscape and no longer interested in upholding the complex theater of social activity that once brewed on public streets. The design of a transit terminal in a small park along queen street has the potential to re-engage the diminishment of the public sphere and has been done so in the proposed design through three sub-principles informed by the site analysis listed below:

a. The design of a subway station with access and views that enrich the relationship between pedestrians and the street corridor.

b. The design of an experience reflecting the feel of Queen Street through rhythm and scale.

c. The creation of a transit hub that offers flexibility for both formal and informal commercial and community events.

\section{Design decisions as direct response to Commodification of Architecture}

Commodification within the practice of architecture has transformed the process of design into a service. As a result, standardized buildings such as Walmarts and Bestbuys are now defining a huge part of the built realm and are making it difficult to experience genuine emotions in response to the surrounding world. Within the design of the proposed project, a site-specific proposal unique to the scope of the project looks to reflect the community, strengthening sense of place within the region. In so doing, architecture becomes an aggregate for cultural expansion rather than reflecting product-dominant societies which much of the urban fabric now does.

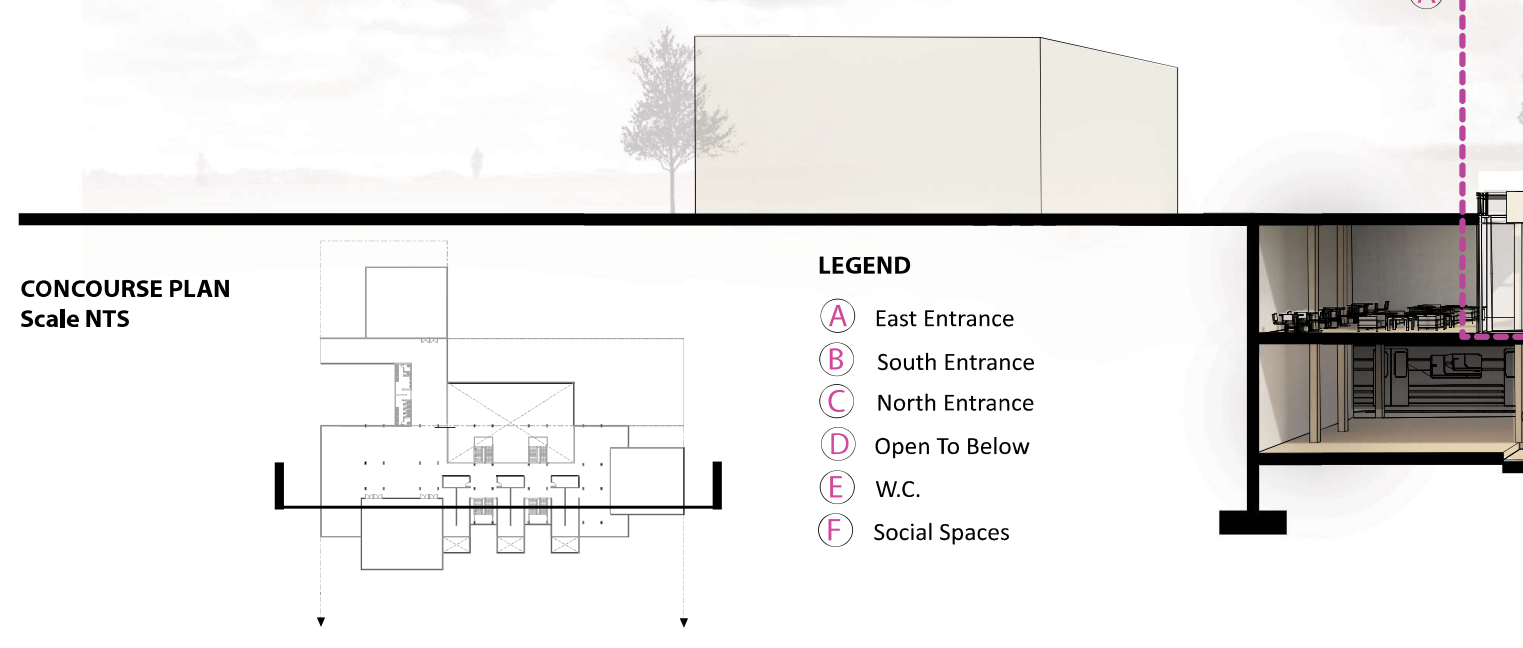



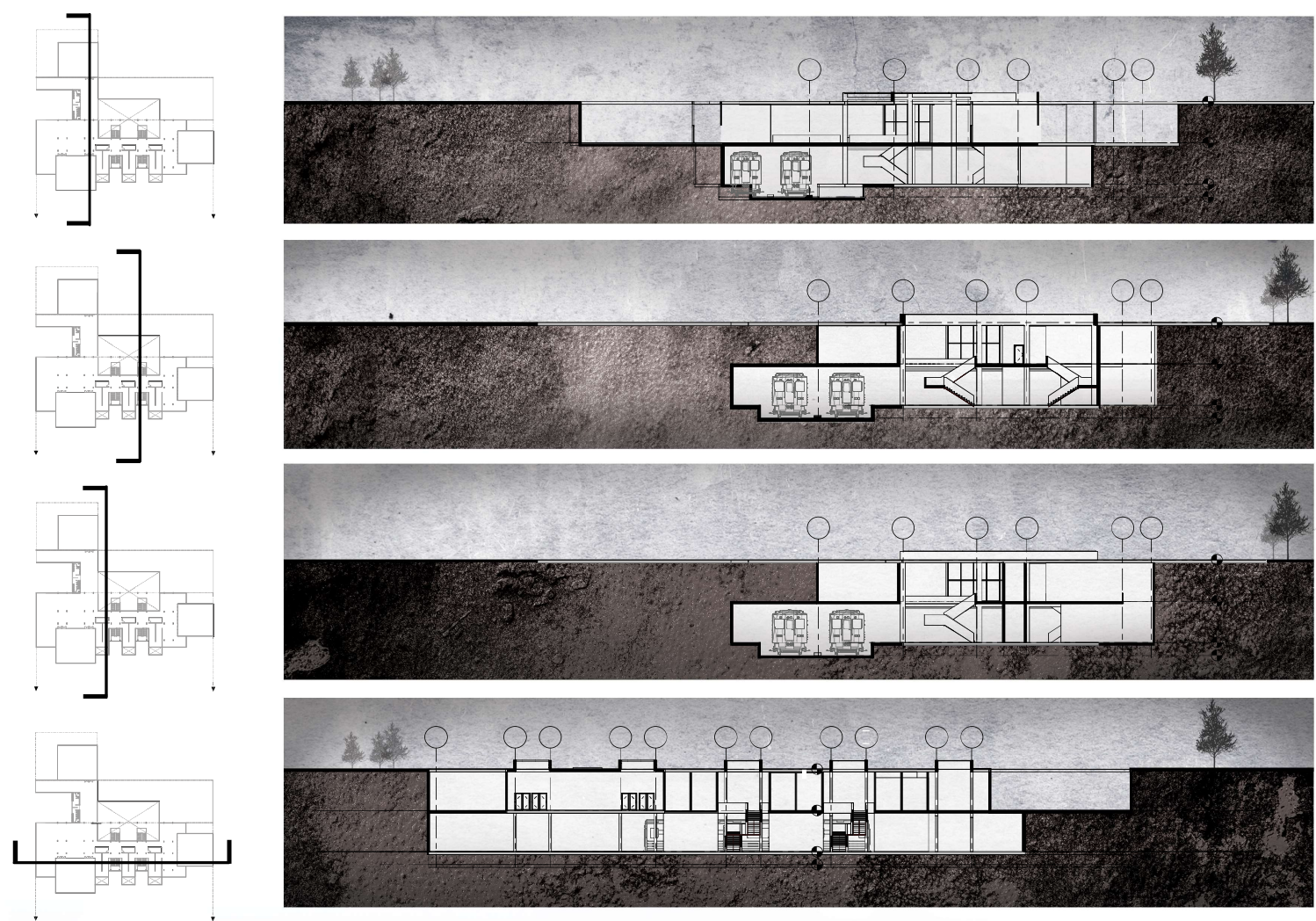

(D)

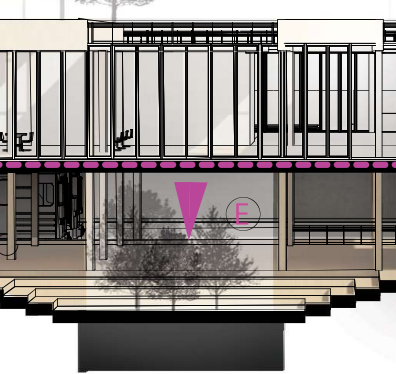

(C)

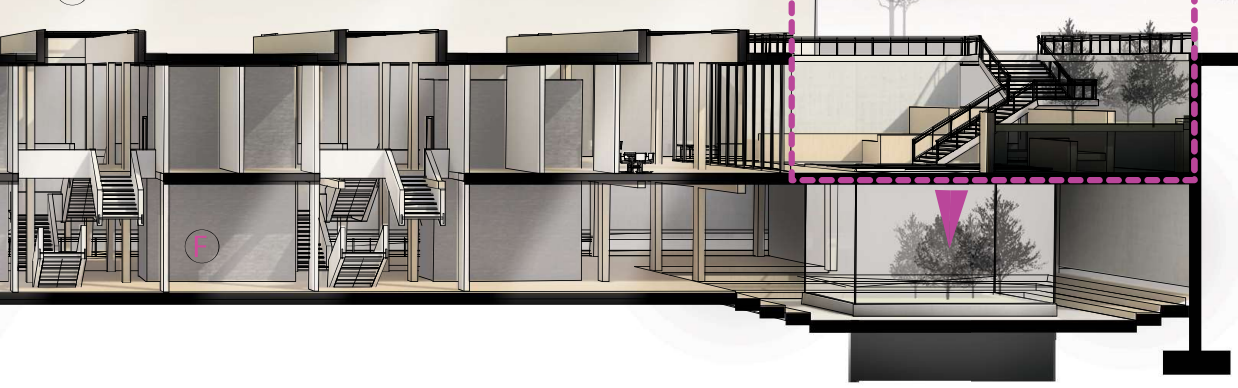

(C) 


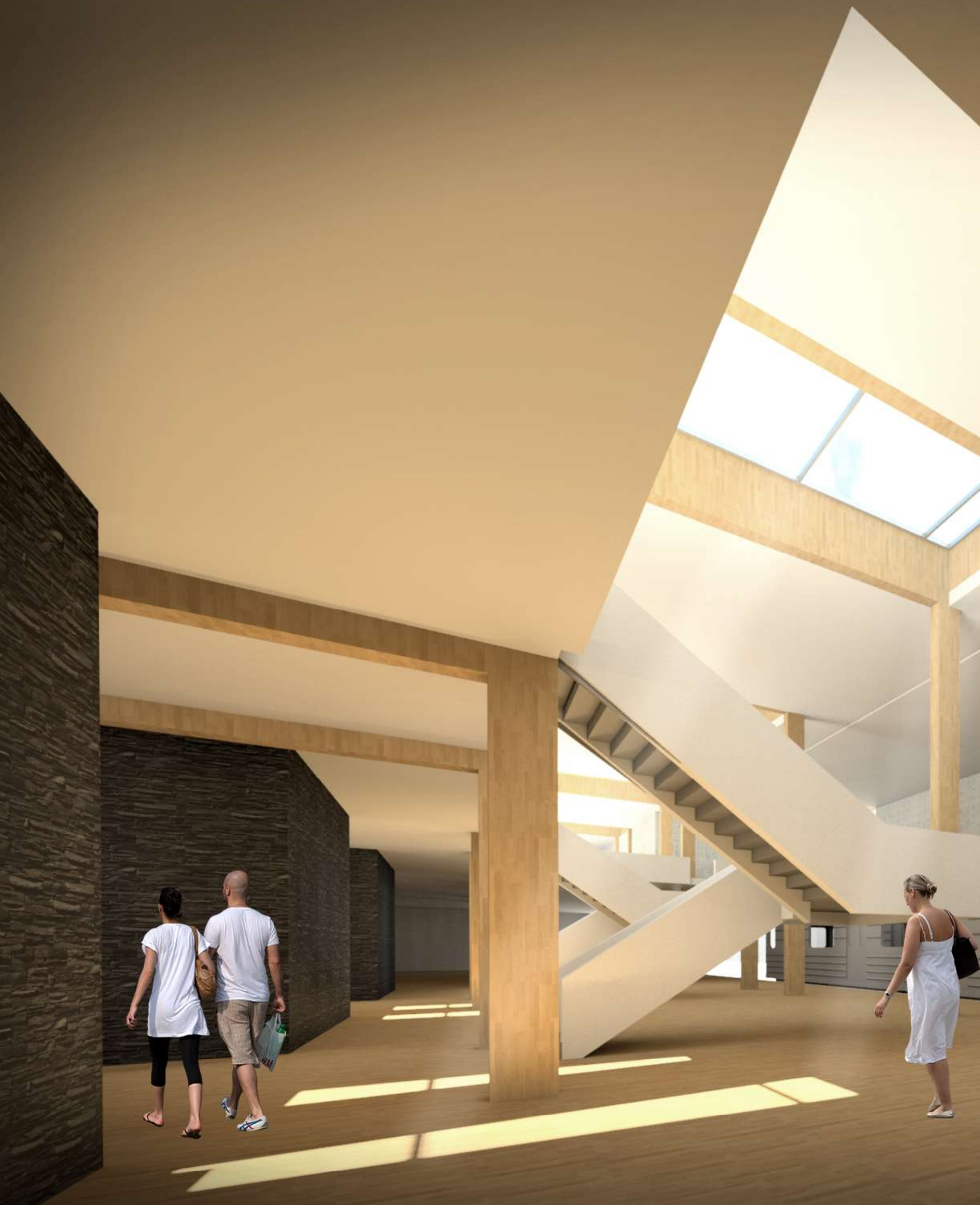





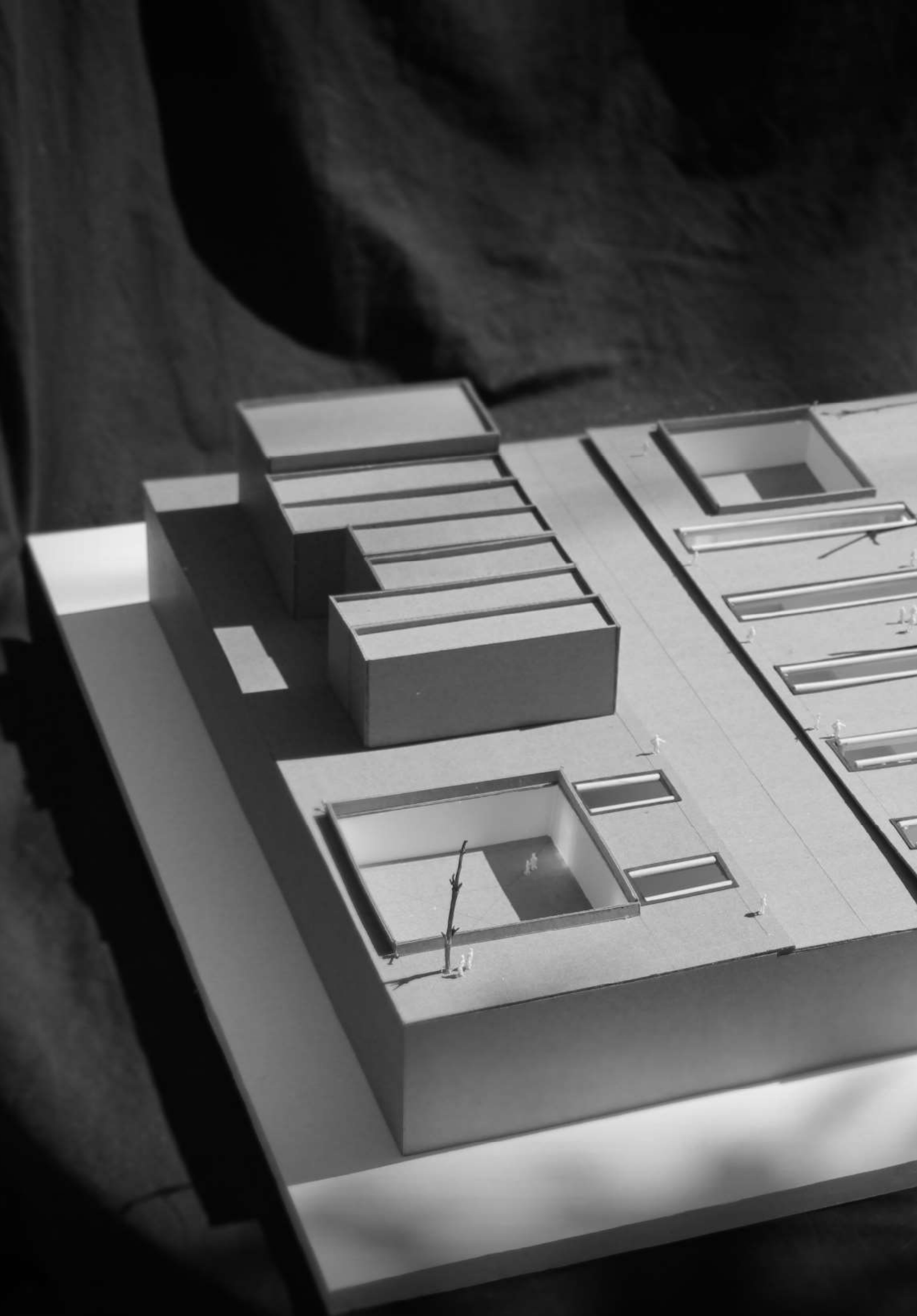




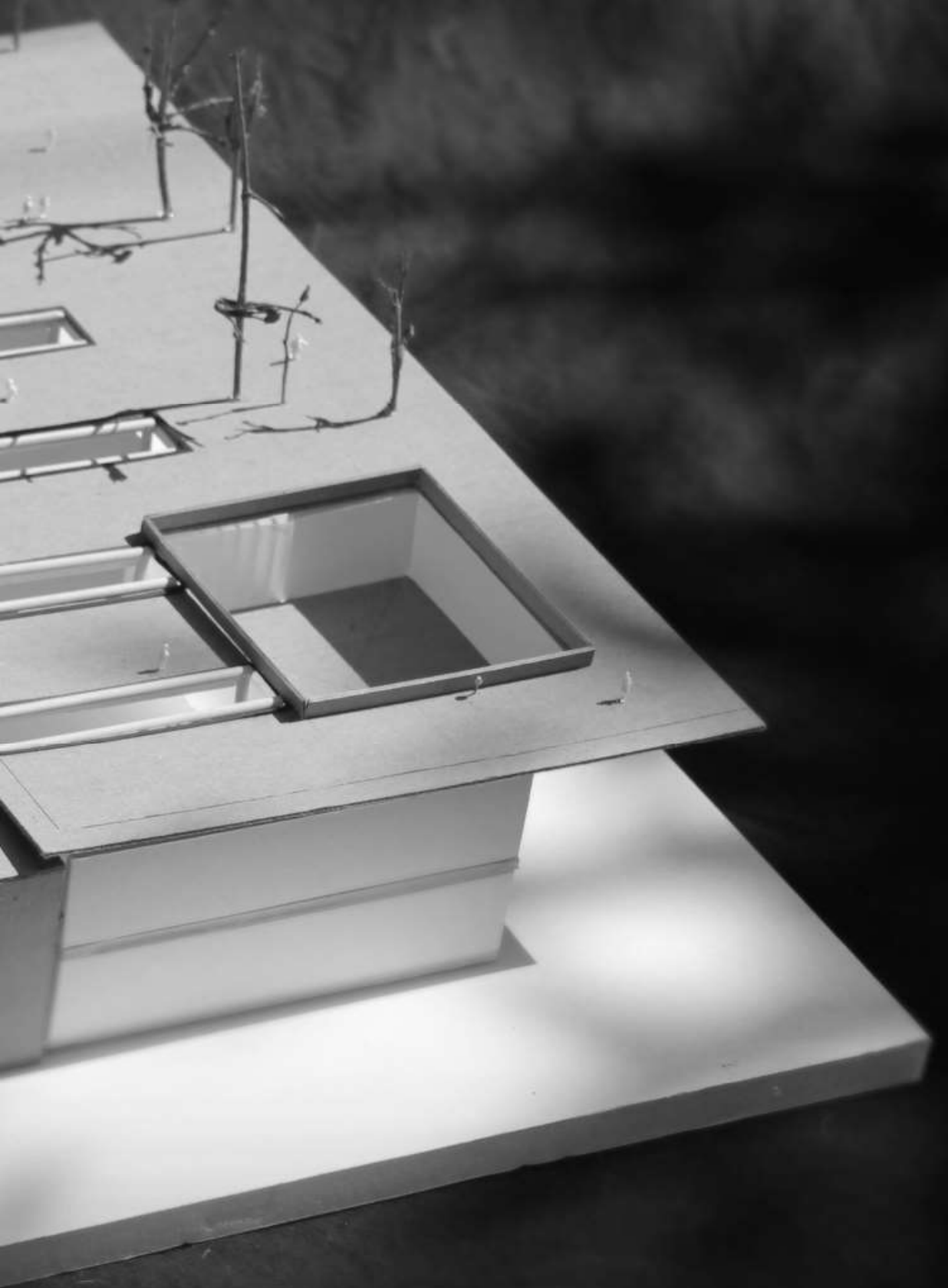




\section{$S_{\text {PECULATION }}$}

This thesis looks to showcase storytelling architecture; a design philosophy drawing inspiration from verbal and text based stories that I have been exploring through case studies and design experimentations for the past year. The foundation of this research critiques modern architecture, specifically the favoritism of scientific thinking, commodification of the profession, and the diminishment of the public realm which have communally weakened captivation between mankind and architecture. Storytelling, known for provoking reader imagination is used as metaphor for a new method of design, drawing parallels between engaging stories and captivating spaces. This new form of design seeks to alleviate the loss of capitation in architecture making way for a new method of design founded on architectural storytelling rekindling the connection between mankind and design.

A number of design experiments were conceived, testing the correlation between stories and design in relation to storyboarding as a design process, the understanding of a building through chapters and the design of spaces with inspiration drawn from literary devices. Each of these experiments yielded a series of models that looks to provide architects insights into how metaphorical inspiration drawn from storytelling can influence the design of architecture while creating captivating spaces that immerse the visitors within experience.

Within this thesis storytelling architecture is showcased in the design of a subway station, a typology in dire need of spaces that foster a sense of captivation and mental intrigue. Although storytelling architecture is a design philosophy not restricted to certain typologies, this thesis looks to implement the theory on a program that is currently lacking the captivation that architectural storytelling architecture can provide. It is intended that through a showcasing of what this design philosophy can achieve on a subway typology, architects are able to understand the value effective stories can bring to architecture influencing the way in which future architecture is created. I hope to have brought about a convincing argument for the integration of story based inspiration in architectural design and look forward to continue the research throughout the years to come. 


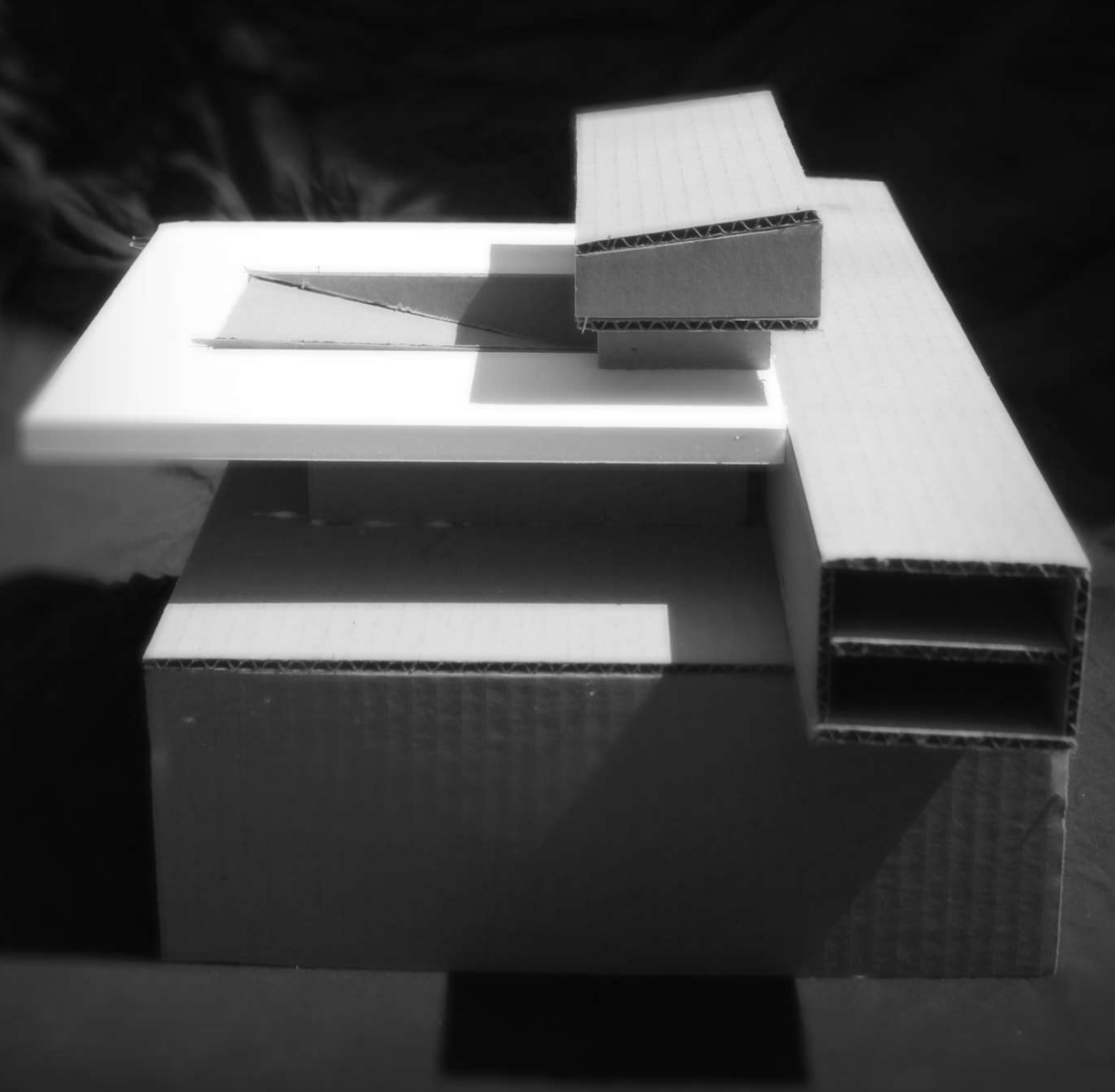




\section{APPENDIX A: TEDx Talk Storytelling Architecture}




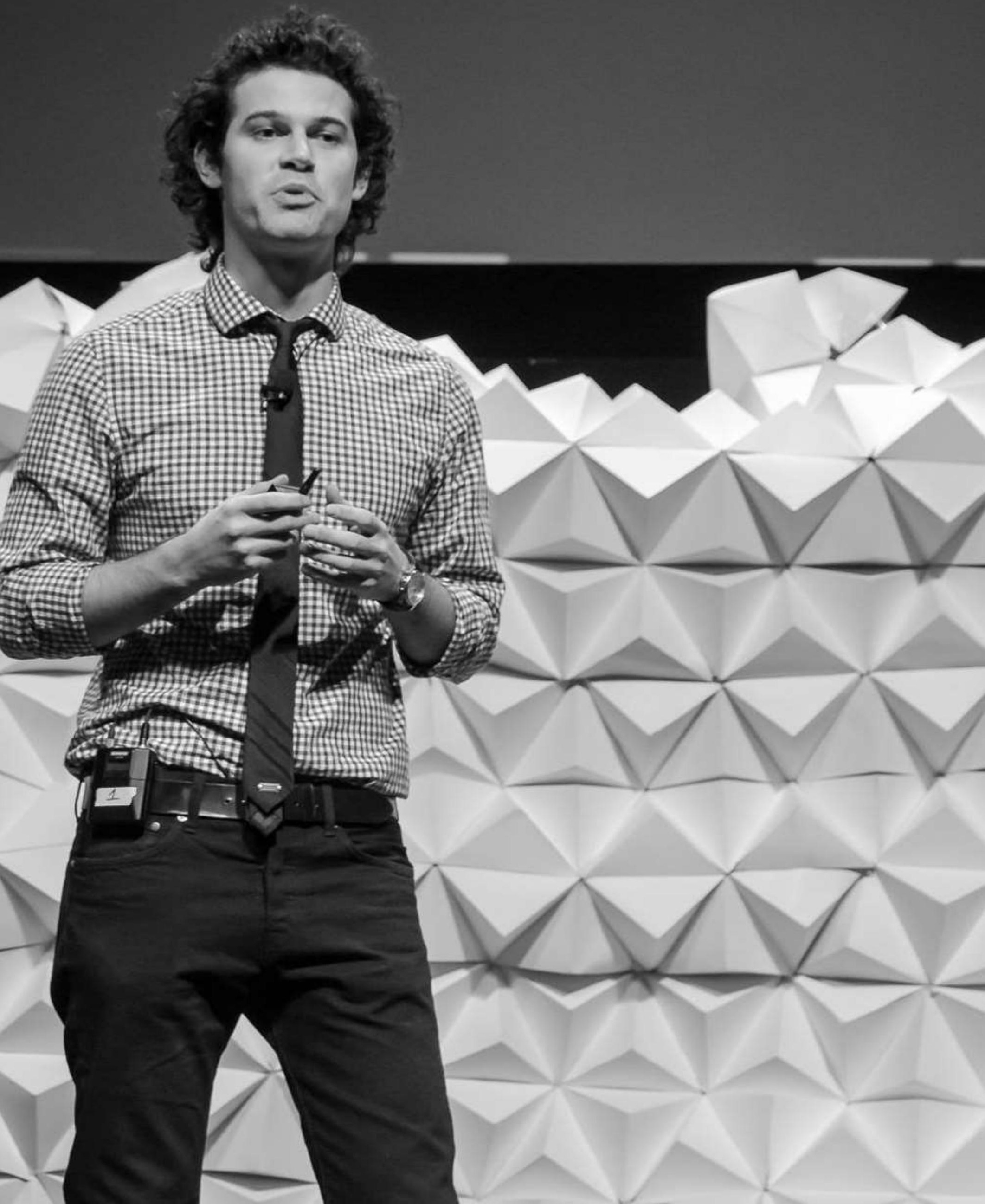




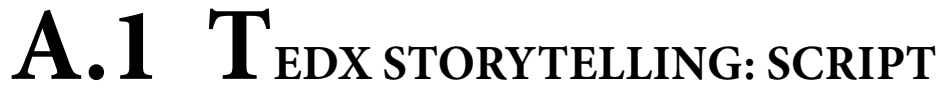

I am here to tell you a story about a relationship you never knew you had. This is a problematic relationship which has evolved from diminishing emotions and general misunderstandings. This toxic affair is between you and the current state of architecture. Design once moved us. Architecture was involved with a sense of spiritual satisfaction and wonder. It once touched us with a sense of beauty, intimacy and memory and offered us an emotional platform through which we could better understand the human collective to which we all belong. Whether or not it ever really achieved that or not is not what I am here to discuss. I am here to outline three reasons why architecture is not currently reaching this plateau and what we can do as a society to realign architectural aspiration with this humanistic pedagogy.

The first was a great transformation that happened at the end of the 17 th century where scientific thinking rejected the interpretive and nontangible aspects of architecture resulting in buildings that no longer were concerned with their relationship to humanity. It is as if buildings became their own objects, having little or no interest with the people that they contained. Things that could not be measured lost their place within the process of design and many of the existential factors which use to heavily influence the creation of our cities lost their traction as we adopted the Cartesian grid as our new architectural bible. As a result, the practice of design was transformed into a technological science predicated on optimizing space yet distancing our world from spirit and emotion. Buildings which we once held sacred have become nothing more than machines satisfying the minimal requirements of contemporary living. Our current understandings of the universe was no longer integrated within our structures and the hot new trendy architectural design words became efficiency, low cost, minimal living, and optimization. Although these are important principles that should influence design, we may be putting too much emphasis on them, because buildings that once looked like this started looking like this. (Fig 92)

Figure 92. Slide 1

The second is the development of a culture rooted within privatization and individualism. Up until the 18th century life occurred in the public realm. It was a form of relaxation, enjoyment and social engagement. People enjoyed being out on the streets and it was the place where one felt connected with the greater social establishment that constituted their society. We now see the public through a different set of eyes. It is a place of transition between the place we are in and the place we want to be. We treat those who stand between us and our destination as obstacles that are to be avoided and ensure that as we hurdle over our fellow citizens, our bodies, 


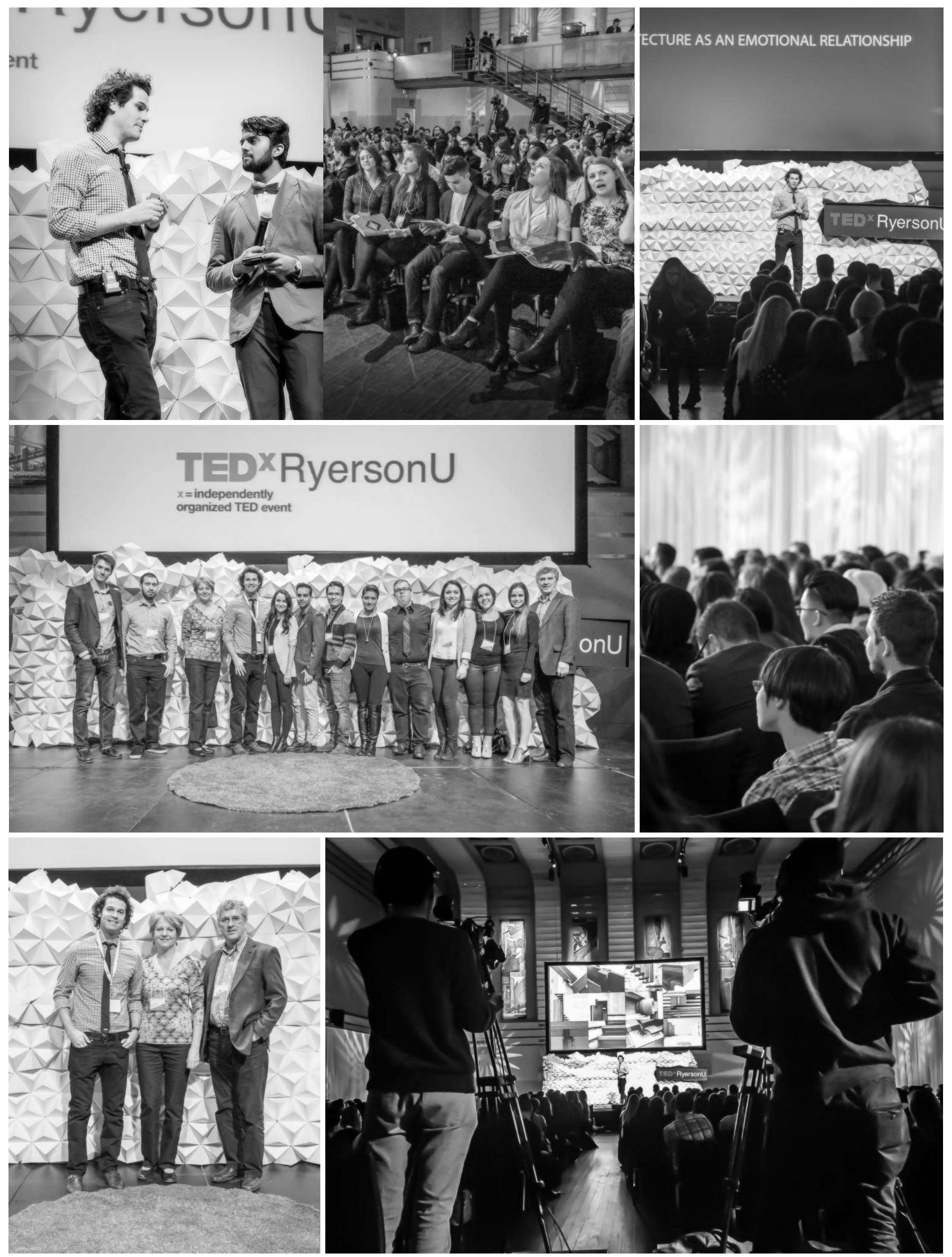




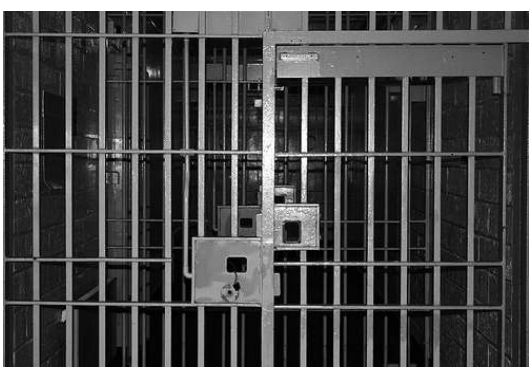

Figure 93. Slide 2

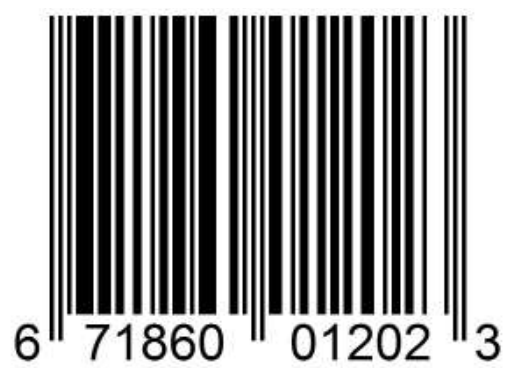

Figure 94. Slide 3 thoughts and eyes never meet. Being in public is no longer desirable, and architecture has started reflecting these principles focusing on creating exclusive private spaces. Architecture use to engage the social complexities of our societies but as we have turned our back to the public realm, architecture that looked like this started feeling like this. (Fig 93)

The third is the commodification of architecture in to a mode of branding. As architecture entered the service industry, design became a marketing strategy and in so doing eliminated the potential for genuine emotions in response to creative architectural design solutions. Consider for instance the design of fast food chain establishments. Hundreds of identical buildings spread across the world resemble products more than they do the creation of our societies. We preserve beautiful historic architecture of the past because within it are contained the values and principles that time period. We as a society invested in architecture and the character that came with this investment has given identity to some of the major cities of today. If we were to consider ourselves as part of an elite historical preservation team of the future, would we decide that what we are building today is worth preservation? Mostly not, and I think it is because architecture that felt like this, started being processed as this. (Fig 94)

I think our solutions to these problems are more obvious than we would like to think. Design is typically grounded within design principles and I think if we were to expand our list to include the follow three principles, we could once again reinvigorate architecture so that we can be proud to call it our own.

The first is the consideration of architecture as a story. We love stories. Stories engage us. They make us think and best of all they make us imagine. If we reflect back to grade school English class, some of us might remember a chart that looks like this. This is a graphic illustration of a narrative structure. A series of incidents and obstacles formulate a tension leading to a high point in the story developing a climactic experience. Now, in much the same way, architecture can take us along for a ride should we choose to design it to do so. Much like a story, architecture has an introduction. We were brought into this building off Bay Street into a large reception area which then took us into a stairwell. We were introduced to the building as artifacts on the walls reflected the buildings history and as we continued up the steps, we were introduced to the buildings past. This presentation room is the heart of the narrative. This massive area within the building is the climactic space that defines 
the story. It is within this space that we will spend most of our day and it will be the area in which a series of events could lead to something climactic. The conclusion of our architectural story will be in a space we have not yet visited. The space is bright and engaging, offering us the opportunity to end our evening through social engagement that concludes our journey within this structure. Now, although this building was not created with the scope of telling an architectural story, the way in which we experience it is much like a story. I think if we were to adopt the telling of narratives through architecture as a fundamental design principle, we can reinvigorate our stale technological buildings with architecture that can once again be worthy of exploring.

The second is the consideration of architecture as an emotional relationship. I would like everyone to reflect back upon a time in their childhood when a space affected you so strongly that all other thoughts in your mind disappeared completely. As children, it was significantly easier to immerse ourselves within experience because as we were learning about space, there was so much unknown. There was mystery, excitement and learning. The built world affected us emotionally and the relationship between us and the world was dynamic and exciting. As we began to understand the world more and more, architecture challenged us less and less and although it may be tempting to blame the loss of mystery as a natural process of learning, I am here to say that the wildly underwhelming state of architecture may be more at fault than we may realize. I think we need to tone up the dial on the intensity of architectural experience so that the built world could once again affect us on an emotional level. Julio Bermudez from the Catholic University of America conducted research study where over 1000 participants were asked to describe their most intense architectural experience. The top word used within the series of responses was emotional which was used in more than 3 thirds of all answers. If an emotional relationship with architecture is what defined our most intimate connections with architecture why are we not choosing to design to attain it? I believe if we consider our experience of architecture as an emotional we can once again rekindle the architectural flame of modern society.

The third is the consideration of architecture as a crafted piece of art. Modernism looked to reduce all unessential aspects of architectural design but by taking these reductionist principles and pushing them to absurdity, we have sterilized architecture from a design processes that fosters character within the built realm. We now often see sleek modernist buildings that hide all architectural details so that the pure form of building is uncompromised by the joints which create it. This type of thinking undermines the potential aesthetic beauty that a well-crafted material assembly can foster.

Think back to a time when you have come across an item in which 
the pieces that created it came together in such a unique way that it almost seemed poetic. I would like to see the same in our architecture. To give you an example, here I had put together a series of details that are fastened together by either interlocking, puncturing, tightening or clamping. The accentuation of each of these types of details, piece by piece, visualize the inner workings of building elements and in so doing create a way in which viewers can understand and relate to the process of building imbuing the structure with a sense of character.

I would like to conclude my talk with the proposal of 2 challenges for the audience. As leaders of tomorrow, it will be us to define the boundaries of future architectural ambition. Although it can be tempting to believe, the architect alone is not only one that has influence over how our buildings are designed. The role of the general public has a huge impact on the decisions that lead into the creation of the buildings that will define our future cities. My first challenge for this audience is to consider yourself as part of the current architectural movement. Starting right now. I challenge you to mentally equip yourself so that when you are given the opportunity to play a part in the creation of the built world, you can be confident that your decisions will have a positive influence on the design of architecture.

In many cases the potential for those of different backgrounds to dive into a conversation of what constitutes spiritually satisfying architecture can be limited. But, I hope to give you that chance today. Under your seat, you will find a necklace with an attached card. During the intermission, I challenge you to find the stranger in the audience with the card matching your own, make a friend and together identify what values you both believe architecture should be aspiring to. 


\section{B IBLIOGRAPHY}

Adrian Forty, "The home," in Objects of Desire (London: Thames and Hudson, 1986),100. Pg 94-120

Agamben, G. (2009). The signature of all things: On method. New York: Zone Books ;.

Bermudez, J. (2011) Empirical Aesthetics: The Body and Emotion in Extraordinary Architectural Experiences. In Considering Research: Reflecting Upon Current Themes In Architectural Research. Lawrence Technical University

Bordwell, D. (1985), Narration in the Fiction Film, London: Routledge.

City of Toronto Planning Division. (2006) Queen Street West Heritage Conservation District Plan

Coates, N. (2012). Narrative architecture. Italy: John Wiley \& Sons Ltd.

Debord, G. (1994). The society of the spectacle. New York: Zone Books.

Eco, U. (1994b), Six Walks in the Fictional Woods, Cambridge, Mass.:

Harvard University Press, p. 27.

Flusser, V., \& Mathews, A. (1999). The shape of things: A philosophy of design. | London: Reaktion.

Feenberg, A. (1999). Questioning technology. London: Routledge.

Frampton, K. (2002). Apropos Ulm: Curriculum and Critical Theory. In K. Frampton, Labour, Work and Architecture: Collected Essays on Architecture and Design (pp. 25-43). New York: Phaidon Press

Frampton, K. (2002). On the Predicament of Architecture at the Turn of the Century. In K. Frampton, Work, Labour and Architecture: Collected Essays on Architecture and Design (pp. 8-19). New York: Phaidon Press. 
Frampton, K. (2002). The Case For The Tectonic. In K. Frampton, Work, Labour and Architecture: Collected Essays on Architecture and Design (pp. 8-19). New York: Phaidon Press.

Frampton, K. (2002). The Status of Man and the Status of his Objects. In K. Frampton, Labour, Work and Architecture: Collected Essays on Architecture and Design (pp. 25-43). New York: Phaidon Press

Frampton, K. (2002). Towards a Critical Regionalism: Six Points for an Architecture of Resistance. In K. Frampton, Labour, Work and Architecture (pp. 77-89). New York: Phaidon Press. Frampton, K. (2010). Intention, Craft and Rationality. In P. Deamer, \& P. G. Bernstein, Building (in) the Future: Recasting Labor in Architecture (pp. 28-73). New York: Princeton Architectural Press.

Frascari, M. (1984). The Tell-the-Tale Detail. VIA, 23-37.

Glendinning, M. (2011). Architecture's Evil Empire? the Triumph and Tragedy of Global Modernism. London: Reaktion Books.

Heidegger, M. (1971). On the way to language. New York: Harper \& Row.

Heidegger, M. (1977). The question concerning technology, and other essays. New York: Harper \& Row.

Heidegger, M., \& Krell, D. (2010). Building, Dwelling, Thinking. In Basic writings: Martin Heindegger. London: Routledge.

Hejduk, J., \& Shkapich, K. (1985). Mask of Medusa: Works, 1947-1983. New York: Rizzoli. Ilhan, I. (2012). The philosophy of curiosity. New York: Routledge.

Koolhaas, R. (1995). Generic city. Sassenheim: Sikkens Foundation.

Koolhaas, R., Wigley, M., Carver, J., Koolhaas, R., \& Otero-Pailos, J. (n.d.). Preservation is overtaking us.

Krampen, M. (1989) Semiotics in Architecture and Industrial/Product Design. Vol. 5, No. 2 (Spring, 1989), pp. 124-140. MIT Press.

Krampen, M. (1989) Semiotics in Architecture and Industrial/Product Design. Vol. 5, No. 2 (Spring, 1989), pp. 124-140. MIT Press. 
MacLuhan, M. (2005). The medium is the message. Corte Madera: Gingko Pr.

Marc J. Neveu (2015) Crisis, Crisis Everywhere, Journal of Architectural Education, Volume 69, Issue 1, Routledge

Maugerauer, R. (1985). Dwelling, Place and Environment. Towards a phenomenology of a person and world. Martinus Nijhoff.

Moore, R. (2012). Desire Shapes Space, and Space shapes Desires. In Why we build: Power and desire in architecture. Picador.

Neveu, M. (2015). Crisis, Crisis Everywhere. Journal of Architectural Education, 69(1).

Pallasmaa, J. (2005). The eyes of the skin: Architecture and the senses.

Chichester: Wiley-Academy;.

Pallasmaa, J. (2011). The embodied image: Imagination and imagery in architecture.

Chichester: John Wiley \& Sons.

Pérez-Gómez, A.(2006). Built upon love architectural longing after ethics and aesthetics.

Cambridge, Mass.: MIT Press.

Pérez-Gómez, A (1983). Introduction. Architecture and the Crisis of Modern Science. Cambridge, MA: MIT,. 3. Print.

Psarra, S. (2009). Architecture and narrative the formation of space and cultural meaning. London: Routledge.

Riesman, D. (1961). The lonely crowd; a study of the changing American character, (Abridged ed.). New Haven: Yale University Press.

Ruskin, J. (1889). The Seven Lamps of Architecture. Kent: George Allen.

Saunders, W. (2005). Commodification and spectacle in architecture a Harvard design magazine reader. Minneapolis: University of Minnesota Press.

Schulz, C. (1980). Genius loci: Towards a phenomenology of architecture. New York: Rizzoli.

Semper, G. (1851). The four elements of architecture and other writings. Cambridge [England: Cambridge University Press.

Sennett, R. (1978). The fall of public man. New York: Vintage Books.

The Excercise of Detailing - Vittorio Gregotti 
Sweetman, B. (1999). The failure of modernism: The Cartesian legacy and contemporary pluralism. Mishawaka, Ind.: American Maritain Association ;.

Wang, D., \& Groat, L. (n.d.). Architectural research methods (Second ed.).

Zumthor, P., \& Turner, M. (2006). Thinking architecture (2nd, expanded ed.). Basel: Birkhäuser. 


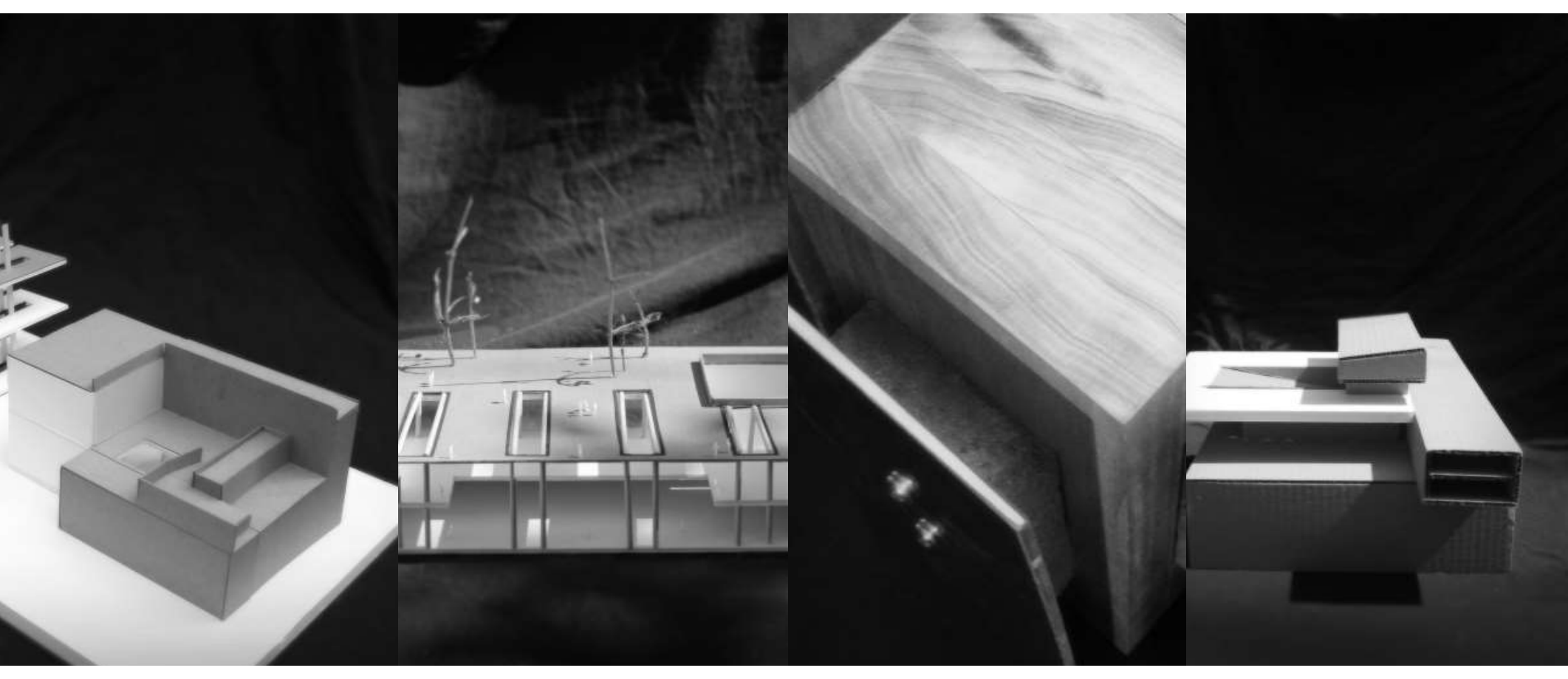




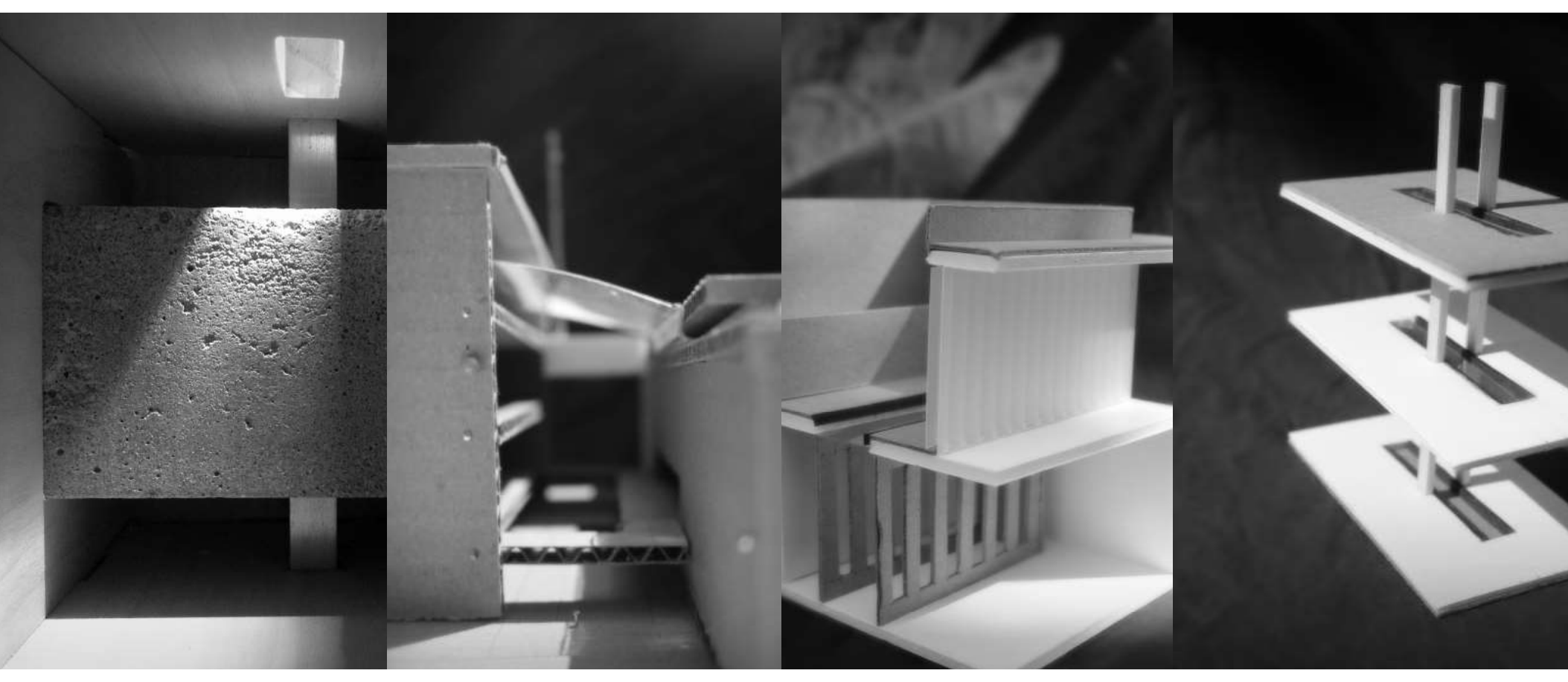

